MARCELO MARINHO

\title{
Correlação entre imagens e sinal elétrico para determinação do diâmetro de bolhas em líquidos
}

Dissertação apresentada à Escola de Engenharia de São Carlos da Universidade de São Paulo para obtenção do título de Mestre em Engenharia Elétrica.

Área de Concentração: Processamento de Sinais e Instrumentação

Orientador: Prof. Dr. Valentin Obac Roda 
AUTORIZO A REPRODUÇÃO E DIVULGAÇÃO TOTAL OU PARCIAL DESTE TRABALHO, POR QUALQUER MEIO CONVENCIONAL OU ELETRÔNICO, PARA FINS DE ESTUDO E PESQUISA, DESDE QUE CITADA A FONTE.

Ficha catalográfica preparada pela Seção de Tratamento da Informação do Serviço de Biblioteca - EESC/USP

Marinho, Marcelo

Correlação entre imagens e sinal elétrico para determinação do diâmetro de bolhas em líquidos / Marcelo Marinho ; orientador Valentin Obac Roda. -- São Carlos, 2006.

Dissertação (Mestrado-Programa de Pós-Graduação em Engenharia Elétrica. Área de Concentração: Processamento de Sinais e Instrumentação) -- Escola de Engenharia de São Carlos da Universidade de São Paulo, 2006.

1. Escoamento bifásico. 2. Tamanho de bolhas.

3. Pontas de prova. 4. Análise de imagens. I. Título. 
FOLHA DE JULGAMENTO

Candidato: Engenheiro MARCELO MARINHO

Dissertação defendida e jụlgada em 08-12-2006 perante a Comissão Julgadora:

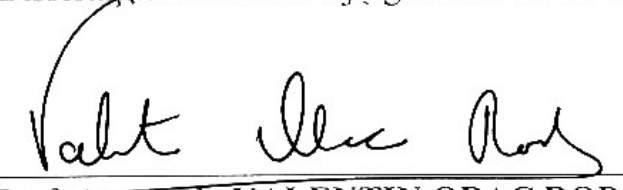

Prof. Assocrado VALENTIN OBAC RODA (Orientador) (Escola de Engenharia de Sño Carjos/USP) aprovado

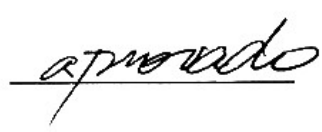

aprovado

Prof. Associgeto PAULO SELEGHIM JUNIOR (Escola de Engenharia de São Carlos/USP)

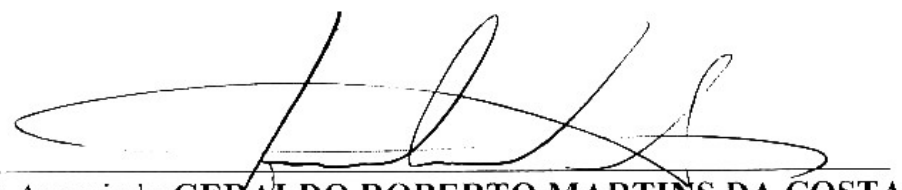

Prof. Associado GER ALDO ROBERTO MARTINS DA COSTA Vice-Coordenador ebr Exercício do Programa de Pós-Graduação em em Engenharia Elétrica

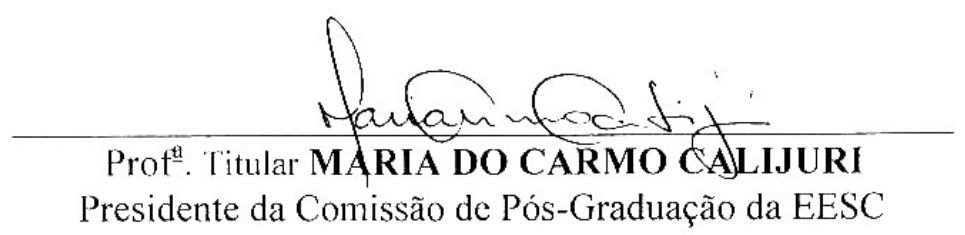


Ao meu pai, Antonio, e minha mãe, Neusa, pelo amor, exemplo e dedicação ao longo de toda minha vida. 


\section{AGRADECIMENTOS}

Agradeço primeiramente a Deus sem o qual nada disso seria possível.

Agradeço, imensamente, ao Prof. Dr. Valentin Obac Roda pela oportunidade, confiança e apoio na realização deste trabalho, e pela significativa contribuição para a minha formação científica e intelectual.

Ao Prof. Dr. Paulo Seleghim Jr. pelo apoio e atenção indispensáveis para a realização deste trabalho.

Aos colegas do Laboratório de Instrumentação Virtual e Microprocessada pela amizade e cooperação.

Aos funcionários e técnicos do Departamento de Engenharia Elétrica e do Núcleo de Engenharia Térmica e Fluidos que contribuíram de alguma forma para a realização deste trabalho, em especial ao técnico Jorge Nicolau dos Santos pela atenção e significativa contribuição através dos seus conhecimentos em LABVIEW.

Ao Conselho Nacional de Desenvolvimento Científico e Tecnológico pelo apoio financeiro. 
"A vida só pode ser compreendida olhando-se para trás; mas só pode ser vivida olhando-se para frente"

Soren Kierkegaard 


\section{RESUMO}

\section{MARINHO, M. Correlação entre imagens e sinal elétrico para determinação do}

diâmetro de bolhas em líquido. 2006. 167 f. Dissertação (Mestrado) - Departamento de Engenharia Elétrica, Escola de Engenharia de São Carlos, Universidade de São Paulo, São Carlos, 2006.

A distribuição do tamanho de bolhas é uma importante característica em sistemas bifásicos. A área interfacial de bolhas está fortemente relacionada às taxas de reações químicas e de transferência de massa em aplicações industriais como colunas de destilação e fermentação, sistemas biológicos, oxidação, hidrogenação, tratamento de água, e em processos naturais, como dinâmicas de aerossóis e transferência de gás oceano-atmosfera. Pontas de provas intrusivas são largamente usadas para determinar a distribuição do tamanho de bolhas em colunas de borbulhamento bifásicas. Embora o tamanho de bolhas não possa ser obtido diretamente pelo uso de uma simples ponta de prova porque estas medem somente comprimentos perfurados em bolhas, é possível relacionar distribuições de cordas à distribuição de tamanho de bolhas usando análises estatísticas. Este trabalho apresenta a implementação de um sistema capaz de medir distribuição de tamanho de bolhas em uma coluna de borbulhamento composta por água e ar através de uma ponta de prova condutiva. Imagens obtidas por uma câmera de vídeo CCD (Charge-Coupled Devices) monocromática são usadas para validar e calibrar o sistema.

Palavras-chave: Escoamento bifásico, tamanho de bolhas, pontas de prova, análise de imagens. 


\section{ABSTRACT}

\section{MARINHO, M. Correlation between images and electrical signals for determination of}

bubble diameters in liquids. 2006. 167 f. Dissertation (Master of Science Degree) Departamento de Engenharia Elétrica, Escola de Engenharia de São Carlos, Universidade de São Paulo, São Carlos, 2006.

The distribution of bubble sizes is a critical feature in two-phase systems. The interfacial area of bubbles is strongly related to chemical reaction and mass transfer rates in industrial applications such as distillation and fermentation columns, biological systems, oxidation, hydrogenation, waste water treatment and in natural processes such as aerosol dynamics and air-sea gas transfer. Intrusive probes are widely used to determine bubble size distribution in two-phase bubble columns. Although bubble size cannot be obtained by a simple probe because it measures only the pierced length of the bubbles, it is possible to relate chord distributions to bubble size distribution by the use of statistical analysis. This work proposes a system implementation which is able to determine bubble size distribution in a water-air bubble column using an intrusive conductance probe. Images obtained by a monochromatic video camera CCD (Charge-Coupled Devices) are used to validate and calibrate the system.

Keywords: Two-phase flows, bubble sizes, probes, image analysis 


\section{SUMÁRIO}

INTRODUÇÃO

$\begin{array}{lll}1.1 & \text { Motivação } & 11\end{array}$

$\begin{array}{lll}1.2 & \text { Objetivos } & 13\end{array}$

$\begin{array}{lll}1.3 & \text { Organização da Monografia } & 14\end{array}$

SISTEMAS DE ESTIMAÇÃO DO TAMANHO DE BOLHAS EM FLUXOS BIFÁSICOS $\quad 16$

$\begin{array}{lll}2.1 & \text { Métodos não intrusivos } & 16\end{array}$

$\begin{array}{lll}2.2 & \text { Métodos intrusivos } & 21\end{array}$

2.3 Conclusão 26

\section{DETERMINAÇÃO DO DIÂMETRO DE BOLHAS ATRAVÉS DE UMA PONTA DE} PROVA CONDUTIVA $\quad 28$

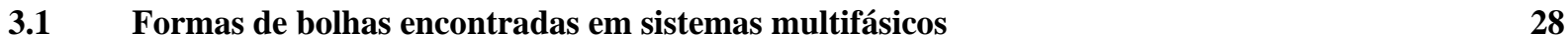

3.2 Determinação de cordas de bolhas utilizando uma ponta de prova condutiva 29

3.3 Relação entre distribuição de tamanho de bolhas e distribuição de comprimento de cordas em colunas de borbulhamento

3.4 Método de regularização baseado em decomposição de uma matriz em valores singulares (SVD) 37

3.5 Instrumentação e processamento do sinal da ponta de prova condutiva 39

$\begin{array}{llr}3.5 .1 & \text { Oscilador Senoidal } & 41\end{array}$

$\begin{array}{lll}3.5 .2 & \text { Conversor tensão-corrente } & 44\end{array}$

$\begin{array}{lll}\text { 3.5.3 Detector de Envoltória } & 46\end{array}$

$\begin{array}{lll}3.5 .4 & \text { Aquisição do sinal elétrico da sonda } & 47\end{array}$

3.5.5 Processamento do sinal elétrico da sonda 49

$\begin{array}{llr}3.6 & \text { Conclusão } & 54\end{array}$

DETERMINAÇÃO DO DIÂMETRO DE BOLHAS UTILIZANDO IMAGENS CAPTURADAS POR UMA CÂMERA DE VÍDEO

4.1 Captura de imagens de bolhas em sistemas bifásicos através de uma câmera de vídeo 55

4.2 Circuito de Sincronização e acionamento da lâmpada estroboscópica 57 
4.4 Processamento das imagens de bolhas $\quad 62$

$\begin{array}{llr}4.4 .1 & \text { Limiarização } & 63\end{array}$

4.4.2 Operações Morfológicas $\quad 65$

4.4.3 Preenchimento de furos e eliminação de pixels de regiões conectadas à borda externa da imagem 69

$\begin{array}{ll}\text { 4.4.4 Cálculo do centro de massa em imagens monocromáticas } & 72\end{array}$

4.4.5 Segmentação da imagem da bolha detectada pelo sistema de sonda condutiva $\quad 73$

$\begin{array}{lll}\text { 4.4.6 Crescimento de regiões por agregação de pixels } & 75\end{array}$

$\begin{array}{lll}\text { 4.4.7 Determinação da borda da imagem Segmentada } & 80\end{array}$

4.4.8 Algoritmo de determinação da melhor elipse formada pela borda de bolha 81

4.5 Conclusão

RESULTADOS EXPERIMENTAIS E CONCLUSÕES 90

5.1 Diagrama de raios obtido através de processamento de imagens e sinal elétrico da sonda condutiva

6.1 Principais contribuições

APÊNDICE A - CIRCUITOS ELETRÔNICOS CONSTRUÍDOS

APÊNDICE B - PROGRAMAS EM LABVIEW 6.1 


\section{Capítulo 1}

\section{Introdução}

\subsection{Motivação}

A estimativa do tamanho de bolhas é essencial para a determinação do comportamento de uma série de processos industriais e naturais que envolvem reações químicas, transferência de matéria, ou calor, entre diferentes fases. Características dinâmicas, como tamanho, velocidade e distribuição de bolhas, estão intimamente ligadas ao desempenho de sistemas industriais que envolvem misturas multifásicas e ao seu respectivo controle e projeto.

$\mathrm{Na}$ literatura encontra-se um grande número de processos industriais nos quais o conhecimento sobre as características físicas de bolhas é de grande importância. Estes processos envolvem reações químicas entre fases líquida e gasosa, fases líquida, gasosa e sólida em reatores ou colunas de borbulhamento como oxidação, hidrogenação, cloração, destilação, tratamento de água e resíduos, fermentação aeróbica e liquefação de carvão (XUE et al., 2003). 
A precisão na determinação das características de um fluxo bifásico é importante no desenvolvimento de sistemas computacionais, como o $\mathrm{CFD}^{1}$, que simulam o comportamento dinâmico em reatores e colunas de borbulhamento, e que precisam de dados experimentais precisos para validar seus modelos (KIAMBI et al., 2003).

Em processos de catalisação, a relação entre o tamanho de bolhas e os outros parâmetros do sistema é importante na determinação da superfície interfacial entre as fases e, em conseqüência, na transferência de massa (HU et al., 2005).

$\mathrm{Na}$ técnica de bombeamento controlado de petróleo por gravidade, a produtividade de óleo é aumentada pela injeção de gás no cano de produção. Através da diminuição da pressão hidrostática na coluna de óleo, melhora-se o fluxo de óleo no cano que transporta o fluido do poço até o reservatório (BOSTROM et al., 2005; GUET et al., 2004).

O fluxo de bolhas em sistema gás-líquido é essencial em um grande número de processos industriais bioquímicos, como biotransformação glicose-ácido glucónico, fermentação em bio-reatores, tratamento biológico de água; e em processos naturais como dinâmica de aerossóis e em geofísica (VAZQUEZ et al., 2005).

Em reatores de coluna de borbulhamento uma fase gasosa é injetada através de uma coluna de líquido para promover uma reação química ou bioquímica na presença, ou não, de um catalisador suspenso em uma fase líquida. Estes reatores são de considerável interesse em processos como oxidação, hidrogenação de óleos pesados, síntese de Fischer-Tropsch, síntese

\footnotetext{
${ }^{1}$ CFD - Computacional Fluid Dynamics
} 
da fase líquida de metanol, cloração, alquilação, e tratamento de água e resíduos (SHAIKH; AL-DAHHAN, 2005).

A distribuição do tamanho de bolhas também é fundamental em ambientes naturais. Por exemplo, na camada superficial do oceano a distribuição de bolhas é importante para muitos aspectos da interação ar-oceano, da geração de partículas de sal carregadas pela atmosfera, do ambiente acústico marinho, incluindo o campo de ruído ambiente, e a detecção acústica de fluxos perto da superfície (KOLLER et al., 1992; SERDULA; LOEWEN, 1998; VAGLE; FARMER, 1998).

Dentro da geofísica, grupos de bolhas formados quando as ondas do oceano quebram são importantes em processos como transferência de gás (ar), formação de aerossol marinho, enriquecimento de superfícies compostas por micro-camadas e geração de turbulência. (LEIFER; LEEUW; COHEN, 2003).

\subsection{Objetivos}

O objetivo deste trabalho é desenvolver um sistema capaz de estimar a distribuição do tamanho de bolhas em colunas de borbulhamento compostas por um fluxo bifásico gáslíquido. O sistema deve ser capaz de medir bolhas que apresentam diâmetros de $2 \mathrm{~mm}$ a 10mm. Para determinar a medida das bolhas serão utilizadas uma ponta de prova sensível à variação de condutividade do meio bifásico e uma câmera de vídeo convencional que permitirá a calibração e validação do sistema de sonda condutiva. O sistema deverá apresentar as seguintes características: 
- Permitir o controle, o monitoramento e a caracterização de colunas de borbulhamento.

- Aplicabilidade a uma grande gama de sistemas industriais.

- Robustez no que diz respeito a variações ambientais e de aplicabilidade.

- Confiabilidade na aferição das medidas do fluxo bifásico.

\subsection{Organização da Monografia}

Esta monografia é constituída por cinco capítulos:

- Neste primeiro capítulo foi realizada uma introdução, destacando a importância e aplicabilidade do assunto. Foram apresentados também os objetivos principais deste trabalho.

- No capítulo 2 são apresentados os principais trabalhos encontrados na literatura sobre determinação do tamanho de bolhas em sistemas de fluxo bifásico.

- No capitulo 3 são apresentados os principais passos para determinar o tamanho de bolhas através de uma ponta de prova condutiva. Circuitos de instrumentação empregados na obtenção do sinal da ponta de prova, uma descrição do sistema utilizado e o algoritmo de processamento de sinal são também apresentados.

- No capitulo 4 é sugerida uma série de processamentos de imagens que possibilitam a obtenção do diâmetro de bolhas através de imagens capturadas 
por uma câmera de vídeo CCD monocromática. Uma descrição do sistema de captura de imagem é também apresentada.

- No capitulo 5 são apresentados e analisados os resultados experimentais obtidos.

- No capítulo 6 são apresentadas sugestões para trabalhos futuros e algumas considerações finais.

- Neste trabalho há também cinco apêndices contendo os programas implementados, o layout dos circuitos impressos construídos, um exemplo do funcionamento da rotina de calibração do sistema de medidas de bolhas, alguns exemplos de imagens utilizadas na determinação do histograma de raios e fotos da coluna de borbulhamento. 


\section{Capítulo 2}

\section{Sistemas de estimação do tamanho de}

\section{bolhas em fluxos bifásicos}

Neste capítulo são descritos os principais trabalhos pesquisados na literatura sobre a determinação do tamanho de bolhas em sistemas de fluxos multifásicos. Os métodos de determinação do tamanho e de outros parâmetros de bolhas podem ser classificados basicamente em intrusivos e não intrusivos, de acordo com o tipo interação entre a mistura gás-líquido e o sensor utilizado para medir as características do fluxo.

\subsection{Métodos não intrusivos}

As técnicas de medidas não intrusivas são baseadas em sensores que não interferem dentro do fluxo multifásico, ou seja, não modificando o campo de velocidade do fluxo de bolhas. Entre este tipo estão: os métodos baseados em aquisição e análise de imagens, anemometria laser, técnicas ópticas não intrusivas, atenuação de raios-X ou raios gama e demarcadores de gás. Embora estes métodos apresentem a vantagem de não modificar o campo de velocidade do fluxo ou causar perturbações no sistema, eles apresentam limitações como, por exemplo, necessidade da existência de um acesso óptico ao fluxo, necessidade de 
observações confinadas às regiões próximas das paredes e de equipamentos pequenos (ROSSI, 1996; SELEGHIM; MILIOLI, 2001).

Métodos fotográficos e de câmeras de vídeo combinados com processamento de imagens têm sido usados para determinar parâmetros dinâmicos de fluxos multifásicos como velocidade e distribuição de tamanho de bolhas, e fração de gás total envolvido no processo. Em Zaruba et al. (2005a) uma câmera de vídeo de alta velocidade é utilizada para capturar imagens de um fluxo bifásico composto por água deionizada e gás. As bolhas são geradas através de uma pedra porosa (do tipo usado em aquários) e de um conjunto de capilares colocados no fundo do canal experimental retangular, cuja seção é de 100 x $20 \mathrm{~mm}$ e comprimento de $1,5 \mathrm{~m}$. Os quadros de vídeos são capturados a uma taxa de 500 quadros por segundo, sendo utilizado um computador pessoal para armazenar e processar as imagens. Para separar as bolhas do fundo da imagem é utilizado um processo de binarização onde se escolhe um limiar fixo que determina se um pixel $^{2}$ da imagem pertence ou não a região de interesse (GONZALEZ; WOODS, 1992). A binarização de imagens utilizando-se um limiar fixo apresentará um resultado satisfatório se a imagem tiver um bom contraste de nível de cinza e não houver variações significativas de fatores externos como, por exemplo, iluminação. Neste trabalho também é utilizado um método de determinação da trajetória de cada bolha para um cálculo posterior do campo de velocidade. A fim de estimar a trajetória de cada bolha, são determinadas as coordenadas dos centros de massa de cada bolha quadro a quadro. Para determinar se o centro de massa encontrado pertence à mesma bolha de um quadro anterior utiliza-se um critério que fixa um deslocamento máximo para cada bolha no intervalo entre dois quadros de vídeo. Através das imagens segmentadas e da trajetória de cada bolha, é possível determinar a distribuição de tamanho de bolhas e de seus respectivos campos de

\footnotetext{
${ }^{2}$ pixel-picture element
} 
velocidade. Apesar de apresentar bons resultados, este sistema apresenta sérias limitações práticas como: necessidade de uma tubulação ou coluna de borbulhamento que permita a captura das imagens; difícil operação em tempo real devido ao grande número de quadros por segundo a serem processados; difícil aplicabilidade a grandes colunas de borbulhamento, pois sua utilização está limitada ao fluxo próximo das paredes de tubos ou reservatórios. Em Zaruba et al. (2005b) também são utilizadas imagens obtidas por uma câmera de vídeo de alta velocidade para estimar a distribuição de tamanho e o campo de velocidade de bolhas, utilizando-se técnicas similares às utilizadas em Zaruba et al (2005a). O algoritmo foi melhorado através do acréscimo de técnicas de pré-processamento de imagens. Primeiramente o fundo da imagem é subtraído, a fim de diminuir a influência de sua não uniformidade. Depois é utilizado um processo de melhoramento de contraste de imagens (GONZALEZ; WOODS, 1992). Este processo interpola linearmente os níveis de cinza dos pixels possíveis entre o valor máximo (nível de branco) e mínimo (nível de preto), aumentando a faixa de valores de níveis de cinza. Posteriormente determina-se um limiar de binarização através da analise do histograma de níveis de cinza da imagem.

Em Grau e Heiskanen (2002) é apresentado um método para estimar o tamanho de bolhas através de processamento de imagens. O dispositivo apresentado neste trabalho foi projetado somente para sistemas bifásicos e tem como objetivo o desenvolvimento de um sistema automatizado para medir tamanho de bolhas em máquinas de flotação. Uma câmera de vídeo monocromática de varredura progressiva é utilizada para capturar imagens do fluxo. A câmera de vídeo é conectada a um computador pessoal equipado com placa de captura e digitalização de imagens. As imagens capturadas são melhoradas utilizando-se um filtro de imagens passa - alta (GONZALEZ; WOODS, 1992), a fim de que as bordas das bolhas sejam ressaltadas. Posteriormente um algoritmo baseado em conectividade de pixels é aplicado à 
imagem para que cada bolha presente na imagem seja rotulada e identificada. Para a validação do método proposto, é utilizado um método desenvolvido na Universidade da Cidade do Cabo, descrito em Randall et al. (1989), que utiliza um tubo capilar, onde bolhas são colhidas através de sucção para que o volume e velocidade das mesmas possam ser estimados com a utilização de dispositivos ópticos.

Em Hassan et al. (2001) é utilizado um sistema composto por quatro câmeras de vídeo para medir parâmetros dinâmicos de bolhas em três dimensões que passam através de um cano de diâmetro pequeno. A técnica é denominada combinação estereoscópica (stereoscopic matching technique), e é utilizada para reconstruir o campo de fluxo e o volume das bolhas.

Bolhas são excelentes dispersores de som e podem ser facilmente detectadas através de um sistema clássico de imagens obtidas por ultra-som. Embora esta técnica tenha sido proposta para fazer estimativas do tamanho de bolhas, ela não é precisa principalmente porque é difícil diferenciar o eco de um grupo de bolhas do eco de uma bolha grande (CATHIGNOL et al., 1990). Como bolhas têm freqüência de ressonância que é inversamente proporcional ao seu próprio raio, muitos autores têm explorado este fato para a estimação do tamanho de bolhas. Diferentes métodos têm sido utilizados, incluindo dispersão por ressonância em Minnaert (1933 apud CATHIGNOL et al., 1990, p.30); geração de segundo harmônico em Miller (1981); técnica de freqüência dupla em Newhouse e Shankar (1984); método de freqüência dupla com efeito Doppler (double frequency Doppler method) em Chapelon et al. (1988).

MINNAERT. On musical air bubbles and sound of running water. Phil. Mag., v.16, p.235, 1933. 
$\mathrm{Na}$ técnica de determinação de tamanho de bolhas através de dupla freqüência proposta em Koller et al. (1992), uma das freqüências está na faixa de ressonância das bolhas enquanto que a outra está em uma freqüência muito mais alta. A freqüência mais alta permite a obtenção de uma resolução espacial melhor. Os ecos emitidos pelas bolhas irão conter as duas freqüências transmitidas e suas bandas laterais que correspondem á soma e diferença entre as duas freqüências, ou seja, a bolha age como um misturador não linear. Para usar a técnica de dupla freqüência é necessário variar o sinal de excitação continuamente sobre uma faixa de freqüências enquanto sinal de eco é medido. A duração do sinal com determinada freqüência de excitação é determinada pela gama de bolhas presentes. O resultado da distribuição de tamanho obtido pelo método de dupla freqüência foi comparado com o resultado obtido por fotografia para a validação do método proposto. O resultado mostrou que para alguns valores de raio de bolhas os gráficos dos dois métodos se aproximaram bastante, enquanto que para outros valores houve uma grande divergência entre os dois métodos.

Em Chen et al. (1998); Shaikh e Al-Dahhan (2005) são utilizadas imagens obtidas por tomografia computadorizada para determinar características de um fluxo bifásico líquido-gás, como velocidade de fluxo e porção volumétrica de gás. Este método utiliza um feixe de partículas radioativas que é atenuado pelos processos de absorção e espalhamento ao longo da trajetória percorrida dentro de um fluxo multifásico. Se o meio é formado por substancias que apresentam coeficientes de atenuação, densidades ou espessuras diferentes, é possível medir a atenuação do feixe durante sua trajetória em varias direções. Algoritmos de reconstrução utilizam a distribuição de densidade para fornecer imagens do fluxo (CHEN et al, 1998). Em alguns casos partículas radioativas (demarcadores) podem ser colocadas numa fase permitindo uma melhor visualização do fluxo. (DEVANATHAN; MOSLERNIAN; DUDUKOVIC, 1990). 
Em Wang, Yin e Hilliday (2002), um sistema de tomografia por impedância elétrica é utilizado para obter imagens de fluxo em um duto cilíndrico. As imagens são obtidas através de pares de eletrodos independentes que estão localizados na parte interior da parede do duto. O conjunto de sensores forma um anel de eletrodos que fornece informações sobre a variação de condutividade ao longo das direções radiais de uma seção ortogonal ao fluxo das fases. As imagens são obtidas através do perfil de condutividade e algoritmos apropriados de reconstrução.

Vários trabalhos têm empregado anemometria laser (laser Doppler anemotry) para estimar parâmetros como velocidade e tamanho de bolhas em fluxos bifásicos, por exemplo: Varty (1986); Durst (1982); Saffman, Buchhave e Tanger (1984). O método de anemometria laser utiliza dois feixes de luz que apresentam direções de propagações conhecidas, e que incidem diretamente sobre o meio onde se deseja medir o fluxo de bolhas. Quando os dois feixes de luz se sobrepõem, após a interação com a bolha, são criadas franjas de interferência. Como os raios das bolhas são muito maiores que o comprimento de onda do feixe de luz, pode-se utilizar óptica geométrica para relacionar o espaçamento entre as franjas e o raio da bolha (VARTY, 1986).

\subsection{Métodos intrusivos}

As técnicas de medidas intrusivas são baseadas em pontas de provas, ou seja, sensores que interagem diretamente com o fluxo de bolhas. Portanto, este processo de medida ocasiona algum tipo de perturbação no sistema. As técnicas intrusivas utilizam pontas de provas para

medir características físicas locais como capacitância, resistência elétrica, diferença de 
pressão e atenuação de luz. Embora este tipo de técnica represente para o sistema algum grau de perturbação, sensores intrusivos são aplicáveis virtualmente a equipamentos e processos de qualquer tamanho (SELEGHIM; MILIOLI, 2001).

$\mathrm{Na}$ literatura são encontrados vários trabalhos que utilizam a variação da condutividade do meio para estimar o tamanho de bolhas em fluxos multifásicos. Exemplos destes sistemas são descritos em Buchholz, Zakrewsky e Schügerl (1981); Dias, França e Rosa (2000); Liu (2002); Lucas e Mishra (2005). Este método de medida utiliza sensores compostos de uma ou mais pontas de provas que medem a variação de condutividade em colunas de borbulhamento. Quando uma bolha de gás, presente em um meio condutivo, está passando através da ponta de prova, há uma diminuição da condutividade medida devido à interface de gás que está entre a ponta do sensor e o terminal de referência (terra). Através do tempo de variação de condutividade provocado por cada bolha que passa pela ponta de prova, é possível determinar a distribuição de tamanho de bolhas que compõem o fluxo bifásico. Como nem sempre a ponta de prova perfura a bolha passando pelo seu centro, o valor medido não pode ser relacionado diretamente ao diâmetro da bolha, mas apenas ao comprimento de uma corda da bolha. Portanto é necessário utilizar métodos estatísticos que correlacionem uma distribuição de comprimentos de cordas à distribuição de tamanho ou diâmetro de bolhas. Em Clark e Turton (1988); Liu, Clark e Karamavruç (1998); Lim e Agarwal (1990); Liu e Clark (1995) são criados modelos matemáticos que levam em conta a forma e distribuição das bolhas em sistemas de fluxo bifásicos para correlacionar comprimentos de cordas ao tamanho de bolhas.

Pontas de provas ópticas são usadas de forma similar às condutivas para determinar cordas de bolhas. O princípio óptico usado neste tipo de sensor é baseado no fato do ângulo 
critico de reflexão ou refração variar significantemente em diferentes fases ou materiais. Este ângulo é muito maior para uma interface vidro-água do que para uma interface vidro-ar, portanto, boa parte da luz que é enviada através de uma fibra óptica a deixará se sua ponta estiver imersa em água, enquanto que uma parcela significativa de luz será refletida se houver ar na ponta da fibra (GUET; LUTHER; OOMS, 2005). Em Guet, Luther e Ooms (2005) $\mathrm{LEDs}^{3}$ conectados às fibras geram o feixe luz e um fotodiodo detecta a luz refletida pela ponta imersa. Pontas de provas ópticas oferecem algumas vantagens em relação a pontas de provas condutivas, tais como: aplicabilidade em meios condutivos assim como em meios isolantes e melhor relação sinal ruído (XUE et al., 2003).

Para determinar cordas de bolhas através de uma ponta de prova simples é necessário conhecer a velocidade com que a bolha passa através da ponta do sensor, permitindo assim relacionar os tempos de passagem da bolha ao tamanho de suas cordas. A informação de velocidade da bolha pode ser obtida através da utilização de pontas de provas duplas, avaliando-se a diferença de tempo entre a chegada da bolha em cada uma das pontas. Em Buchholz, Zakrewsky e Schügerl (1981); Liu e Bankoff (1993) são utilizadas pontas de provas duplas que medem a variação de condutividade em fluxos bifásicos em cada uma das pontas.

Em Wu e Ishii (1999) foi realizado um estudo da sensibilidade de pontas de provas duplas condutivas para medição de área interfacial local em fluxos bifásicos, considerando os efeitos de movimentos laterais de bolhas e espaçamento entre as pontas do sensor. Através de métodos numéricos foram definidos alguns fatores de calibração teóricos. Em $\mathrm{Wu}$ et al. (2001) um estudo analítico de critérios de projeto e um fator teórico de calibração de pontas

\footnotetext{
${ }^{3}$ LED - Light Emitting Diode
} 
de provas duplas condutivas são apresentados para determinar velocidade de bolhas. Neste trabalho também são considerados os efeitos de movimentos laterais de bolhas e espaçamento entre as pontas do sensor na determinação da relação entre valor medido e a velocidade real da bolha. $\mathrm{O}$ valor médio medido é obtido através de funções de densidade de probabilidade, então uma analise numérica é realizada para determinar o fator teórico de calibração e a razão entre a velocidade média da bolha e o valor medido. Em Dias, França e Rosa (2000) é apresentada uma analise estatística que generaliza o cálculo de variáveis locais obtidos através de pontas de provas duplas em fluxo de bolhas. Uma aproximação que depende de um algoritmo de pós-processamento é usada para relacionar a função de distribuição de probabilidade da velocidade aparente de bolhas e os comprimentos de cordas à distribuição real destas variáveis.

Para que uma ponta de prova dupla realmente estime o valor real do comprimento da corda e da velocidade de bolha, algumas condições devem ser satisfeitas, tais como: plano de simetria da bolha deve ser perpendicular ao vetor de velocidade, a deformação ou variação da forma da bolha deve ser desprezível e a velocidade da bolha não deve variar durante a passagem da mesma pela ponta de prova. Na maioria das situações práticas estas condições não são verdadeiras (XUE et al., 2003).

Um sensor óptico composto por quatro pontas e um algoritmo para a determinação do tamanho e velocidade de bolhas são apresentados em Xue et al. (2003) como uma alternativa para um sistema mais preciso de estimação de parâmetros dinâmico de bolhas. Três dos quatro sensores possuem o mesmo comprimento e são espaçadas de tal forma que suas pontas formem um triangulo eqüilátero. A quarta ponta está localizada sobre o eixo inercial do triangulo, e em uma posição abaixo das demais. A diferença de tempo medida na passagem da 
bolha pela ponta central e entre as demais é usada conjuntamente com três equações trigonométricas para resolver, numericamente, um sistema de equações não lineares. As três equações trigonométricas são obtidas através da relação geométrica dos ângulos entre o vetor normal ao plano de simetria bolha elíptica e o eixo formado pela ponta central do sensor. Para possibilitar a solução do sistema de equações assume-se que o ângulo entre a ponta de prova e o eixo de simetria da bolha é menor que $30^{\circ}$, levando a um erro máximo calculado de $13,4 \%$ se e a condição angular for satisfeita.

Um sensor composto por duas grades de 16 fios paralelos, dispostos em duas camadas, é usado em Prasser, Scholz e Zippe (2001) para medir a distribuição de tamanho de bolhas em um fluxo bifásico água-ar. Este sensor é baseado na determinação da condutividade instantânea da mistura bifásica entre todos os pares de fios paralelos e adjacentes das duas camadas de eletrodos, resultando em uma matriz 16x16 composta por pontos sensíveis à variação de condutividade. Apesar de uma boa resolução temporal (mais de 1000 quadros por segundo), este tipo de sensor provoca a fragmentação e deformação das bolhas ao passar através dos eletrodos. Este problema foi verificado em Prasser, Scholz e Zippe (2001) através de imagens obtidas por uma câmera de vídeo de alta velocidade.

Quando a freqüência do sinal de excitação de uma sonda condutiva é suficientemente alta (acima de megahertz), o comportamento do eletrólito (líquido condutivo) se torna capacitivo. Pontas de prova capacitivas permitem a avaliação de propriedades de fluxos bifásicos mesmo quando imersas em meio não condutivo, mas requerem sofisticados circuitos de instrumentação, e cuidados específicos para a calibração (FOSSA, 1998). Este tipo de sensor é empregado em Lare et al. (1997) para obter informações de bolhas em um fluxo bifásico. 
Em Barigou e Greaves (1991) é apresentado um método de determinação do tamanho de bolhas que utiliza uma ponta de sucção que consiste de um tubo capilar de vidro transparente na forma de um funil invertido. O método faz uso de um vácuo para drenar continuamente uma pequena quantidade da mistura gás-líquido através do tubo capilar. O funil invertido apresenta um tubo com diâmetro interno de $0,39 \mathrm{~mm}$ e uma entrada que possui diâmetro interno de $7 \mathrm{~mm}$. Na lateral do tubo foram introduzidos dois pares de detectores de bolhas que são formados por um LED e um fototransistor. Estes detectores estão alinhados de tal forma que quando há a passagem de uma fração de gás no tubo ocorre uma diminuição do sinal luminoso recebido pelo fototransistor. A diminuição da quantidade de luz recebida ocorre porque o gás possui um índice de refração menor que o líquido. Como a distância entre cada par de detectores é conhecida, pode-se determinar a velocidade da bolha no tubo através da diferença de tempo do sinal medido por cada sensor, e, portanto, estimar o tamanho da bolha.

\subsection{Conclusão}

A revisão bibliográfica apresentada neste capítulo descreveu os principais métodos encontrados na literatura para a determinação do tamanho de bolhas em fluxos bifásicos e multifásicos. A grande variedade de métodos existente demonstra a importância e a dificuldade de se obter resultados satisfatórios na determinação das características dinâmicas deste tipo de sistema. 
Os métodos de determinação do tamanho de bolhas foram divididos em dois grupos: métodos intrusivos e não intrusivos. Esta classificação é realizada de acordo com o grau de interação entre a mistura multifásica e o tipo de sensor utilizado para aferir as medidas.

Os métodos intrusivos são aqueles que causam algum tipo de perturbação no sistema, ou modificam o fluxo multifásico. Apesar da interferência no sistema decorrente da interação entre sensor e fluxo, os métodos intrusivos apresentam a vantagem de serem aplicáveis a uma grande gama de aplicações, independentemente do tamanho das colunas de borbulhamento, e possibilita a obtenção de informações em qualquer região do fluxo de fases (SELEGHIM; MILIOLI, 2001).

Os métodos não intrusivos apresentam a vantagem de não causar perturbação, ou modificação no fluxo multifásico, embora estejam limitados às regiões próximas da parede da coluna de borbulhamento, pequenos equipamentos ou à necessidade de acesso óptico ao fluxo (ROSSI, 1996; SELEGHIM e MILIOLI, 2001). 


\section{Capítulo 3}

\section{Determinação do diâmetro de bolhas}

\section{através de uma ponta de prova condutiva}

Neste capítulo são apresentados os principais conceitos envolvidos na determinação de tamanho de bolhas em fluxos bifásicos compostos por uma fase líquida condutiva e outra fase gasosa, através da utilização de uma ponta de prova condutiva. Na parte final do capítulo é apresentada uma descrição detalhada do sistema utilizado para realizar as medidas experimentais do fluxo bifásico, assim como algoritmo de processamento de sinal empregado.

\subsection{Formas de bolhas encontradas em sistemas multifásicos}

Bolhas podem assumir varias formas dependendo do seu tamanho e do sistema multifásico utilizado. Por exemplo, bolhas esféricas são encontradas em sistemas gás-líquido e em sistemas compostos por dois líquidos insolúveis. Bolhas com diâmetros maiores que 1,5 mm em sistemas ar-água assumem a forma de um elipsóide com um eixo de simetria horizontal maior que o vertical. Bolhas muito grandes em líquidos e aquelas encontradas em leitos fluidizados possuem a forma de um elipsóide truncado (CLARK; TURTON, 1988). Há 
também fluxos compostos por uma mistura gás-líquido que apresentam o fenômeno de coalescência (fusão de duas ou mais bolhas) e quebra de bolhas, cujas formas de bolhas são irregulares ou não têm uma forma bem definida. Um exemplo de processo envolvendo uma grande quantidade de bolhas em líquidos, e que apresenta características irregulares no que diz respeito à forma é encontrado em Taitel, Barnea e Dukler (1980). A figura 3.1 mostra algumas formas geométricas que são usadas para modelar bolhas em fluxos multifásicos.

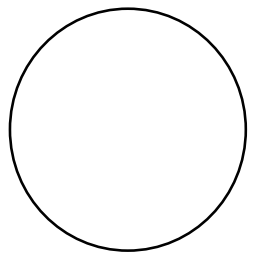

(a)

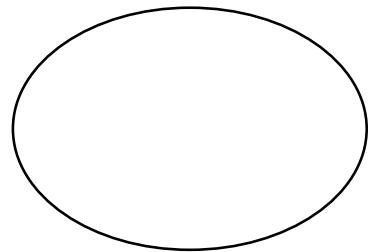

(b)

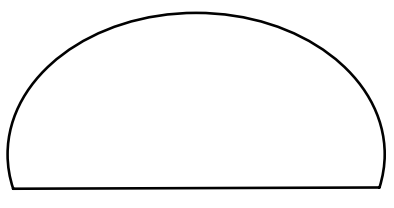

(c)

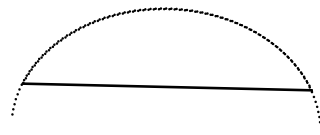

(d)

Figura 3.1: Formas geométricas usadas para modelar bolhas em fluxos multifásicos: (a) e (b) representam uma bolha esférica e uma bolha na forma de um elipsóide, respectivamente. Os modelos (c) e (d) representam bolhas na forma de elipsóides truncados.

\subsection{Determinação de cordas de bolhas utilizando uma ponta de}

\section{prova condutiva}

A utilização de uma sonda condutiva na determinação de características dinâmicas de fluxos bifásicos, como tamanho e velocidade de bolhas, está baseada na diferença significativa de condutividade apresentada pelas fases líquida e gasosa. (BUCHHOLZ; ZAKREWSKY; SCHÜGERL, 1981).

O sensor condutivo normalmente é formado por um fio de cobre isolado eletricamente, exceto nas pontas, e um tubo metálico que fornece sustentação ao fio condutor e pode ser utilizado como eletrodo de referência. A figura 3.2 mostra o esquema de uma sonda 
condutiva. Quando uma bolha está passando através da ponta do sensor, uma porção de gás encontra-se no caminho da corrente elétrica de excitação, provocando uma variação na condutividade elétrica medida. Como a condutividade do gás é muito menor que a do líquido, será notada uma diminuição da condutividade quando houver uma porção da bolha passando através da ponta de prova.

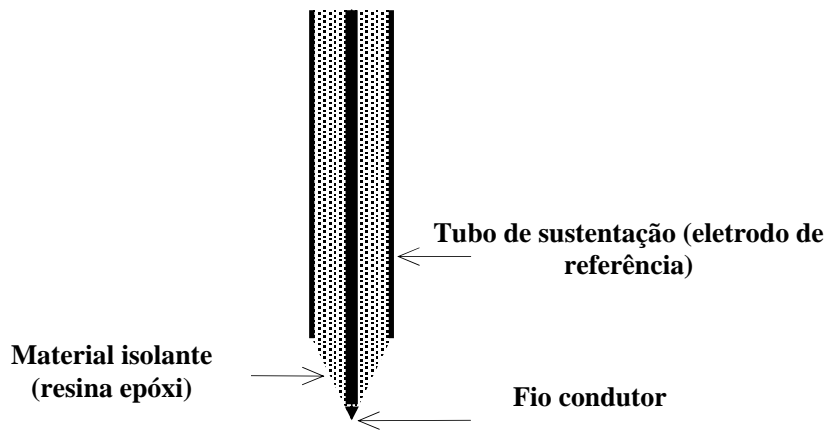

Figura 3.2: Ponta de prova condutiva.

Supondo que a velocidade média da bolha na direção da ponta de prova durante sua passagem pela mesma, $v_{B}$, é conhecida, pode-se calcular o comprimento médio de corda da bolha que provocou a variação de condutividade medida pelo sensor, utilizando a seguinte equação:

$$
x_{C}=v_{B} \cdot \Delta t
$$

Onde $\Delta t$ é o instante de tempo levado para a bolha passar completamente pela ponta do sensor e $x_{C}$ é o valor médio de corda da bolha. A velocidade de subida da bolha pode ser tomada como constante na tentativa de se obter um valor aproximado das cordas, o que pode ser válido para bolhas que compõem fluxos rápidos em leitos de fluidização (TURTON; CLARK, 1989). Uma outra possibilidade é escolher um modelo que descreva a velocidade em função do tamanho da bolha. Em Turton e Clark (1989) é sugerida a seguinte equação: 


$$
u=c \cdot \sqrt{g \cdot R}
$$

Onde $u, c, g$ e $R$ são velocidade de subida da bolha, constante de proporcionalidade que relaciona velocidade da bolha ao seu tamanho, aceleração da gravidade e raio horizontal da bolha, respectivamente. $\mathrm{O}$ valor de c pode ser determinado experimentalmente, por exemplo, através de um método fotográfico ou utilizando imagens obtidas por uma câmera de vídeo. A velocidade de subida também pode ser determinada através da utilização de uma ponta de prova dupla. Neste caso duas pontas são dispostas paralelamente, apresentando um pequeno espaçamento vertical entre si. Medindo a defasagem entre os sinais elétricos das duas pontas de prova condutivas pode-se estimar a velocidade de subida da bolha pela equação 3.3.

$$
u=\frac{\Delta s}{\Delta T}
$$

Onde $\Delta s$ e $\Delta T$ são o espaçamento entre as pontas de prova e a defasagem entre seus sinais, respectivamente. A figura 3.3 mostra o esquema de uma ponta de prova dupla.

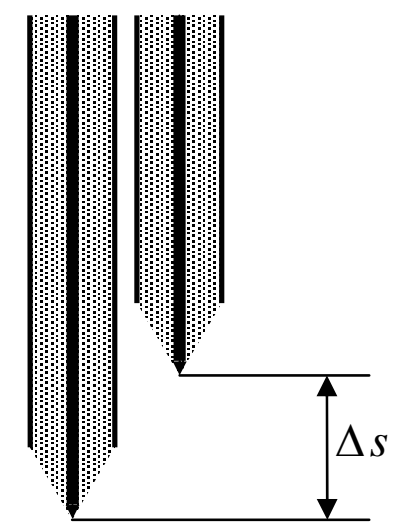

Figura 3.3: ponta de prova dupla 
Para que a ponta de prova dupla ou simples apresente medidas precisas e confiáveis, é preciso que o plano de simetria horizontal da bolha seja perpendicular ao vetor de velocidade da bolha. Caso contrário, a corda medida não estará numa direção perpendicular ao plano de simetria da bolha, ocasionando um erro significativo na determinação da dimensão de bolha ou no cálculo da função de distribuição de tamanho de bolhas (XUE et al., 2003). Devido a esta dificuldade Guet, Luther e Ooms (2005); Shen et al. (2005); Xue et al. (2003) propuseram o uso de um sensor composto por quatro pontas, com a finalidade de determinar com maior precisão velocidade e tamanho de bolhas.

\subsection{Relação entre distribuição de tamanho de bolhas e distribuição de comprimento de cordas em colunas de borbulhamento}

As pontas de provas condutivas realizam medidas baseando-se na diminuição da condutividade elétrica quando uma bolha é perfurada pela ponta do sensor. Como a perfuração da bolha nem sempre ocorre no seu eixo central, o valor medido pela sonda corresponde apenas ao intervalo de tempo que uma corda da bolha levou para ser perfurada. Desta forma, o valor medido não pode ser relacionado isoladamente ao diâmetro da bolha que passou pela sonda em um determinado instante de tempo. Porém se a distribuição do tamanho de cordas for conhecida, é possível estimar a distribuição de raios utilizando modelos estatísticos. A figura 3.4 apresenta um diagrama simplificado do processo envolvido na determinação de cordas através de uma sonda condutiva. 


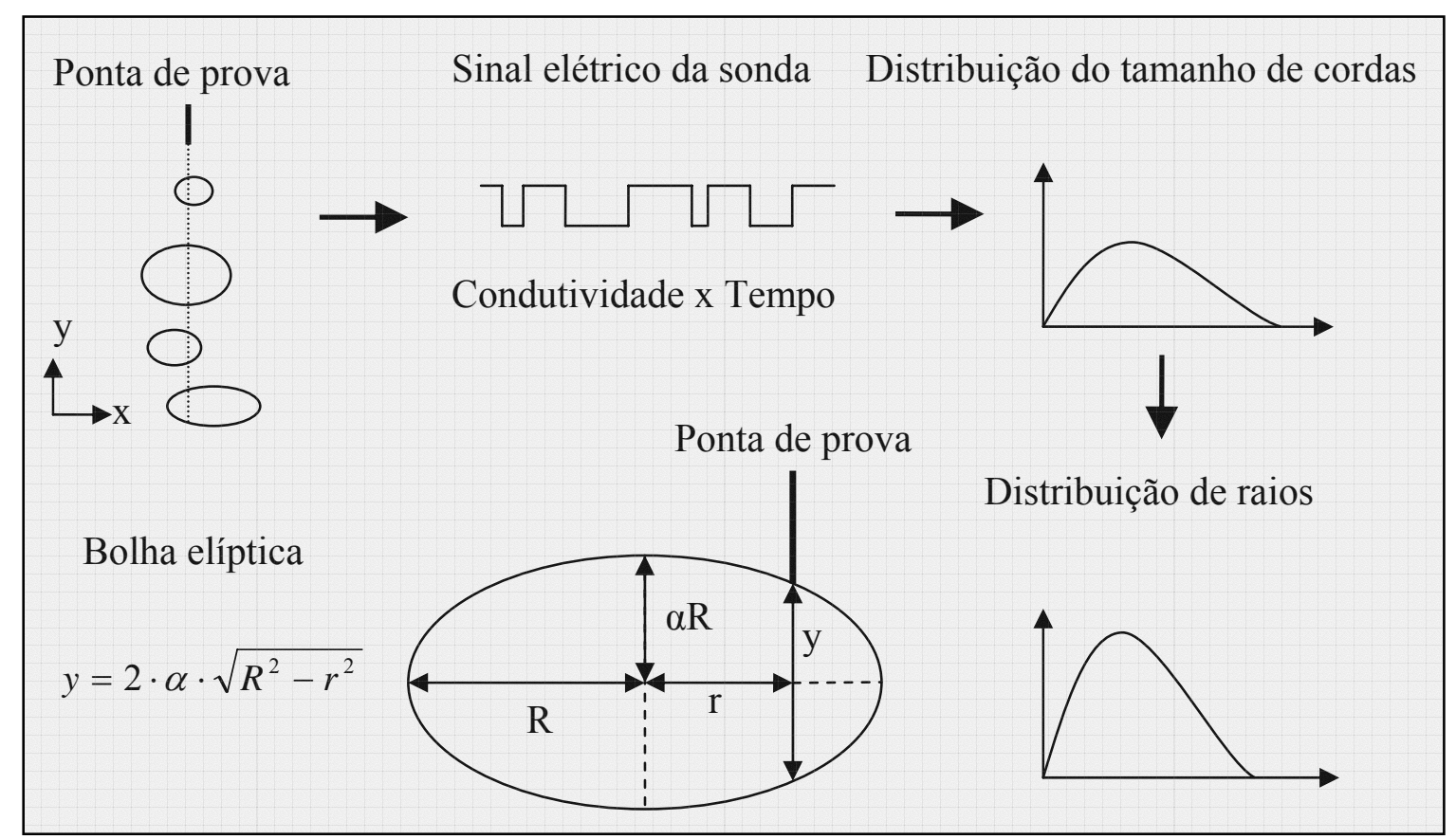

Figura 3.4: Determinação da distribuição de raio de bolhas através da distribuição do tamanho de cordas utilizando uma ponta de prova.

Considerando-se a situação ideal em que o sinal obtido pela sonda é livre de ruído, as bolhas sobem verticalmente com velocidade constante e as mesmas são perfuradas instantaneamente pela ponta de prova, um sinal composto de pulsos retangulares é obtido. Em Clark e Turton (1988) é mostrado que a probabilidade condicional de uma bolha elíptica de raio horizontal $R$ ter uma corda $y$ medida por uma ponta de prova ideal é:

$$
\begin{cases}P(y \mid R)=\frac{y}{2 \cdot \alpha^{2} \cdot R^{2}} & 0 \leq y \leq 2 \alpha R \\ \mathrm{P}(\mathrm{y} \mid \mathrm{R})=0 & \text { caso contrário }\end{cases}
$$

A função de distribuição de cordas pode ser obtida da largura dos pulsos do sinal obtido pela ponta de prova quando a velocidade de subida bolha é medida, ou determinada através de equações empíricas que correlacionem velocidade da bolha ao seu tamanho. A relação entre a função de distribuição de cordas $P_{C}(y)$ e a função de distribuição de raios 
$P_{B}(R)$ pode ser encontrada através da probabilidade condicional de medir uma corda $y$ de uma bolha de raio $R$, realizando-se a integração sobre toda a faixa de valores de raios possíveis (CLARK; TURTON, 1988; SELEGHIM; MILIOLI, 2001). Isto pode ser definido matematicamente através da seguinte equação:

$$
P_{C}(y)=\int_{0}^{\infty} P(y \mid R) \cdot P_{B}(R) \cdot d R
$$

Na maioria das situações práticas mede-se $P_{C}(y)$ para determinar $P_{B}(R)$, portanto é necessário inverter a equação 3.5, o que corresponde a resolver uma equação integral de Fredholm de primeira ordem. Este tipo de equação é conhecida por ser mal condicionada, ou seja, a solução é extremamente sensível a pequenas variações ou erros experimentais, e erros de natureza numérica, podendo haver comprometimento dos resultados (SELEGHIM; MILIOLI, 2001). Substituindo-se 3.4 em 3.5 obtém-se:

$$
P_{C}(y)=\int_{y / 2 \alpha}^{\infty} \frac{y}{2 \cdot \alpha^{2} \cdot R^{2}} \cdot P_{B}(R) \cdot d R
$$

O método apresentado abaixo foi sugerido em Seleghim e Milioli (2001) para resolver numericamente a equação 3.6 no caso de bolhas elípticas. Para resolver a equação integral 3.6 numericamente é preciso primeiramente discretizar $y$ e $R$. Isto pode ser feito da seguinte forma:

$$
\begin{aligned}
& y_{i}=i \cdot \Delta y \\
& R_{j}=j \cdot \Delta R
\end{aligned}
$$


Onde i e j são índices dos vetores de discretização; $\Delta y$ e $\Delta R$ são os passos de discretização de $y$ e $R$, respectivamente. Os valores assumidos pelas funções de probabilidade nestes pontos são dados por:

$$
\begin{aligned}
& P_{y_{i}}=P_{C}\left(y_{i}\right) \\
& P_{R j}=P_{B}\left(R_{j}\right)
\end{aligned}
$$

Adotando-se uma função de interpolação de ordem zero $\phi_{j}(R)$ tem-se:

$$
\begin{cases}\phi_{j}(R)=1 & R_{j} \leq R \leq R_{j+1} \\ \phi_{j}(R)=0 & \text { caso contrário }\end{cases}
$$

Então $P_{B}(R)$ pode ser escrito em termo de seus valores nodais $P_{R j}$ na equação 3.12 .

$$
P_{B}(R)=\sum_{j=0}^{N} P_{R j} \cdot \phi_{j}(R)
$$

Onde $N$ é o número de subintervalos da discretização de $R$. A equação 3.12 pode ser simplificada consideravelmente se condição de discretização 3.13 for aplicada.

$$
\Delta y=2 \cdot \alpha \cdot \Delta R
$$


Neste caso a equação 3.6 torna-se:

$$
P_{y_{i}}=\frac{i \cdot \Delta R}{\alpha} \sum_{j=i}^{N}\left(P_{R j} \cdot \int_{j \Delta R}^{(j+1) \Delta R} \frac{1}{R^{2}} d R\right)
$$

Depois de calcular a integral da equação 3.14, esta pode ser escrita na seguinte forma matricial:

$$
\mathbf{P}_{\mathbf{y}}=\mathbf{K} \cdot \mathbf{P}_{\mathbf{R}}
$$

Onde K é a matriz triangular superior com coeficientes dados por:

$$
\left\{\begin{array}{cc}
K(i, j)=\frac{i}{\alpha \cdot j \cdot(j+1)} & i \leq j \leq N \\
K(i, j)=0 & \text { caso contrário }
\end{array}\right.
$$

Invertendo-se a matriz $\mathbf{K}$ obtém-se a equação 3.17 onde a função de distribuição de raio, $\mathbf{P}_{\boldsymbol{R}}$, pode ser determinada em função da distribuição do tamanho de cordas $\mathbf{P}_{y}$.

$$
\mathbf{P}_{\mathbf{R}}=\mathrm{K}^{-1} \cdot \mathbf{P}_{\boldsymbol{y}}
$$

Este método permite a determinação da distribuição de raios de bolhas através da distribuição de cordas medidas por uma ponta de prova. Entretanto, como é demonstrado em Seleghim e Milioli (2001) pequenos erros ou variações nas medidas das cordas de bolhas 
podem resultar em resultados incorretos na determinação da distribuição de raios, devido ao fato da equação integral de Fredholm ser mal condicionada.

\subsection{Método de regularização baseado em decomposição de uma matriz em valores singulares $\left(\mathrm{SVD}^{4}\right)$}

Como mencionado na seção 3.3, pequenos erros ou variações nas medidas das cordas podem representar resultados incorretos na determinação da distribuição de raios, devido ao mal-condicionamento deste tipo de sistema. Para evitar que este tipo de comportamento do sistema afete de maneira significativa a determinação da distribuição de raios, a matriz $\mathbf{K}$ será decomposta utilizando o algoritmo SVD (PRESS et al., 1992).

SVD é baseado no teorema de álgebra linear que afirma ser possível escrever qualquer matriz A cujo número de linhas, $M$,é maior ou igual ao número de colunas, $N$, como o produto de uma matriz ortogonal $\mathbf{U} M x N$, uma matriz diagonal $\mathbf{W} N x N$ e uma matriz ortogonal $\mathbf{V} N x N$ transposta. A matriz $\mathbf{W}$ é formada por elementos positivos e zeros (valores singulares) (PRESS et al., 1992). A decomposição SVD pode ser expressa matematicamente da seguinte forma:

$$
\mathbf{A}_{M \times N}=\mathbf{U}_{M \times N} \cdot\left(\begin{array}{cccc}
w_{1} & 0 & \ldots & 0 \\
0 & w_{2} & 0 & \vdots \\
\vdots & 0 & \ddots & 0 \\
0 & \cdots & 0 & w_{N}
\end{array}\right)_{N \times N} \cdot \mathbf{V}_{N \times N}^{T}
$$

Onde a diagonal de $\mathbf{W}$ é formada pela raiz quadrada de cada autovalor de $\mathbf{A} \cdot \mathbf{A}^{T}$ e $\mathbf{A}^{T} \cdot \mathbf{A}$, em ordem decrescente $\left(w_{1}>w_{2}>w_{3} \ldots w_{N-1}>w_{N}\right)$. As colunas de $\mathbf{U}$ são autovetores de

\footnotetext{
${ }^{4}$ SVD - Singular Value Decomposition
} 
$\mathbf{A} \cdot \mathbf{A}^{T}$ e as colunas de $\mathbf{V}$ são autovetores de $\mathbf{A}^{T} \cdot \mathbf{A}$ (STRANG, 1988). Se a matriz $\mathbf{A}$ é quadrada com dimensão $N x N$, então $\mathbf{U}, \mathbf{W}, \mathbf{V}$ são todas matrizes quadradas de mesmo tamanho, e suas inversas são bastante triviais de se calcular. Como U e V são ortogonais então suas inversas são iguais as suas transpostas. A inversa de $\mathbf{W}$ é também uma matriz diagonal cujos elementos da diagonal principal são o inverso dos seus correspondentes valores da matriz $\mathbf{W}$. A partir da equação 3.19 pode-se calcular a inversa da matriz $\mathbf{A}$ que é conhecida com pseudo-inversa.

$$
\mathbf{A}^{-1}=\mathbf{V} \cdot\left(\begin{array}{cccc}
1 / w_{1} & 0 & \cdots & 0 \\
0 & 1 / w_{2} & 0 & \vdots \\
\vdots & 0 & \ddots & 0 \\
0 & \cdots & 0 & 1 / w_{N}
\end{array}\right)_{N \times N} \cdot \mathbf{U}^{T}
$$

Quando alguns valores da diagonal de $\mathbf{W}$ forem zero, ou numericamente muito próximos à zero, pode haver problemas com o cálculo da pseudo-inversa. Isso ocorre porque os erros experimentais ou de arredondamento se tornam significativos quando os valores da diagonal de $\mathbf{W}$ são muito pequenos. Neste caso os valores singulares tornam-se desconhecidos, e, portanto, o sistema se torna mal-condicionado. Para evitar que erros experimentais afetem a solução da equação 3.17, devido ao fato do mal-condicionamento, os valores da diagonal principal da matriz inversa $\mathbf{W}^{-1}$ são determinados através de um limiar da seguinte forma (PRESS et al., 1992):

$$
w_{i}^{-1}=\left\{\begin{array}{cc}
\frac{1}{w_{i}} & \text { se } w_{i}>L_{D} \\
0 & \text { caso contrário }
\end{array}\right.
$$

Onde $L_{D}$ é o limiar que determina os valores da diagonal da matriz $\mathbf{W}^{-1}$ 


\subsection{Instrumentação e processamento do sinal da ponta de prova}

\section{condutiva}

Muitos estudos têm sido feitos para verificar o comportamento de uma fase líquida com relação a suas características elétricas. Para determinar estas características tem-se utilizado um par de eletrodos imerso com um liquido condutivo. Coney (1973), por exemplo, utiliza um par de eletrodos planos dentro de um líquido condutivo para determinar as características elétricas do meio. A partir destes estudos sabe-se que a impedância elétrica medida entre dois eletrodos imersos em um líquido condutivo é essencialmente resistiva se o sinal de excitação apresentar freqüência suficientemente alta. Para água de uso comum a impedância é basicamente resistiva quando o sinal de excitação tiver freqüência de $10 \mathrm{~K}$ até $100 \mathrm{kHz}$. Para freqüências mais altas (na faixa de megahertz) o comportamento do líquido condutivo, conhecido como eletrólito, se torna capacitivo (FOSSA, 1998).

A utilização de uma tensão $\mathrm{DC}^{5}$ é uma das formas mais simples de medir a variação de condutividade de um fluxo bifásico, mas apresenta serias limitações devido à polarização da fase líquida, ataques eletroquímicos e alterações na medida de resistência entre os eletrodos devido a depósitos eletroquímicos nos sensores. (JONES; DELHAYE, 1976; TEYSSEDOU; TAPUCU, 1988). Em Liu 2002 uma ponta de prova dupla resistiva é excitada por uma tensão DC. O circuito é alimentado por baterias de $1.5 \mathrm{~V}$ e potenciômetros que permitem o ajuste da tensão de excitação em cada sensor. Para evitar o efeito de eletrólise nos sensores, a tensão sobre a ponta de prova deve ser a menor possível. Neste caso as tensões medidas entre os

\footnotetext{
${ }^{5}$ DC - Direct Current
} 
eletrodos na presença da fase líquida apresentaram valores entre 0,3 e 0,4. Para a fase gasosa as tensões medidas estiveram entre 0,5 e 0,8 .

Uma forma de eliminar o fenômeno eletroquímico sobre o sensor é a utilização de uma tensão de excitação $\mathrm{AC}^{6}$. Neste caso as mudanças de fase são detectadas pela modulação em amplitude do sinal de saída. É, portanto, necessário um sinal de excitação com freqüência maior que a freqüência do fenômeno físico observado, ou seja, quanto mais rápido o fluxo de bolhas maior será a freqüência do sinal de excitação necessário para distinguir a presença de diferentes fases. No caso de fluxos de alta velocidade a freqüência do sinal pode alcançar valores muito altos. Para freqüências da ordem de $\mathrm{MHz}$ ocorrem muitos problemas com os dispositivos utilizados como, por exemplo, capacitâncias parasitas (JONES; DELHAYE, 1976).

O equivalente elétrico correspondente a uma ponta de prova composta por eletrodos pouco espaçados é mostrado na figura 3.5 (TEYSSEDOU; TAPUCU, 1988), onde a resistência $R$ depende da condutividade do meio, a indutância $L$ depende da permeabilidade magnética e a capacitância $C$ da permissividade dielétrica. A impedância do circuito equivalente, $Z$, é dada pela equação 3.21 .

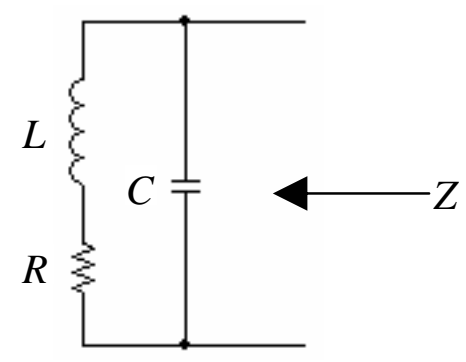

Figura 3.5: Equivalente elétrico de uma ponta de prova.

\footnotetext{
${ }^{6} \mathrm{AC}-$ Alternating Current
} 


$$
Z=\frac{\omega L+R}{\omega^{2} L C+\omega R C+1}
$$

Na equação 3.21, $\omega=2 \pi f$ e $f$ é a freqüência do sinal de excitação. Assim, é necessário que a freqüência de excitação seja suficientemente baixa para que a impedância $Z$ seja essencialmente resistiva.

Com objetivo de poder determinar a variação de condutividade medida por uma ponta de prova, foi projetado e construído um circuito dedicado. O circuito é composto basicamente de um oscilador senoidal que gera um sinal de excitação AC, um conversor tensão-corrente e um detector de envoltória. Na figura 3.6 é mostrado um diagrama em blocos para ilustrar o sistema de determinação do tamanho de bolhas através do sinal elétrico de uma sonda.

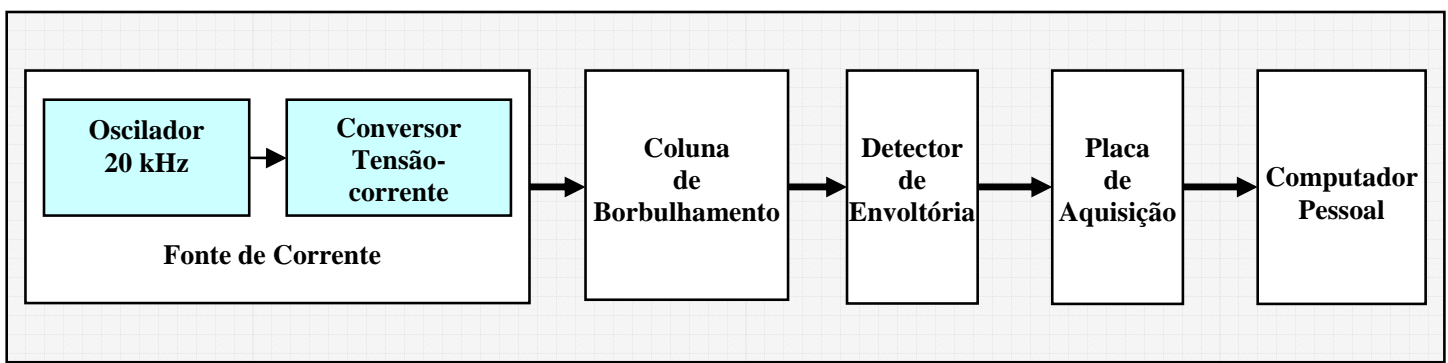

Figura 3.6: Diagrama em blocos do sistema de determinação do tamanho de bolhas através do sinal elétrico.

\subsubsection{Oscilador Senoidal}

Para gerar um sinal de excitação AC foi construído um oscilador com ponte de Wien (mostrado na figura 3.7). Este tipo de oscilador utiliza um amplificador operacional na configuração não inversora com ganho de $1+\frac{R_{2}}{R_{1}}$, e uma malha de realimentação RC. O 
ganho de malha, $L(s)$, pode ser obtido facilmente multiplicando-se a função transferência $\frac{V_{a}(s)}{V_{0}(s)}$ da malha de realimentação pelo ganho do amplificador (SEDRA; SMITH, 2000).

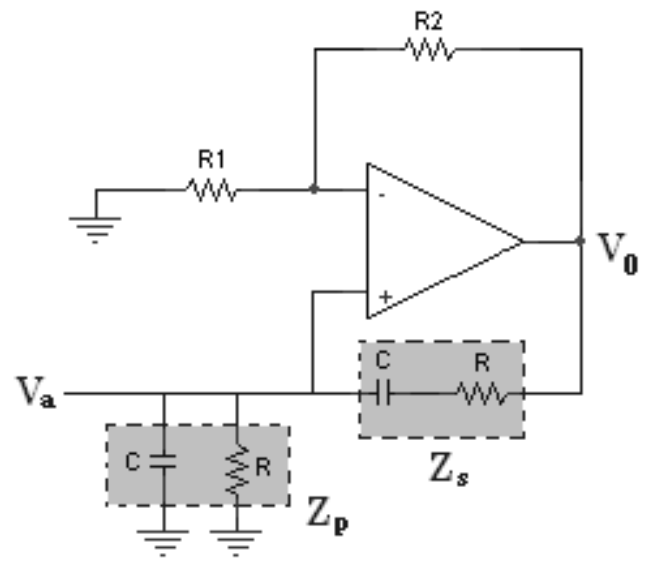

Figura 3.7: Oscilador com ponte de Wien.

$$
L(s)=\left[1+\frac{R_{2}}{R_{1}}\right] \cdot \frac{Z_{p}}{Z_{p}+Z_{s}}=\frac{1+R_{2} / R_{1}}{3+s C R+1 / s C R}
$$

Onde $Z_{s}=R+1 / s C$ e $Z_{p}=\frac{R}{1+s C R}$

Substituindo-se $s=j \omega$ obtém-se:

$$
L(j \omega)=\frac{1+R_{2} / R_{1}}{3+j(\omega C R-1 / \omega C R)}
$$

O ganho de malha será um número real (isto é, a fase será zero) em uma freqüência, $\omega_{0}$, dada por: 


$$
\omega_{0}=\frac{1}{R C}
$$

Para que as oscilações se mantenham, deve-se fazer a amplitude do ganho da malha unitário. Isto corresponde a fazer $\frac{R_{2}}{R_{1}}=2$.

Para minimizar a distorção do oscilador e estabilizar a amplitude da saída senoidal deve-se utilizar um circuito automático de controle de ganho (MANCINI; PALMER, 2002; STANLEY, 2002). Uma das formas de se obter um controle automático de ganho é utilizando um $\mathrm{JFET}^{7}$ como mostrado na figura 3.8. O circuito também possui um outro amplificador na configuração inversora que é utilizado para ajustar o ganho de saída para um valor apropriado.

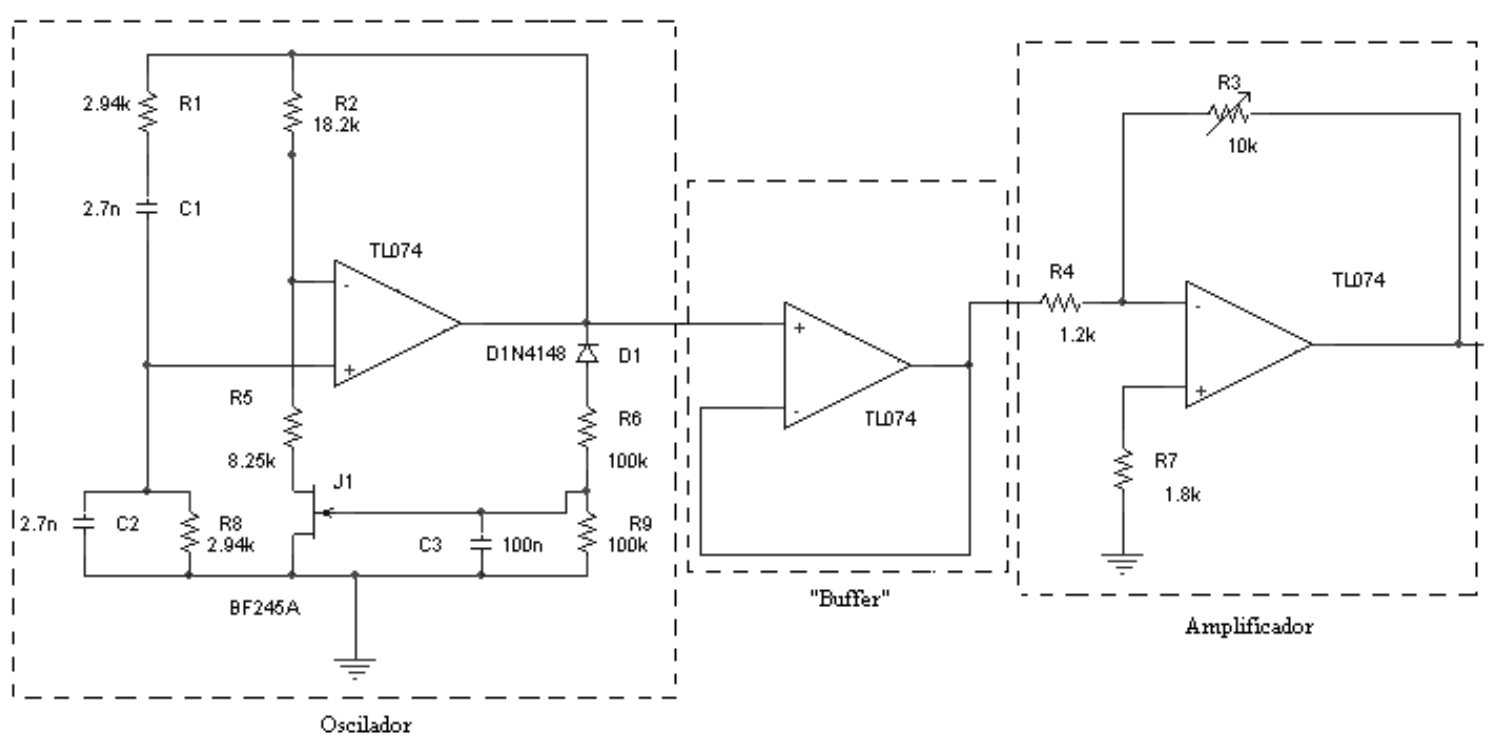

Figura 3.8: Oscilador com ponte de Wien com controle automático de ganho.

\footnotetext{
${ }^{7}$ Junction field-effect transistor
} 
De acordo com o critério mencionado na seção 3.4, foi escolhida uma freqüência de oscilação de $20 \mathrm{kHz}$. Então o circuito foi projetado determinando os valores dos outros componentes mostrados na figura 3.8.

\subsubsection{Conversor tensão-corrente}

Para medir a variação de condutividade no fluxo bifásico entre os eletrodos da sonda, é utilizada uma fonte de corrente senoidal. A fonte de corrente foi implementada utilizando um conversor tensão-corrente para converter o sinal de tensão senoidal gerado pelo oscilador em um sinal de corrente. O conversor mostrado no circuito da figura 3.9 produz uma saída de corrente que é proporcional à entrada de tensão. Este circuito é conhecido como fonte de corrente de Howlan (DAILEY, 1995; STANLEY, 2002), e a corrente em uma determinada carga $\mathrm{R}_{\mathrm{L}}$ é dada pela seguinte expressão:

$$
i_{L}=\frac{R_{1} R_{3}}{R_{1} R_{3} R_{4}+R_{L}\left(R_{1} R_{3}-R_{2} R_{4}\right)} \cdot v_{i}
$$




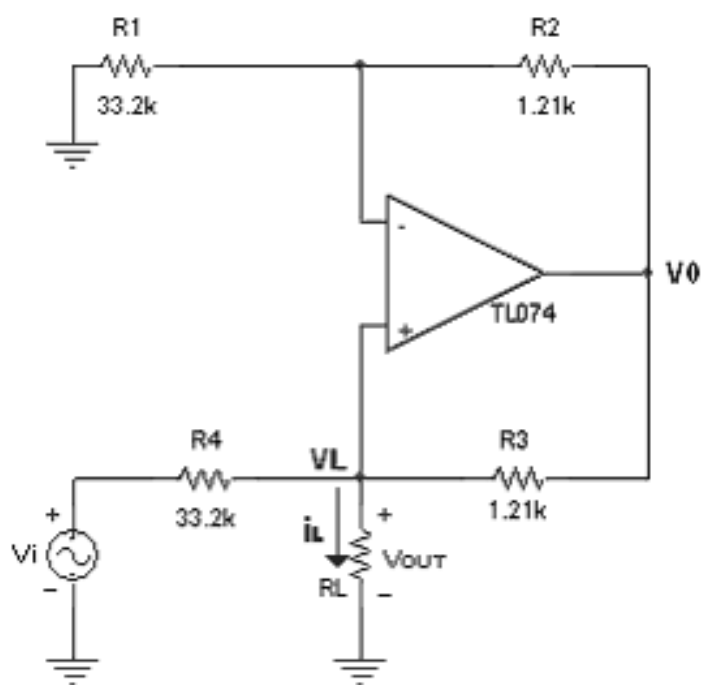

Figura 3.9: Fonte de corrente; Conversor tensão corrente em destaque.

Fazendo-se $R_{2} R_{4}=R_{1} R_{3}$, é obtida uma fonte de corrente cuja saída independe do valor da carga $R_{L}$, desde que a tensão sobre a carga não alcance valores que levem o amplificador operacional a região de saturação. Para que isto aconteça a tensão na saída do amplificador operacional, $V_{0}$, deve ser:

$$
v_{0}=\frac{R_{L}\left(R_{1}+R_{2}\right)}{R_{1} R_{4}} \cdot v_{i} \leq V_{S A T}
$$

Portanto se as condições acima forem satisfeitas, a corrente na carga será dada pela seguinte equação:

$$
i_{L}=\frac{v_{i}}{R_{4}}
$$


No caso da carga ser o meio composto por uma mistura bifásica, o valor pico a pico do sinal de tensão medido entre os eletrodos aumentará quando houver a passagem de uma bolha devido à diminuição da condutividade, visto que a amplitude do sinal de corrente idealmente não depende da carga. Desta forma é possível medir o tempo levado para que uma bolha atravesse a sonda. Quando a fase entre os eletrodos for ar, a carga $R_{L}$ tende, idealmente, ao infinito, causando o efeito de saturação no amplificador operacional. Para evitar este problema foi utilizado um resistor entre os eletrodos da sonda.

\subsubsection{Detector de Envoltória}

Como o sinal de tensão medido entre os eletrodos da ponta de prova é alternado, é necessário aplicar algum tipo de processamento ou condicionamento de sinal para poder medir a variação de condutividade na mistura bifásica. Em Andreussi, Donfrancesco e Messia (1988) é utilizado um filtro passa - baixa para se obter a envoltória do sinal alternado de uma ponta de prova condutiva.

Neste trabalho foi utilizado um detector de envoltória (STANLEY, 2002) para determinar a variação da amplitude do sinal senoidal. O circuito do detector de envoltória, mostrado na figura 3.10, é constituído basicamente de amplificadores operacionais operando em modo de não saturação, diodos e um circuito RC que fazem o sinal na saída do detector acompanhar o valor do pico positivo do sinal senoidal medido pela sonda. A variação de tensão sobre a rede RC pode ser calculada pela equação 3.28 , ou aproximada pela equação 3.29 (STANLEY, 2002).

$$
\left|\Delta v_{C}\right|=V_{C} \cdot\left(1-e^{-\Delta t / \tau}\right)
$$




$$
\left|\Delta v_{C}\right| \cong \frac{V_{C} \Delta t}{\tau} \quad \text { para } \quad \Delta \mathrm{t}<<\tau
$$

Onde $\tau=R_{2} \cdot C_{1}$ é a constante de tempo e $V_{C}$ é o pico de tensão. A constante de tempo, $\tau$, deve ser grande o suficiente para que a tensão no capacitor não varie entre os picos do sinal senoidal e pequena o suficiente para que seja possível detectar variações de amplitudes do sinal.

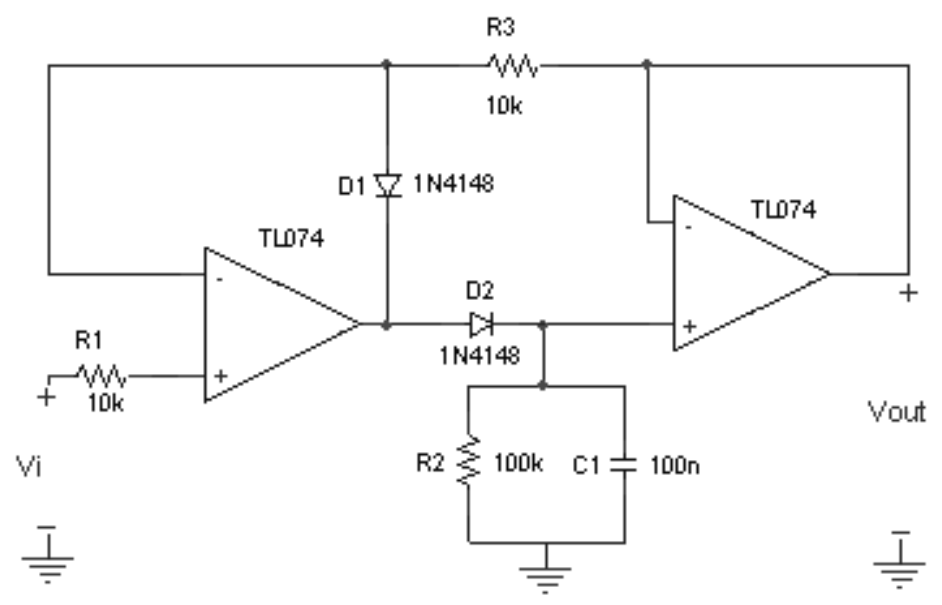

Figura 3.10: Detector de envoltória.

\subsubsection{Aquisição do sinal elétrico da sonda}

Para realizar a aquisição do sinal foi utilizada uma placa de aquisição NI PXI-5112 (Osciloscópio Digital) da NATIONAL INSTRUMENTS que permite fazer aquisições de sinais elétricos com 8 bits por amostra a uma taxa máxima de $100 \mathrm{M}$ amostras por segundo. Para a realização das medidas do sinal de saída do detector de envoltória, é realizada uma aquisição com taxa de $3 \mathrm{k}$ amostras por segundo, garantindo a reconstrução do sinal amostrado. A placa de aquisição permite o processamento digital do sinal através de um computador pessoal usando-se o programa LABVIEW 6.1 da NATIONAL INSTRUMENTS. O sistema de medição da variação de condutividade possui dois eletrodos que são colocados 
diretamente no meio composto pela mistura gás-líquido. Um dos eletrodos é a ponta da sonda (condutor central) onde as bolhas são perfuradas e outro é o próprio tubo metálico de sustentação da sonda, permitindo o fluxo de corrente e servindo como referência da tensão (terra) para o sistema.

A coluna de borbulhamento possui seção retangular e paredes de vidro transparentes. Água tratada é utilizada como fase líquida do sistema bifásico, e um sistema de ar comprimido introduz a fase gasosa. As bolhas de ar são geradas através de um pequeno tubo capilar, com diâmetro interno de aproximadamente $2,6 \mathrm{~mm}$, colocado em uma posição central do fundo da coluna de borbulhamento. Utilizando um tubo capilar de aço inox e uma agulha hipodérmica, foi construída uma sonda que pode ter sua altura ajustada. A figura 3.11 mostra a configuração da coluna de borbulhamento e da sonda que foi posicionada verticalmente no centro da coluna de borbulhamento. Uma válvula colocada na mangueira de ar comprimido permite ajustar manualmente, de forma imprecisa, a pressão do ar que entra na coluna, sendo possível mudar a taxa de entrada de gás ou a quantidade de bolhas gerada. 


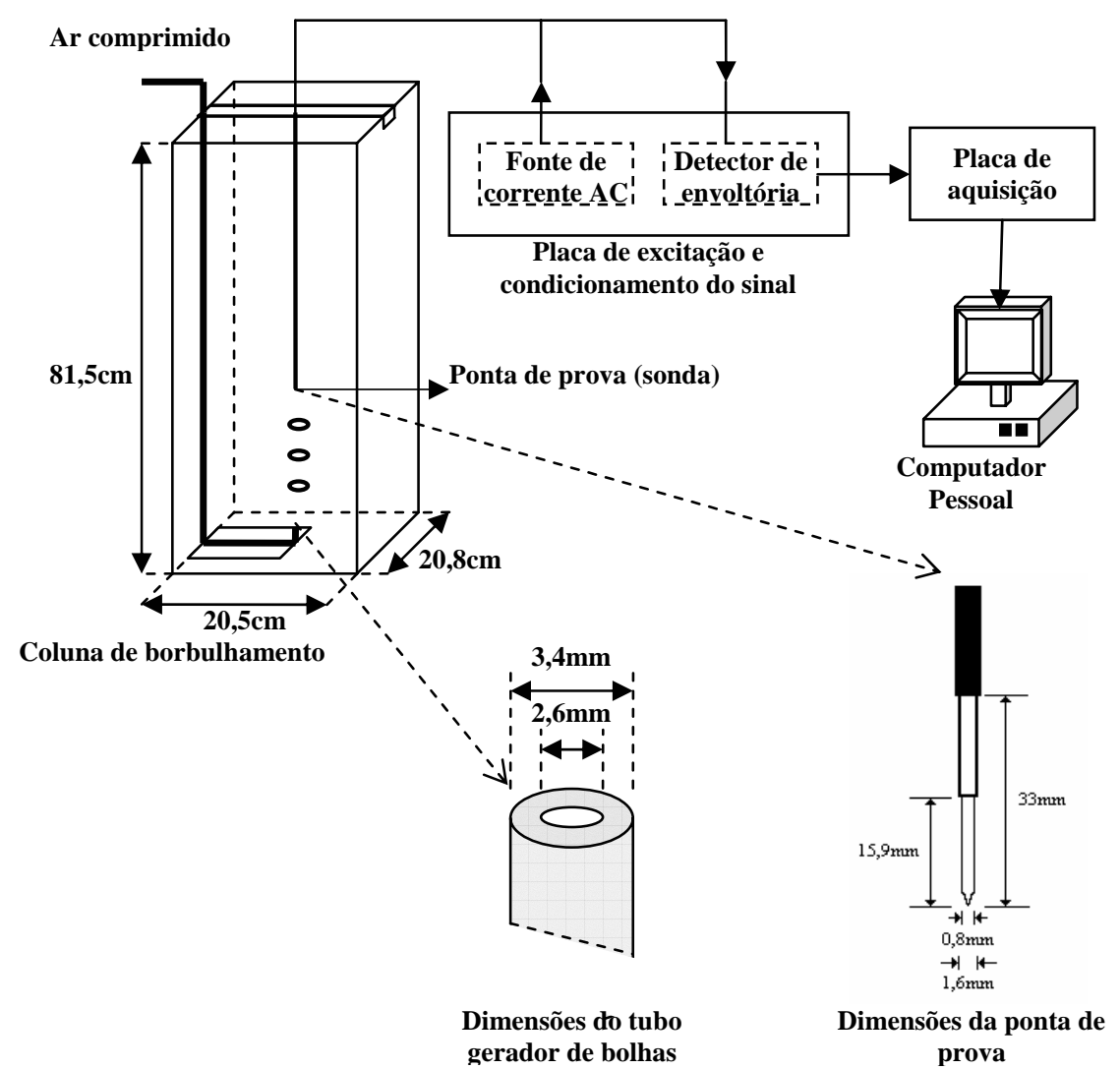

Figura 3.11: Sistema de medida do tamanho de cordas de bolhas através de uma sonda condutiva.

\subsubsection{Processamento do sinal elétrico da sonda}

Utilizando o sistema descrito na seção 3.4 .4 foram realizadas medidas da variação de tensão na sonda devido à passagem de bolhas, tendo como objetivo a determinação de um histograma de cordas. Uma amostra do sinal obtido na saída do detector de envoltória é mostrada na figura 3.12. Neste gráfico o aumento do da tensão medida significa que houve uma significativa diminuição da condutividade entre os eletrodos, causada pela passagem de uma bolha pela ponta da sonda. Portanto, é possível estimar o comprimento da corda através da largura do pulso no sinal como descrito na seção 3.2. Este sinal pode ser usado também para controlar um outro método de medida de tamanho de bolha, como, por exemplo, métodos 
que utilizam imagens obtidas através de uma câmera de vídeo, permitindo a calibração do sistema ou a comparação de resultados entre os dois métodos.

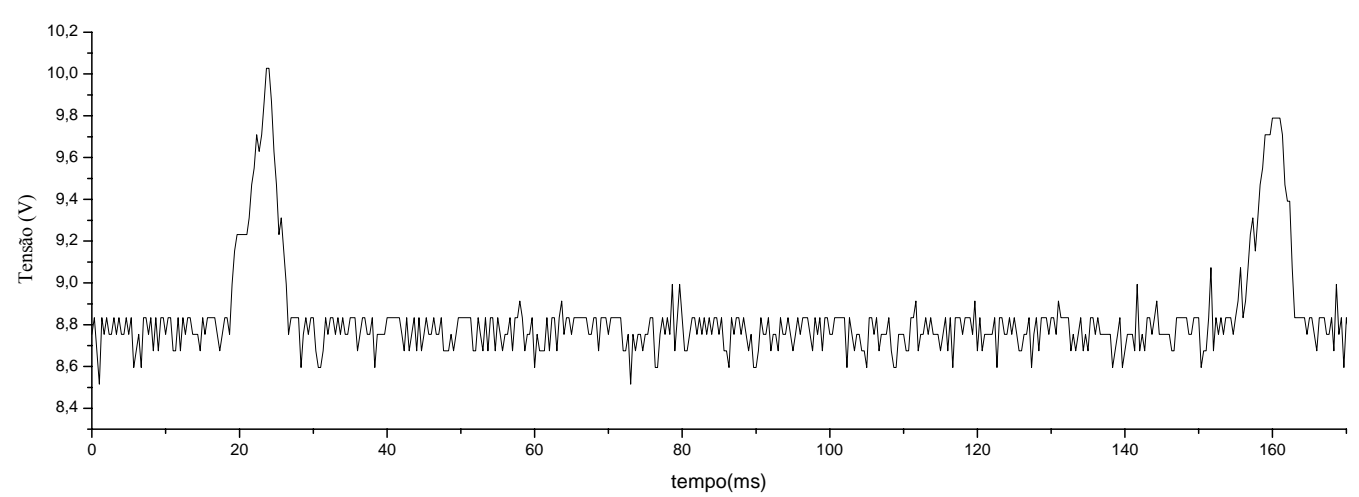

Figura 3.12: Envoltória do Sinal AC da sonda.

Para construir um diagrama de cordas, a partir do sinal mostrado na figura 3.12 , é necessário aplicar algum critério heurístico que permita a extração do tempo levado por cada bolha para atravessar a ponta de prova. A técnica aplicada com maior freqüência é baseada na utilização de um limiar para converter o sinal original em um sinal binário. A escolha do valor de limiar é de fundamental importância para se obter sucesso na analise dos dados experimentais. $\mathrm{O}$ grande problema é que não existe um método objetivo para determinar este valor, e a escolha de um particular limiar normalmente restringe sua aplicabilidade a um número restrito de problemas práticos, ou a casos onde as condições experimentais são muito similares ao caso estudado (SELEGHIM; MILIOLI, 2001).

Com o objetivo de se obter um método de extração do tamanho de cordas que seja menos sensível às variações intrínsecas de cada aplicação, é utilizado o cálculo numérico da fase instantânea da envoltória do sinal de tensão na sonda, através da transformada de Hilbert (POULARIKAS, 1996). Considerando-se $x(t) \in L^{2}(\mathfrak{R})$ representando o sinal original, pode- 
se definir o sinal analítico, $Z_{x}(t)$, associado ao sinal $x(t)$ da seguinte forma (SELEGHIM; MILIOLI, 2001):

$$
Z_{x}(t)=x(t)+j H[x(t)]=x(t)+\frac{j}{\pi} \int_{-\infty}^{+\infty} \frac{x(\tau)}{t-\tau} d \tau
$$

Onde $H[x(t)]$ é a transformada de Hilbert do sinal $x(t)$ e $j=\sqrt{-1}$. O sinal analítico pode também ser expresso na forma polar como:

$$
Z_{x}(t)=A_{x}(t) e^{j \phi_{x}(t)}
$$

Onde $A_{x}(t)$ e $\phi_{x}(t)$ representam amplitude e fase instantâneas, respectivamente. Desta forma quando o sinal apresentar bordas de subida e descida serão obtidos picos negativos (vales), e positivos, respectivamente. Para ressaltar os picos e vales, a fase instantânea é multiplicada pela envoltória do sinal, $x(t)$. A figura 3.13 mostra o resultado do cálculo descrito acima para o sinal mostrado na figura 3.12 .

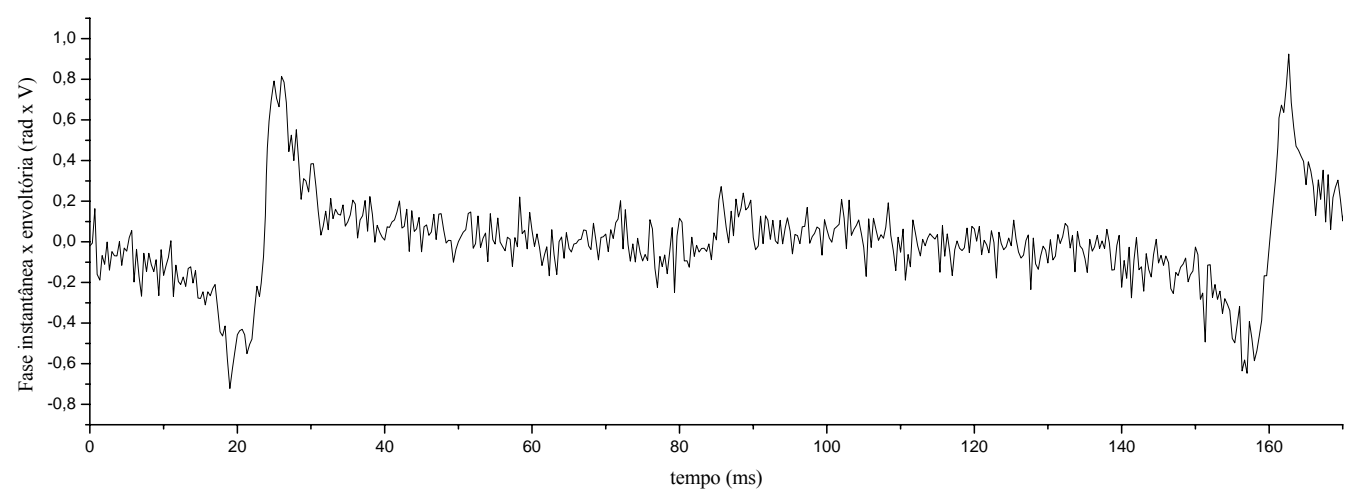

Figura 3.13: Utilização da fase instantânea para detectar bordas de subida e descida da envoltória do sinal da ponta de prova. 
O intervalo de tempo entre um vale e um pico adjacentes permite estimar o tempo de passagem da bolha pela sonda.

Para determinar a largura dos pulsos gerados pela passagem de uma fração de gás pela sonda, são detectados os instantes que o sinal de fase instantânea apresenta valores acima e abaixo de certos limiares. Podem ser consideradas bordas de subidas todos os instantes em que o sinal mostrado na figura 3.13 apresentar valores menores que certo limiar, Limiar $_{S}$, e bordas de descida todos instantes que apresentar valores maiores que o limiar, Limiar $_{D}$. Para diminuir o número de falsas detecções e erros na estimativa da largura do pulso, somente serão consideradas bordas de subida se a última borda detectada tiver sido de descida (com exceção na primeira borda de subida). Da mesma forma somente serão consideradas bordas de descida se a última borda detectada tiver sido de subida. Através da detecção dos instantes de detecção de borda de subida, $t_{S}$, e descida, $t_{D}$, pode-se calcular o tempo, $t_{R}$, levado para que a ponta de prova perfure o seguimento de bolha, da seguinte forma:

$$
t_{R}=t_{D}-t_{S}
$$

A figura 3.14 mostra um exemplo da aplicação do algoritmo de detecção de borda para o sinal da figura 3.12, utilizando-se $\operatorname{Limiar}_{S}=-0,6$ e $\operatorname{Limiar}_{D}=0,7$. A figura 3.15 mostra o sinal do detector de envoltória e o sinal binário onde as larguras dos pulsos representam os tempos de residência das bolhas. 


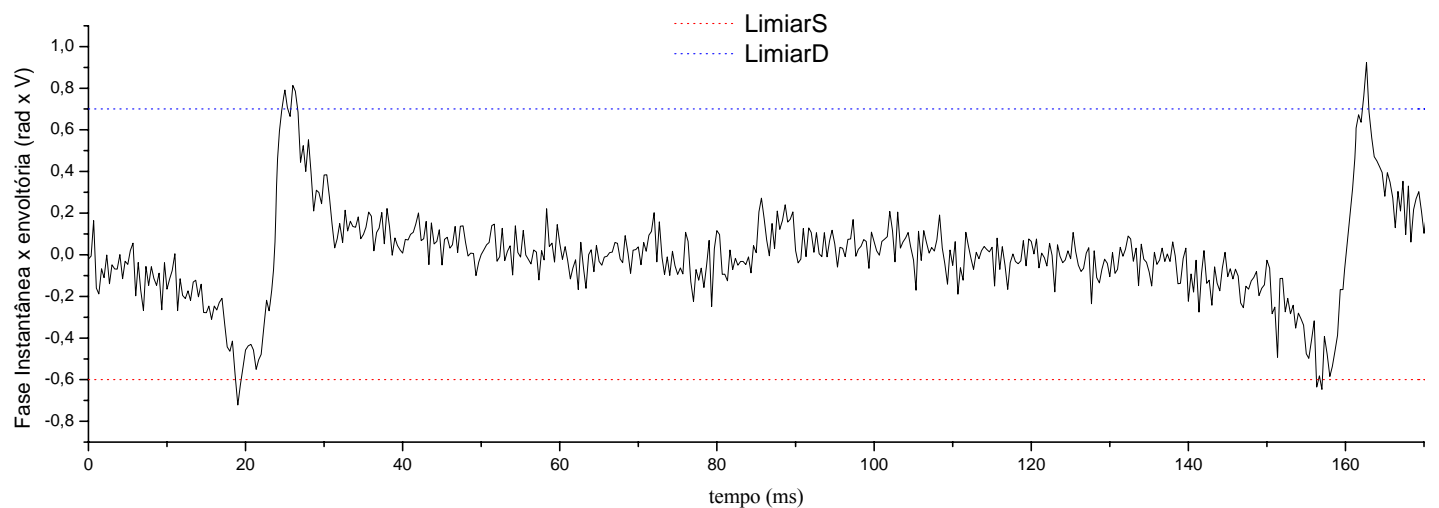

Figura 3.14: Fase instantânea e limiares utilizados para determinar os tempos de residência.

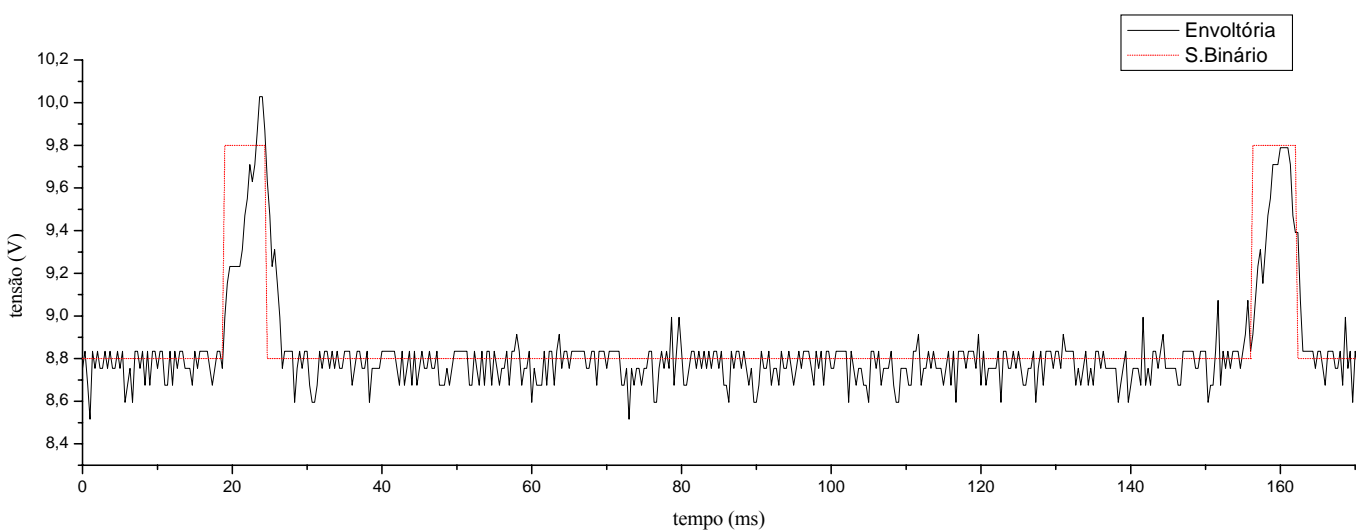

Figura 3.15: Sinal do detector de envoltória e o sinal binário onde as larguras dos pulsos representam os tempos de residência.

Com o cálculo dos tempos de residência, $t_{R}$, de cada bolha, é possível determinar o tamanho de suas respectivas cordas através do valor estimado da velocidade de cada bolha. Com um número grande de amostras de cordas medidas, é possível determinar a distribuição do tamanho de cordas de bolhas que foram perfuradas pela ponta da sonda condutiva, possibilitando assim o cálculo da distribuição de raios de bolhas como descrito na seção 3.3. 


\subsection{Conclusão}

Neste capítulo foram apresentados os principais conceitos envolvidos na determinação do tamanho de bolhas através de uma sonda condutiva, o projeto de circuitos de instrumentação utilizados na aquisição e condicionamento do sinal de uma sonda, e o processamento do sinal da ponta de prova usado para medir comprimento de cordas de bolhas em colunas de borbulhamento bifásicas. Uma descrição detalhada do sistema utilizado para realizar as medidas também é apresentada.

Nas seções 3.1, 3.2 e 3.3 foram apresentados os principais conceitos envolvidos na determinação de tamanho de bolhas através das cordas medidas por uma sonda elétrica em fluxo bifásico composto por uma fase líquida condutiva. A seção 3.3 apresenta um modelo matemático para correlacionar distribuição do tamanho de cordas medidas por uma ponta de prova à distribuição de raios de bolhas. Na seção 3.4 foi apresentado um método de regularização baseado em decomposição em valores singulares para controlar o problema de mal-condicionamento do sistema.

Nas seções 3.5 é apresentada uma descrição do sistema utilizado para realizar as medidas da sonda elétrica, incluindo circuitos eletrônicos utilizados para excitar o fluxo bifásico e condicionar o sinal medido. Neste capítulo também é apresentado um método de processamento de sinal para determinar o tamanho das cordas das bolhas que passam pelo sensor. 


\section{Capítulo 4}

\section{Determinação do diâmetro de bolhas}

\section{utilizando imagens capturadas por uma}

\section{câmera de vídeo}

Neste capítulo são apresentados os principais conceitos envolvidos na utilização de uma câmera de vídeo para determinar o diâmetro de bolhas em colunas de borbulhamento. Um algoritmo de processamento de imagens é proposto baseado em algumas técnicas encontradas na literatura e uma descrição do sistema utilizado na captura e processamento das imagens também é apresentada.

\subsection{Captura de imagens de bolhas em sistemas bifásicos através de uma câmera de vídeo}

Como mostrado no capítulo anterior, uma ponta de prova condutiva permite utilizar as cordas de bolhas medidas para determinar, através de métodos estatísticos, a distribuição de raios na coluna de borbulhamento. Portanto, é conveniente utilizar um outro método de 
determinação de tamanho de bolhas para poder calibrar e validar o sistema de medida de ponta de prova (LIU; CLARK; KARAMAVRUÇ, 1998). Com este objetivo foi utilizado um sistema de aquisição e processamento de imagens para determinar os diâmetros de bolhas.

O sistema é composto por uma câmera de vídeo $\mathrm{CCD}^{8}$ monocromática utilizada para capturar imagens do fluxo de bolhas, como mostra a figura 4.1. Para realizar o processamento das imagens, foi utilizada a placa de aquisição de vídeo NI PXI-1407 da NATIONAL INSTRUMENTS que permite a captura de imagens de vídeo monocromáticas com varredura entrelaçada de 30 quadros por segundo. Esta placa possui um conversor $\mathrm{AD}^{9}$ com saída de 8bits, taxa de amostragem de 5 a $20 \mathrm{MHz}$ e uma interface que permite o processamento das imagens digitais através do programa LABVIEW instalado em um computador pessoal. Uma lâmpada estroboscópica que é acionada em sincronia com a câmera de vídeo é utilizada para se obter imagens com bom nível de contraste e evitar que as imagens das bolhas sejam borradas devido ao seu deslocamento. Para permitir o acionamento da lâmpada em sincronia com a varredura da câmera de vídeo, um circuito eletrônico impresso foi projetado e implementado.

\footnotetext{
${ }^{8} \mathrm{CCD}$ - Charge-coupled device

${ }^{9} \mathrm{AD}$ - Analógico-Digital
} 


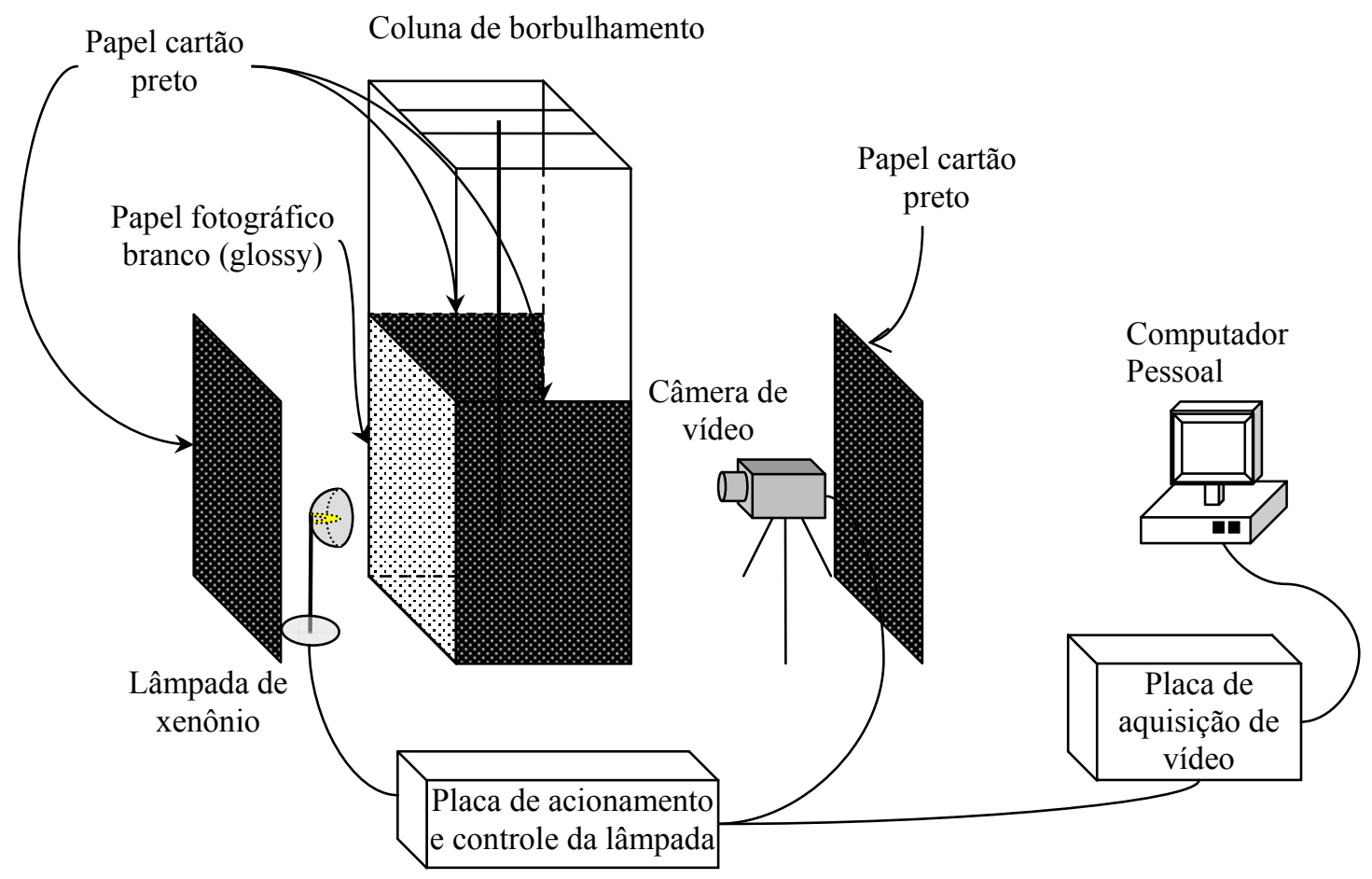

Figura 4.1: Aquisição das imagens de vídeo.

\subsection{Circuito de Sincronização e acionamento da lâmpada estroboscópica}

Apesar da câmera de vídeo utilizada para capturar as imagens apresentar um sistema de controle automático de exposição à luz, denominado obturador, durante os experimentos realizados este dispositivo mostrou-se ineficaz, mesmo com uso de um sistema de iluminação. Devido ao funcionamento incorreto do obturador da câmera, as imagens das bolhas ficavam borradas. Isto ocorre porque o tempo de varredura da câmera não é suficientemente alto quando comparado à velocidade de subida da bolha. Além disso, o modo de varredura entrelaçado da câmera ocasiona a obtenção de um efeito de duplicação de imagens da bolha devido à diferença de tempo levado para que duas linhas adjacentes sejam varridas, visto que 
neste tipo de sistema são percorridas todas as linhas impares para depois serem varridas as linhas pares de um quadro de vídeo. A figura 4.2 ilustra o problema do aparecimento de imagem borrada.

\section{Deslocamento da bolha}

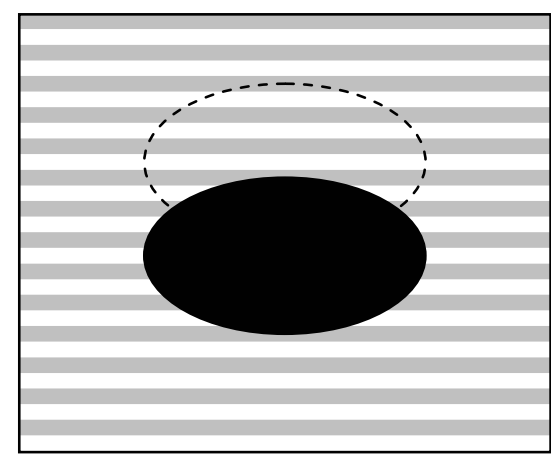

Início da varredura do campo ímpar

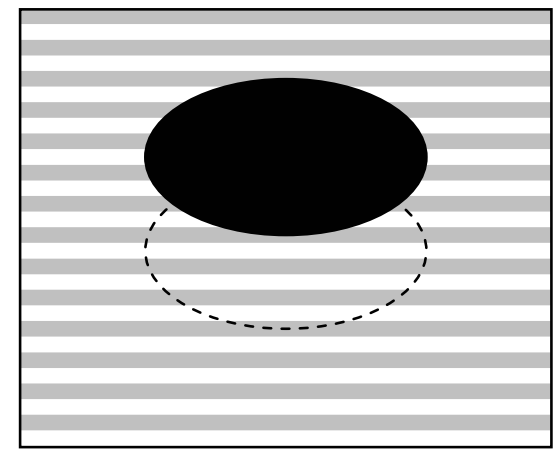

Início da varredura do campo par

Linhas do campo ímpar

Linhas do campo par

Figura 4.2: Aparecimento da imagem de bolha borrada

Para resolver o problema descrito acima, foi projetado e implementado um sistema de acionamento de uma lâmpada de xenônio que opera em sincronia com a varredura da câmera. Este tipo de lâmpada é comumente empregada para se obter efeito estroboscópico, sendo composta por dois terminais de alimentação que devem ser alimentados com uma tensão $\mathrm{DC}^{10}$ em torno de $320 \mathrm{~V}$ e um terminal de disparo que deve ser excitado através de um pulso de alta tensão (aproximadamente $5 \mathrm{kV}$ ). Lâmpadas de xenônio emitem um feixe de luz durante um intervalo de tempo extremamente curto, o que permite sensibilizar o sensor de captura da câmera sem que a bolha apareça borrada na imagem. Um refletor parabólico também foi utilizado para direcionar o feixe de luz na região de interesse.

\footnotetext{
${ }^{10}$ DC - Direct Current
} 
O circuito utilizado é composto basicamente por uma lógica de controle e um circuito de acionamento da lâmpada. A lógica de controle é utilizada para sincronizar o sistema estroboscópico com a varredura da câmera de vídeo. Para realizar a sincronização, o sinal de sincronismo vertical do vídeo é extraído através do circuito integrado LM1881. A figura 4.3 mostra os sinais de vídeo gerados pelo $\mathrm{CI}^{11}$ que são utilizados no circuito lógico.

(a)
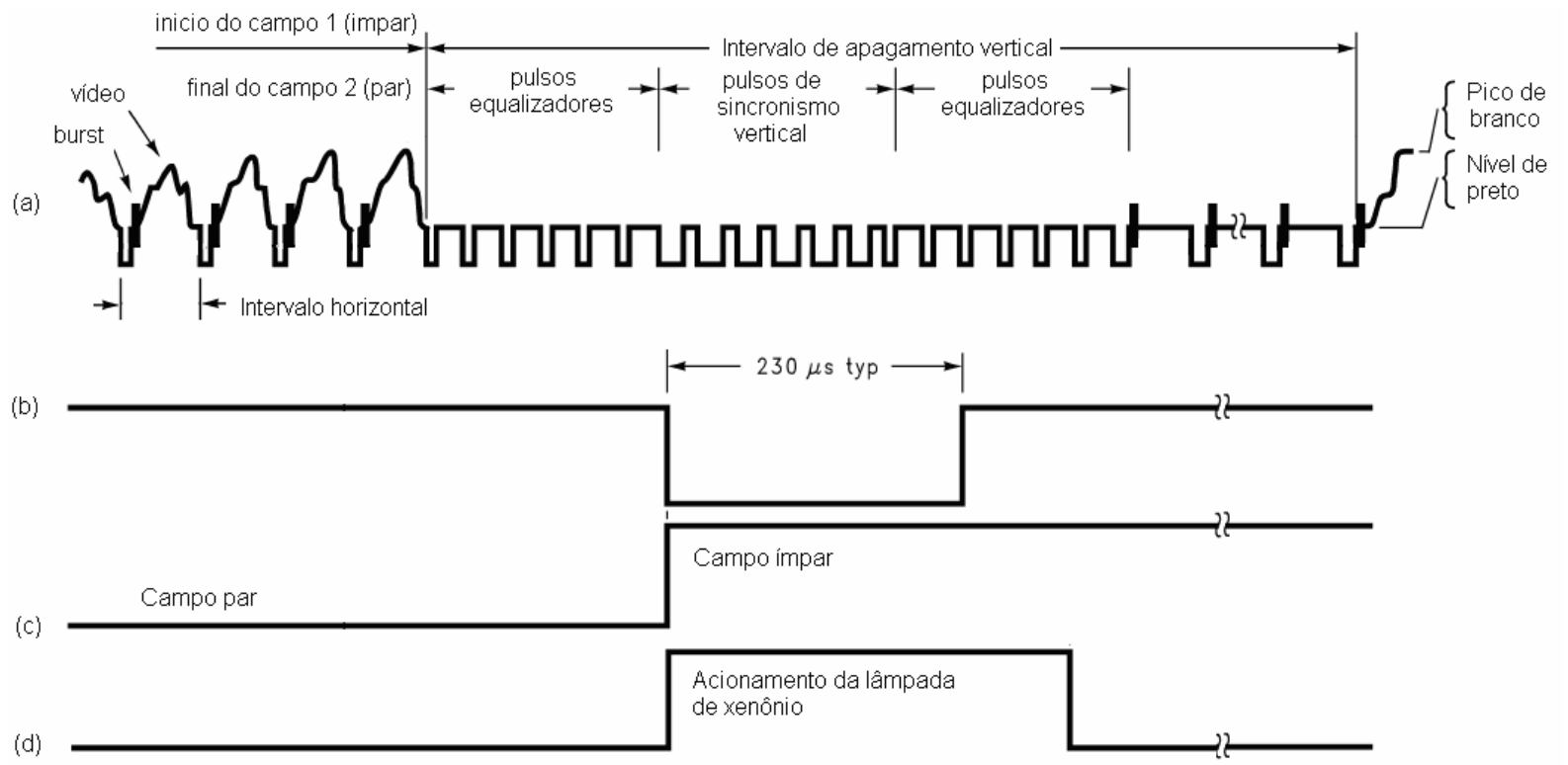

Figura 4.3: (a) Sinal de vídeo composto; (b) pulso de sincronismo extraído pelo LM1881; (c) campo par em nível baixo e campo ímpar em nível alta; (d) Pulso gerado pelo monoestável.

Para se obter um pulso a cada início de quadro foram utilizadas portas lógicas e um circuito integrado temporizador LM555 na configuração monoestável. A figura 4.4 mostra a lógica de controle. Um acoplador óptico TL111 é utilizado para isolar eletricamente o circuito lógico do circuito de acionamento da lâmpada estroboscópica. O circuito de acionamento da lâmpada é composto basicamente de um circuito dobrador de tensão e um transformador de disparo que converte pulsos de baixa tensão gerados pela lógica de controle em pulsos de alta tensão que excitam o terminal de disparo da lâmpada. O chaveamento do transformador é realizado pelo $\mathrm{SCR}^{12}$ TIC126, permitindo que o capacitor $\mathrm{C}_{2}$ seja descarregado sobre o

\footnotetext{
${ }^{11} \mathrm{CI}$ - Circuito Integrado

${ }^{12}$ SCR - Silicon Controlled Rectifier
} 
transformador. A figura 4.4 mostra o circuito de acionamento e sincronização da lâmpada estroboscópica ou flash.

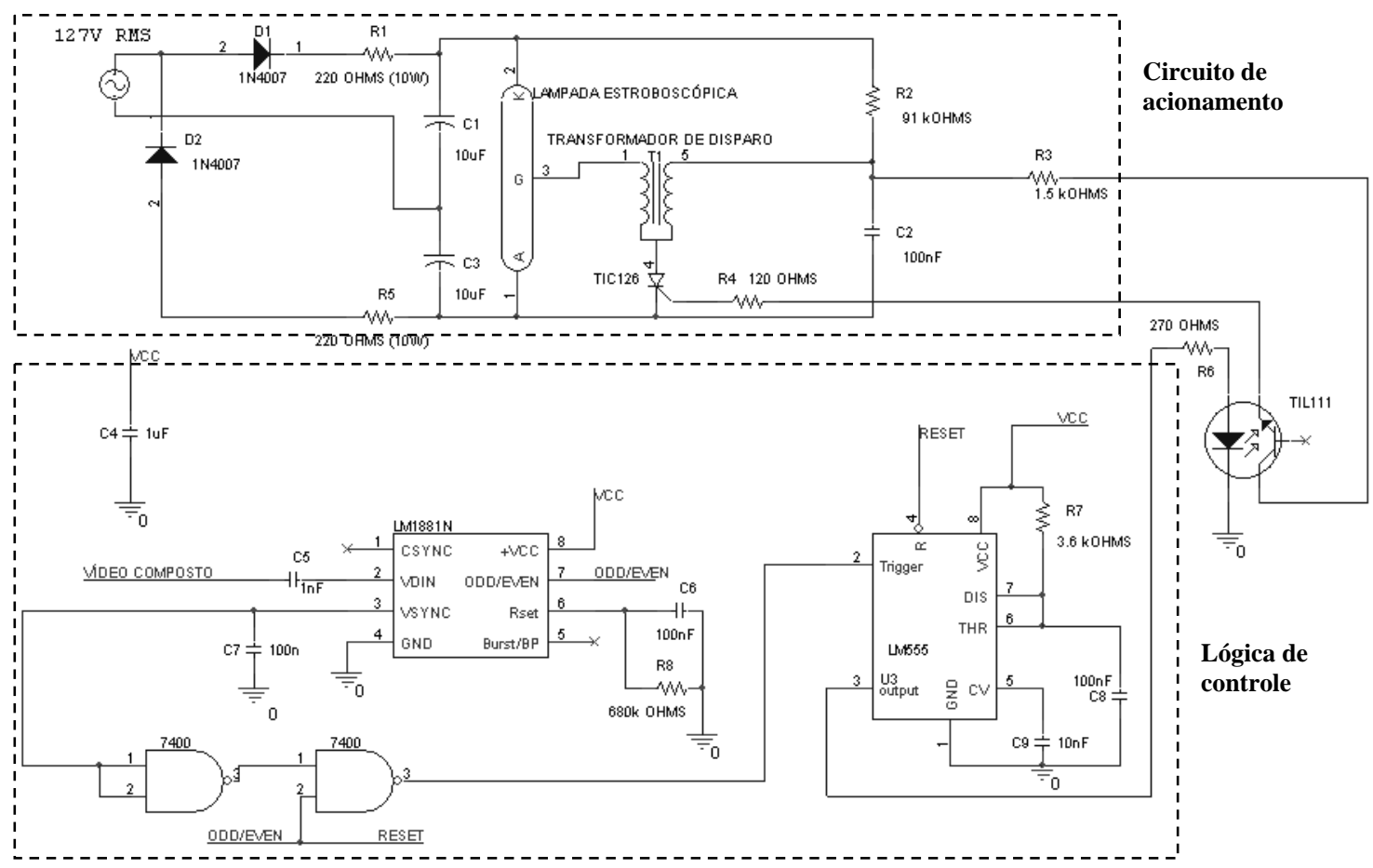

Figura 4.4: Circuito de acionamento e sincronização do flash.

Para evitar que a luz exterior sensibilize o sensor da câmera, proteções de papel cartão preto foram colocadas nas paredes laterais da coluna de borbulhamento e atrás da câmera. Um papel fotográfico de alto brilho (glossy paper) também foi utilizado na parede de fundo da coluna para obter um efeito de realce das bordas de bolhas e tornar a iluminação mais homogênea. A lâmpada estroboscópica então foi colocada na parte de trás da coluna, permitindo a captura das imagens sem que ocorra o borramento. Uma outra proteção também foi colada atrás da lâmpada para que a luz externa proveniente da parte de trás da coluna não sensibilizasse a câmera. A figura 4.1 ilustra o sistema de aquisição e iluminação utilizados.

Na figura 4.5 são mostradas imagens de bolhas obtidas através de uma câmera de vídeo com a utilização do sistema de iluminação e sem a sua utilização. A imagem obtida sem 
a utilização de lâmpada estroboscópica mostra uma imagem de bolha borrada devido ao fato da câmera de vídeo não conseguir ajustar automaticamente o obturador. A imagem obtida pelo uso da lâmpada de xenônio é composta apenas pelo campo impar do quadro de vídeo.

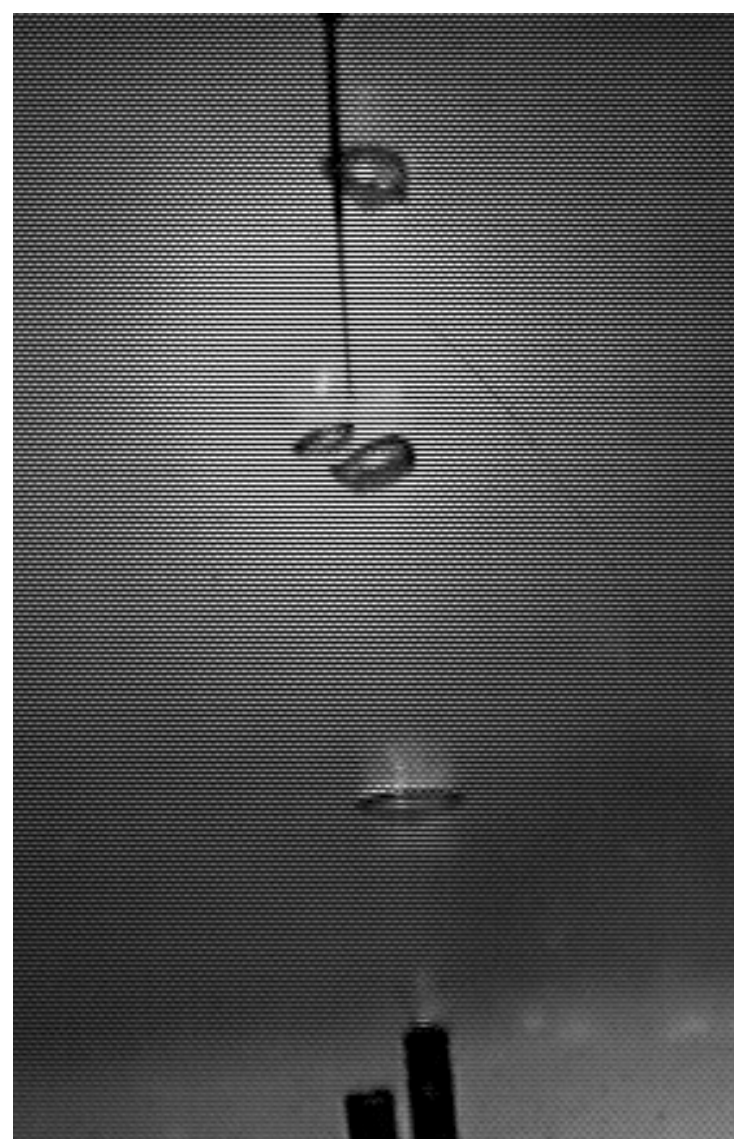

(a)

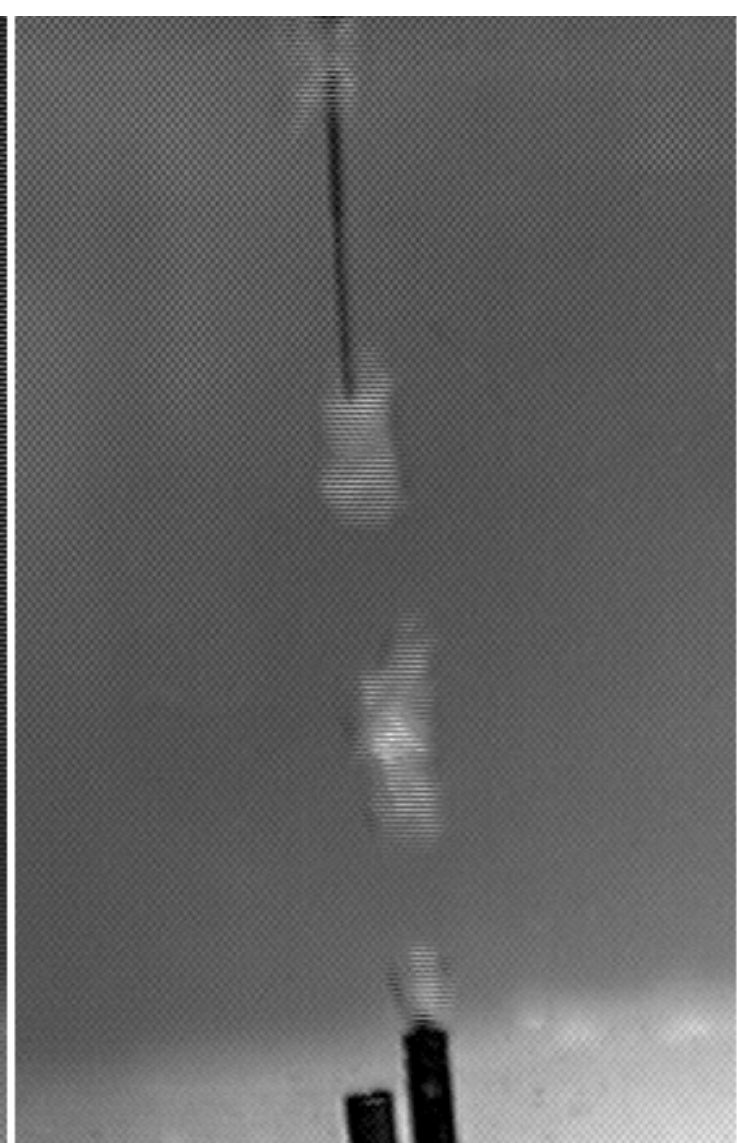

(b)

Figura 4.5: (a) Imagem obtida com flash; (b) Imagem obtida sem flash.

\subsection{Aquisição e armazenamento das imagens}

A placa de aquisição de vídeo digitaliza os quadros de vídeo, permitindo que estes sejam processados através do software LABVIEW. O programa desenvolvido utiliza um sistema de aquisição circular que consiste de uma série de buffers que são atualizados 
constantemente. A figura 4.6 ilustra o funcionamento da aquisição circular. Quando o programa detecta a passagem de uma bolha através do sinal elétrico da sonda, algumas imagens são retiradas dos buffers, para que o algoritmo de processamento de imagem determine o tamanho desta bolha.

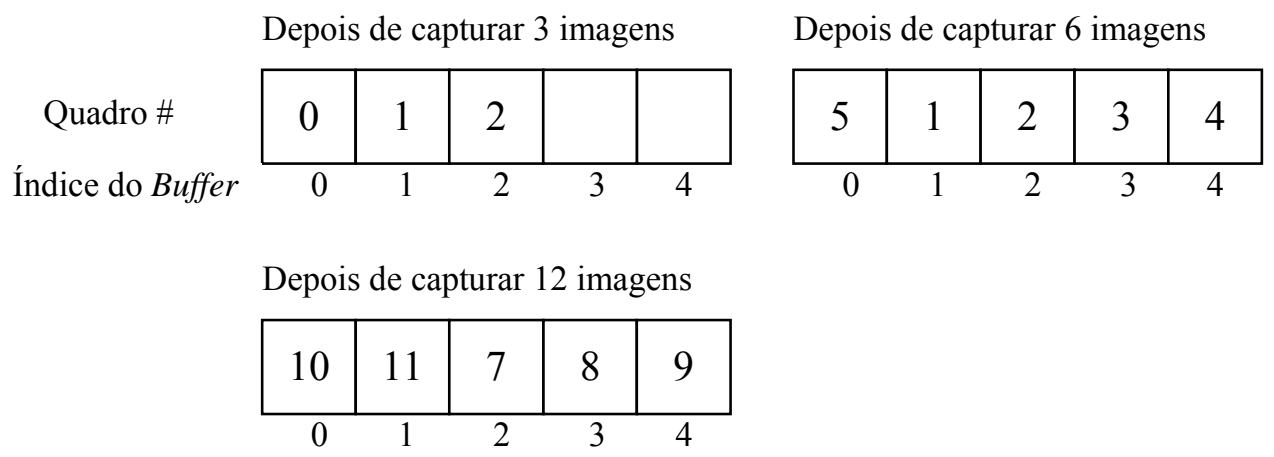

Figura 4.6: Aquisição circular de imagens atraves de um conjunto de buffers.

\subsection{Processamento das imagens de bolhas}

Para medir o tamanho de bolhas através de imagens é preciso empregar algumas técnicas de processamento de imagem que permitam segmentar, ou separar, as áreas úteis da imagem original para depois se obter as informações desejadas. O processo de segmentação de imagens é uma das áreas mais difíceis relacionada ao processamento de imagens, determinando na maioria das vezes o sucesso e robustez da análise. Em imagens monocromáticas geralmente os métodos de segmentação são baseados em características básicas como valores de níveis de cinza, descontinuidade e similaridade (GONZALEZ; WOODS, 1992). A figura 4.7 mostra um diagrama de blocos com os principais passos do algoritmo de processamento de imagens de bolhas. 


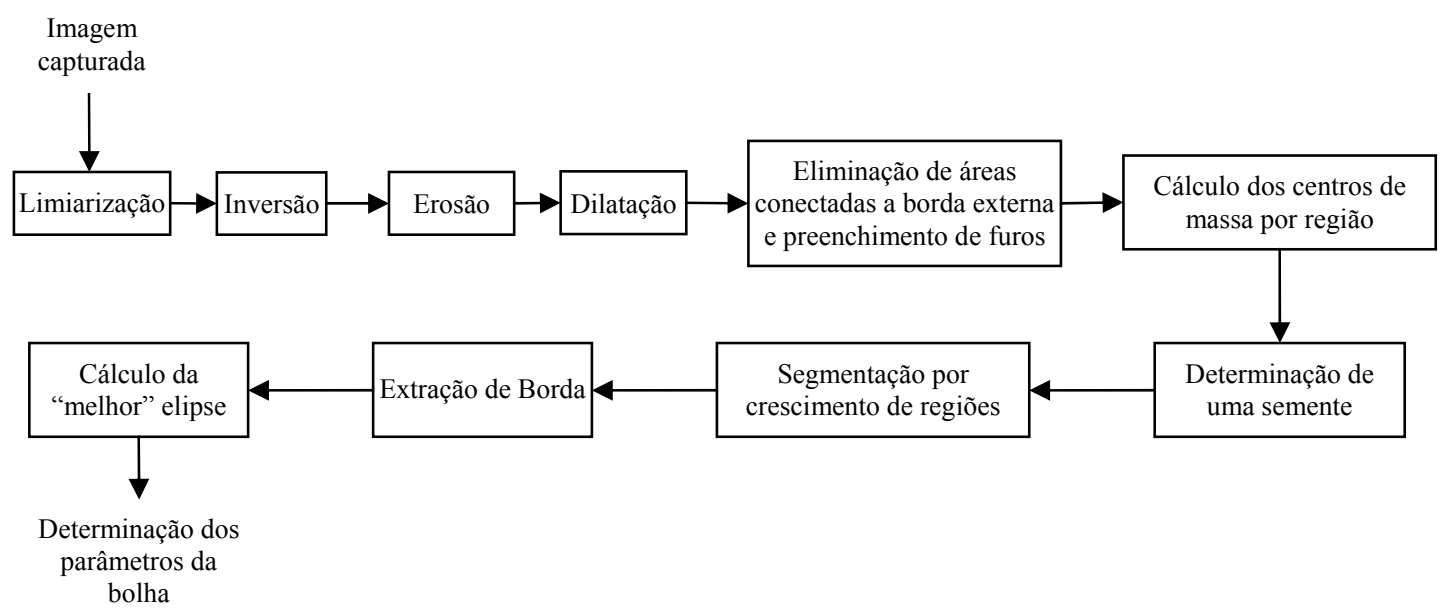

Figura 4.7: Diagrama de blocos das principais etapas do processamento das imagens de bolhas

\subsubsection{Limiarização}

Considerando $I(x, y)$ o nível de cinza do pixel com coordenadas $(x, y), p(x, y)$ denotando alguma propriedade local deste ponto e o par de eixos utilizado para representar uma imagem digital mostrado na figura 4.8, pode-se definir o processo de limiarização como:

$$
B(x, y)=\left\{\begin{array}{lc}
1 & \text { se } \mathrm{I}(\mathrm{x}, \mathrm{y})>\mathrm{T} \\
0 & \text { caso contrário }
\end{array}\right.
$$

Onde T é uma função dependente de $(x, y), p(x, y)$ e $I(x, y)$, que determina se um pixel pertence à região de interesse. $B(x, y)$ é a imagem binária resultante onde um pixel 1 determina que este ponto pertence a um objeto e 0 corresponde ao fundo da imagem. Quando T depende somente da função $I(x, y)$ o limiar é chamado global, e se $\mathrm{T}$ depende tanto de 
$p(x, y)$ quanto de $I(x, y)$, então o limiar é chamado de dinâmico (GONZALEZ; WOODS, 1992).

As imagens originais possuem $148 \times 250$ pixels com 256 níveis de cinza. Como as imagens das bolhas capturadas apresentam um bom contraste, foi utilizada uma limiarização global para iniciar a segmentação. Neste caso o limiar é uma constante que representa um determinado valor de nível de cinza. Aplicando-se ponto a ponto a condição 4.1, são determinados os pixels pertencentes à bolha. O limiar foi determinado experimentalmente através de uma analise visual, escolhendo-se um valor que apresentasse um melhor resultado para o maior número de imagens.

A figura 4.8 apresenta um exemplo de aplicação de limiarização em uma imagem de bolha capturada pelo sistema descrito na seção 4.1, utilizando um limiar, T, de 170. Em imagens que apresentam um bom contraste e que a iluminação não tem variações significativas, o limiar global funciona bem, mas quando estas condições não são satisfeitas é necessário utilizar critérios mais sofisticados ou mesmo um limiar dinâmico.

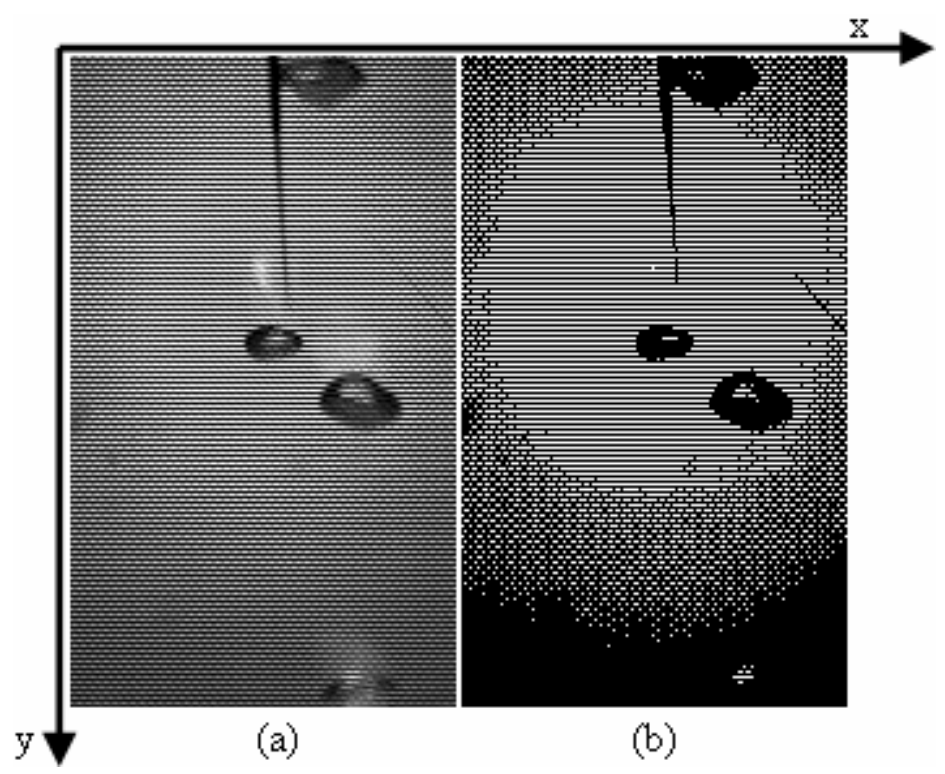

Figura 4.8: Eixos utilizados para representar uma imagem digital (a) Imagem Original; (b) Imagem binarizada por limiarização. 


\subsubsection{Operações Morfológicas}

Operações morfológicas usualmente trabalham com imagens binárias, processando cada pixel baseado na sua vizinhança. Cada pixel pode ser colocado tanto em nível 0 ou 1 dependendo dos valores dos pixels da sua vizinhança e da operação utilizada. Este tipo de procedimento pode ser usado para expandir ou reduzir partículas, suavizar bordas de objetos, determinar bordas internas e externas, e localizar configurações particulares de pixels na imagem. Alguns exemplos de operações morfológicas são erosão, dilatação, abertura, fechamento, hit-or-miss, afinamento, espessamento e preenchimento (GONZALEZ; WOODS, 1992; IMAQ..., 2000).

\subsubsection{Erosão}

Considerando-se que os pixels de um objeto assumem valores iguais a 1 e o fundo da imagem pixels iguais a 0 , o processo de erosão elimina pixels 1 isolados e o contorno de partículas de acordo com um template denominado de elemento estruturante. Para cada pixel $P_{0}$, o elemento estruturante é centrado em $P_{0}$. Os pixels do elemento estruturante que são considerados durante a operação apresentam valores iguais a 1 , e $P_{i}$ representa cada pixel da imagem considerado pelo elemento estruturante centrado em $P_{0}$. Então a operação de erosão pode ser definida seguinte forma (IMAQ..., 2000):

- Se o valor de um pixel $P_{i}$ é igual a 0 , então $P_{0}$ é colocado em 0 , caso contrário $P_{0}$ é colocado em 1. 
- Se a operação lógica AND entre os valores de $P_{i}$ e seus correspondentes valores no elemento estruturante resultar em 1, então $P_{0}$ é colocado em 1, caso contrário $P_{0}$ é colocado em 0.

Exemplo:

Considere o seguinte elemento estruturante $\mathbf{E}$ :

$$
\mathbf{E}=\left[\begin{array}{lll}
0 & 0 & 0 \\
1 & 0 & 1 \\
0 & 0 & 0
\end{array}\right]
$$

Aplicando uma erosão na imagem binária da figura $4.9 \mathrm{~b}$ através do elemento estruturante E mostrado na figura 4.9a, obtém-se a imagem da figura 4.9c.

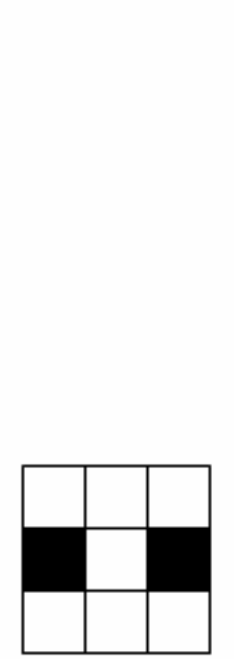

(a)

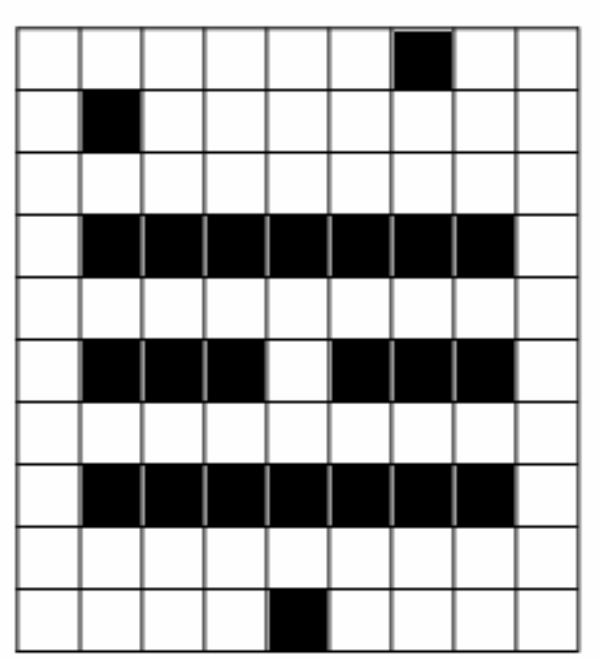

(b)

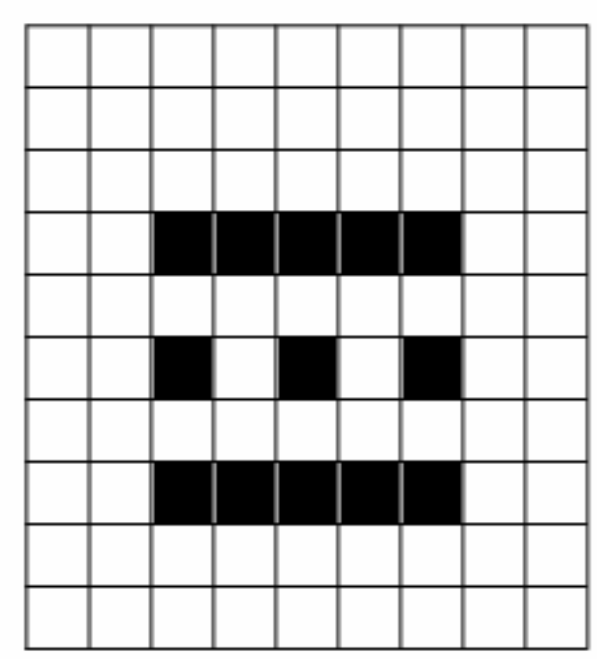

(c)

Figura 4.9: (a) Elemento estruturante; (b) imagem original (c) imagem resultante do processo de erosão. 
A operação de erosão pelo elemento estruturante $\mathbf{E}$ é utilizada para diminuir o ruído da imagem de bolha que não é eliminado após o processo de limiarização, descrito na seção 4.3.1. O processo de erosão também elimina a não uniformidade do fundo da imagem devido à presença de apenas um campo do quadro de vídeo. A figura 4.10 mostra um exemplo da aplicação desta técnica utilizando a imagem binária da figura $4.8 \mathrm{~b}$ invertida.

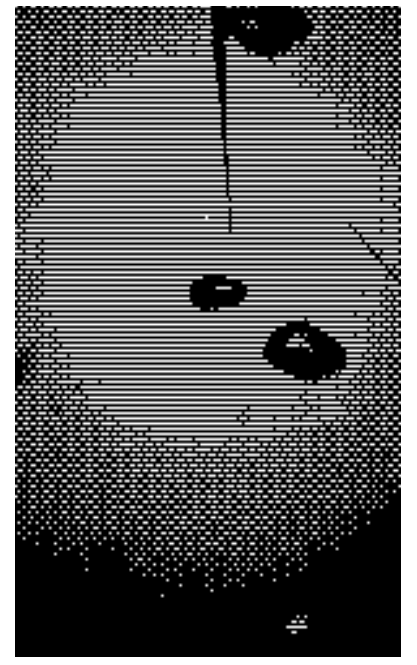

(a)

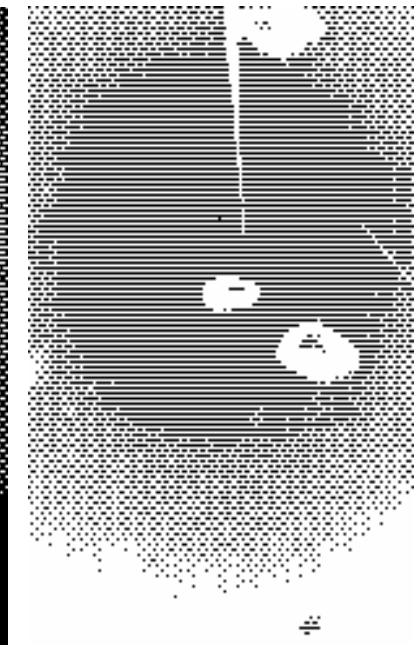

(b)

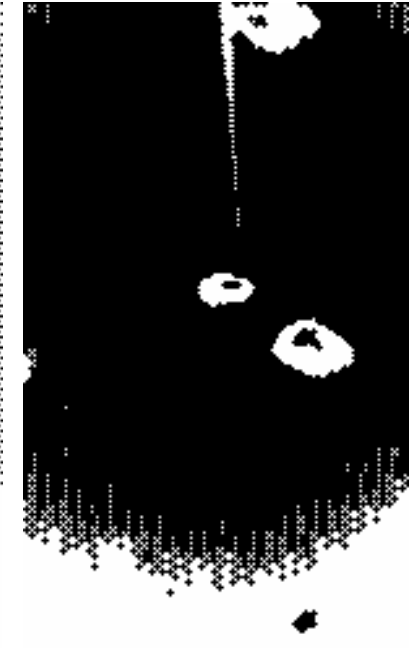

(c)

Figura 4.10: (a) Imagem binarizada; (b) imagem binarizada invertida; (c) Imagem após erosão.

\subsubsection{Dilatação}

A operação de dilatação elimina pequenos furos em partículas isoladas e expande o contorno de acordo com o elemento estruturante aplicado sobre a imagem. A função de dilatação tem efeito inverso ao da erosão, visto que o processo de dilatação é equivalente a aplicar uma erosão no fundo da imagem. Considerando um elemento estruturante centrado em um pixel $P_{0}$, e os pixels $P_{i}$ da imagem que são afetados pelo elemento estruturante, pode-se determinar o novo valor de $P_{0}$ da seguinte forma (IMAQ..., 2000): 
- Se o valor de um pixel $P_{i}$ é igual a 1 , então $P_{0}$ é colocado em 1 , caso contrário $P_{0}$ é colocado em 0.

- Se a operação lógica OR entre os valores de $P_{i}$ e seus correspondentes valores no elemento estruturante resultar em 1 , então $P_{0}$ é colocado em 1 , caso contrário $P_{0}$ é colocado em 0.

Exemplo

Considere o seguinte elemento estruturante $\mathbf{E}$ :

$$
\mathbf{E}=\left[\begin{array}{lll}
1 & 1 & 0 \\
1 & 1 & 0 \\
0 & 0 & 0
\end{array}\right]
$$

Aplicando uma dilatação na imagem binária da figura 4.11b, utilizando o elemento estruturante E mostrado na figura 4.11a, obtém-se a imagem da figura 4.11c. A operação de dilatação é utilizada para preencher elementos vazios dentro da bolha, além de recuperar parte da borda da imagem que é perdida devido à operação de erosão aplicada anteriormente. A figura 4.12 mostra um exemplo de aplicação do processo de dilatação na imagem de uma bolha resultante do processo de erosão. 


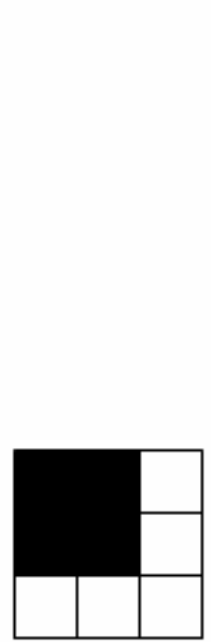

(a)

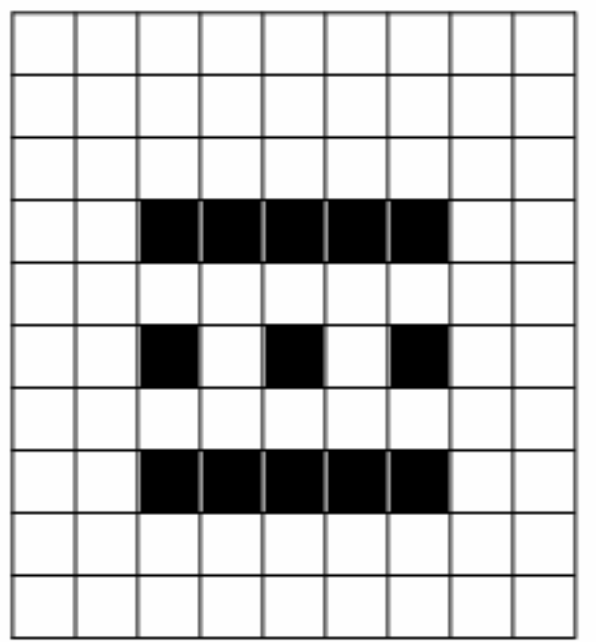

(b)

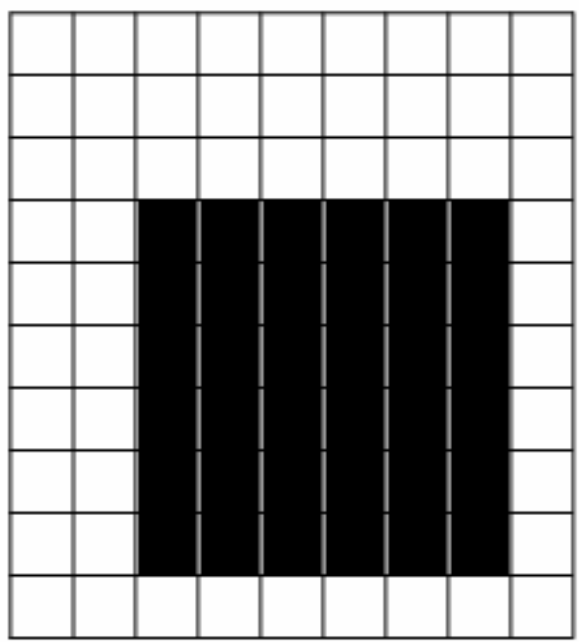

(c)

Figura 4.11: (a) Elemento estruturante; (b) imagem original (c) imagem resultante do processo de dilatação.

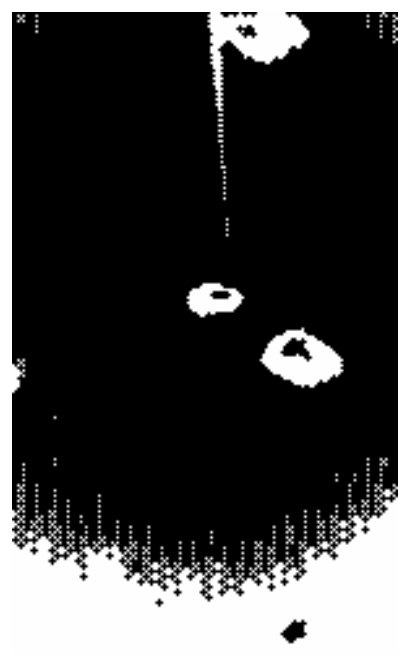

(a)

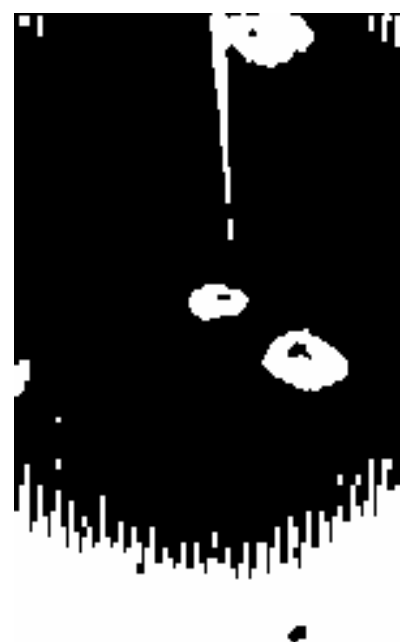

(b)

Figura 4.12: (a) Imagem original; (b) Imagem resultante do processo de dilatação.

\subsubsection{Preenchimento de furos e eliminação de pixels de regiões}

\section{conectadas à borda externa da imagem}

Após realizar as operações de erosão e dilatação, descritas na seção anterior, a imagem binária resultante (figura 4.12b) ainda apresenta áreas espúrias que não são de interesse para a segmentação das imagens de bolhas e cálculo das dimensões das mesmas. Além disso, essas 
regiões podem afetar a extração de características e o processamento das imagens, portanto deve-se aplicar algum algoritmo que minimize a influência ou elimine os pixels que não pertencem às imagens de bolhas.

Com objetivo de eliminar áreas que não são de interesse, são determinados todos os pixels iguais a 1 que pertencem às áreas conectadas à borda mais externa da imagem. Assim todos os "objetos" que tocam os limites extremos da imagem serão eliminados juntamente com as bordas externas da imagem. Para eliminar estas áreas da imagem é utilizado o critério de conectividade-de-4 (GONZALEZ; WOODS, 1992). Considerando-se um pixel central $p(x, y)$ com valor igual a 1 , é definido que um outro pixel está conectado-de-4 em relação a ele, se eles forem adjacentes na vertical ou horizontal, e ambos apresentarem valor igual a 1 . A figura 4.13 mostra um exemplo da definição de conectividade-de-4.

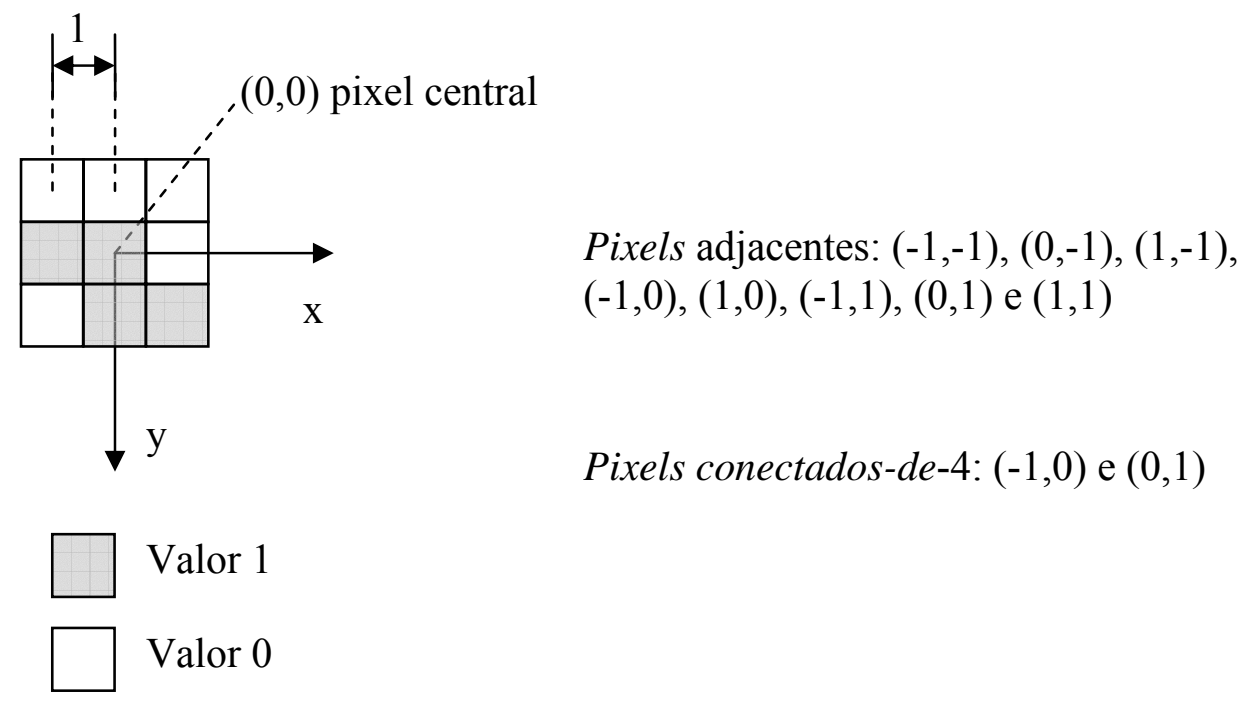

Figura 4.13: Exemplo de conectividade-de-4.

Utilizando o critério descrito acima, verifica-se a conectividade pixel a pixel na imagem binária a fim de determinar as áreas da imagem que tocam a borda mais externa. $\mathrm{O}$ processo é repetido até que não se encontre nenhum novo pixel conectado. Assim é obtida 
uma imagem onde todos os pixels iguais a 0 representam as regiões que tocam a borda externa da imagem. A fim de obter uma imagem resultante que apresente apenas possíveis imagens de bolhas, é realizada uma operação lógica AND entre a imagem original (figura 4.12b) e a imagem resultante do processo de verificação de pontos conectados a bordas externas da imagem. A figura 4.14 ilustra a aplicação do algoritmo descrito acima.

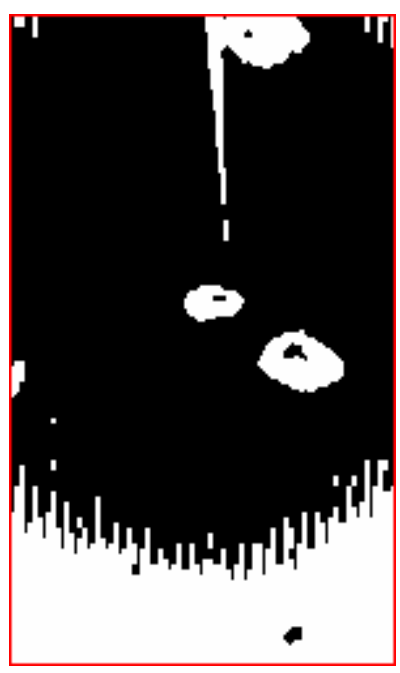

(a)

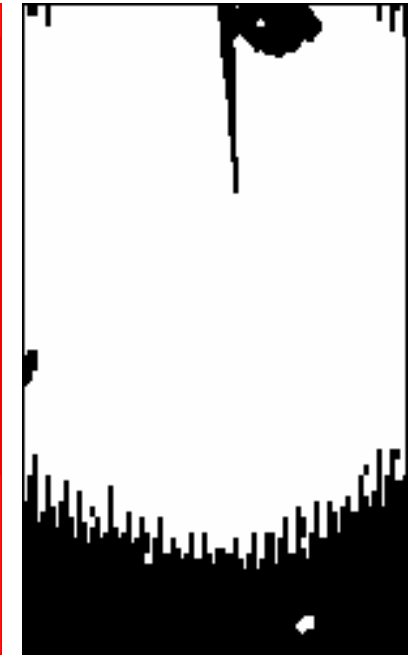

(b)

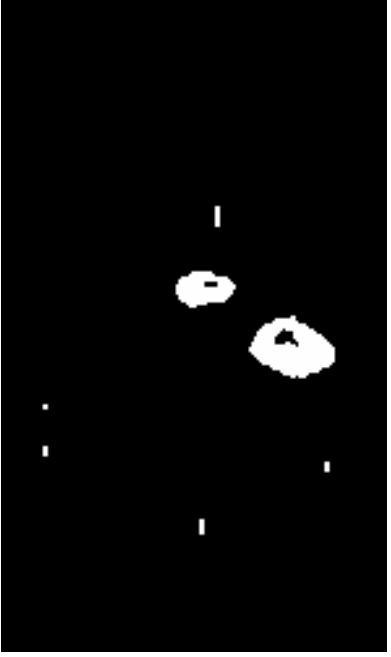

(c)

Figura 4.14: (a) imagem binária e borda externa em destaque; (b) imagem após a operação de extração dos pixels que tocam a borda; (c) imagem resultante após a operação AND entre as imagens “(a)” e “(b)”.

Obtida uma imagem das possíveis bolhas, verifica-se que estas apresentam um furo ou vazio. Desta forma, é interessante o preenchimento destes furos com a finalidade de possibilitar a extração da borda da imagem que corresponde à interface entre a bolha e a fase líquida. Além disso, o preenchimento destes vazios evita que os mesmos afetem posteriormente o processo de segmentação da imagem de bolha.

Com a finalidade de preencher furos da imagem, é realizada uma verificação na imagem binária (figura 4.14c) das áreas de fundo que não estão conectados á borda mais externa da imagem (RUSS, 1995). Para determinar se um pixel pertence a uma área que toca a borda mais externa é utilizado novamente o critério de conectividade-de- 4 . Se um pixel de 
fundo (valores binários iguais a zero) não for conectado a uma área que toca a borda externa, o valor do mesmo é alterado para 1, caso contrário o pixel permanece inalterado. O processo é repetido até que não seja encontrado nenhum novo pixel pertencente a uma região de furo. A figura 4.15 mostra um exemplo da aplicação do algoritmo de preenchimentos de furos.

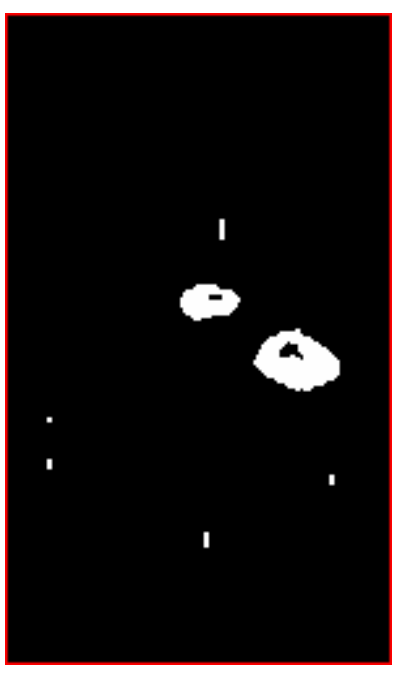

(a)

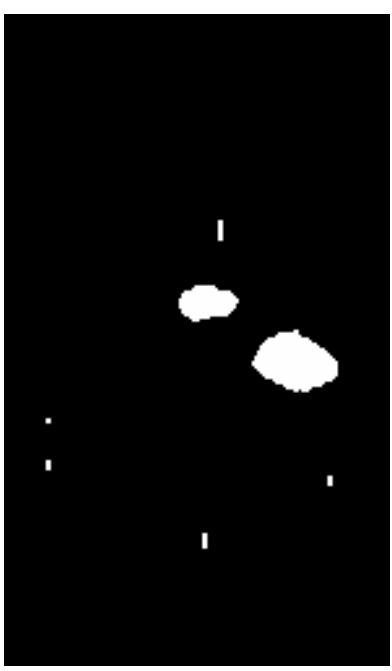

(b)

Figura 4.15: (a) imagem binária; (b) imagem binária resultante da aplicação do algoritmo de preenchimento de furos.

\subsubsection{Cálculo do centro de massa em imagens monocromáticas}

O centro de massa de um objeto é o ponto onde toda sua massa pode ser concentrada sem alterar seu primeiro momento em qualquer um dos eixos. Podemos definir de maneira análoga o centro de massa de imagem da seguinte forma (LEVINE, 1985):

$$
\begin{aligned}
& m_{00}=\sum_{x=0}^{M-1} \sum_{y=0}^{N-1} I(x, y) \\
& m_{10}=\sum_{x=0}^{M-1} \sum_{y=0}^{N-1} x \cdot I(x, y)
\end{aligned}
$$




$$
\begin{aligned}
& m_{01}=\sum_{x=0}^{M-1} \sum_{y=0}^{N-1} y \cdot I(x, y) \\
& X_{M}=\frac{m_{10}}{m_{00}} \\
& Y_{M}=\frac{m_{01}}{m_{00}}
\end{aligned}
$$

Onde $m_{00}$ é o momento de ordem zero; $m_{10}$ e $m_{01}$ são os momentos de ordem 1 com relação aos seus respectivos eixos. As coordenadas $X_{M}$ e $Y_{M}$ do centro de massa de uma imagem monocromática podem ser calculadas pelas equações 4.5 e 4.6 , respectivamente. $I(x, y)$ corresponde ao valor em nível de cinza dos pixels localizado em um ponto $(x, y)$ de uma imagem composta por $(M-1) \times(N-1)$ pixels.

Para uma imagem binária as coordenadas do centro de massa $\left(X_{M}, Y_{M}\right)$ podem ser obtidas através das equações 4.2, 4.3, 4.4, 4.5 e 4.6, utilizando os pontos onde os valores dos pixels são iguais a 1 , portanto no cálculo do centro de massa de uma imagem binária todos os pontos pertencentes ao objeto possuem um mesmo peso.

\subsubsection{Segmentação da imagem da bolha detectada pelo sistema de}

\section{sonda condutiva}

Como pode ser visto na figura 4.8, as imagens podem apresentar mais de uma bolha. Portanto é necessário aplicar algum critério para determinar qual bolha foi detectada pela ponta de prova condutiva. É preciso também o desenvolvimento de um algoritmo de 
segmentação que extraia somente a bolha desejada. Foi constatado experimentalmente que havia um atraso entre a detecção de uma bolha através do sinal elétrico e a captura do quadro atual, devido ao processamento de sinal. Portanto no instante de captura da imagem no buffer a bolha já tinha sido perfurada pela ponta da sonda, e algumas vezes deformando a bolha, tornando a medida através da imagem incerta. Como o programa utilizado para capturar as imagens armazena em um buffer o quadro atual mais dois quadros anteriores, é possível utilizar estes quadros para determinar o tamanho da bolha.

Para determinar o tamanho da bolha através da imagem de vídeo será utilizado o primeiro quadro anterior ao atual. Nesta imagem a bolha que foi detectada pela sonda elétrica ainda não foi perfurada pela ponta de prova. Supondo-se que $\left(x_{B}, y_{B}\right)$ seja o ponto da imagem mais provável que a bolha esteja no instante da detecção, e que os centros de massa de cada bolha, $\left(X_{M i}, Y_{M i}\right)$ sejam conhecidos, é possível determinar a bolha que tem a maior probabilidade de ter passado pelo sensor. Considerando que a coordenada da ponta de prova, $\left(x_{\text {SONDA }}, y_{\text {SONDA }}\right)$, é conhecida, pode-se obter os seguintes parâmetros:

$$
\begin{gathered}
\text { Dist }_{i}=\sqrt{\left(x_{B}-X_{M i}\right)^{2}+\left(y_{B}-Y_{M i}\right)^{2}} \quad \text { para } \mathrm{i}=1 \ldots \mathrm{N}_{\mathrm{B}} \\
x_{B}=x_{\text {SONDA }} \\
y_{B}=y_{S O N D A}+\Delta y
\end{gathered}
$$

Onde $\mathrm{N}_{\mathrm{B}}$ é o número de bolhas presentes na imagem, e $\Delta y$ é um valor de calibração obtido experimentalmente. Dist ${ }_{i}$ é a distância euclidiana entre o centro de massa de cada bolha e o ponto mais provável $\left(x_{B}, y_{B}\right)$. A figura 4.16 ilustra o modelo utilizado. Então a bolha que 
satisfizer simultaneamente os critérios 4.10 e 4.11 será considerada como a mais provável de ter sido detectada pela sonda condutiva.

$$
\begin{aligned}
& \operatorname{MIN}\left\{\text { Dist }_{i}\right\} \quad \text { para } \mathrm{i}=1 \ldots \mathrm{N}_{\mathrm{B}} \\
& Y_{M i}>y_{\text {SONDA }}
\end{aligned}
$$

$\operatorname{MIN}\left\{\right.$ Dist $\left._{i}\right\}$ representa o menor valor de distância encontrado pela equação 4.7.

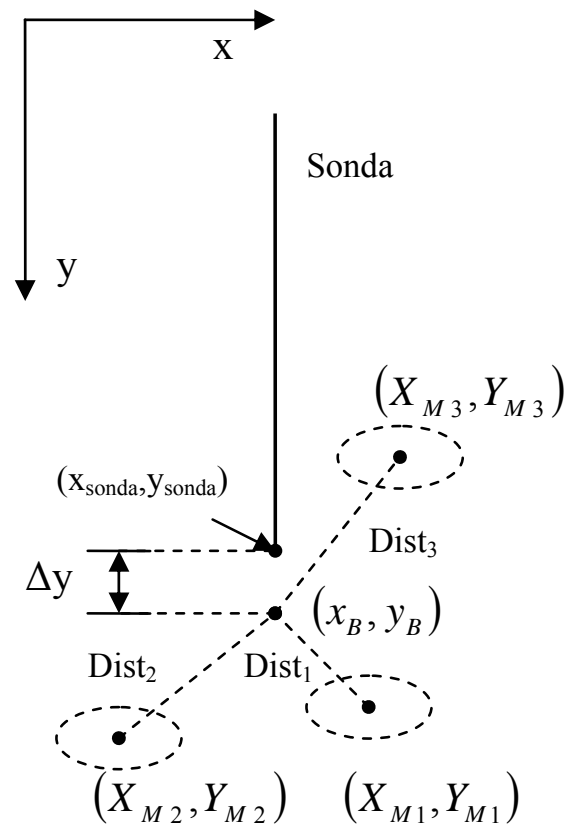

Figura 4.16: Parametros de segmentação da bolha mais provável.

\subsubsection{Crescimento de regiões por agregação de pixels}

Crescimento de regiões é um procedimento que agrega pixels ou sub-regiões em regiões maiores e têm como finalidade permitir a segmentação de regiões distintas em uma 
imagem. A forma mais simples desta abordagem consiste da agregação de pixels começando com um conjunto de pontos denominados "sementes". A partir destes pontos, pixels que possuem propriedades similares são anexados a cada "semente", resultando na segmentação das regiões que apresentam determinada característica como nível de cinza, conectividade e cor, entre outras (GONZALEZ; WOODS, 1992). Neste trabalho foi utilizado o processo de crescimento de região para segmentar a imagem da bolha mais provável de ter causado a detecção através do sinal elétrico.

Para determinar "sementes" que possibilitem a segmentação de uma única bolha em cada imagem, é proposta a utilização do cálculo dos centros de massa, descrito na seção 4.4.5, dividindo a imagem em regiões. Cada região consiste de uma área retangular de pixels de mesmo tamanho onde a janela é centrada. Os centros de massa encontrados serão possíveis "sementes" para o crescimento da região que compõe a bolha desejada. Entre todos os centros de massa calculados, somente serão considerados aqueles cuja região apresentar um número mínimo de pixels iguais a 1 . No caso de imagens binárias, $m_{00}$ determina o número total de pixels iguais a 1 numa dada região retangular. Portanto um centro de massa somente será considerado uma possível "semente" se a condição 4.12 for verdadeira.

$$
m_{00} \geq N_{P}
$$

$N_{P}$ é o valor de limiar para que um centro de massa seja considerado uma possível semente. Considerando uma região retangular composta por 10x10 pixels e um limiar $N_{P}$ de 15 , foram calculados os centros de massa de cada região, através das equações 4.2, 4.3, 4.4, 4.5 e 4.6., e aplicados os critérios 4.11 e 4.12. A imagem binária utilizada para o cálculo dos centros de 
massa, uma ilustração do deslocamento da janela e as possíveis sementes são mostradas na figura 4.17.

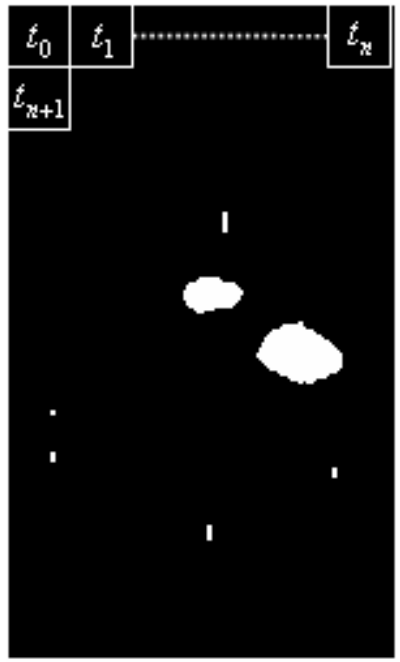

(a)

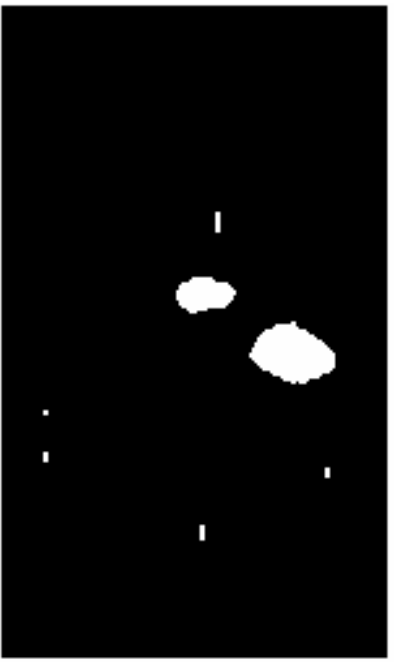

(b)

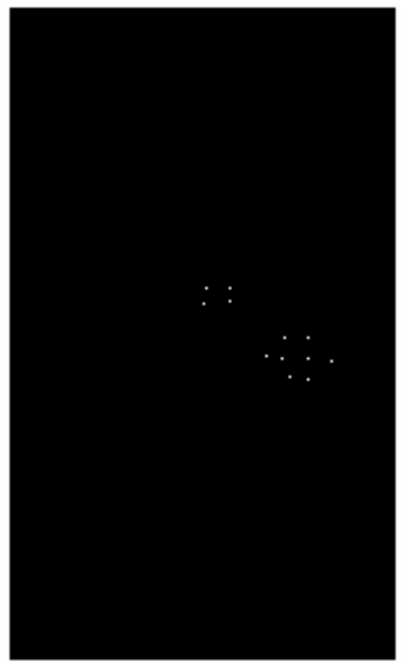

(c)

Figura 4.17: (a) Posições das janelas nos instantes $t_{0}, t_{1}, t_{n}$ e $t_{n+1}$ (b) Imagem binária; (c) Centros de massa encontrados

Foram obtidos 12 pontos que são prováveis "sementes" para realizar o crescimento de uma região e, em conseqüência, segmentar uma única bolha. Para determinar qual destes centros massa será a "semente", são utilizadas as equações 4.7, 4.8, 4.9 descritas na seção 4.4.5. Considerando as distâncias Dist $_{i}$ entre os centros de massa encontrados e o ponto mais provável $\left(x_{B}, y_{B}\right), \Delta y$ igual a 2 pixels, posição da sonda $\left(x_{\text {SONDA }}, y_{\text {SONDA }}\right)$ igual a $(83,97) \mathrm{e}$ aplicando os critérios de seleção dos pontos 4.10 e 4.11, obtém-se uma única "semente" que é mostrada na figura 4.18 . 


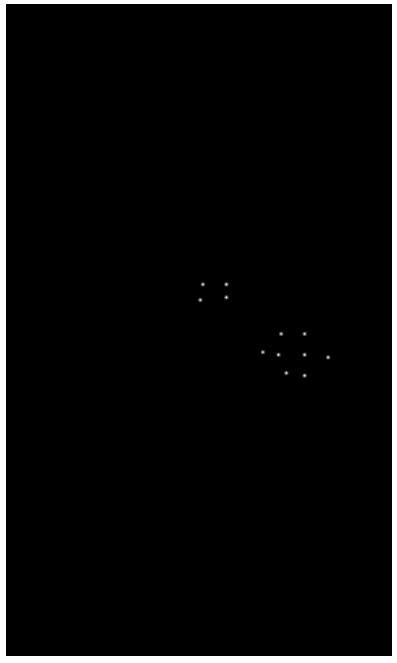

(a)

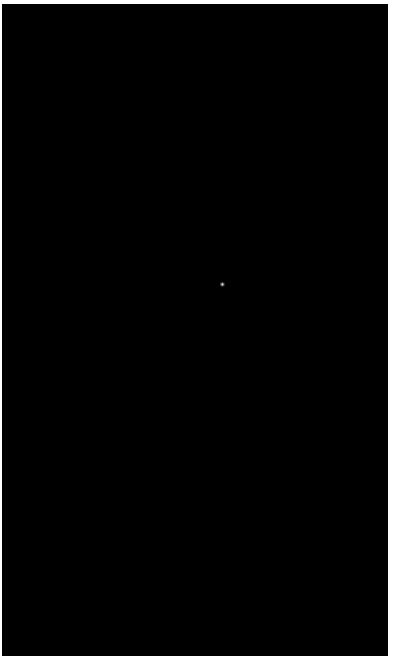

(b)

Figura 4.18: (a) centros de massa que podem ser possíveis sementes; (b) "semente” encontrada.

A fim de evitar que seja escolhido um centro de massa como "semente" onde não há um pixel de valor 1, aplica-se o seguinte critério:

- Se o valor do pixel na imagem binária correspondente ao centro de massa escolhido como "semente" for igual a 1, então este ponto é escolhido como semente para realizar o crescimento de região.

- Caso contrário é realizada uma varredura na imagem binária para encontrar uma nova "semente" próxima ao centro de massa escolhido que possua valor igual 1.

O primeiro pixel igual a 1 da imagem binária encontrado na varredura é escolhido como semente. A figura 4.19 ilustra o este processo de varredura. 


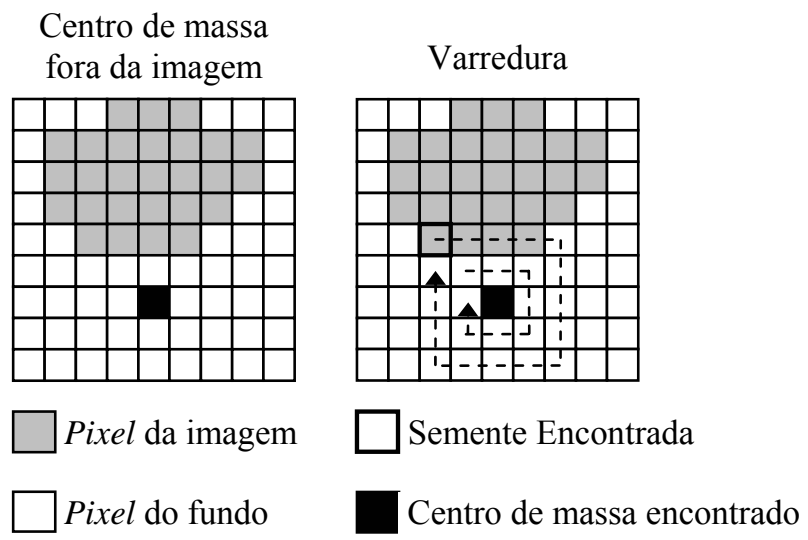

Figura 4.19 - Processo de varredura.

A propriedade utilizada para agregar novos pixels à "semente" será a conectividadede-8 em imagens binárias. Considerando-se um pixel central $p(x, y)$ com valor igual a 1 , é definido que um outro pixel está conectado-de-8 em relação a ele, se eles forem adjacentes e ambos apresentarem valor igual a 1 (GONZALEZ; WOODS, 1992). A figura 4.20 mostra um exemplo da definição de conectividade-de-8.

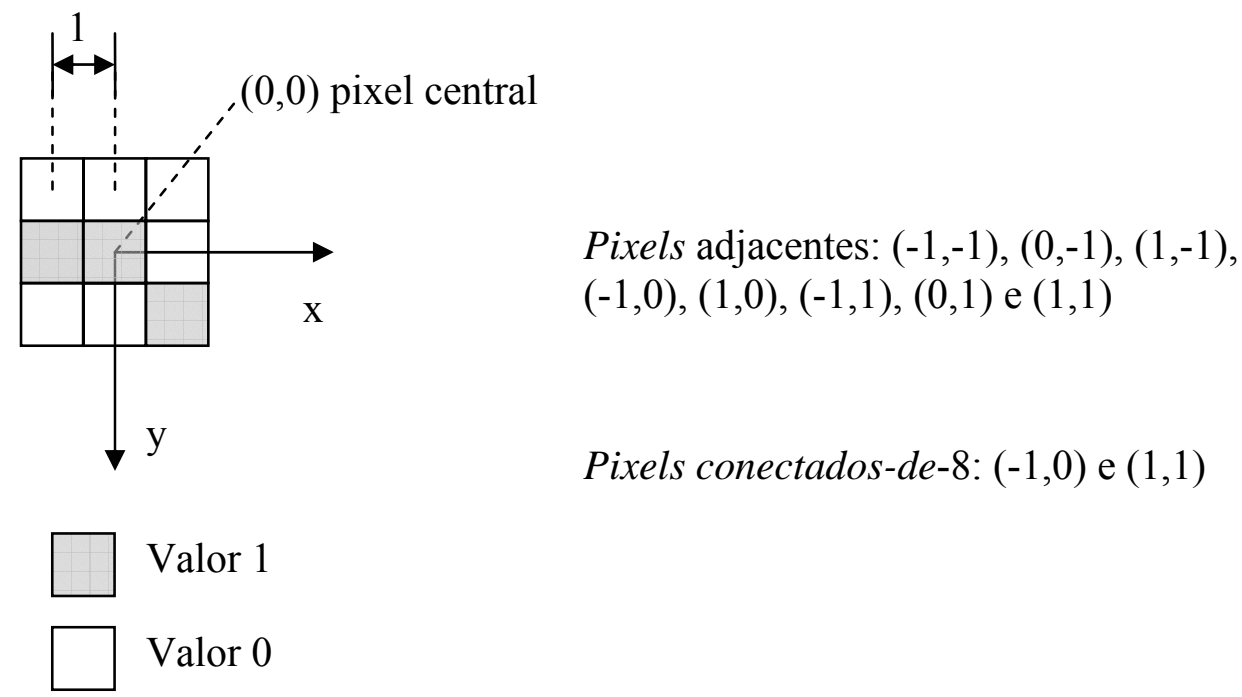

Figura 4.20: Exemplo de conectividade-de-8.

A imagem da bolha é segmentada através da agregação de novos pixels que são conectados de 8 à "semente". Para agregar os pixels, uma janela de 3x3 é fixada na 
"semente", verificando-se os pontos onde a condição de conectividade é satisfeita. Os pontos que obedecem a esta condição são agregados e considerados novas "sementes". O algoritmo é repetido até que nenhuma nova "semente" seja encontrada. A figura 4.21 mostra um exemplo de uma imagem binária onde se aplicou o algoritmo de crescimento de região, através de uma única "semente" inicial.

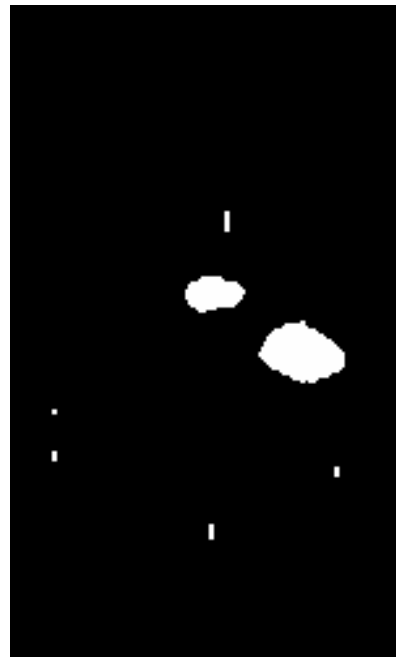

(a)

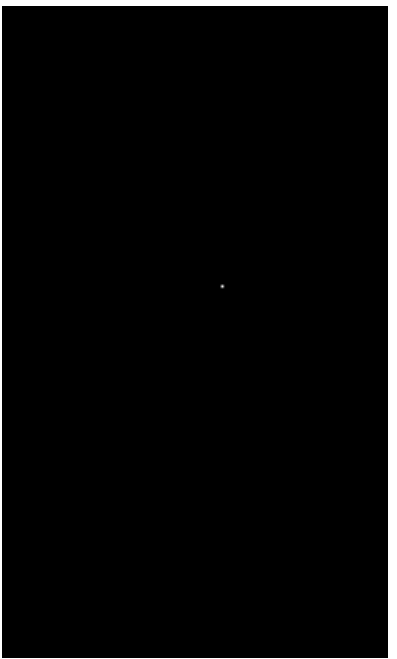

(b)

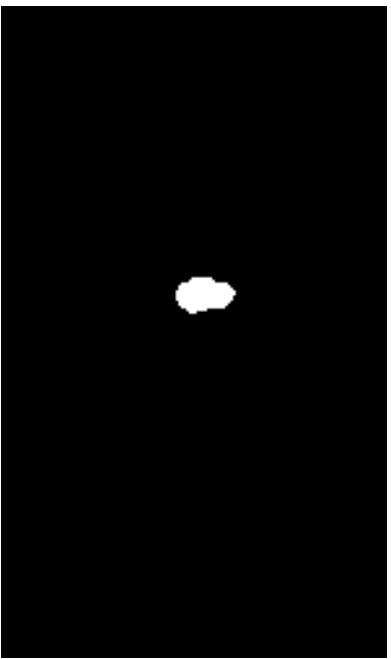

(c)

Figura 4.21: (a) Imagem binária; (b) “semente” inicial; (c) imagem segmentada

\subsubsection{Determinação da borda da imagem Segmentada}

A determinação da borda é fundamental para extrair características da imagem de bolha, como diâmetros maior e menor, e ângulo de rotação. Para extração da borda é realizada uma operação binária definida da seguinte forma (GONZALEZ; WOODS, 1992):

$$
\text { Borda }=I_{S E G}-\operatorname{Erosão}\left(I_{S E G}\right)
$$


Onde $I_{S E G}$ é a imagem segmentada. A figura 4.22 mostra um exemplo de aplicação do algoritmo de extração de borda e o elemento estruturante utilizado.

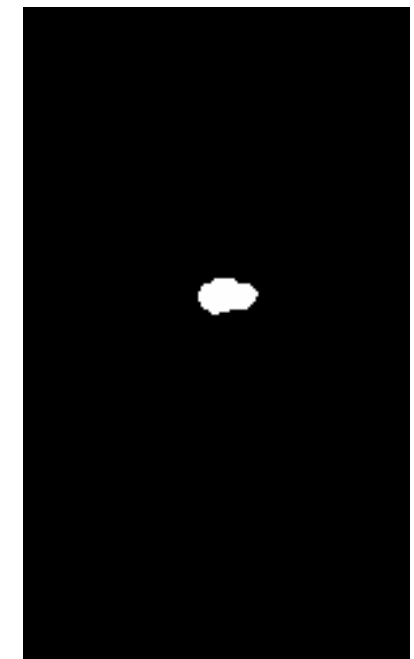

Imagem Binária segmentada

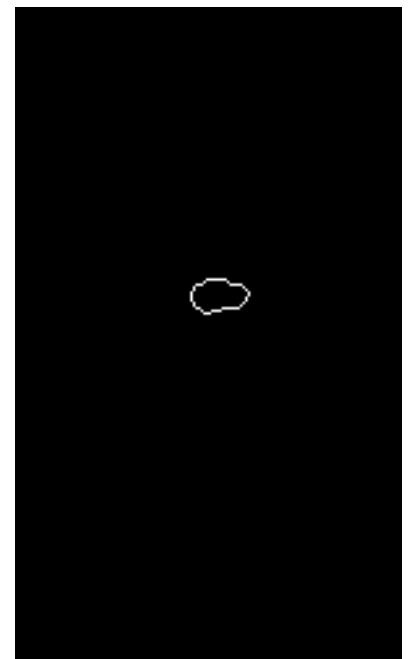

Borda Extraída

\begin{tabular}{|l|l|l|}
\hline 0 & 1 & 0 \\
\hline 1 & 1 & 1 \\
\hline 0 & 1 & 0 \\
\hline
\end{tabular}

Elemento Estruturante

Figura 4.22 - Extração de borda

\subsubsection{Algoritmo de determinação da melhor elipse formada pela}

\section{borda de bolha}

Após a segmentação da bolha, é necessário utilizar algum tipo de algoritmo nas imagens binárias para se calcular as dimensões da bolha, possibilitando, desta forma, a determinação de um diagrama de raios de bolhas. Como as bolhas, em determinadas situações práticas, possuem forma esférica, ou são elipsóides, dependendo de suas dimensões (CLARK; TURTON, 1988), uma possível forma de determinar o tamanho, é encontrando a equação da elipse, ou círculo, formada pelos pontos de borda da imagem. 
Na literatura existem vários métodos de determinação da "melhor" elipse formada por um conjunto de pontos. As duas técnicas mais comuns são métodos que utilizam minimização de erro quadrático (FITZGIBBON; PILU; FISHER, 1999; ROSIN, 1993b; AGIN,1981) e transformada de Hough (HUNG, 1989; BALLARD, 1981). Métodos que utilizam minimização de erro quadrático, empregam uma função de distância para determinar a equação de elipse que minimiza o erro médio em função de um conjunto de pontos. No caso da transformada de Hough, é realizada uma varredura em todos os pixels da imagem para cada equação possível de uma dada curva analítica. Toda vez que um ponto satisfizer uma equação com certos parâmetros, incrementa-se um acumulador na posição representada pelos mesmos. Assim no caso de uma elipse, é necessária a utilização de um acumulador de cinco dimensões para se aplicar diretamente a transformada de Hough (BALLARD, 1981). Depois de varrer todo o espaço possível de equações, cada posição do acumulador determina o número de pontos que pertence àquela equação.

A transformada de Hough é pouco afetada por pontos fora de uma curva específica, ruído, ou descontinuidades da borda. Em contra partida, a transformada de Hough necessita de uma grande quantidade de pontos para um bom resultado, um acumulador multidimensional para equações de ordens mais elevadas e não fornece solução única (ROSIN, 1993a, 1993b). Métodos baseados na minimização de erro quadrático são mais eficientes computacionalmente, mas apresentam menos robustez em relação ao ruído. Além disso, pontos distantes da curva média influenciam fortemente a determinação da "melhor" curva representada por um conjunto de pontos. (ROSIN, 1993a).

Em Rosin 1993a é apresentado um método de determinação da "melhor" elipse que seleciona várias combinações de conjuntos de cinco pontos, e acumula os parâmetros da 
equação de elipse que passa por cada conjunto de pontos. Como nem todo conjunto de cinco pontos formam uma elipse, os conjuntos que não satisfazem à equação da curva são rejeitados. Finalmente, para determinar os parâmetros resultantes, são calculadas as medianas de cada parâmetro.

Para determinar a "melhor" elipse que constitui a borda da bolha é utilizada a seleção de todos os conjuntos de cinco pontos, $\mathbf{p}$, da seguinte forma (ROSIN, 1993a):

$$
\begin{aligned}
& \mathbf{p}=\left(p_{i}, p_{i+s}, p_{i+2 s}, p_{i+3 s}, p_{i+4 s}\right) \\
& i=1,2, \ldots, N-4 \\
& s=1,2, \ldots, \operatorname{INT}\left(\frac{N-i}{4}\right)
\end{aligned}
$$

Onde $p_{i}\left(x_{i}, y_{i}\right)$ representa cada pixel de borda da imagem em um total de $N$ pontos e $\operatorname{INT}(x)$ é a parte inteira de $x$. A equação de uma cônica pode ser escrita da seguinte forma geral (AGIN, 1981):

$$
A x^{2}+B x y+C y^{2}+D x+E y+F=0
$$

Como para definir uma elipse são necessários apenas 5 parâmetros, a equação é normalizada, adotando-se $A=1$. Assim, para cada 5 pontos é possível determinar os parâmetros $B, C, D, E$ e $F$ de uma possível elipse resolvendo o seguinte sistema matricial: 


$$
\left(\begin{array}{lllll}
x_{1} y_{1} & y_{1}^{2} & x_{1} & y_{1} & 1 \\
x_{2} y_{2} & y_{2}^{2} & x_{2} & y_{2} & 1 \\
x_{3} y_{3} & y_{3}^{2} & x_{3} & y_{3} & 1 \\
x_{4} y_{4} & y_{4}^{2} & x_{4} & y_{4} & 1 \\
x_{5} y_{5} & y_{5}^{2} & x_{4} & y_{5} & 1
\end{array}\right)\left(\begin{array}{l}
B \\
C \\
D \\
E \\
F
\end{array}\right)=\left(\begin{array}{l}
-x_{1}^{2} \\
-x_{2}^{2} \\
-x_{3}^{2} \\
-x_{4}^{2} \\
-x_{5}^{2}
\end{array}\right)
$$

Onde $x_{1}, x_{2}, x_{3} x_{4}$ e $x_{5}$ representam as coordenadas do eixo $x$ para os cinco pontos de cada conjunto, e $y_{1}, y_{2}, y_{3}, y_{4}$ e $y_{5}$ as coordenadas do eixo $y$. Um conjunto de pontos forma uma elipse se os critérios $4.22,4.23$ e 4.24 forem satisfeitos, onde $\Delta, J$ e $I$ são determinados por 4.19, 4.20 e 4.21, respectivamente (ZWILLINGER, 2003).

$$
\begin{gathered}
\Delta=\left(A C F+\frac{B D E}{4}\right)-\left(\frac{C D^{2}+A E^{2}+F B^{2}}{4}\right) \\
J=A C-\frac{B^{2}}{4} \\
I=A+C \\
\Delta \neq 0 \\
\frac{\Delta}{I}<0 \\
\qquad
\end{gathered}
$$


Quando um conjunto de pontos forma uma elipse, são calculados os parâmetros 4.25, 4.26, 4.27, 4.28 e 4.29 (MATHWORLD..., 2006), caso contrário, aquela equação é rejeitada. A seguir o algoritmo determina o número de pontos, $n_{p}$, que possui uma distância mínima, $D_{M I N}$, da elipse encontrada. Para isso encontra-se a distância entre o ponto da borda $\left(x_{i}, y_{i}\right)$ e a elipse. A distância é encontrada determinando-se o ponto de intersecção entre a reta que passa pelo centro da elipse $\left(x_{0}, y_{0}\right)$ e pelo ponto de borda a ser testado. A figura 4.23 ilustra o processo de determinação das distâncias.

$$
\begin{gathered}
R_{x}=\sqrt{\frac{\left(\frac{A E^{2}+C D^{2}+F B^{2}-B D E-4 A C F}{2}\right)}{\left(\frac{B^{2}}{4}-A C\right)\left((C-A) \sqrt{1+\frac{B^{2}}{(A-C)^{2}}}-(C+A)\right)}} \\
R_{y}=\sqrt{\left.\frac{\left(\frac{A E^{2}+C D^{2}+F B^{2}-B D E-4 A C F}{2}\right)}{\left(\frac{B^{2}}{4}-A C\right)\left((A-C) \sqrt{1+\frac{B}{(A-C)^{2}}}-(C+A)\right.}\right)} \\
x_{0}=\frac{2 C D-B E}{B^{2}-4 A C} \\
y_{0}=\frac{2 A E-B D}{B^{2}-4 A C}
\end{gathered}
$$


$\theta=\left\{\begin{array}{cc}\frac{1}{2} \tan ^{-1}\left(\frac{B}{A-C}\right) & \text { se } A \neq C \\ \frac{\pi}{4} & \text { caso contrário }\end{array}\right.$

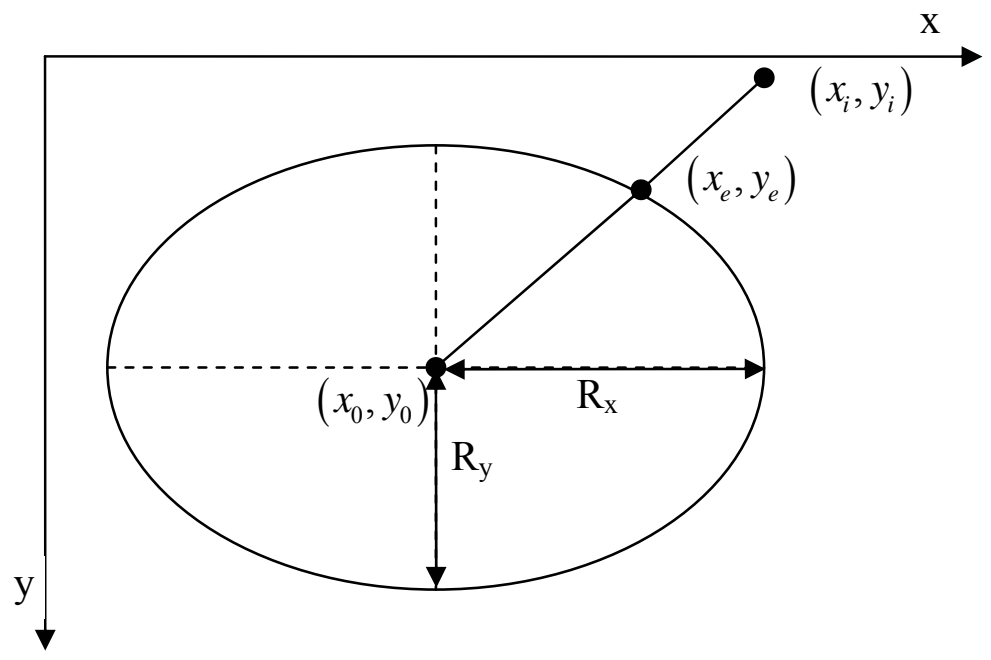

Figura 4.23 - Determinação da distancia entre a elipse e o ponto de borda.

O ponto $\left(x_{e}, y_{e}\right)$ pode ser determinado calculando-se a intersecção entre a reta formada pelos pontos $\left(x_{i}, y_{i}\right)$ e $\left(x_{0}, y_{0}\right)$, e a elipse, substituindo-se 4.31 em 4.30:

$$
\begin{gathered}
A x_{e}^{2}+B x_{e} y_{e}+C y_{e}^{2}+D x_{e}+E y_{e}+F=0 \\
y_{e}=y_{0}+m\left(x_{e}-x_{0}\right)
\end{gathered}
$$

Onde $m$ é o coeficiente angular da reta definida por $\left(x_{i}, y_{i}\right)$ e $\left(x_{0}, y_{0}\right)$. Assim $x_{e}$ pode ser encontrado resolvendo a seguinte equação do segundo grau:

$$
a x_{e}^{2}+b x_{e}+c=0
$$


Onde $a, b$ e $c$ são os coeficientes dados pelas equações 4.33, 4.34 e 4.35, respectivamente.

$$
\begin{gathered}
a=A+m B+m^{2} C \\
b=B\left(y_{0}-m x_{0}\right)+C\left(2 y_{0} m-2 x_{0} m^{2}\right)+D+m E \\
C=C\left(y_{0}^{2}-2 y_{0} m x_{0}+m^{2} x_{0}^{2}\right)+E\left(y_{0}-m x_{0}\right)+F
\end{gathered}
$$

Como a equação 4.32 pode resultar em duas soluções, são calculadas duas distâncias possíveis entre os pontos, $d_{1}$ e $d_{2}$, da seguinte forma:

$$
\begin{aligned}
& d_{1}=\sqrt{\left(x_{e 1}-x_{i}\right)^{2}+\left(y_{e 1}-y_{i}\right)^{2}} \\
& d_{2}=\sqrt{\left(x_{e 2}-x_{i}\right)^{2}+\left(y_{e 2}-y_{i}\right)^{2}}
\end{aligned}
$$

Então a menor distância, Dist, é escolhida, ignorando-se a maior. Finalmente, para determinar se um ponto de borda será computado como fazendo parte de uma elipse aplica-se o seguinte critério:

- Se Dist $<D_{M I N}$ considera-se o ponto $\left(x_{i}, y_{i}\right)$ como pertencente à elipse.

- Caso contrário o ponto não pertence à elipse. 
Aplicando-se o algoritmo descrito acima para todos os conjuntos de cinco pontos determinados por 4.14, 4.15 e 4.16, obtêm-se os seguintes vetores:

$$
\begin{aligned}
& \left(R x_{1}, R x_{2}, \ldots, R x_{n}\right) \\
& \left(R y_{1}, R y_{2}, \ldots, R y_{n}\right) \\
& \left(x_{01}, x_{02}, \ldots, x_{0 n}\right) \\
& \left(y_{01}, y_{02}, \ldots, y_{0 n}\right) \\
& \left(\theta_{1}, \theta_{2}, \ldots, \theta_{n}\right) \\
& \left(n_{P 1}, n_{P 2}, \ldots, n_{P n}\right)
\end{aligned}
$$

Onde $n$ é o número total de equações de elipses válidas; $R x, R y, x_{0}, y_{0}, \theta$ são o raio x, raio y, coordenada $\mathrm{x}$ do centro, coordenada y do centro e ângulo de inclinação da elipse, respectivamente. $n_{P}$ é o número total de pontos que obedecem aos critérios $4.22,4.23$ e 4.24 para uma dada elipse. Para determinar a melhor elipse formada pelos pontos de borda é escolhida equação que apresentar o maior número de pontos $n_{P}$. A figura 4.24 mostra a utilização da borda para encontrar a "melhor" elipse, utilizando-se $D_{\text {MIN }}$ igual a 1,5 pixels. O apêndice D mostra o resultado da aplicação do algoritmo de processamento de imagens em alguns exemplos de imagens de bolhas capturadas. 


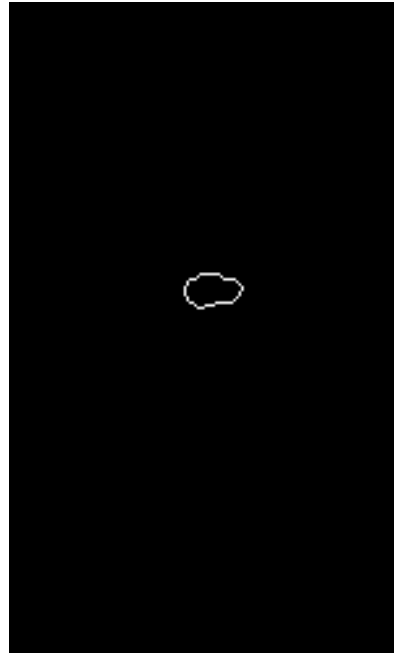

(a)

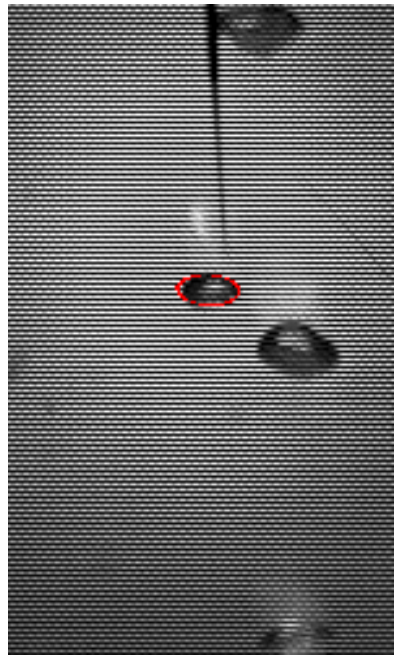

(b)
$R_{x}=11,77$ pixels

$R_{Y}=5,75$ pixels

$x_{0}=77,35$ pixels

$y_{0}=110,33$ pixels

$\theta=2,9^{\circ}$

Figura 4.24: (a) Borda utilizada; (b) melhor elipse (em destaque) sobreposta à imagem original; (c) parâmetros obtidos no processo de determinação da “melhor” elipse.

\subsection{Conclusão}

Neste capítulo foram apresentados basicamente o sistema de aquisição de imagens utilizado e o algoritmo de processamento de imagens de bolhas. A seção 4.1 apresenta uma descrição detalhada do sistema de aquisição e equipamento utilizado na captura das imagens. Na seção 4.2 é apresentado o projeto de um circuito de sincronização e acionamento de uma lâmpada estroboscópica que permite a obtenção de imagens de bolhas não borradas e com bom nível de contraste. A seção 4.3 é uma breve explicação sobre o sistema de armazenamento de imagens em buffers que possibilitam o processamento de imagens quando uma bolha é detectada pela sonda condutiva. Na seção 4.4 é sugerido um algoritmo de processamento de imagens e os respectivos conceitos teóricos utilizados. 


\section{Capítulo 5}

\section{Resultados experimentais e conclusões}

Neste capítulo são apresentados os resultados experimentais de determinação do histograma de raios obtidos através do processamento do sinal elétrico de uma sonda condutiva. O diagrama de raios é encontrado através do modelo estatístico, descrito no capítulo 3, que correlaciona o diagrama de cordas ao diagrama de raios de bolhas em uma coluna de borbulhamento bifásica. Para avaliar os resultados obtidos pelo sistema de sonda condutiva, é utilizado o sistema de determinação de tamanho de bolhas através do processamento de imagens obtidas por uma câmera de vídeo, cujo algoritmo é descrito no capítulo 4. As imagens de vídeo também permitiram a obtenção de alguns parâmetros do fluxo bifásico importantes como, por exemplo, velocidade média de subida das bolhas.

\subsection{Diagrama de raios obtido através de processamento de imagens e sinal elétrico da sonda condutiva}

Como pode ser visto na figura 4.23 do capítulo 4 , os raios ou semi-eixos da elipse são obtidos em pixels, portanto estes valores precisam ser convertidos para uma unidade de medida que permita a comparação com os resultados obtidos pelo diagrama de cordas. Para 
que isto seja possível, é necessário saber qual é a dimensão física de um pixel nas imagens capturadas pela câmera. Desta forma, deve-se encontrar algum parâmetro que relacione a unidade em pixel à unidade de medida padrão de comprimento. Uma das formas de encontrar esta relação é saber a dimensão de um pixel no sensor da câmera e o zoom utilizado. Mas estes valores, na maioria das vezes não são conhecidos ou fáceis de determinar. Outra possibilidade é utilizar um objeto cujas dimensões são conhecidas e relacioná-las ao número de pixels na imagem. Neste trabalho optou-se por utilizar a própria ponta de prova como padrão de referência, visto que foi possível determinar o seu tamanho com precisão aceitável através de um paquímetro. Uma das vantagens de utilizá-la como referência é que esta se encontra posicionada no mesmo plano em que as bolhas são perfuradas, facilitando o processo de determinação do tamanho das bolhas. A figura 5.1 mostra as dimensões da ponta de prova utilizada.

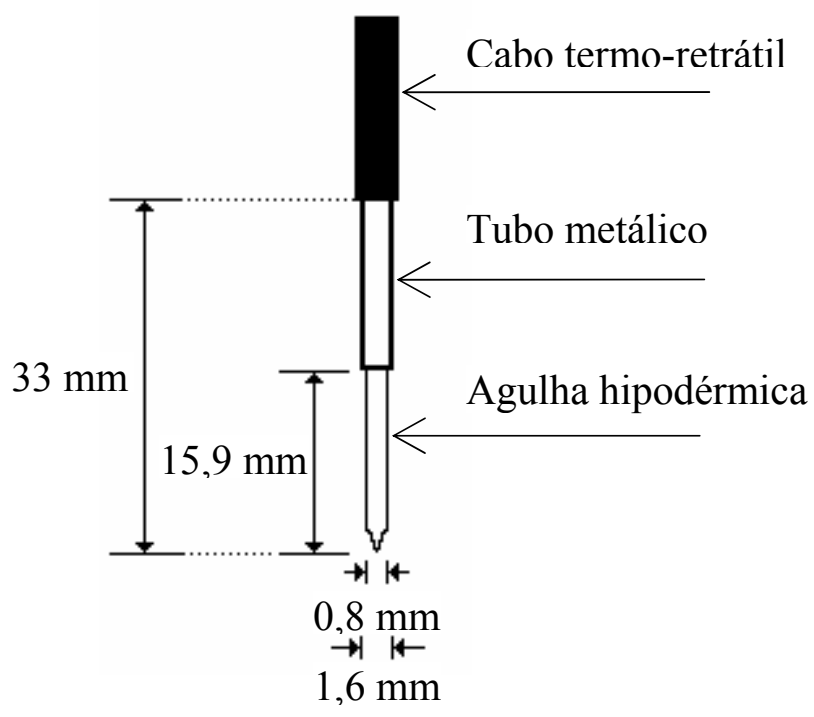

Figura 5.1: Dimensões da ponta de prova.

Com a finalidade de obter a dimensão de um pixel foi construída uma rotina no software LABVIEW da NATIONAL INSTRUMENTS que permite a calibração e obtenção de alguns parâmetros utilizados no processamento das imagens. Estes parâmetros são a coordenada da ponta da sonda e a dimensão de um pixel. Esta rotina permite a captura de uma 
imagem da coluna de borbulhamento e a seleção, através do mouse, dos pontos de interesse. Primeiramente o usuário seleciona o ponto na imagem que corresponde à ponta da sonda, depois um segmento de reta que corresponde à parte da sonda formada pela agulha hipodérmica. Como este segmento possui um comprimento de 15,9mm (figura 5.1), é possível determinar a dimensão de um pixel em mm, $D_{\text {pixel }}$, através da expressão 5.1 que relaciona a dimensão de um pixel às coordenadas dos pontos extremos do segmento de reta selecionado pelo usuário.

$$
D_{\text {pixel }}=\frac{15,9}{\sqrt{\left(x_{2}-x_{1}\right)^{2}+\left(y_{2}-y_{1}\right)^{2}}}
$$

Onde $x_{1}, x_{2}, y_{1}$ e $y_{2}$ são as coordenadas dos pontos extremos do segmento de reta. Desta forma é possível determinar, através das imagens, as dimensões das bolhas que passaram pela ponta da sonda e provocaram uma detecção. É importante realizar uma nova calibração antes de uma aquisição de imagens caso a posição da câmera ou ajuste no zoom sejam alterados. O apêndice $\mathrm{C}$ mostra um exemplo de execução de calibração.

A rotina de calibração foi executada, fornecendo $D_{\text {pixel }}=0,1958 \mathrm{~mm}$ e $\left(x_{\text {SONDA }}, y_{\text {SONDA }}\right)=(83,104)$. Então foram realizadas as detecções das bolhas e medição dos tempos de residência de 1001 eventos. O sistema de aquisição armazenou 918 imagens dos quadros de vídeos do instante de detecção e 918 imagens dos quadros anteriores. O sistema não foi capaz de obter imagens em todos os instantes de detecção, obtendo-se, assim, um número menor de imagens comparado ao número de cordas aferidas. Mas isso não trouxe maiores problemas devido ao caráter estatístico do método de obtenção do histograma de raios. 
As imagens foram processadas através do algoritmo descrito no capitulo 4, utilizandose um limiar, T, de 190*. Posteriormente, foi construído um histograma de raios horizontais, $R_{X}$, apresentando largura de intervalos, $\Delta x$, definida pela equação 5.2.

$$
\Delta x=\frac{\max -\min }{m}
$$

Onde $m$, max e min são o número de intervalos do histograma, o valor máximo e o valor mínimo de raios considerados, respectivamente. O histograma de raios, mostrado na figura 5.2, apresenta 100 intervalos e $\Delta x$ de $0,1 \mathrm{~mm}$.

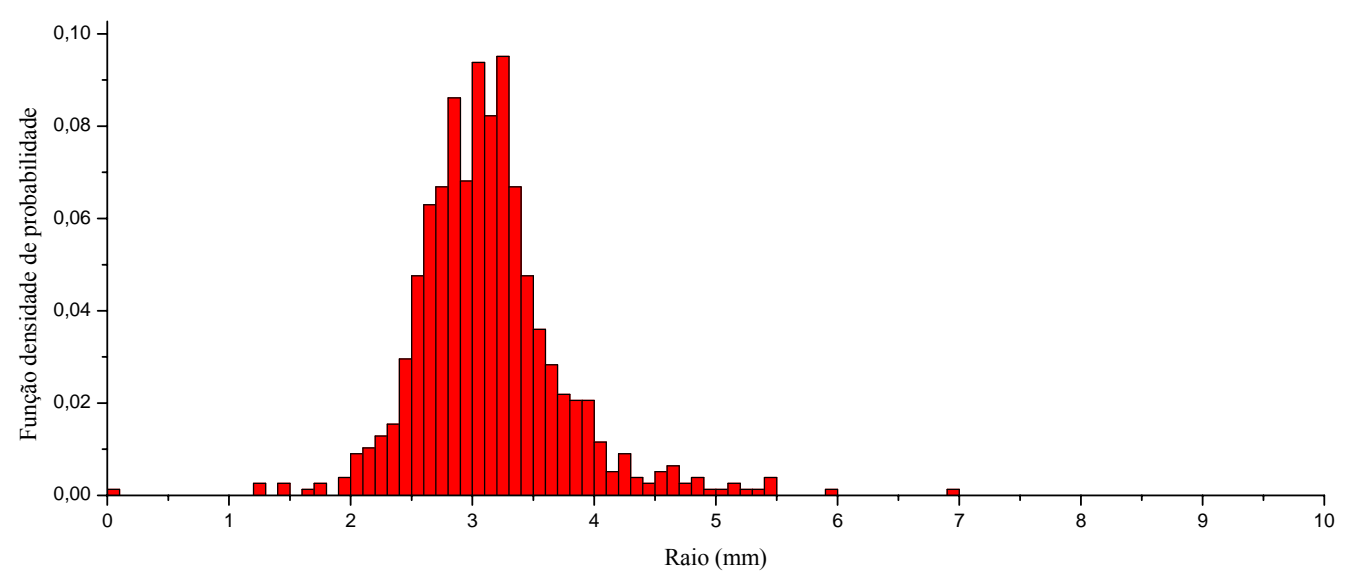

Figura 5.2: Diagrama de raios obtido através das imagens de bolhas.

Utilizando-se os raios maiores e menores de cada imagem de bolha, determinou-se a razão entre o semi-eixo menor, $R_{Y}$, e o semi-eixo maior, $R_{X}$, definido como $\alpha$. Calculou-

\footnotetext{
* Os outros parâmetros do algoritmo de processamento são os mesmos descritos no capítulo 4.
} 
se, então, um $\alpha$ médio de 0,42 . Este valor médio de $\alpha$ foi utilizado na equação 3.17 , descrita no capitulo 3, para calcular o diagrama de raios. O gráfico da figura 5.3 mostra o número de bolhas em função de $\alpha$.

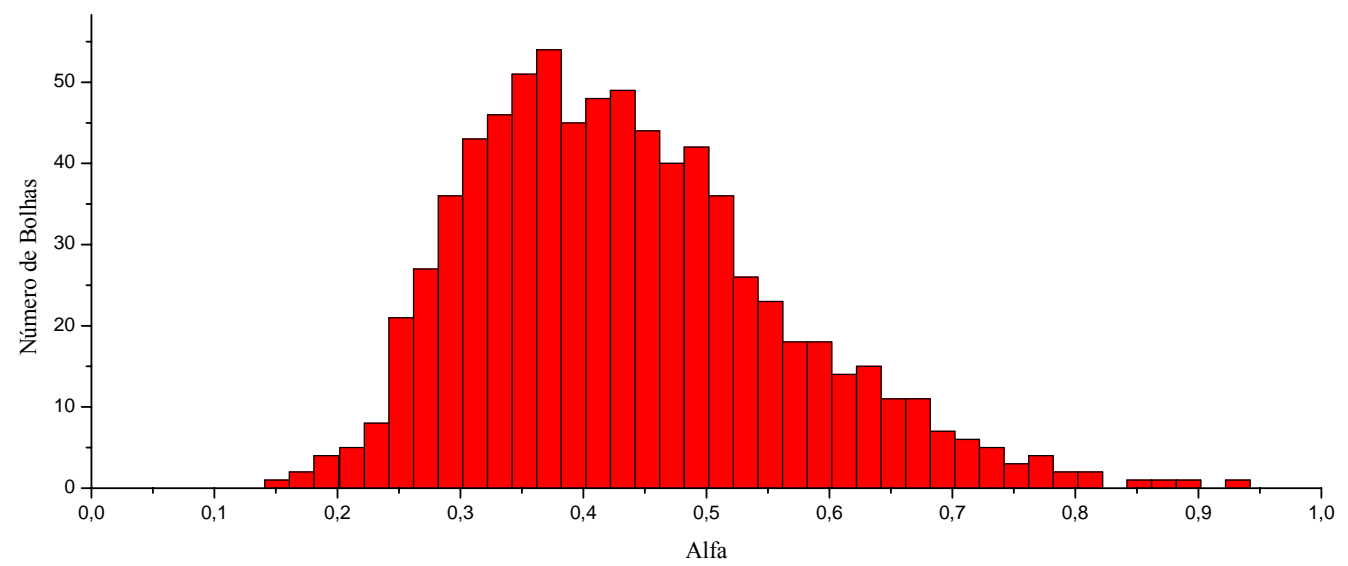

Figura 5.3: Número de bolhas em função de $\alpha$.

Utilizando-se cada imagem capturada no instante de detecção e o quadro anterior correspondente, calculou-se o perfil de velocidade de subida das bolhas. As velocidades foram obtidas através da determinação das coordenadas do eixo y do centro da melhor elipse de cada borda de bolha, da seguinte forma:

$$
v_{B}=D_{\text {pixel }} \cdot\left(y_{01}-y_{02}\right) \cdot 30
$$

Onde $y_{01}$ e $y_{02}$ são as coordenadas do eixo $y$ dos centros das elipses no quadro de imagem anterior e atual, respectivamente. A taxa de quadros é de aproximadamente $30 \mathrm{~Hz}$. Calculando-se a velocidade média, $\overline{v_{B}}$, obteve-se um valor de $290,52 \mathrm{~mm} / \mathrm{s}$. A figura 5.4 mostra o perfil de velocidades encontrado. 


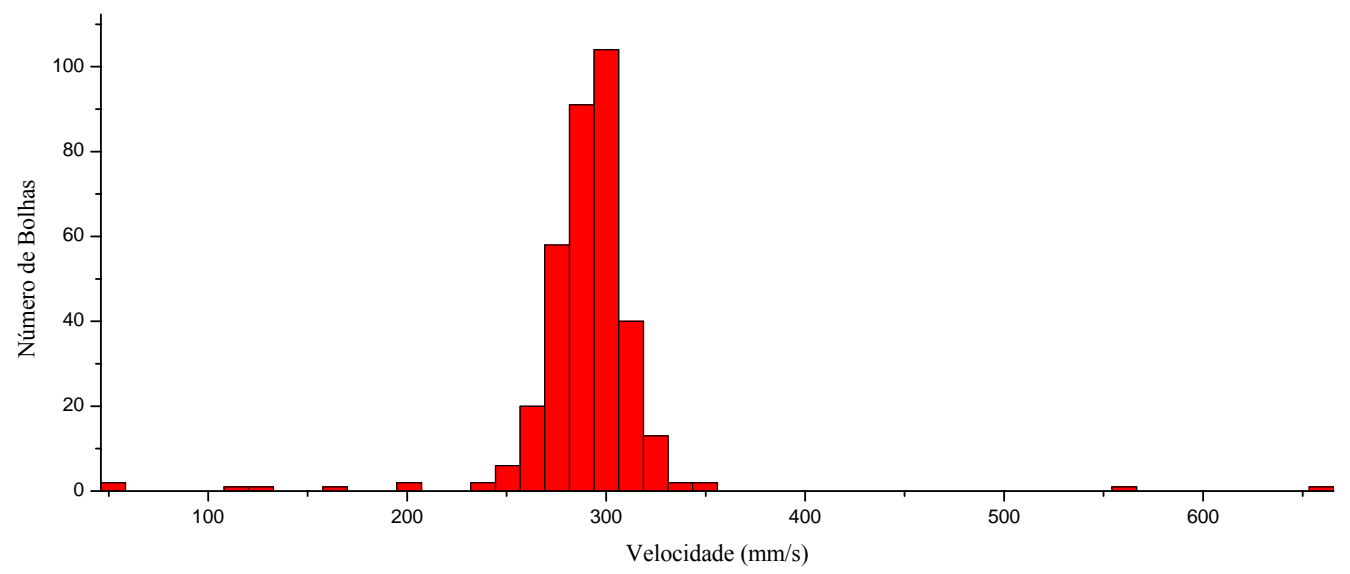

Figura 5.4: Número de bolhas em função da velocidade de subida.

Os tempos de residência de cada bolha detectada foram estimados através do algoritmo de processamento de sinal da seção 3.5.5 do capítulo 3. Utilizando-se a velocidade média, $\overline{v_{B}}$, calculada através dos quadros de vídeo, foi possível determinar o tamanho médio de cada corda de bolha detectada, através da equação 3.1. A figura 5.5 mostra o diagrama de cordas encontrado.

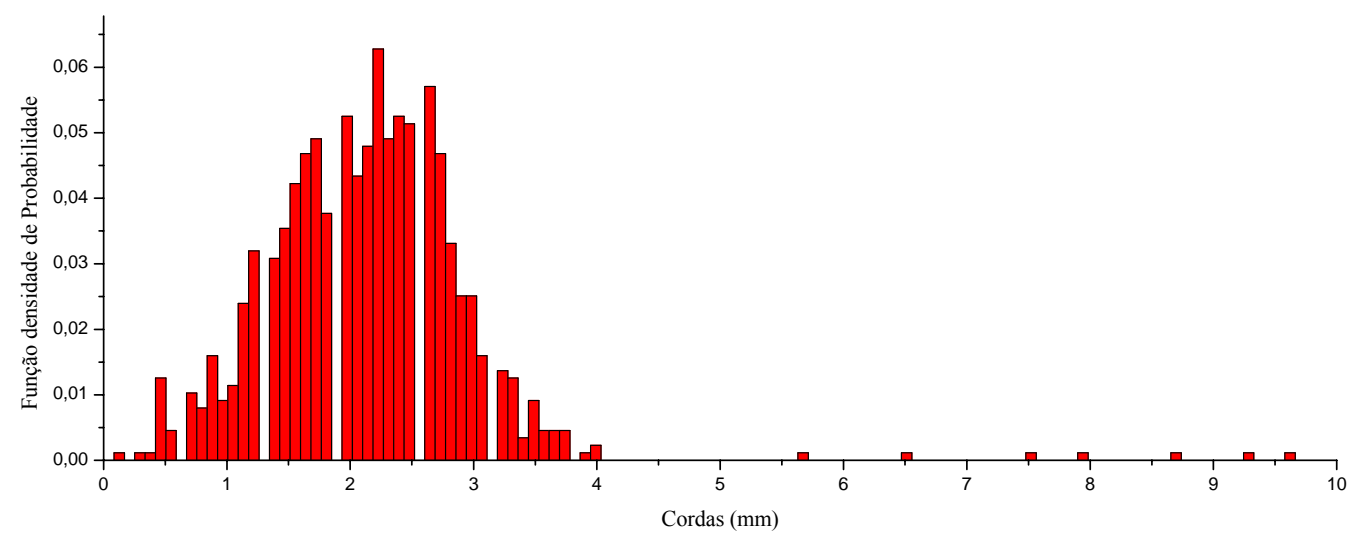

Figura 5.5: Diagrama de cordas obtido através do processamento do sinal da sonda condutiva. 
O intervalo de cada barra do histograma de cordas utilizado foi de $0,084 \mathrm{~mm}$, respeitando a condição de discretização 3.13, descrita na seção 3.3. Aplicando-se o método de correlação entre diagrama de cordas de uma ponta de prova e o diagrama de raios, descrito na seção 3.3 do capítulo 3 , juntamente com o método de regularização baseado em decomposição de valores singulares, descrito na seção 3.4 do capítulo 3, obteve-se o diagrama de raios através das cordas medidas pela sonda condutiva. $O$ limiar de regularização $L_{D}$, definido na seção 3.4 , foi escolhido igual a 0,29 com o objetivo de minimizar o malcondicionamento da equação integral 3.5 , descrita no capítulo 3 . O gráfico 5.6 mostra o diagrama de raios encontrado pelo método de correlação entre cordas e raios. O gráfico 5.7 mostra os diagramas de raios obtidos usando as cordas medidas pela sonda condutiva e pelo processamento das imagens.

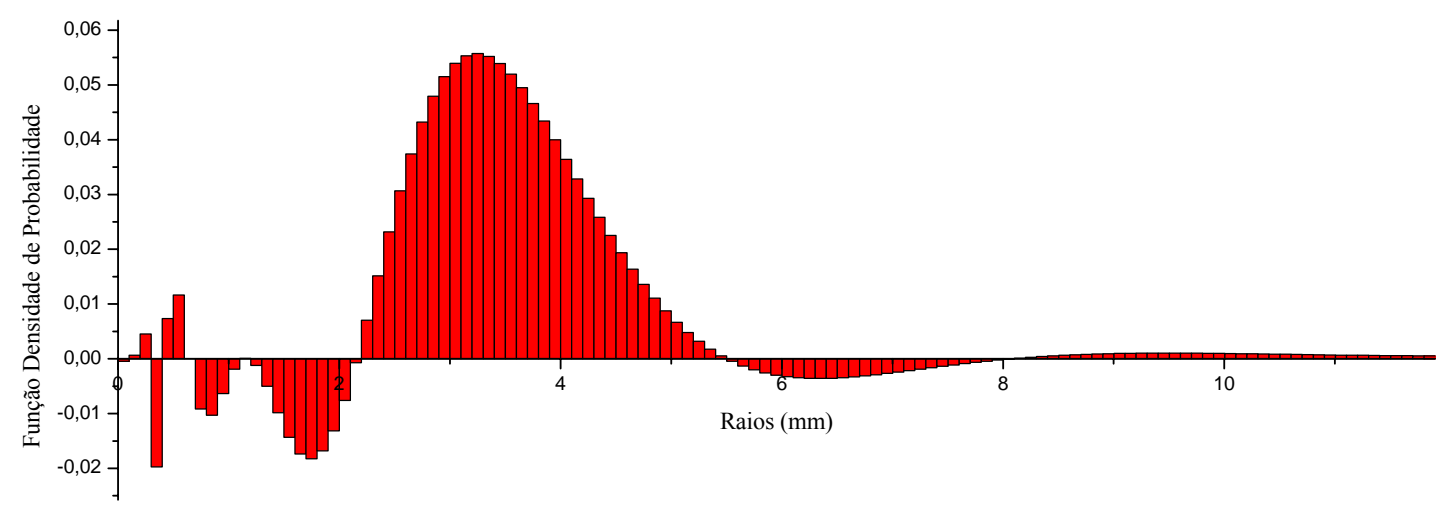

Figura 5.6: Diagrama de raios obtido através das cordas medida pela sonda condutiva. 


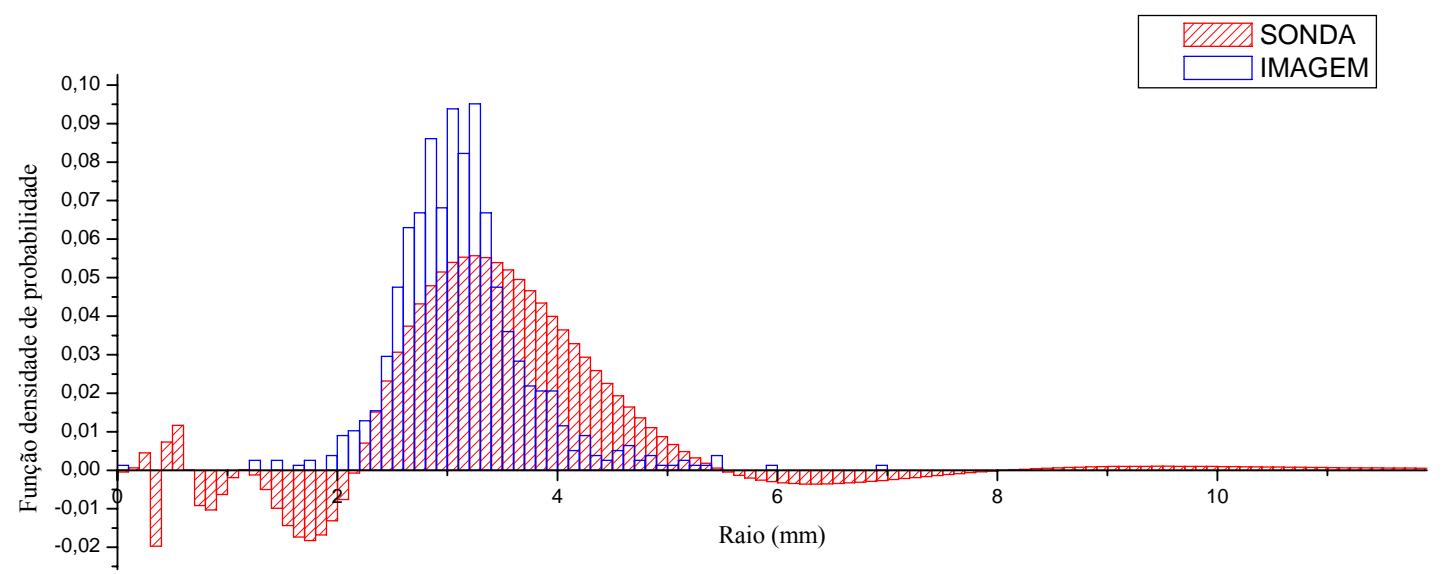

Figura 5.7: Comparação entre os diagramas de raios utilizando imagens e uma sonda condutiva.

Para demonstrar o comportamento mal-condicionado da equação integral 3.5, descrita no capítulo 3, foi determinado o histograma de raios utilizando-se a sonda condutiva sem a utilização do método de regularização. $\mathrm{O}$ resultado mostrado na figura 5.8 mostra que o diagrama encontrado apresenta grande discrepância em relação ao perfil de cordas esperado.

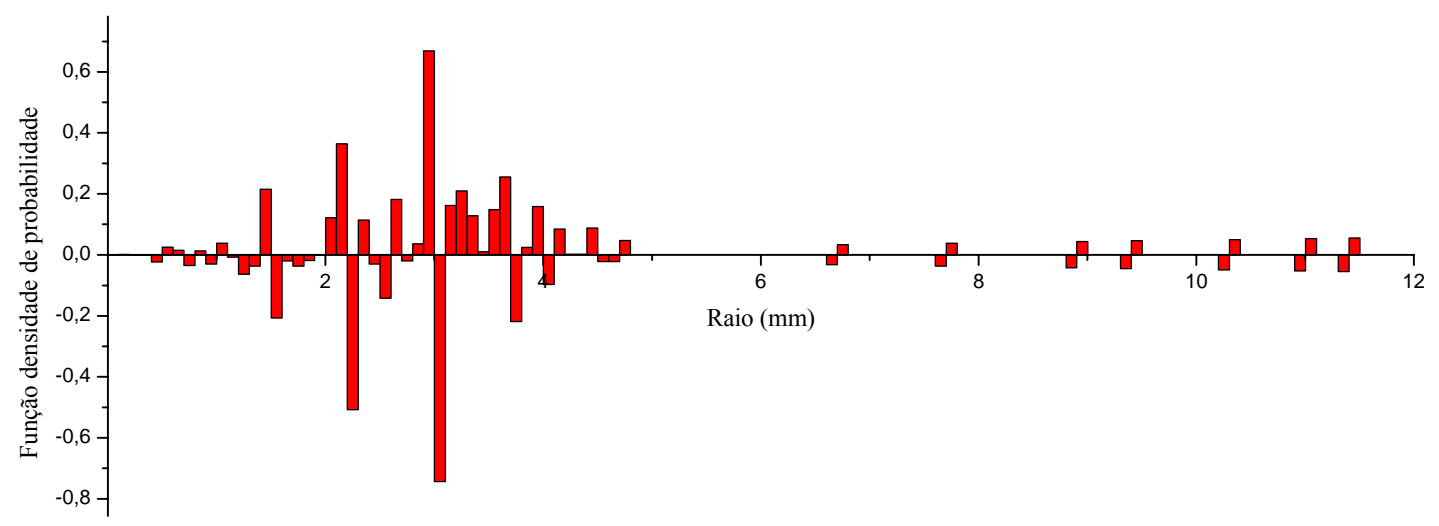

Figura 5.8: Diagrama de cordas obtido sem a utilização do método de regularização por decomposição em valores singulares. 


\subsection{Análise dos resultados obtidos}

O gráfico da figura 5.7 mostra que o diagrama de raios obtido através da sonda condutiva apresentou um número maior de bolhas entre 2 e $5,5 \mathrm{~mm}$, enquanto o diagrama obtido pelo processamento de imagens apresentou a maior parte das bolhas entre 2 e 4,5 mm. Levando-se em consideração fatores como a presença de ruído do sinal medido pela sonda, alteração do fluxo de bolhas ocasionado pela presença da ponta de prova, utilização de uma velocidade média na determinação do diagrama de cordas e utilização de um $\alpha$ médio no cálculo da correlação entre diagrama de cordas e raios, pode-se concluir que o resultado obtido foi satisfatório.

$\mathrm{Na}$ literatura não foi encontrado um trabalho similar que fizesse a comparação entre um sistema de determinação da distribuição de raios através de uma sonda condutiva e um sistema de determinação de tamanho de bolhas pelo uso de imagens. Em Kiambi et al 2003 é utilizada uma ponta de prova óptica dupla para medir o perfil de velocidade e os tempos de residência de bolhas em uma coluna de borbulhamento. Também se utiliza uma câmera para medir a velocidade real das bolhas e comparar com as velocidades medidas pela ponta de prova dupla, mas o perfil dos tamanhos de bolhas não é determinado.

O sinal medido pela sonda condutiva apresentou considerável ruído, dificultando assim a obtenção dos tempos de residência com maior precisão, e também ocasionou algumas falsas detecções de bolhas. O fato da sonda apresentar um efeito intrusivo no comportamento do fluxo de bolhas também influenciou a determinação do diagrama de cordas, visto que a ponta de prova tende a desviar as bolhas do eixo vertical formado pela sonda, além de diminuir a velocidade de subida da bolha durante sua passagem pela ponta de prova. Todos 
estes fatores, somados ao fato do mal-condicionamento do sistema de determinação da distribuição do diagrama de raios a partir do diagrama de cordas, ocasionaram erros e alguns valores de distribuição de raios negativos, os quais não possuem significado físico.

Uma das dificuldades encontradas foi a determinação de um valor ótimo do limiar de regularização $L_{D}$ que resultasse no menor erro do sistema sem que ocorresse uma interferência significativa no resultado final do processo. Infelizmente não foi encontrado nenhum método analítico na literatura que determinasse um valor ideal para o limiar para o método regularização baseado em decomposição de valores singulares. Então foi determinado um valor ótimo através do cálculo do erro absoluto entre os diagramas de raios obtidos, variando-se o valor do limiar dentro de certo intervalo.

Foi notado também que as bolhas na maioria das vezes não perfuram a ponta de prova perpendicularmente em relação ao plano do seu eixo maior. Isto faz com que o diagrama de cordas encontrado não corresponde àquele levado em consideração nos modelos teóricos que relacionam funções de distribuição de diagrama de raios aos diagramas de cordas. Portanto este fator também influencia o diagrama de raios encontrados a partir das cordas medidas pela sonda. A figura 5.9 mostra uma imagem de bolha com um ângulo de $38,4^{\circ}$ entre o eixo maior da bolha e o eixo horizontal. A figura 5.10 mostra um histograma do número de bolhas em função do ângulo de inclinação.

O sistema de processamento de imagens se mostrou bastante robusto, ou seja, mesmo variando-se os vários parâmetros, descritos no capítulo 4, não houve alterações significativas no diagrama de raios encontrado. O tempo de processamento do algoritmo em um computador pessoal (processador PENTIUM 4 de 3GHz, 1GB de memória RAM e sistema 
operacional WINDOWS XP) foi medido para um conjunto de cinqüenta imagens. O tempo de processamento medido para cada imagem variou entre 1 e $1,7 \mathrm{~s}$, dependendo da imagem utilizada.

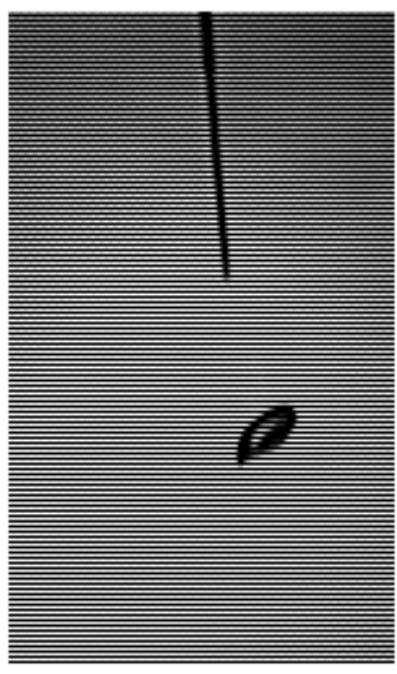

(a)

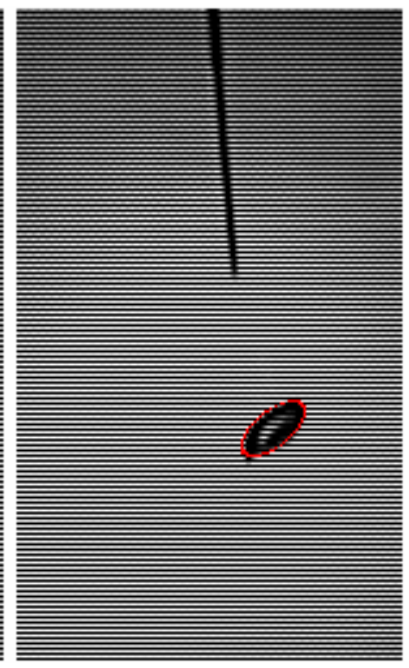

(b)

Figura 5.9: (a) Imagem original da bolha com ângulo de $38,4^{\circ}$ entre o eixo maior da bolha e o eixo horizontal; (b) imagem original da bolha e a "melhor" elipse encontrada em destaque.

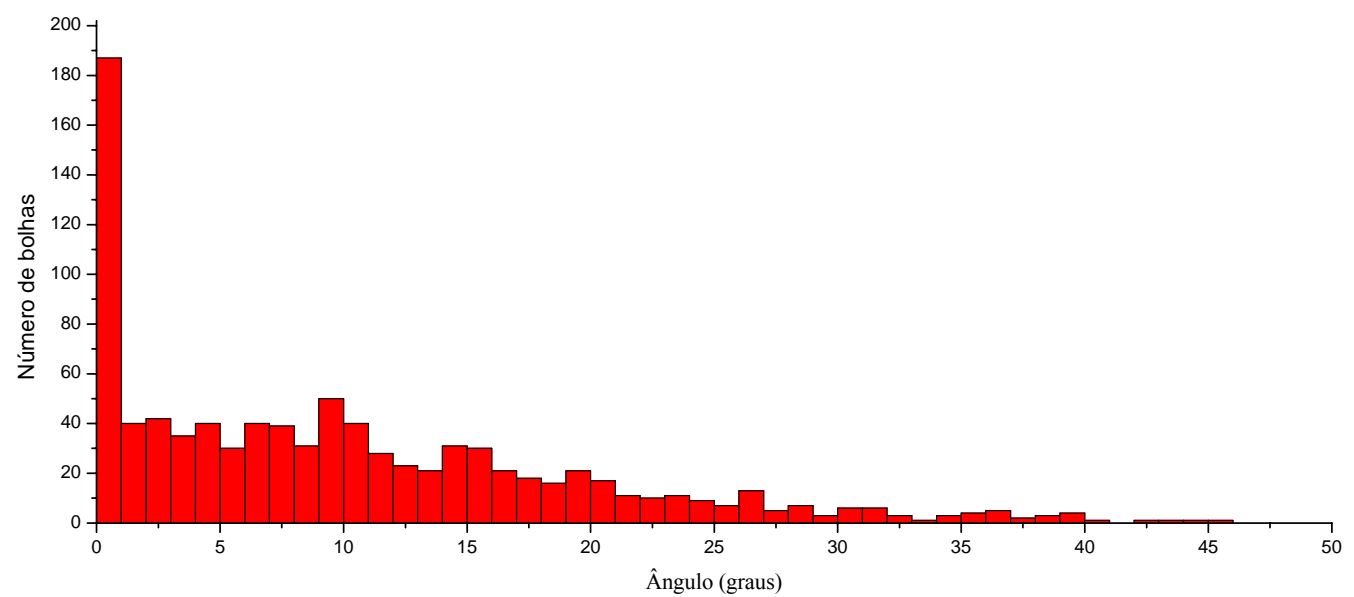

Figura 5.9: (a) Histograma do número de bolhas em função do ângulo de inclinação. 


\section{Capítulo 6}

\section{Conclusões e sugestões para trabalhos}

\section{futuros}

O trabalho apresentou uma metodologia de determinação da distribuição de raios de bolhas em uma coluna de borbulhamento composta por meio bifásico. A distribuição de raios é determinada através do processamento do sinal de uma sonda condutiva que mede os tempos de residência das bolhas de acordo com a variação de condutividade entre dois eletrodos presentes na ponta de prova. Um modelo estatístico é utilizado para correlacionar o diagrama de cordas encontrado com o diagrama de raios. Este resultado é comparado com medidas de tamanho de bolhas realizadas através do processamento de imagens capturadas por uma câmera de vídeo. Foram também apresentados os resultados experimentais obtidos e algumas conclusões baseadas nos mesmos. 


\subsection{Principais contribuições}

As principais contribuições do trabalho foram:

- Desenvolvimento de um sistema de medida dos tempos de residência de bolhas em uma coluna de borbulhamento bifásica;

- Utilização de um método estatístico para correlacionar diagrama de cordas ao diagrama de raios de bolhas em uma coluna de borbulhamento bifásica;

- Desenvolvimento de um sistema de determinação de tamanho de bolhas através do processamento de imagens monocromáticas capturadas por uma câmera de vídeo;

- Correlação entre os resultados obtidos pelos sistemas de determinação de distribuição de raios de bolhas através de uma sonda condutiva e pelo sistema de medida de tamanho de bolhas baseado em imagens;

- Publicação e apresentação do trabalho "Processamento e aquisição de imagens de vídeo para correlacionar histograma de cordas ao diâmetro de bolhas" no I Workshop de Visão Computacional - WVC 2005;

- Publicação e apresentação do trabalho "Segmentação de Imagens de Bolhas em Sistemas Bifásicos utilizando Morfologia Matemática e Crescimento de Região” no II Workshop de Visão Computacional - WVC 2006;

- Artigo "Arquitetura para crescimento de regiões de imagens binárias" submetido no III Southern Conference on Programmable Logic -SPL 2007 (Resultado da avaliação não conhecido até este momento). 


\subsection{Sugestões para trabalhos futuros}

As sugestões para trabalhos futuros são:

- Implementação de um hardware dedicado;

- Construção de um sistema de medida de variação de condutividade com melhor relação sinal ruído;

- Construção de um modelo estatístico de correlação entre diagrama de cordas obtidos por uma ponta de prova condutiva e diagrama de raios que considere o ângulo de inclinação das bolhas;

- Utilização de uma ponta de prova dupla ou múltipla que permita a obtenção direta do tamanho das cordas de bolhas;

- Utilização de uma câmera com controle de obturador e com lentes que permitam a captura de imagens com melhor resolução;

- Utilização de uma câmera com maior taxa de quadros que permita o estudo da interação entre as bolhas e a ponta de prova;

- Realização de medidas em uma coluna de borbulhamento prática ou industrial. 


\section{REFERÊNCIAS}

AGIN, G. J. (1981). Fitting ellipses and general second-order curves. Technical Report, Robotics Institute, Carnegie-Mellon University, p.1-28, Jul.

ANDREUSSI, P.; DONFRANCESCO, A.; MESSIA, M. (1988). An impedance method for the measurement of liquid hold-up in two-phase flow. International Journal of Multiphase Flow, v.14, n.6, p.777-785, November-December.

BALLARD, D. H. (1981). Generalizing the Hough transform to detect arbitrary shapes. Pattern Recognition, v.13, n.2, p.111-1981.

BARIGOU, M.; GREAVES, M. (1991). A capillary suction probe for bubble size measurement. Measurement Science and Technology, v.2, n.4, p.318-326, April.

BOSTROM, N. W.; GRIFFIN, D. D.; KLEINBERG, R. L.; LIANG, K. K. (2005). Ultrasonic bubble point sensor for petroleum fluids in remote and hostile environments. Measurement Science and Technology, v.16, n.11, p.2336-2343, November.

BUCHHOLZ, R.; ZAKREWSKI, W.; SCHÜGERL, K. (1981). Techniques for determining the properties of bubbles in bubble columns. International Chemical Engineering, v.21, n.2, p.180-187. April.

CATHIGNOL, D.; CHAPELON, J. Y.; NEWHOUSE, V. L.; SHANKAR, P. M. (1990). Bubble sizing with high spatial resolution. IEEE Transactions on Ultrasonics, Ferroelectrics, and Frequency Control, v37, n.1, p.30-37, January.

CHAPELON, J. Y.; NEWHOUSE, V. L.; CATHIGNOL, D.; SHANKAR, P. M. (1988). Bubble detection and sizing with a double frequency Doppler system. Ultrasonics, v.26, n.3, p148-154, May.

CHEN, J.; GUPTA, P.; DEGALEESAN, S.; AL-DAHHAN, M. H.; DUDUKOVIC, M. P.; TOSELAND, B. A. (1998). Gas holdup distributions in large-diameter bubble columns measured by computed tomography. Flow Measurement and Instrumentation, v.9, n.2, p.91101, June.

CLARK, N. N.; TURTON, R. (1988). Chord length distributions related to bubble size distributions in multiphase flows. International Journal of Multiphase Flow, v.14, n.4, p.413424, July-August. 
CONEY, M. W. E. (1973). The theory and application of conductance probes for the measurement of liquid film thickness in two phase flow. Journal of Physics E: Scientific Instrumentation, v.6, n.9, p.903-910, September.

DAILEY, D. J. (1995). Operational Amplifiers and Linear Integrated Circuits: Theory and applications. Glencoe/ Mc Graw-Hill.

DEVANATHAN, N.; MOSLERNIAN, D.; DUDUKOVIC M. P. (1990). Flow mapping in bubble columns using CARPT. Chemical Engineering Science, v.45, n.8, p.2285-2291.

DIAS, S. G.; FRANÇA, F. A.; ROSA, E. S. (2000). Statistical method to calculate local interfacial variables in two-phase bubbly flows using intrusive crossing probes. International Journal of Multiphase Flow, v.26, n.11, p.1797-1830, November.

DURST, F. (1982). Combined measurements of particle velocities, size distributions and concentrations. Transaction - ASME, Journal of Fluids Engineering, v104, p.284-296.

FITZGIBBON, A.; PILU, M.; FISHER, R. B. (1999). Direct least square fitting of ellipses. IEEE transaction on Pattern Analysis and Machine Intelligence, v.21, n.5, p.476-480, May.

FOSSA, M. (1998). Design and performance of a conductance probe for measuring the liquid fraction in two-phase gas-liquid flows. Flow Measurement and Instrumentation, v.9, n.2, p103-109, June.

GONZALEZ, R. C.; WOODS, R. E. (1992). Processamento de imagens digitais. São Paulo, Edgard Blücher.

GRAU, R. A.; HEISKANEN, K. (2002). Visual technique for measuring bubble size in flotation machines. Minerals engineering, v.15, n.7, p.507-513, July.

GUET, S.; LUTHER, S.; OOMS, G. (2005). Bubble shape and orientation determination with a four-point optical fiber probe. Experimental Thermal and Fluid Science, v.29, n.7, p.803812, August.

GUET, S.; OOMS, G.; OLIEMANS, R. V. A.; MUDDE, R. F. (2004). Bubble size effect on low liquid input drift-flux parameters. Chemical Engineering Science, v.59, n.16, p.33153329, August. 
HASSAN, Y. A.; ORTIZ-VILLAFUERTE, J.; SCHMIDL, W. D. (2001). Three-dimensional measurements of single bubble dynamics in a small diameter pipe using stereoscopic particle image velocimetry. International Journal of Multiphase Flow, v.27, n.5, p.817-842, May.

HU, B.; PACEK, A. W.; STITT, E. H.; NIENOW, A. W. (2005). Bubble sizes in agitated airalcohol systems with and without particles: turbulent and transitional flow. Chemical Engineering Science, v.60, p.6371-6377, June.

HUNG, C. L. (1989). Elliptical feature extraction via an improved Hough transform. Pattern Recognition Letters, v10, n.2, p.93-100, August.

IMAQ Vision Concepts Manual (2000), p.9-10, October.

JONES JUNIOR, O. C.; DELHAYE, J.-M. (1976). Transient and statistical measurement techniques for two-phase flows: a critical review. International Journal of Multiphase Flow, v3, n.2, p.89-116, December.

KIAMBI, S. L.; DUQUENNE, A.; DUPONT, J.; COLIN, C.; RISSO, F.; DELMAS, H. (2003). Measurements of bubble characteristics: comparison between double optical probe and imaging. The Canadian Journal of Chemical Engineering, v.81, p.764-770, June-August.

KOLLER, D.; LI, Y.; SHANKAR, P. M.; NEWHOUSE, V. L. (1992). Communications: High-speed bubble sizing using the double frequency technique for oceanographic applications. IEEE Journal of Oceanic Engineering, v.17, n.3, p.288-291, July.

LARE, C. E. J. V.; PIEPERS, H. W.; SCHOONDERBEEK, J. N.; THOENES, D. (1997). Investigation on bubble characteristics in a gas fluidized bed. Chemical Engineering Science, v.52, n.5, p.829-841, March.

LEIFER, I.; LEEUW, G.; COHEN, L. H. (2003). Optical measurement of bubble: System design and application. Journal of Atmospheric and Ocean Technology, v.20, n. 9, p.13171332, September.

LEVINE, M. D. (1985). Vision in man and machine. New York, McGraw-Hill.

LIM, K. S.; AGARWAL, P. K. (1990). Conversion of pierced lengths measured at a probe to bubble size measures: an assessment of the geometrical probability approach and bubble shape models. Powder Technology, v.63, n.3, p.205-219, December. 
LIU, T. J. (2002). An effective signal processing method for resistivity probe measurements in a two-phase bubbly flow. Measurement Science and Technology, v13, n.2, p.206-217, February.

LIU, T. J.; BANKOFF, S. G. (1993). Structure of air-water bubbly flow in a vertical pipe - II. Void fraction, bubble velocity and bubble size distribution. International Journal of Heat and Mass Transfer, v.36, n.4, p.1061-1072, March.

LIU, W.; CLARK, N. N. (1995). Relationships between distributions of chord lengths and distributions of bubble sizes including their statistical parameters. International Journal of Multiphase Flow, v.21, n.6, p.1073-1089, November.

LIU, W.; CLARK, N. N.; KARAMAVRUÇ, A. I. (1998). Relationship between bubble size distribution and chord-length distribution in heterogeneously bubbling systems. Chemical Engineering Science, v.53, n.6, p.1267-1276, March.

LUCAS, G. P.; MISHRA, R. (2005). Measurement of bubbles velocity components in a swirling gas-liquid pipe flow using a local four-sensor conductance probe. Measurement Science and Technology, v.16, n.3, p.749-758, March.

MANCINI, R.; PALMER R. (2002). Op amps for everyone. Design Reference, Texas Instruments.

MATHWORLD. Disponível em: <http://mathworld.wolfram.com/Ellipse.html>. Acesso em: 18 set. 2006.

MILLER, D. L. (1981). Ultrasonic detection of resonant cavitation bubble in a flow tube by their second-harmonic emissions. Ultrasonics, v.19, n.5, p.217-224, September.

NEWHOUSE, V. L.; SHANKAR, P. M. (1984). Bubble size measurements using the nonlinear mixing of two frequencies. Journal of the Acoustical Society of America, v.75, n.5, p.1473-1477, May.

POULARIKAS, A. D. (1996). The transforms and its applications handbook. Boca Raton, CRT Press.

PRASSER, H. M.; SCHOLZ, D.; ZIPPE, C. (2001). Bubble size measurement using wiremesh sensors. Flow Measurement and Instrumentation, v.12, n.4, p299-312, August. 
PRESS, W. H.; TEUKOLSKY, S. A.; VETTERLING, W. T.; FLANNERY, B. P. (1992). Numerical Recipes in C. Cambridge, Cambridge University Press, 1992.

RANDALL, E. W.; GOODALL, C. M.; FAIRLAMB, P. M.; DOLD, P. L.; O'CONNOR, C. T. (1989). A method for measuring the sizes of bubbles in two- and three-phase systems. Journal of Physics, Section E, Scientific Instrumentation, v.22, n.10, p.827-833, October.

ROSIN, P. L (1993a). Ellipse fitting by accumulating five point fits. Pattern Recognition Letters, v14, n.8, p.661-669, August.

ROSIN, P. L. (1993b). A note on the least squares fitting of ellipses. Pattern Recognition Letters, v.14, n.10. p.799-808, October.

ROSSI, G. L. (1996). Error analysis based development of a bubble velocity measurement chain. Flow Measurement and instrumentation, v.7, n.1, p.39-47, March.

RUSS, J. C. (1995). The image processing handbook. Boca Raton, CRC press.

SAFFMAN M.; BUCHHAVE, P; TANGER, H. (1984). Simultaneous measurement of size, concentration and velocity of spherical particles by a laser Doppler method. Proc. Second International Symp. On Applications of Laser Anemometry to Fluid Mechanics, Lisbon, p.85103.

SEDRA, A. S.; SMITH, K. C. (2000). Microeletrônica. São Paulo, Pearson Makron Books.

SELEGHIM JÚNIOR, P.; MILIOLI, F. E. (2001). Improving the determination of bubble size histograms by wavelets de-noising techniques. Powder Technology, v.115, n.2, p.114-123, April.

SERDULA, C. D.; LOEWEN, M. R. (1998). Experiments investigating the use of fiber-optic probes for measuring bubble-size distributions. IEEE Journal of Oceanic Engineering, v.25, n.4, p.185-399, October.

SHAIKH, A.; AL-DAHHAN, M. (2005). Characterization of the hydrodynamic flow regime in bubble columns via computed tomography. Flow Measurement and Instrumentation, v.16, n.2-3, p.91-98, April-June.

SHEN, X.; SAITO, Y.; MISHIMA, K.; NAKAMURA, H. (2005). Methodological improvement of an intrusive four sensor probe for the multi-dimensional two phase flow measurement. International Journal of Multiphase Flow, v.31, n.5, p.593-617, May. 
STANLEY, W. D. (2002). Operational amplifiers with linear integrated circuits. Upper Saddlle River, Prentice Hall.

STRANG, G. (1988). Linear algebra and its applications. Thomson learning.

TAITEL, Y.; BARNEA, B.; DUKLER, A. E. (1980). Modeling flow pattern transitions for steady upward gas-liquid flow. Journal of American Institute of Chemical Engineers, v.26, n.3, p.345-354, May.

TEYSSEDOU, A.; TAPUCU, A. (1988). Impedance probe to measure local void fraction profiles. Review of Scientific Instruments, v59, n.4, p.631-638, April.

TURTON, R.; CLARK, N. N. (1989). Interpreting Probe Signals from Fluidized beds. Powder Technology, v.59, n.2, p.117-123, October.

VAGLE, S.; FARMER, D. M., (1998). A comparison of four methods for bubble size and void fraction measurements. IEEE Journal of Oceanic Engineering, v.23, n.3, p.211-222, July.

VARTY, R. L. (1986). Fringe method of bubble sizing using a laser Doppler anemometer. Journal of Physics, Section E: Scientific Instrumentation, v19, n.10, p.858-863, October.

VAZQUEZ, A.; SANCHES, R. M.; SALINAS-RODRÍGUES, E.; SORIA, A.; MANASSEH, R. (2005). A look at three measurement techniques for bubble size determination. Experimental Thermal and Fluid Science, v.30, n.1, p.49-57, October.

WANG, M.; YIN, W.; HOLLIDAY, N. (2002). A highly adaptive electrical impedance sensing system for flow measurement. Measurement Science and Technology, v.13, n.12, p.1884-1889, December.

WU, Q.; ISHII, M. (1999). Sensitivity study on double-sensor conductivity probe for the measurement of interfacial area concentration in bubbly flow. International Journal of Multiphase Flow, v.25, n.1, p.155-173, February.

WU, Q.; WELTER, K.; MCCCREARY, D.; REYES, J. N. (2001). Theoretical studies on the design criteria of double-sensor probe for the measurement of bubble velocity. Flow Measurement and Instrumentation, v.12, n.1, p.43-51, March. 
XUE, J.; AL-DAHHAN, M.; DUDUKOVIC, M. P.; MUDDE, R. F. (2003). Bubble dynamics measurements using four-point optical probe. The Canadian Journal of Chemical Engineering, v.81, p.375-381, June-August.

ZARUBA, A.; KREPPER, E.; PRASSER, H. M.; SCHLEICHER, E. (2005a). Measurement of bubble velocity profiles and turbulent diffusion coefficients of the gaseous phase in rectangular bubble column using image processing. Experimental Thermal and Fluid Science, v.29, n.7, p.851-860, August.

ZARUBA, A.; KREPPER, E.; PRASSER, H.-M.; VANGA, B. N. R. (2005b). Experimental study on bubble motion in a rectangular bubble column using high-speed video observations. Flow Measurements and Instrumentation, v.16, n.5, p.277-287, October.

ZWILLINGER, D. 2003. Standard mathematical tables and formulae. Boca Raton, Chapman \& Hall/CRT. 
APÊNDICE A - Circuitos Eletrônicos Construídos 


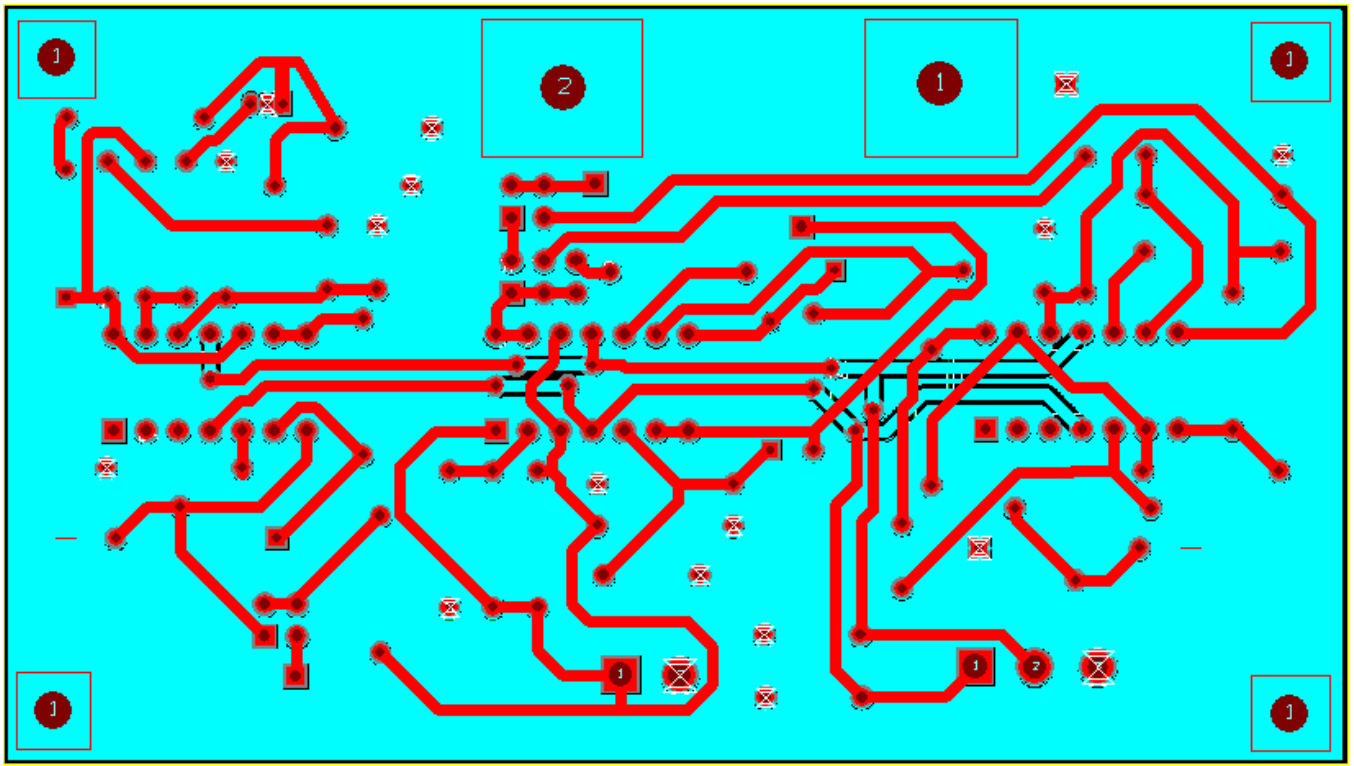

Figura A.1: Esquema da placa impressa do circuito de instrumentação utilizado na obtenção do sinal eletrico da sonda.

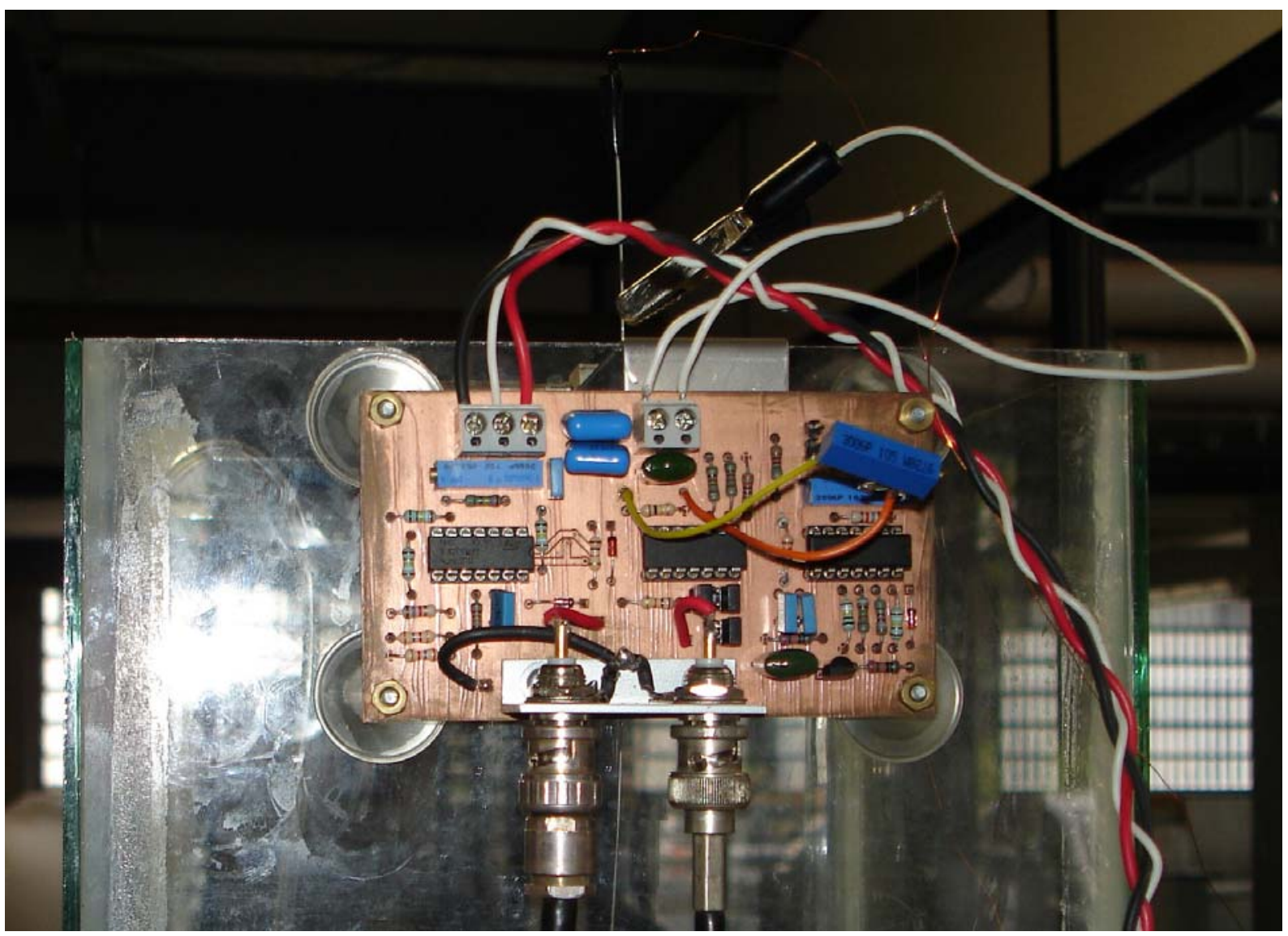

Figura A.2: Foto do circuito de instrumentação. 


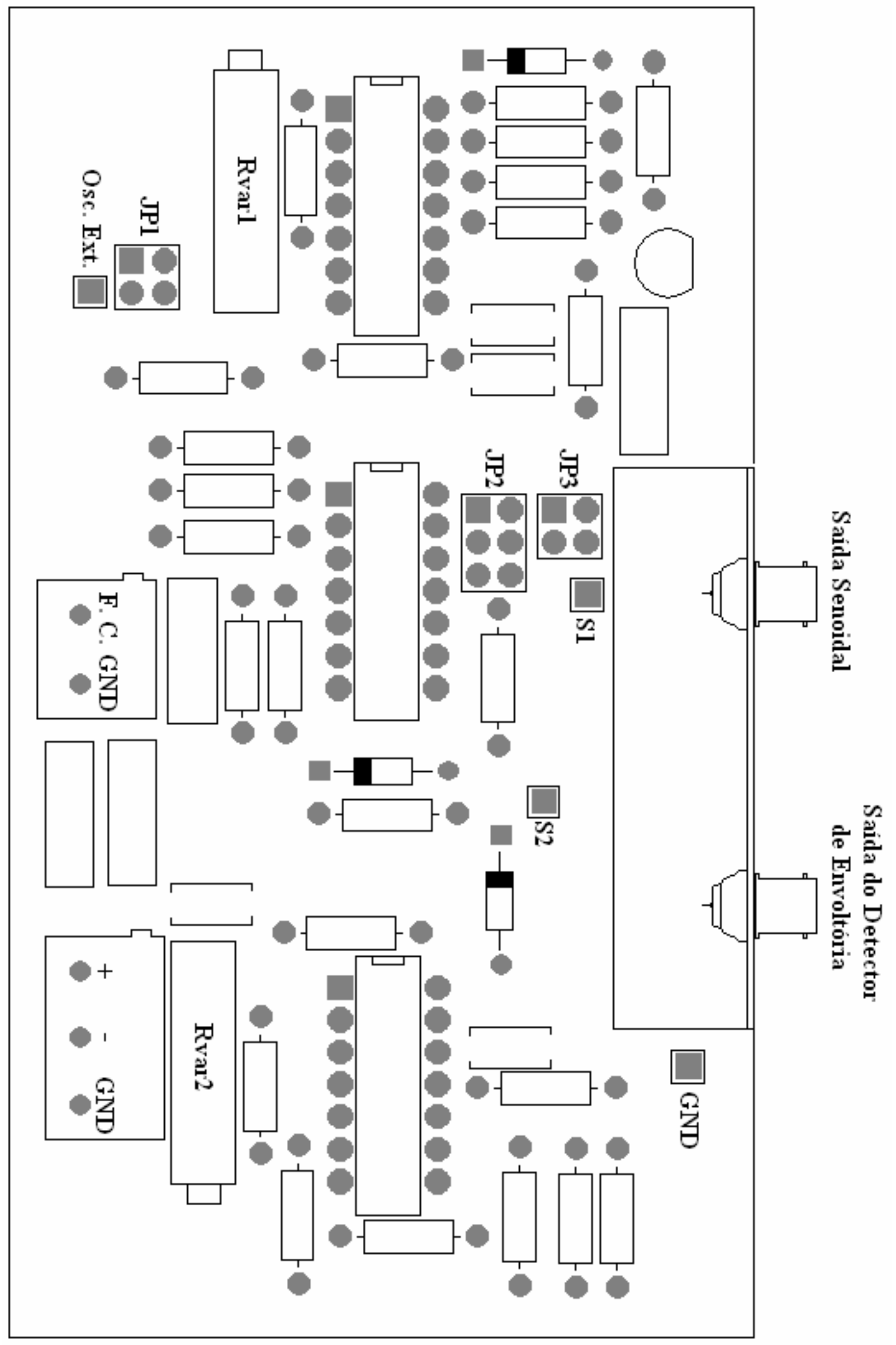

Figura A.3: Posicionamento das entradas, saídas, trimpots e jumpers na placa de instrumentação. 


\begin{tabular}{|c|c|}
\hline Rvar1 & Ajuste de amplitude do Oscilador Interno \\
\hline Rvar2 & Ajuste de freqüência central do filtro passa-faixa \\
\hline S1 & Saída senoidal \\
\hline S2 & Saída do detector de envoltória \\
\hline Osc. Ext. & Entrada para oscilador externo \\
\hline F. C. & Fonte de corrente \\
\hline GND & "Terra" \\
\hline
\end{tabular}

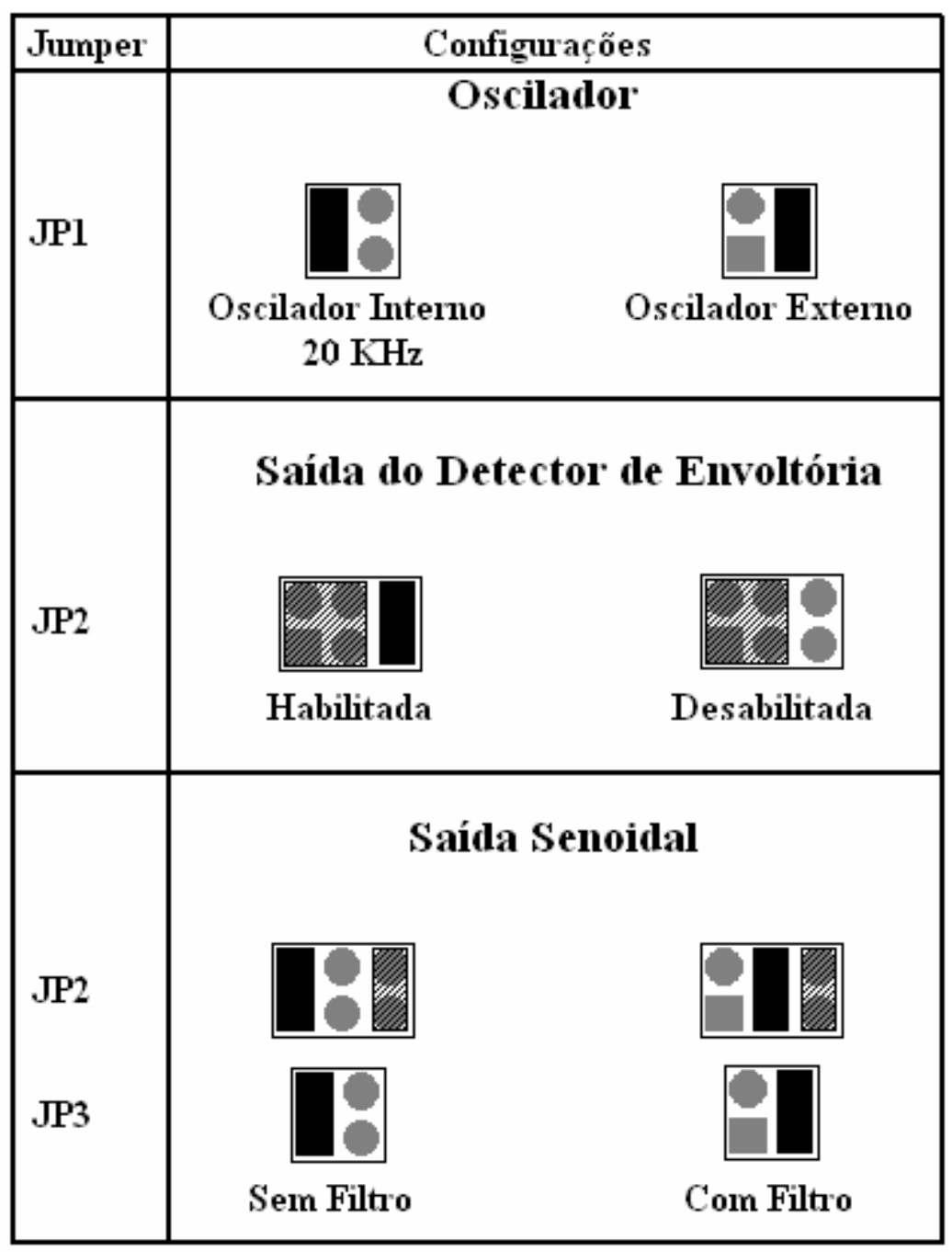

Obs:

Indiferente para a respectiva saida

Figura A.4: Nomenclatura utilizada (acima) e configurações dos “jumpers” na placa de instrumentação (abaixo). 


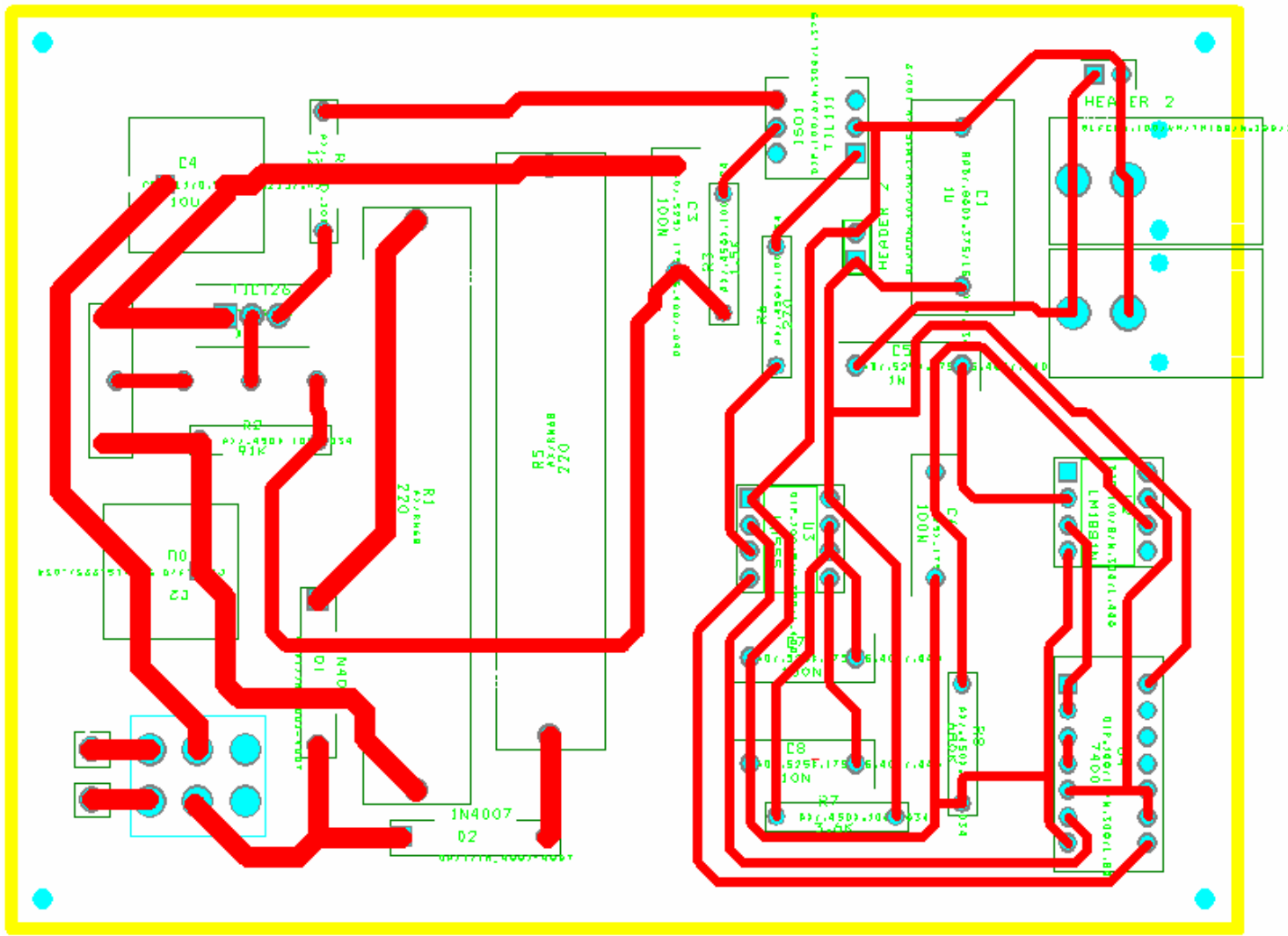

Figura A.5: Esquema da placa impressa do circuito de sincronização e acionamento da lâmpada de xenônio.

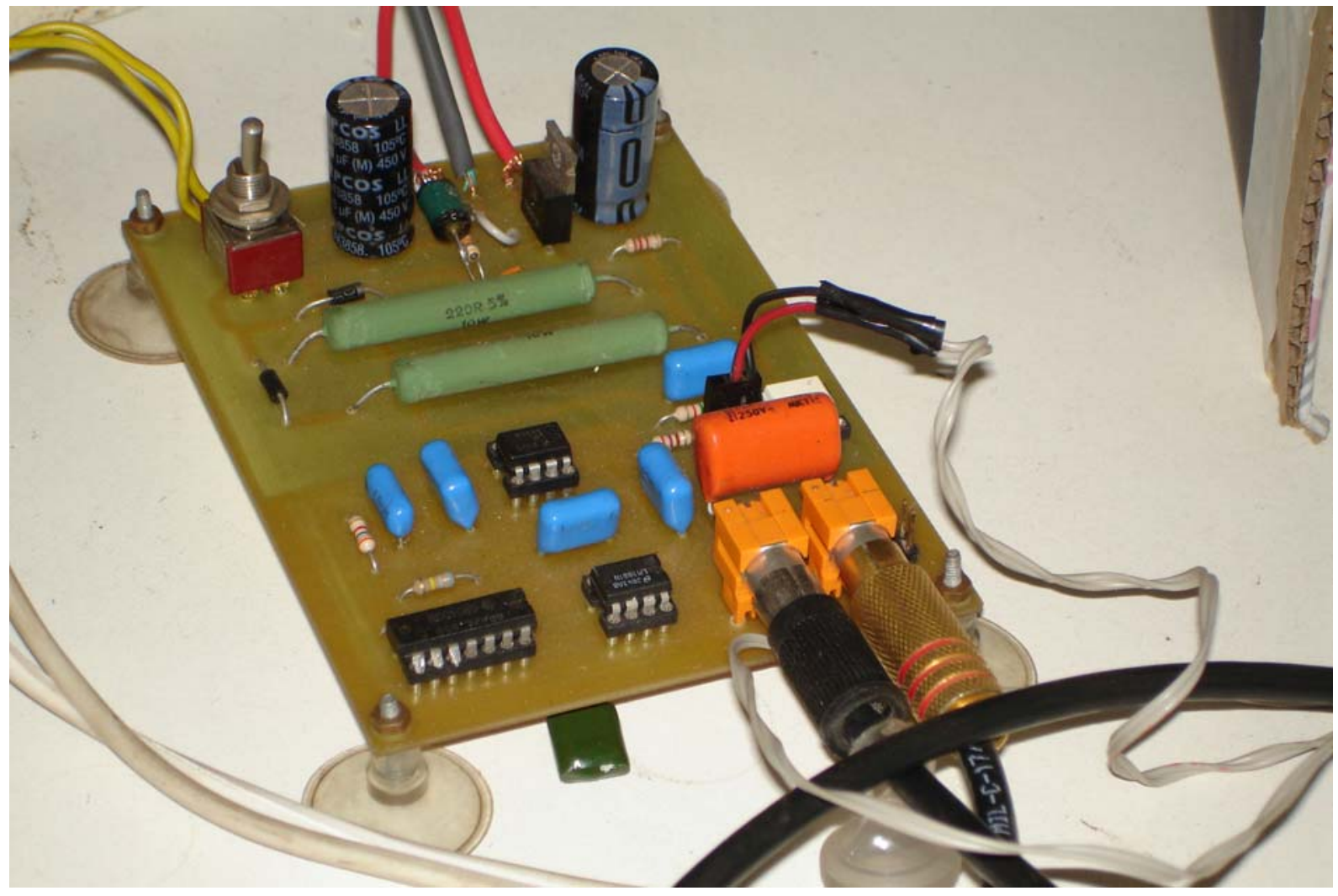

Figura A.6: Foto do circuito de acionamento e sincronização da lâmpada de xenônio. 
APÊNDICE B - Programas em LABVIEW 6.1 


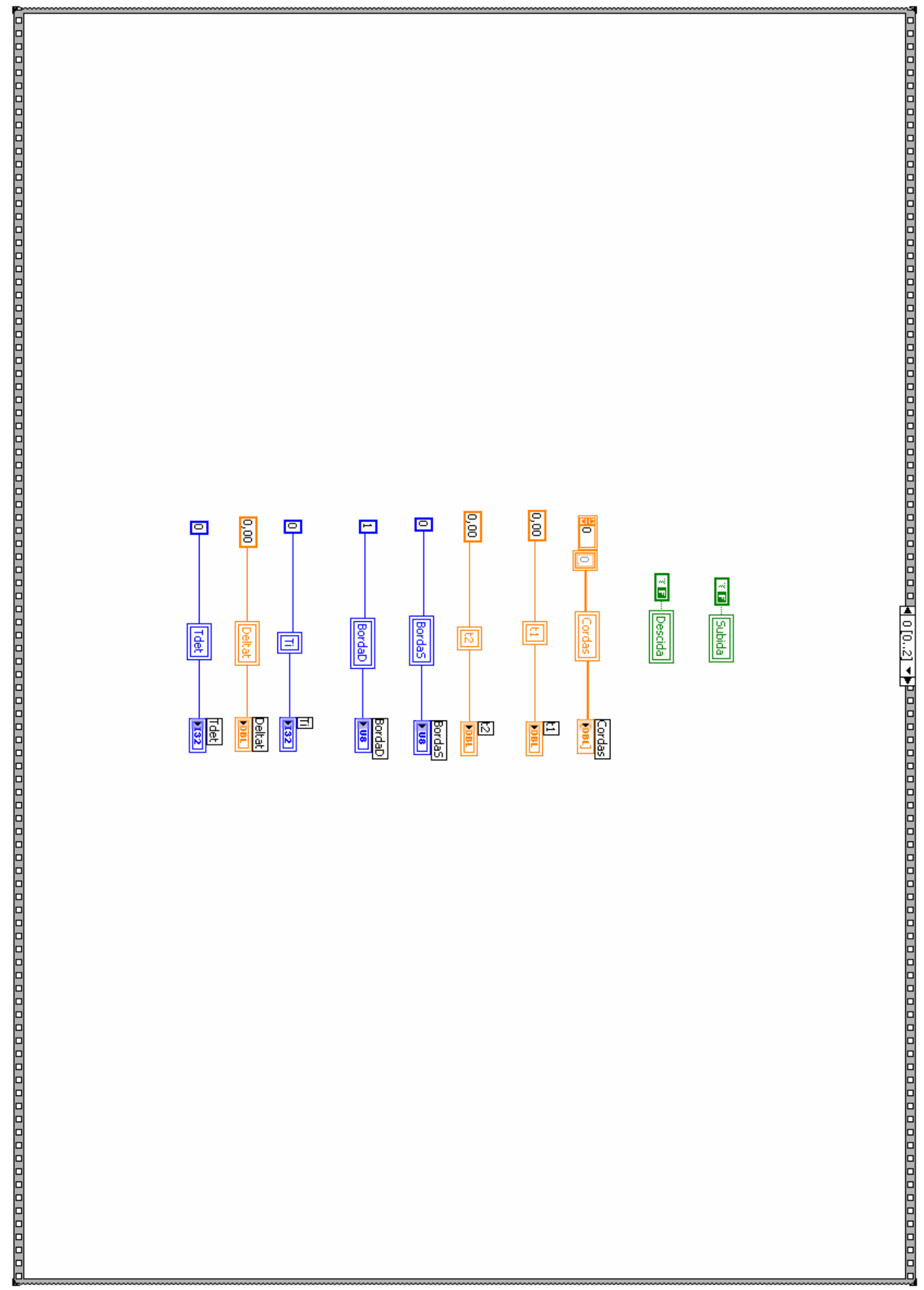

Figura B.1: Programa de aquisição de imagens de bolhas e do sinal elétrico da sonda. 


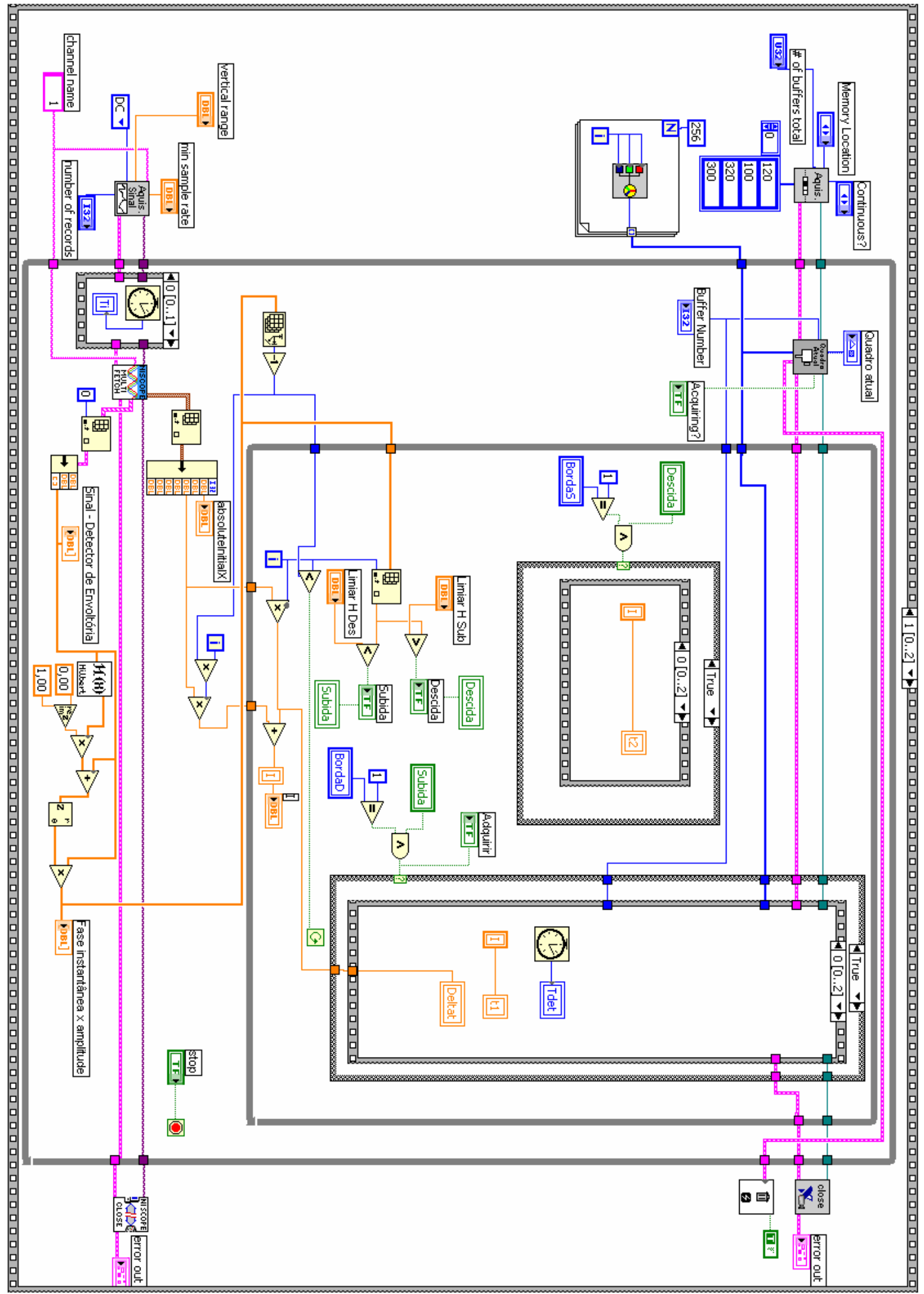

Figura B.2: Programa de aquisição de imagens de bolhas e do sinal elétrico da sonda (Cont.). 


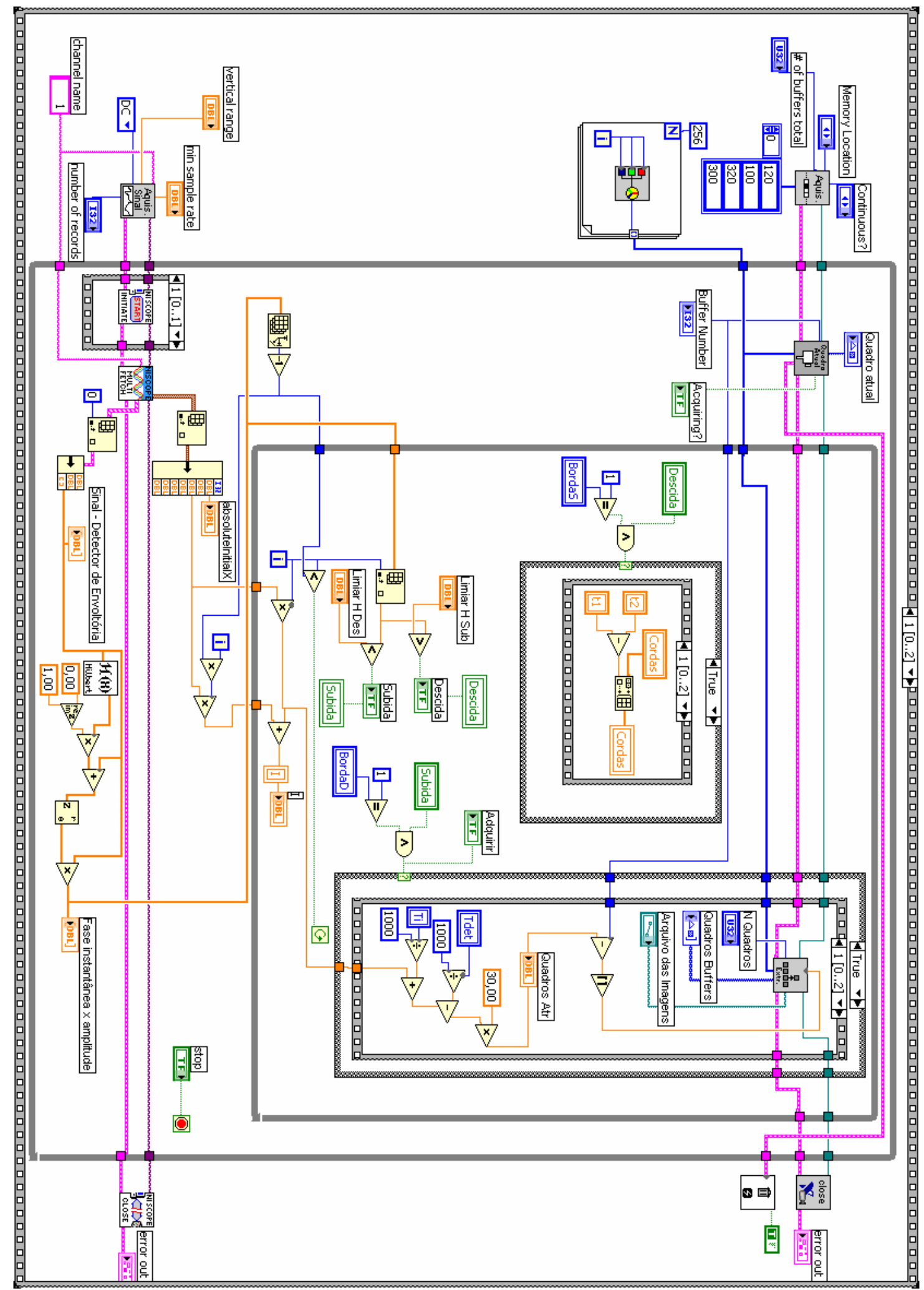

Figura B.3: Programa de aquisição de imagens de bolhas e do sinal elétrico da sonda (Cont.). 


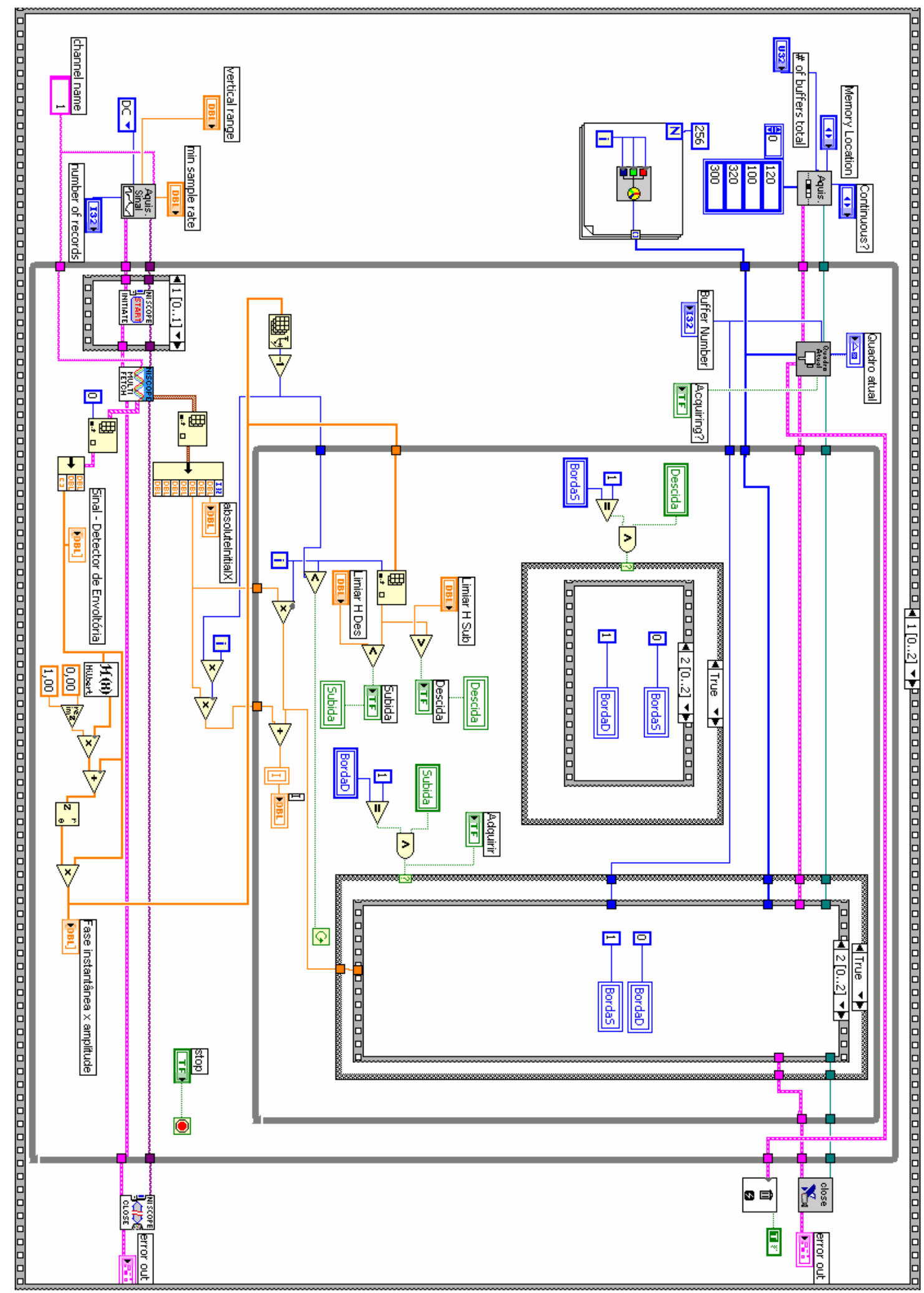

Figura B.4: Programa de aquisição de imagens de bolhas e do sinal elétrico da sonda (Cont.). 


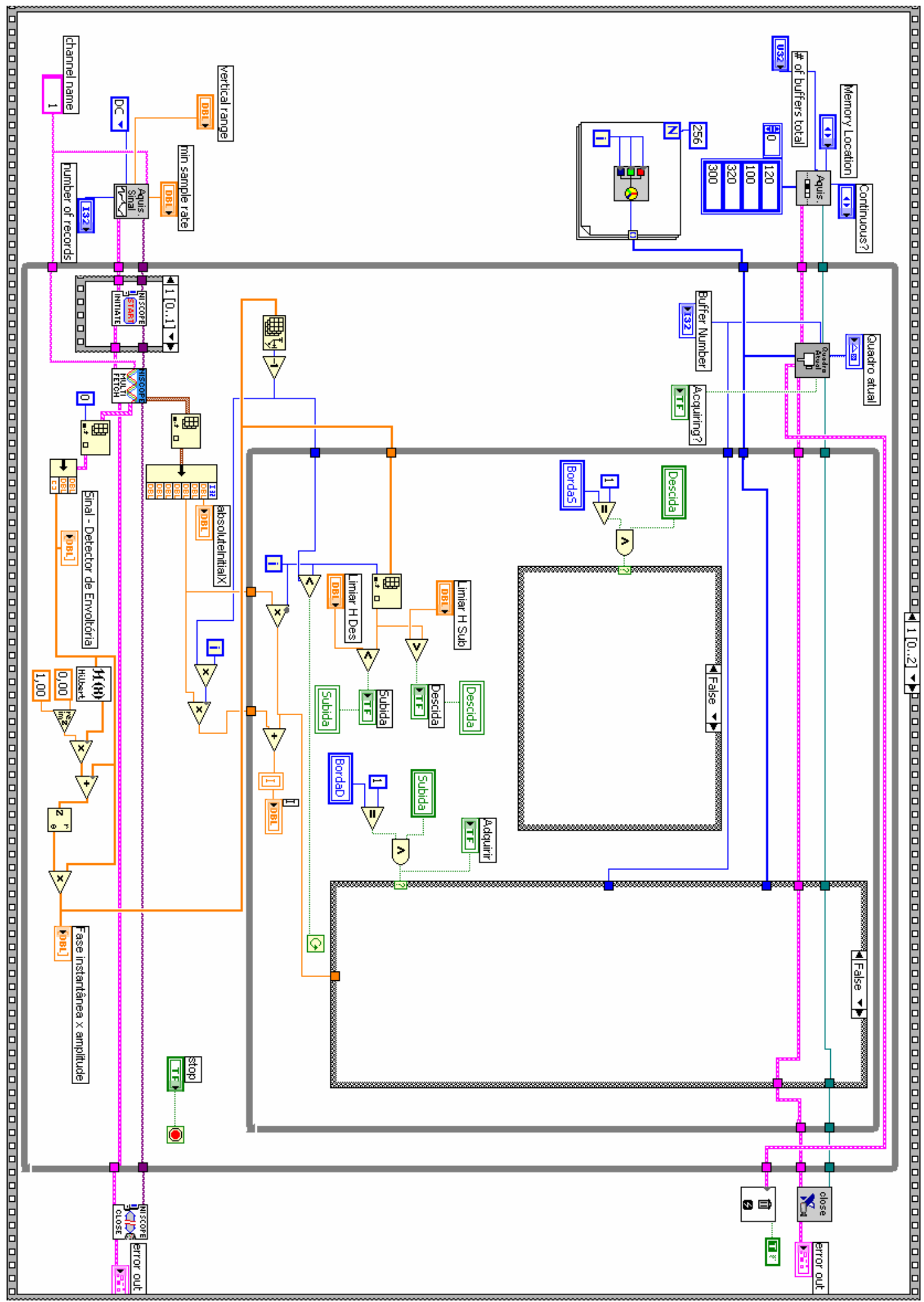

Figura B.5: Programa de aquisição de imagens de bolhas e do sinal elétrico da sonda (Cont.). 


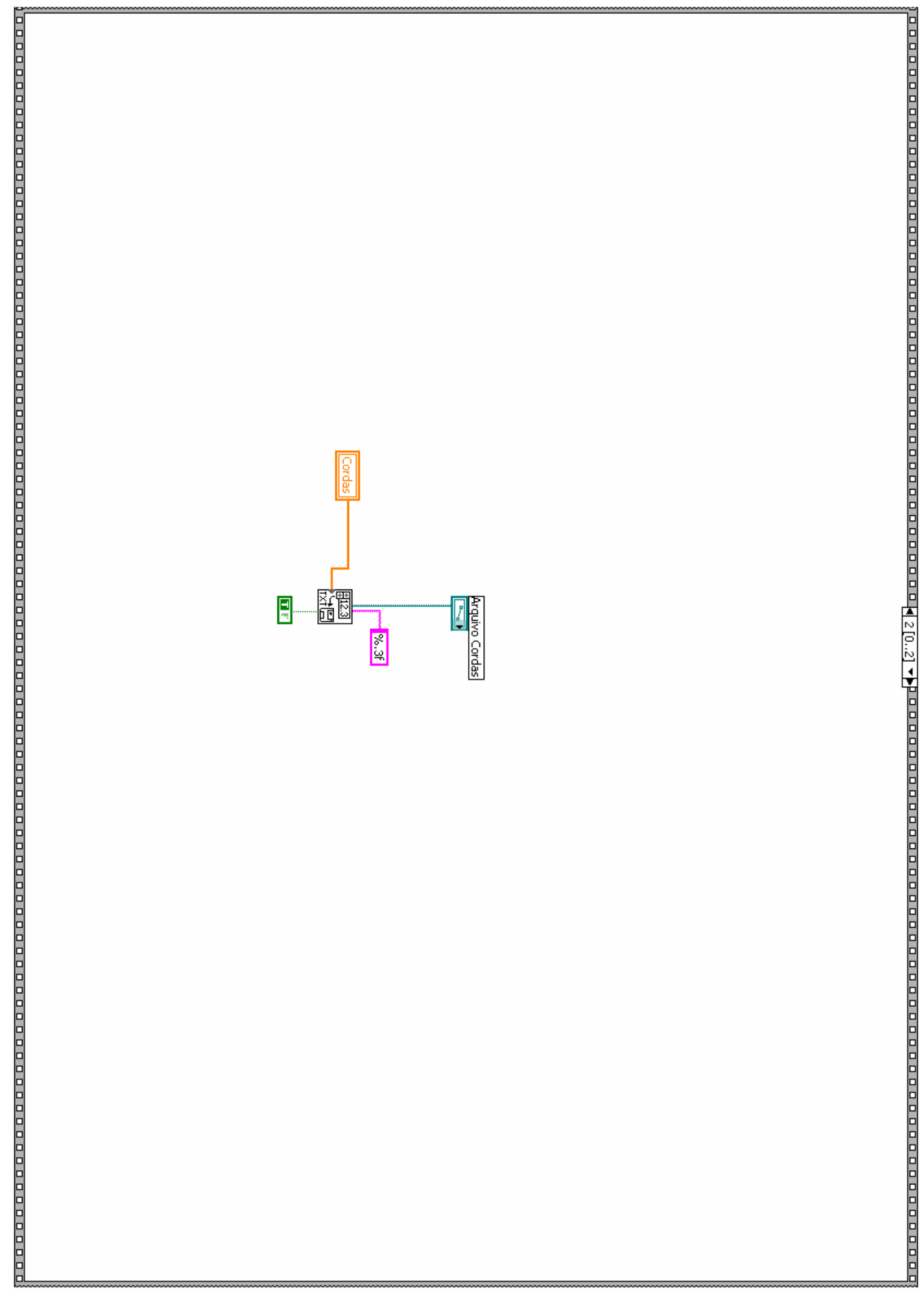

Figura B.6: Programa de aquisição de imagens de bolhas e do sinal elétrico da sonda (Cont.). 


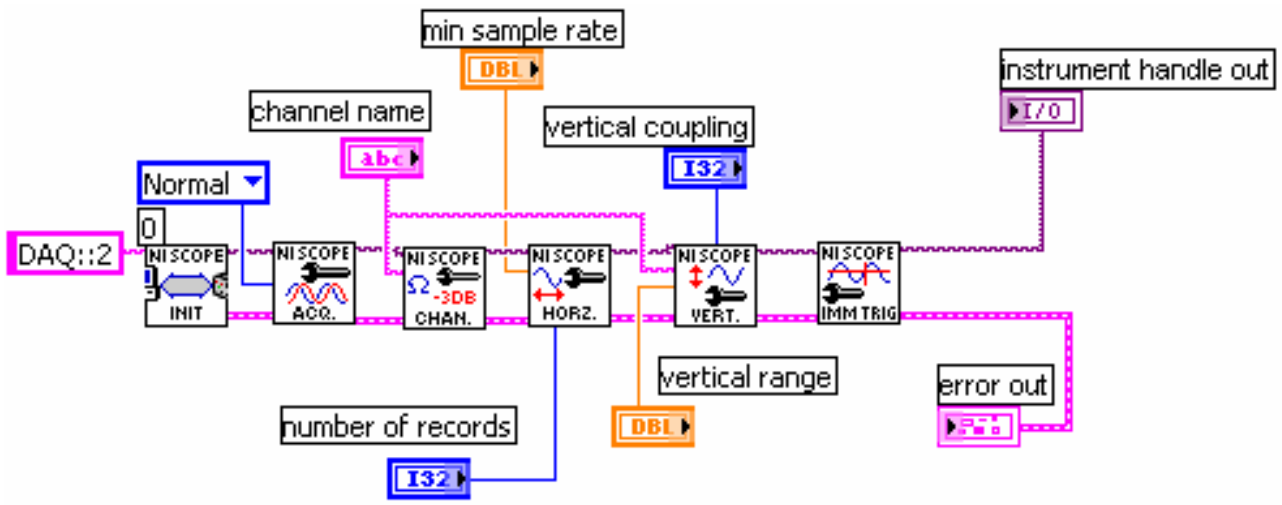

Figura B.7: Bloco de aquisição de sinal.

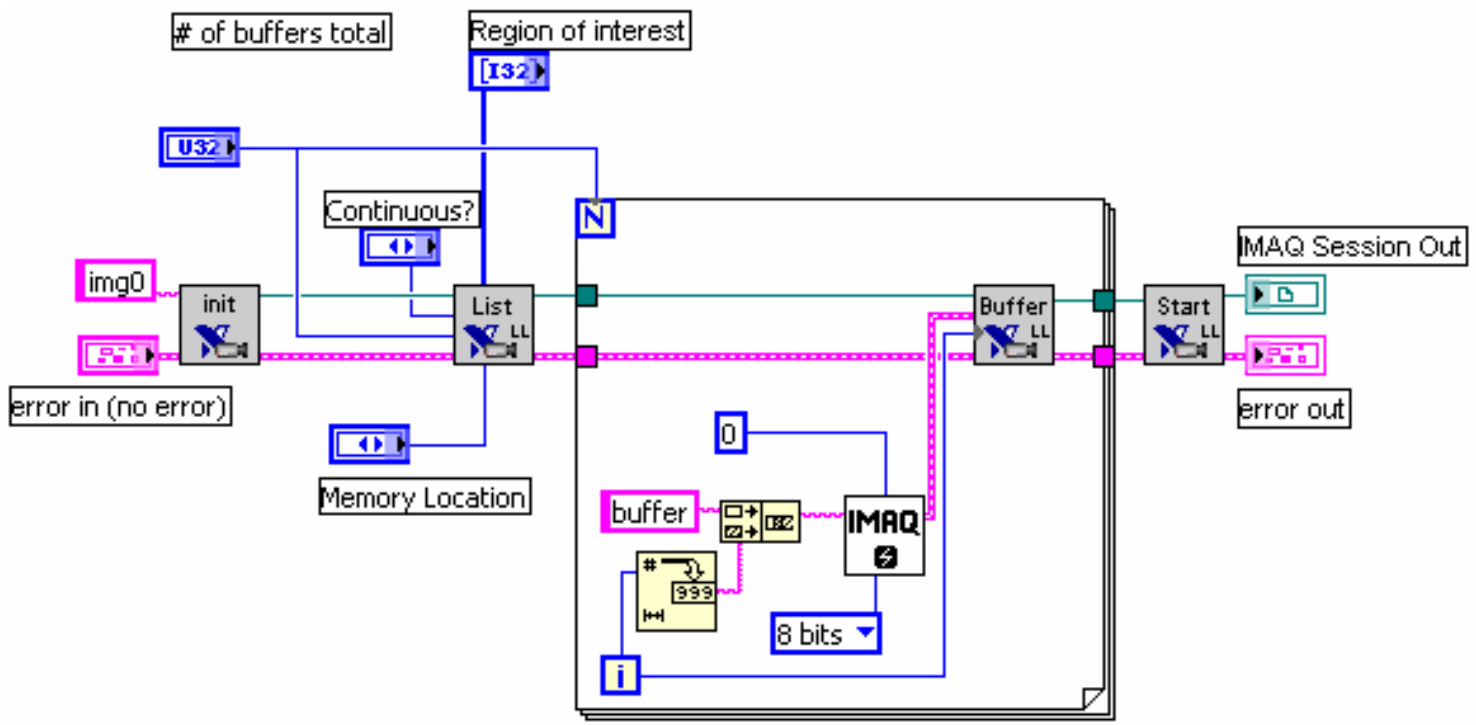

Figura B.8: Bloco de configuração da aquisição circular.

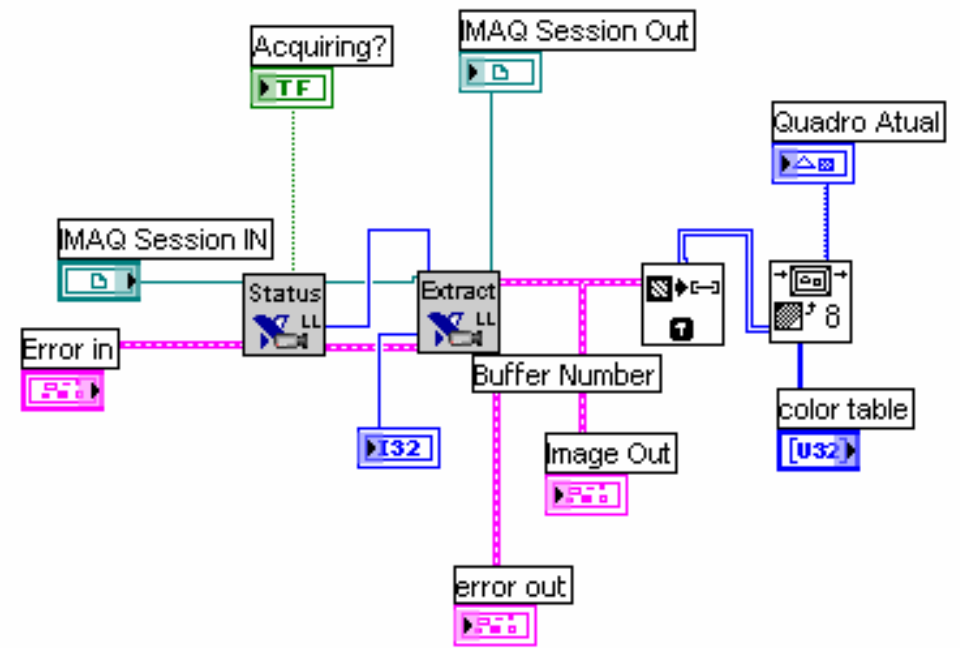

Figura B.9: Bloco de extração do quadro atual. 


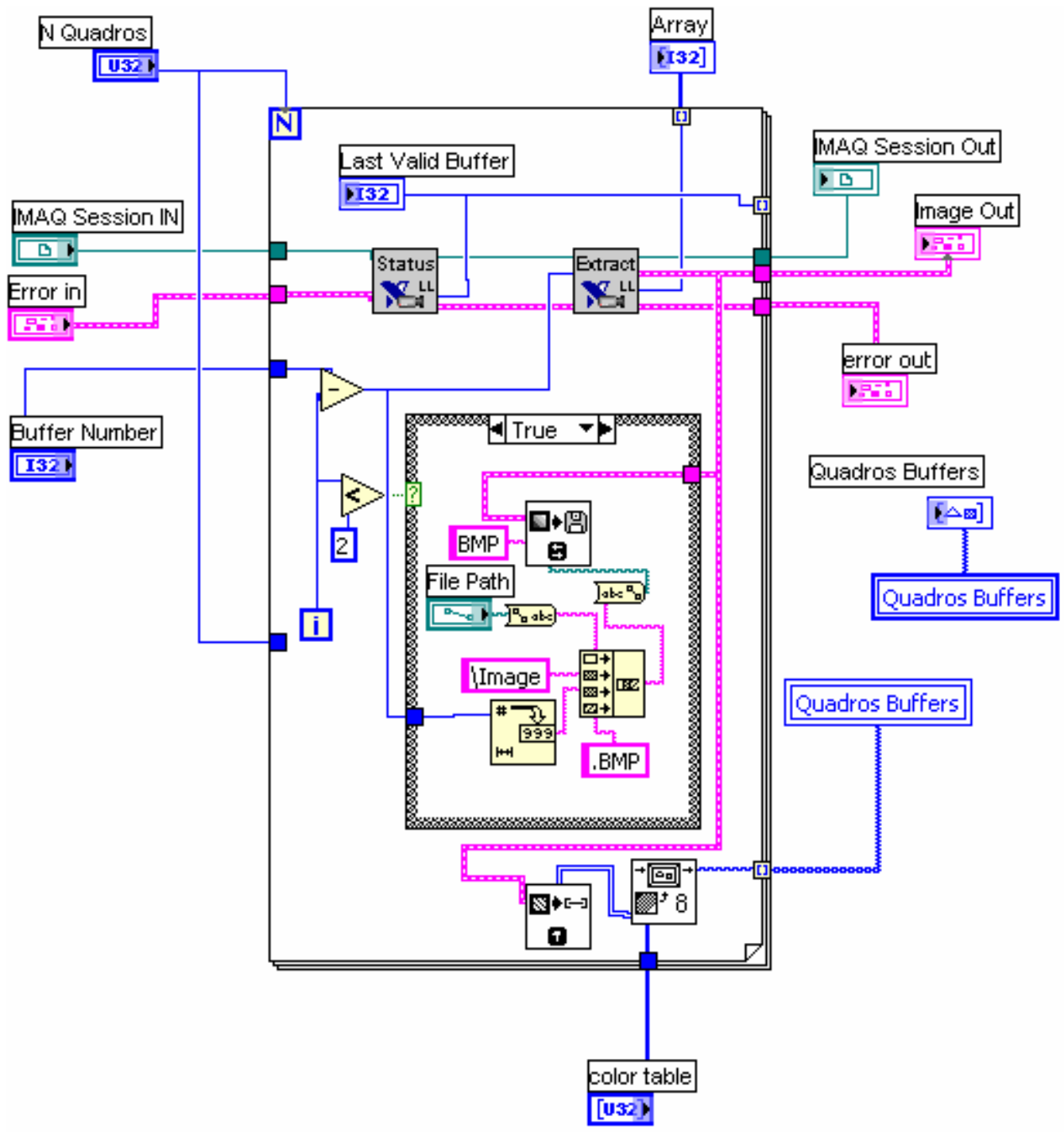

Figura B.10: Bloco de extração dos quadros do Buffer. 


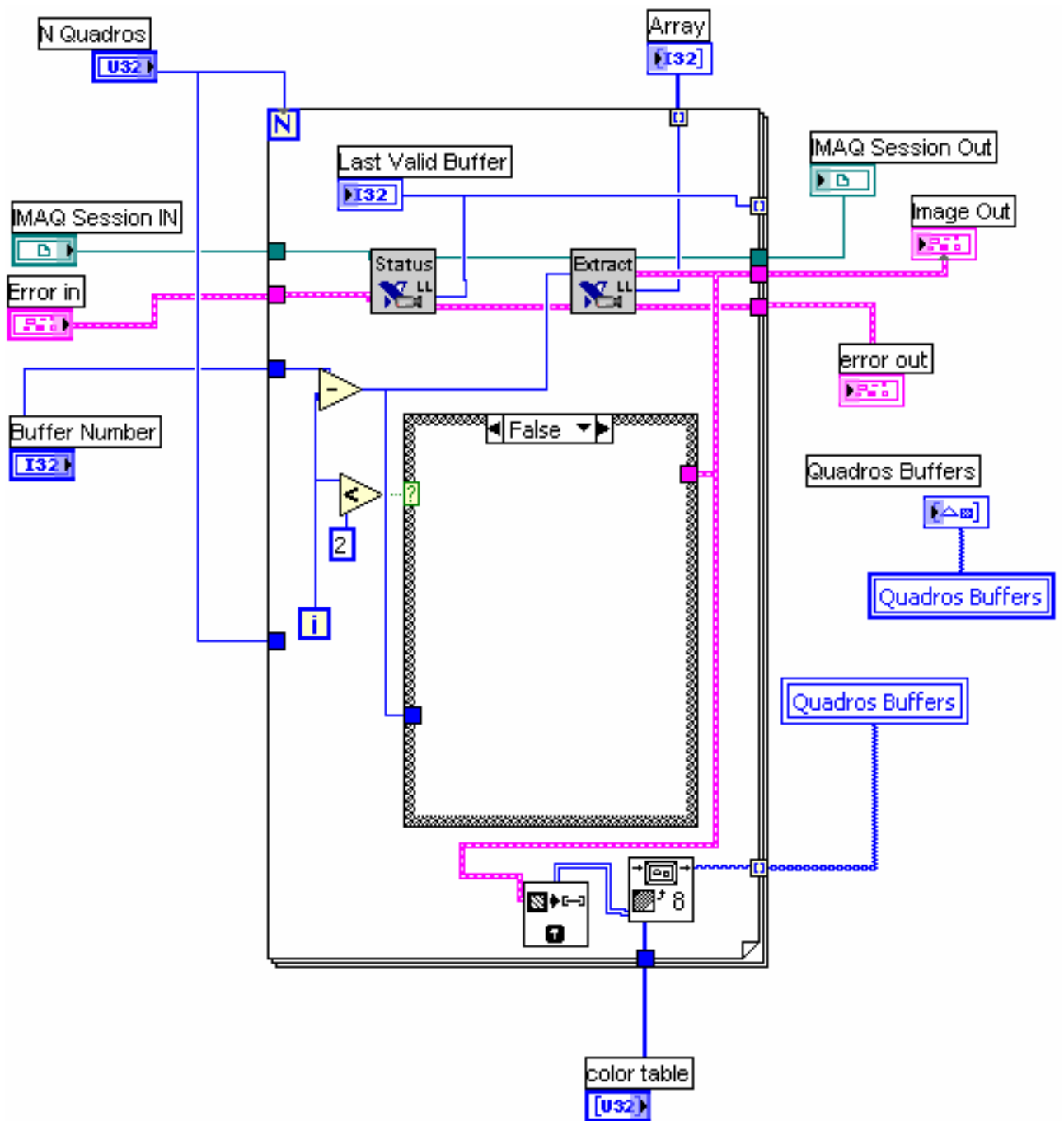

Figura B.11: Bloco de extração dos quadros do Buffer. (Cont.) 


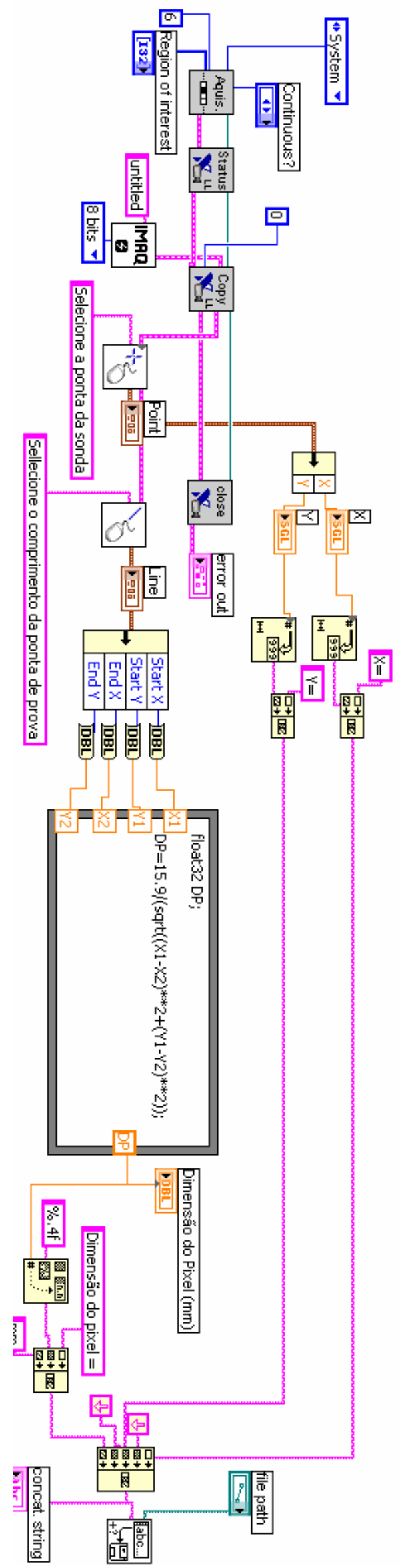

Figura B.12: Programa de calibração. 


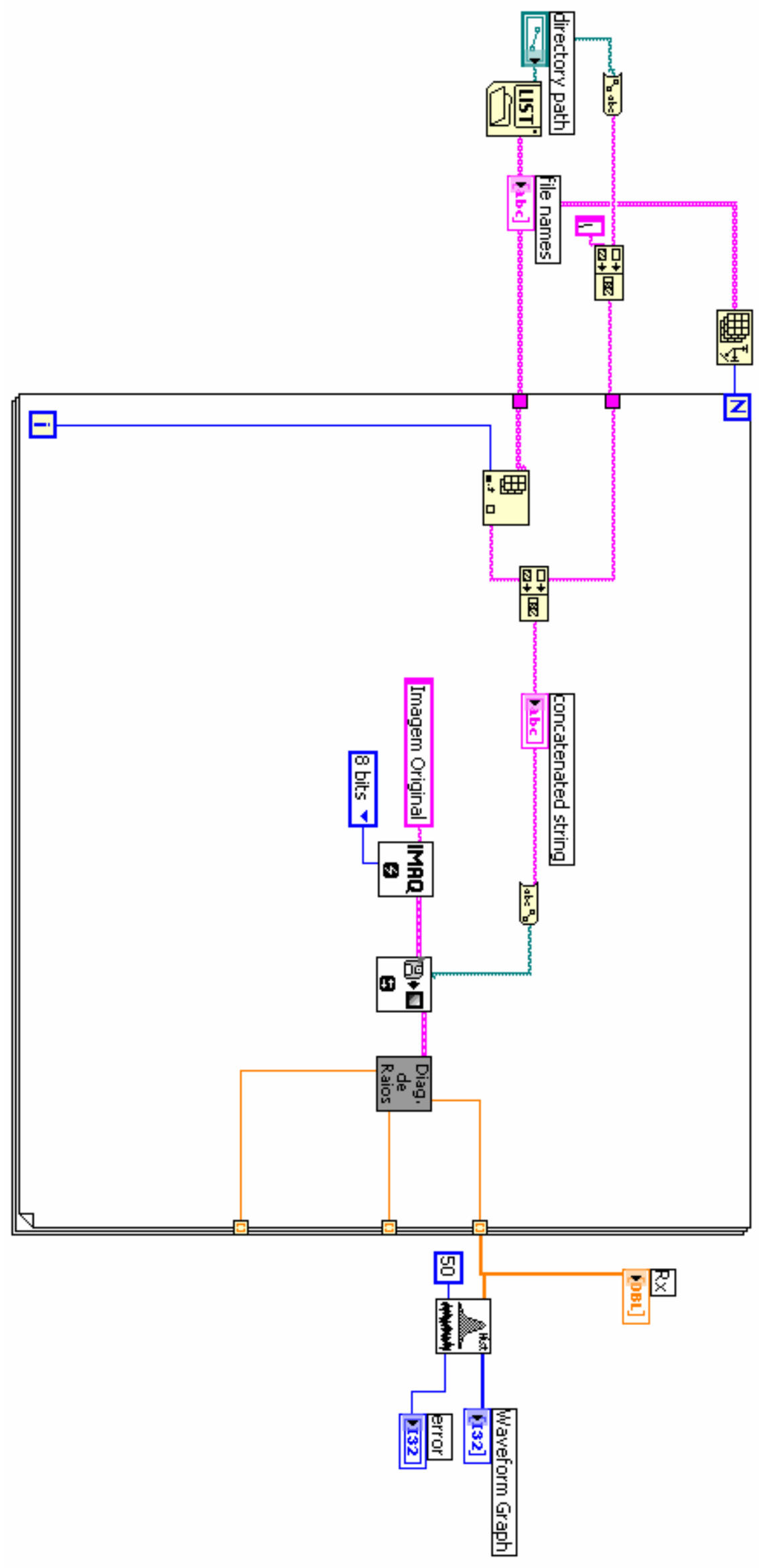

Figura B.13: Programa de determinação do diagrama de raios através das imagens. 


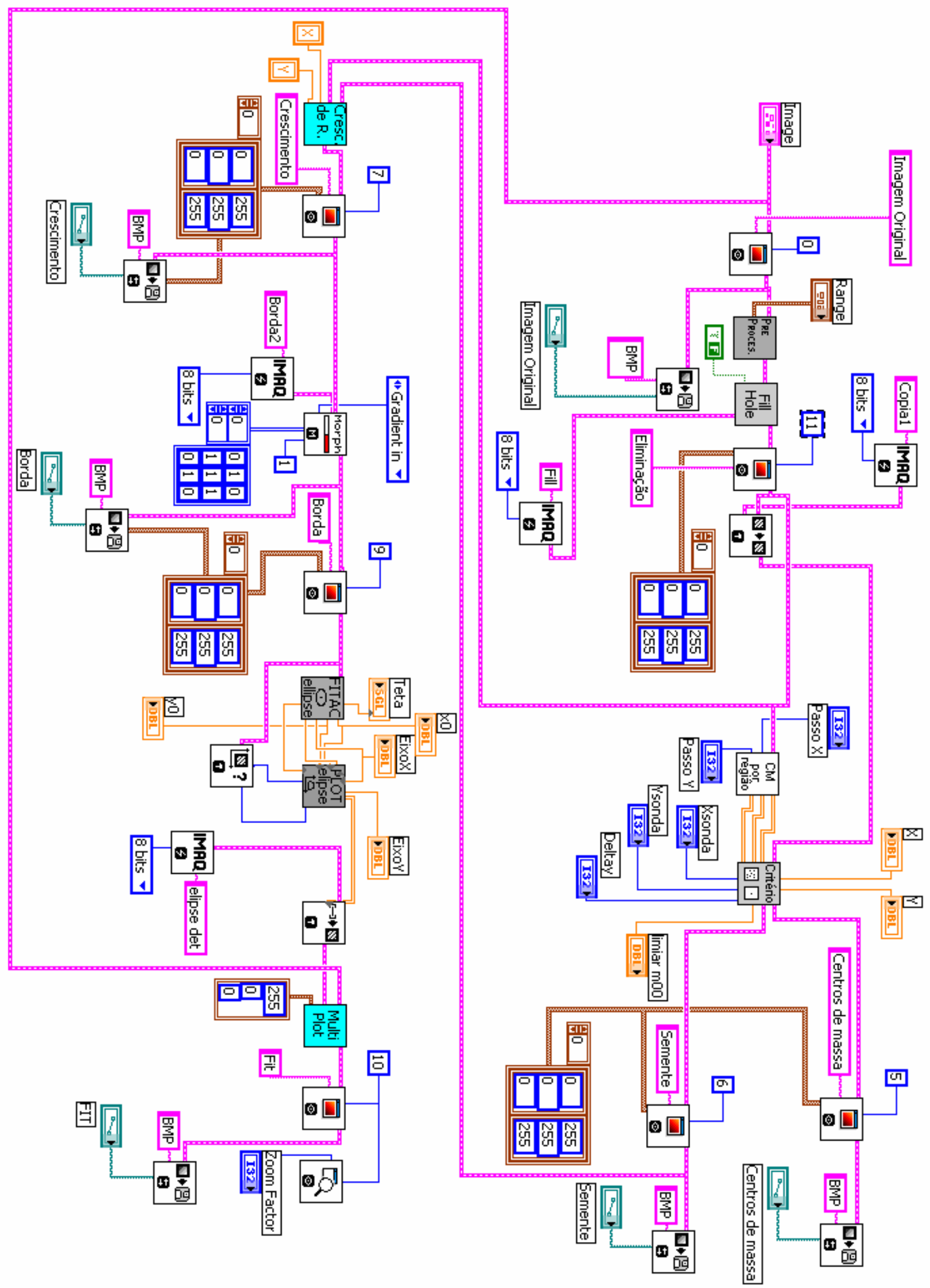

Figura B.14: Bloco de processamento (Diag. de raios). 

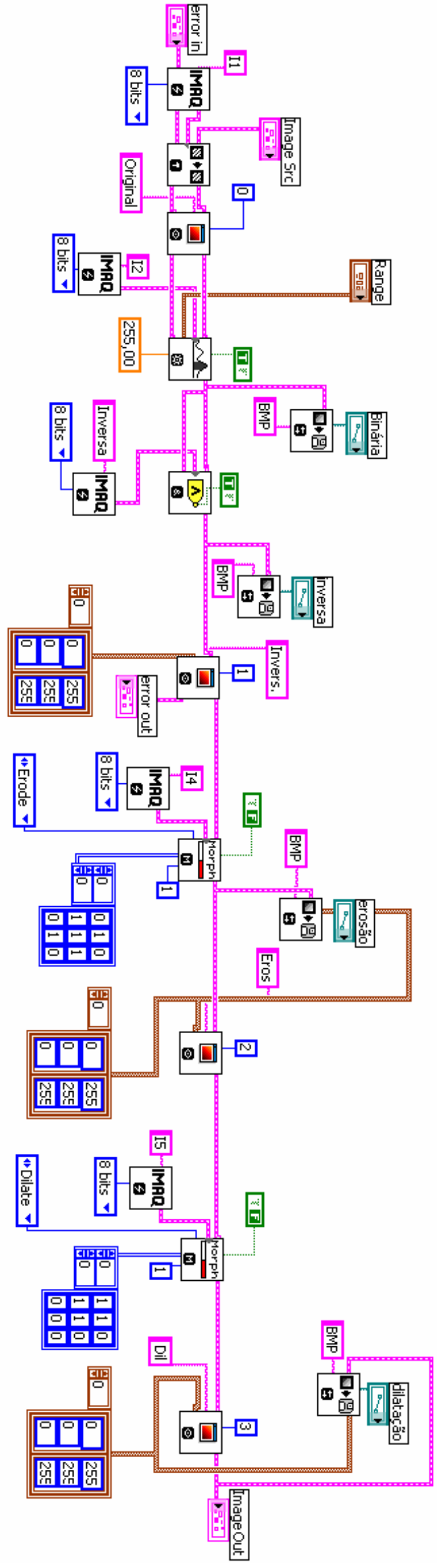

Figura B.15: Bloco de pré-processamento de imagens. 


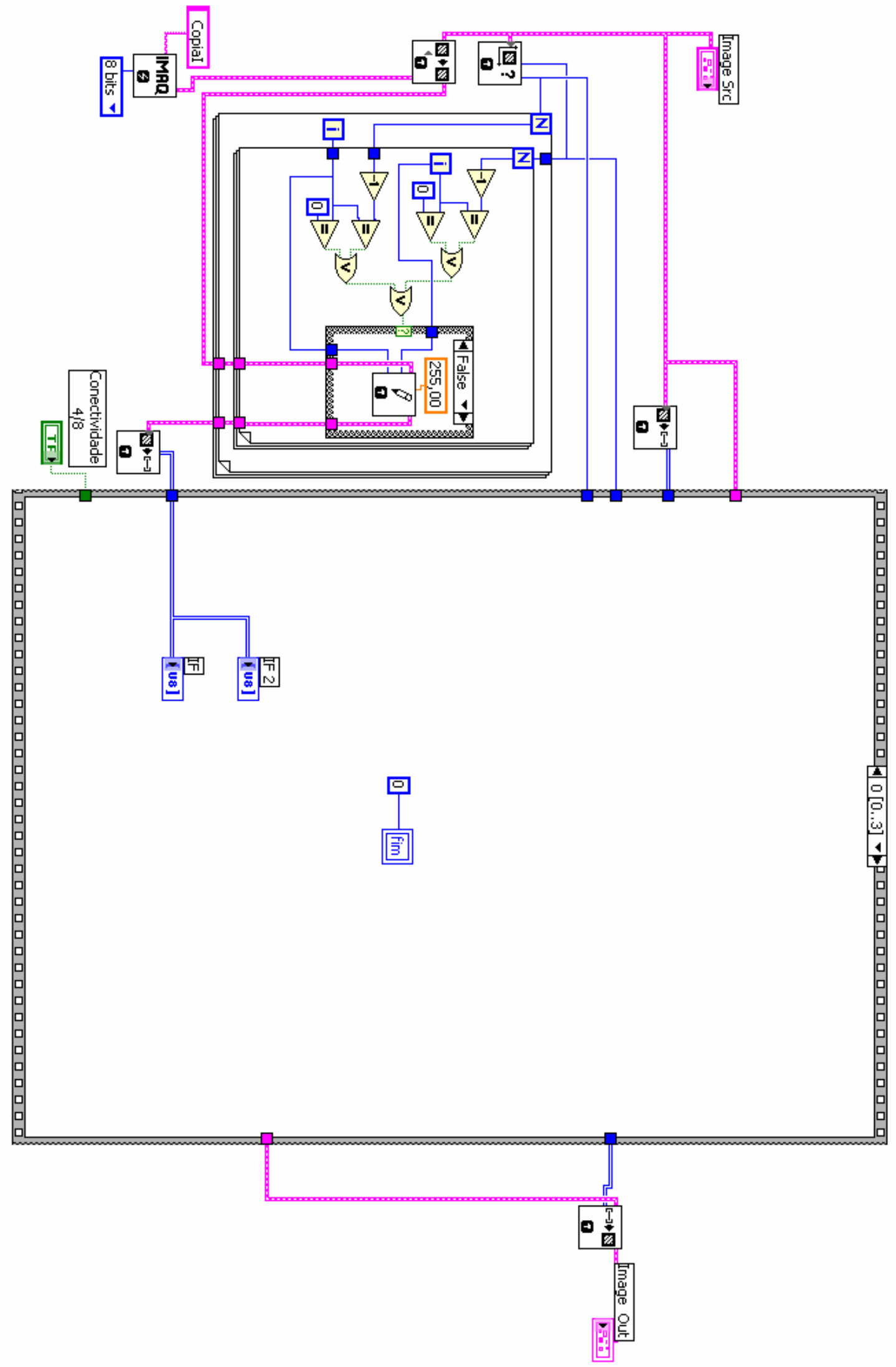

Figura B.16: Bloco de preenchimento de furos e eliminação de pixels de regiões conectadas à borda. 


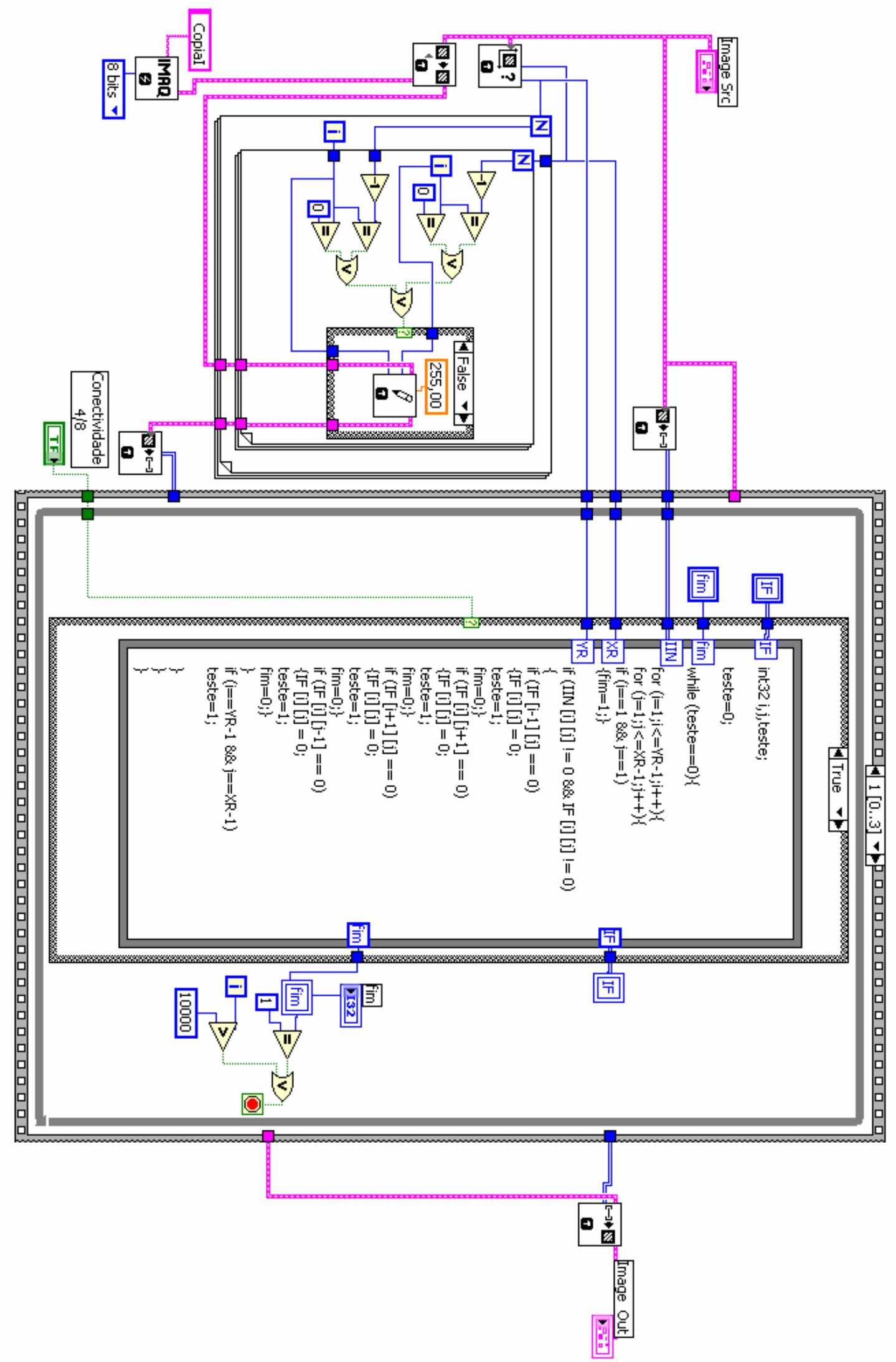

Figura B.17: Bloco de preenchimento de furos e eliminação de pixels de regiões conectadas à borda (Cont.). 


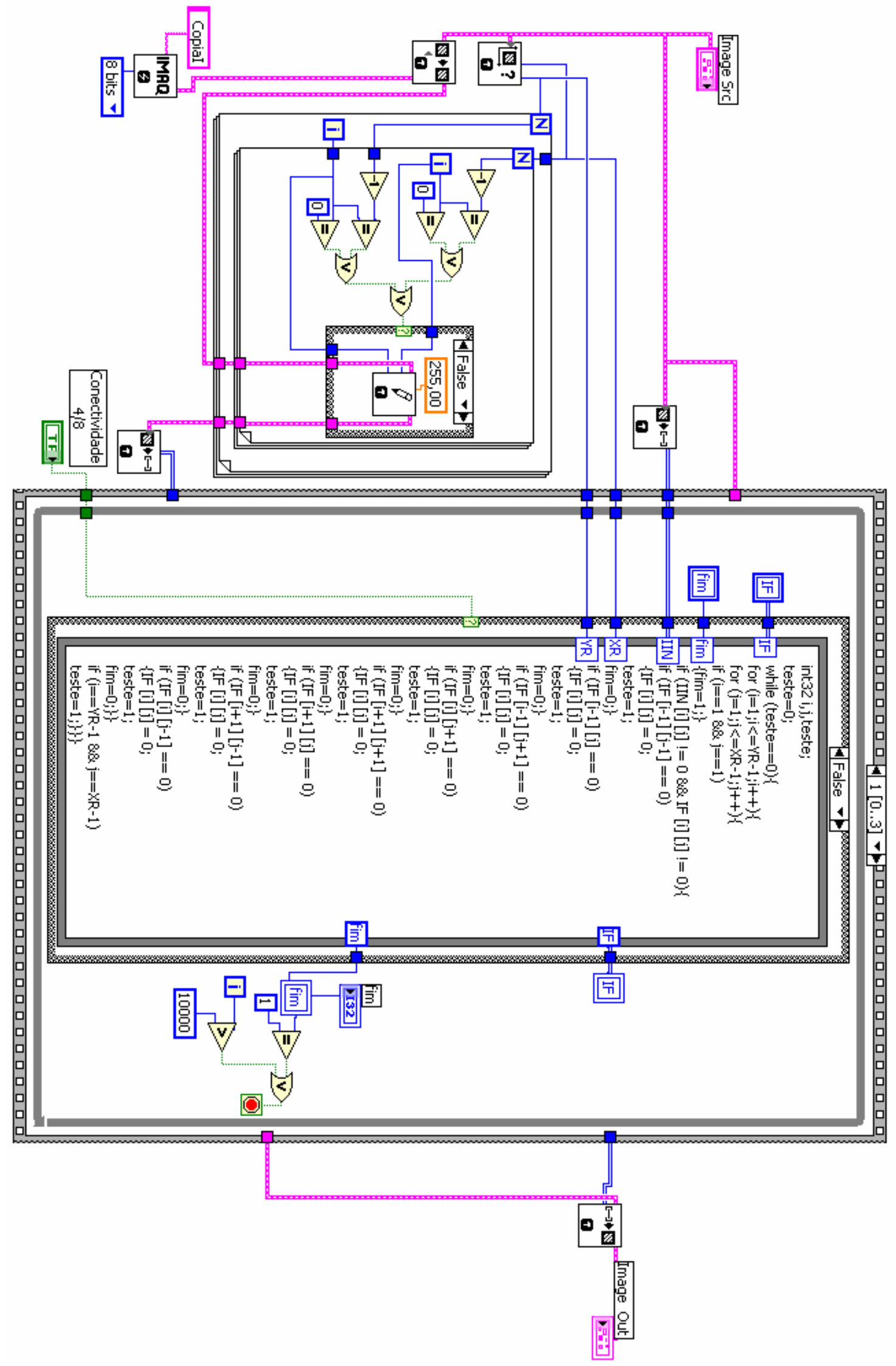

Figura B.18: Bloco de preenchimento de furos e eliminação de pixels de regiões conectadas à borda. (Cont.). 


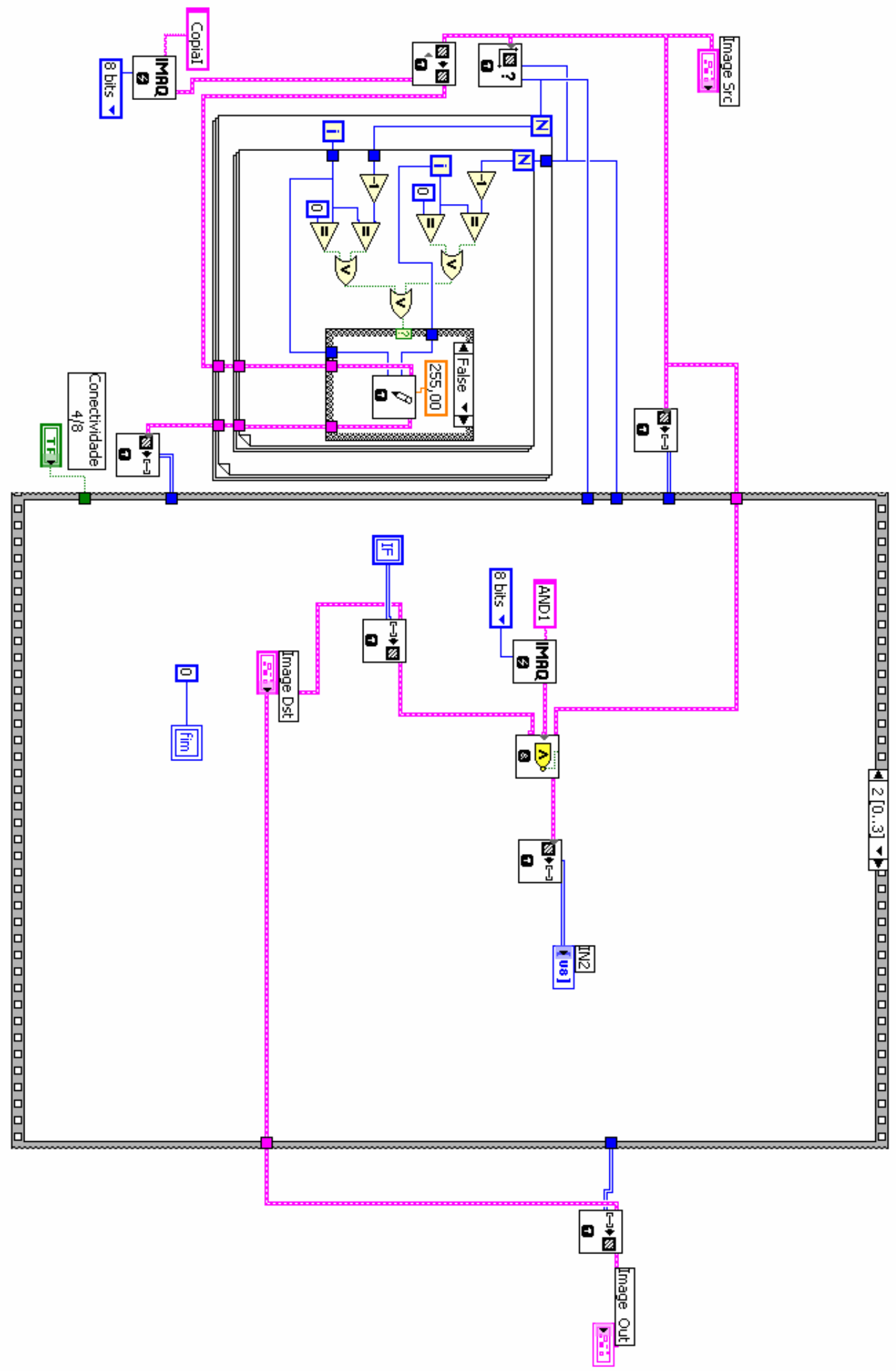

Figura B.19: Bloco de preenchimento de furos e eliminação de pixels de regiões conectadas à borda. (Cont.). 


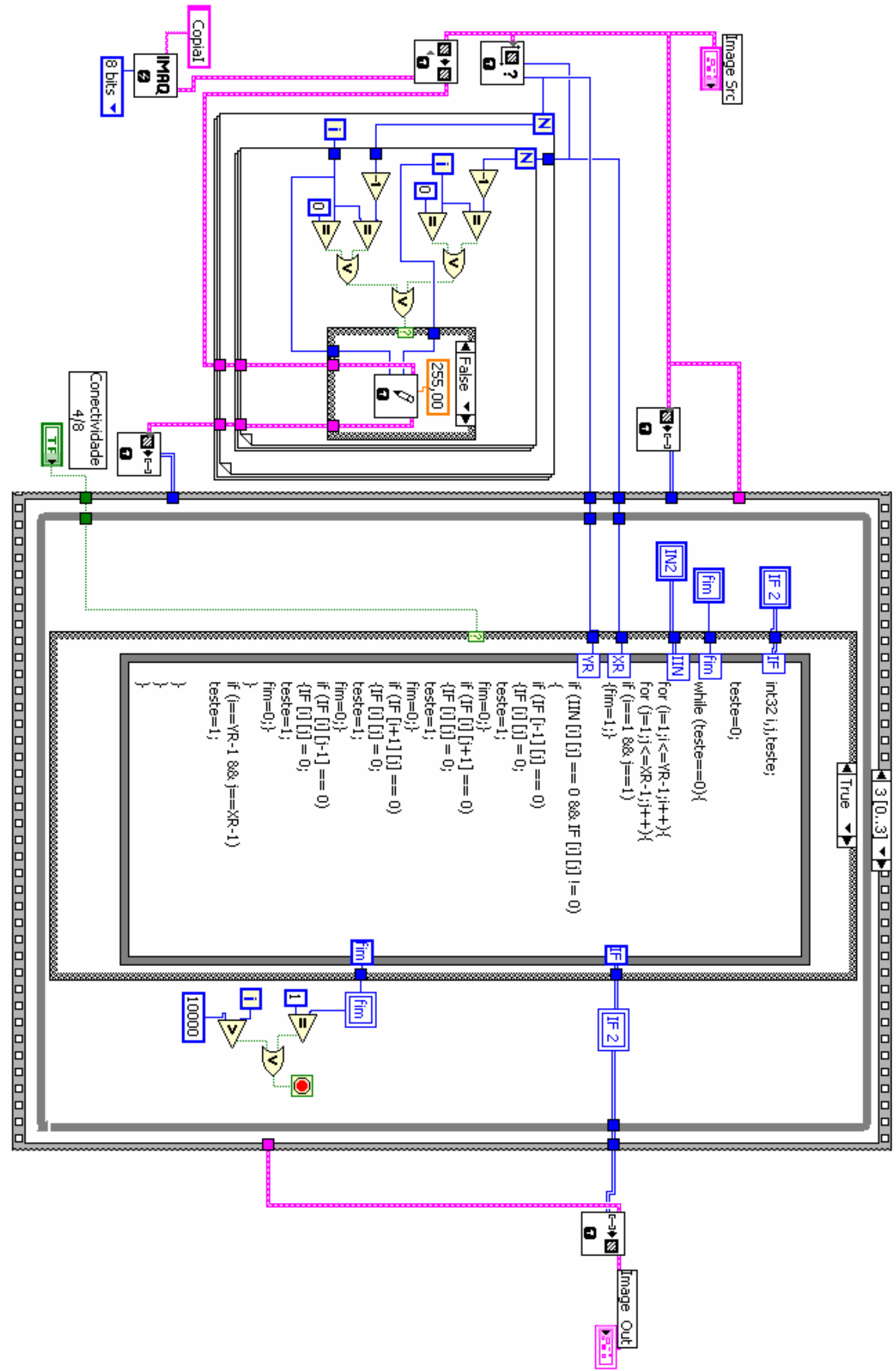

Figura B.20: Bloco de preenchimento de furos e eliminação de pixels de regiões conectadas à borda. (Cont.). 


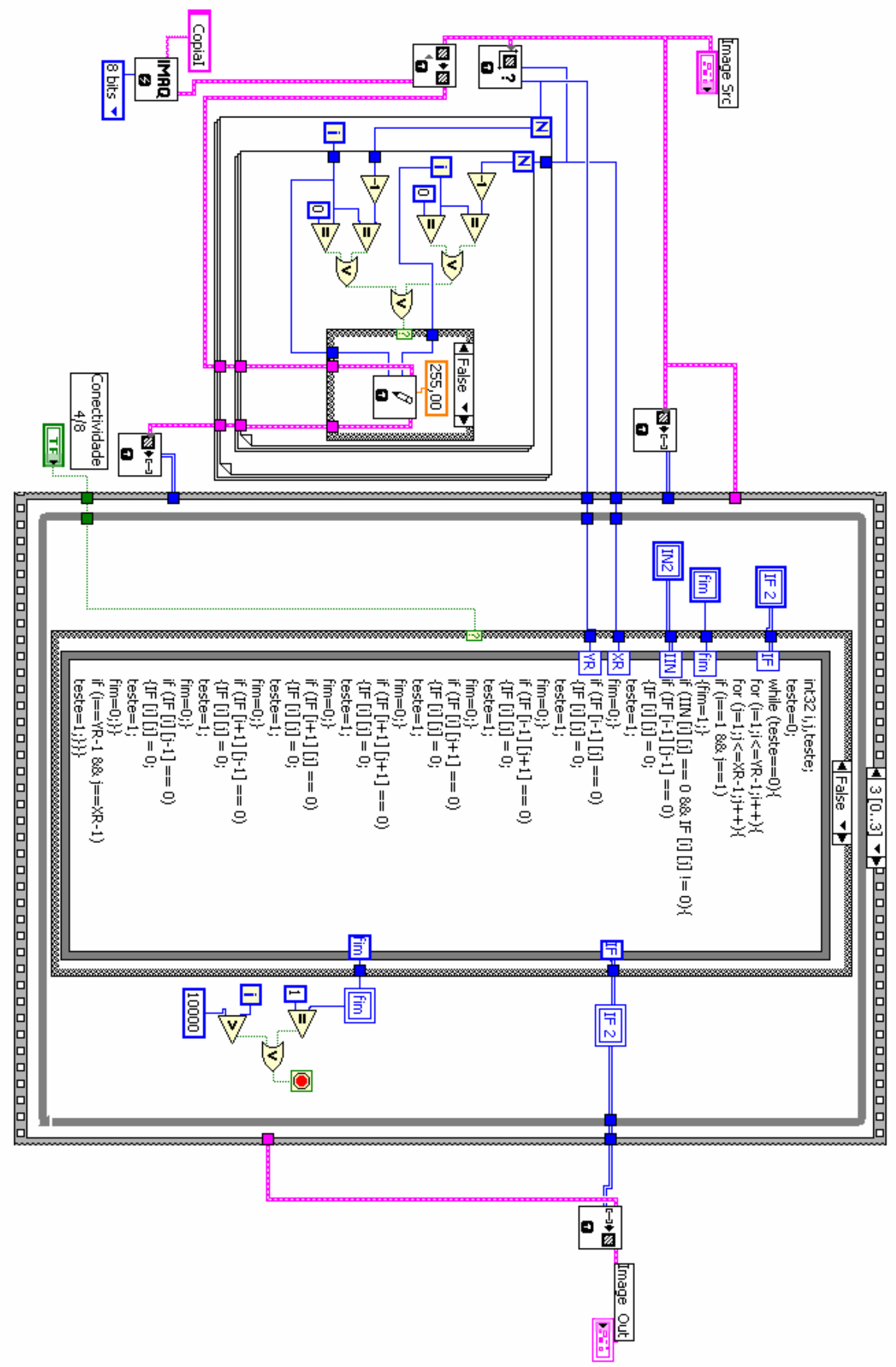

Figura B.21: Bloco de preenchimento de furos e eliminação de pixels de regiões conectadas à borda. (Cont.). 


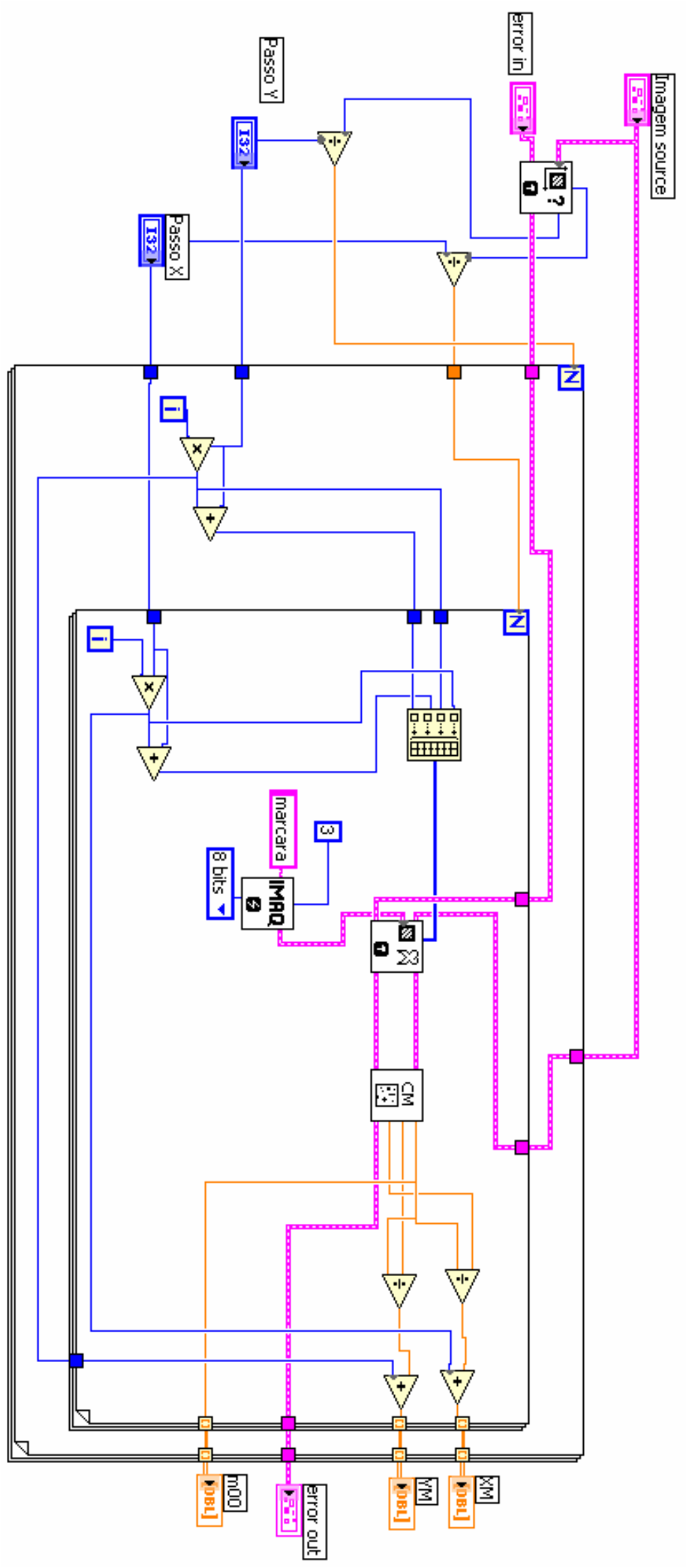

Figura B.22: Bloco do cálculo dos centros de massa por região. 


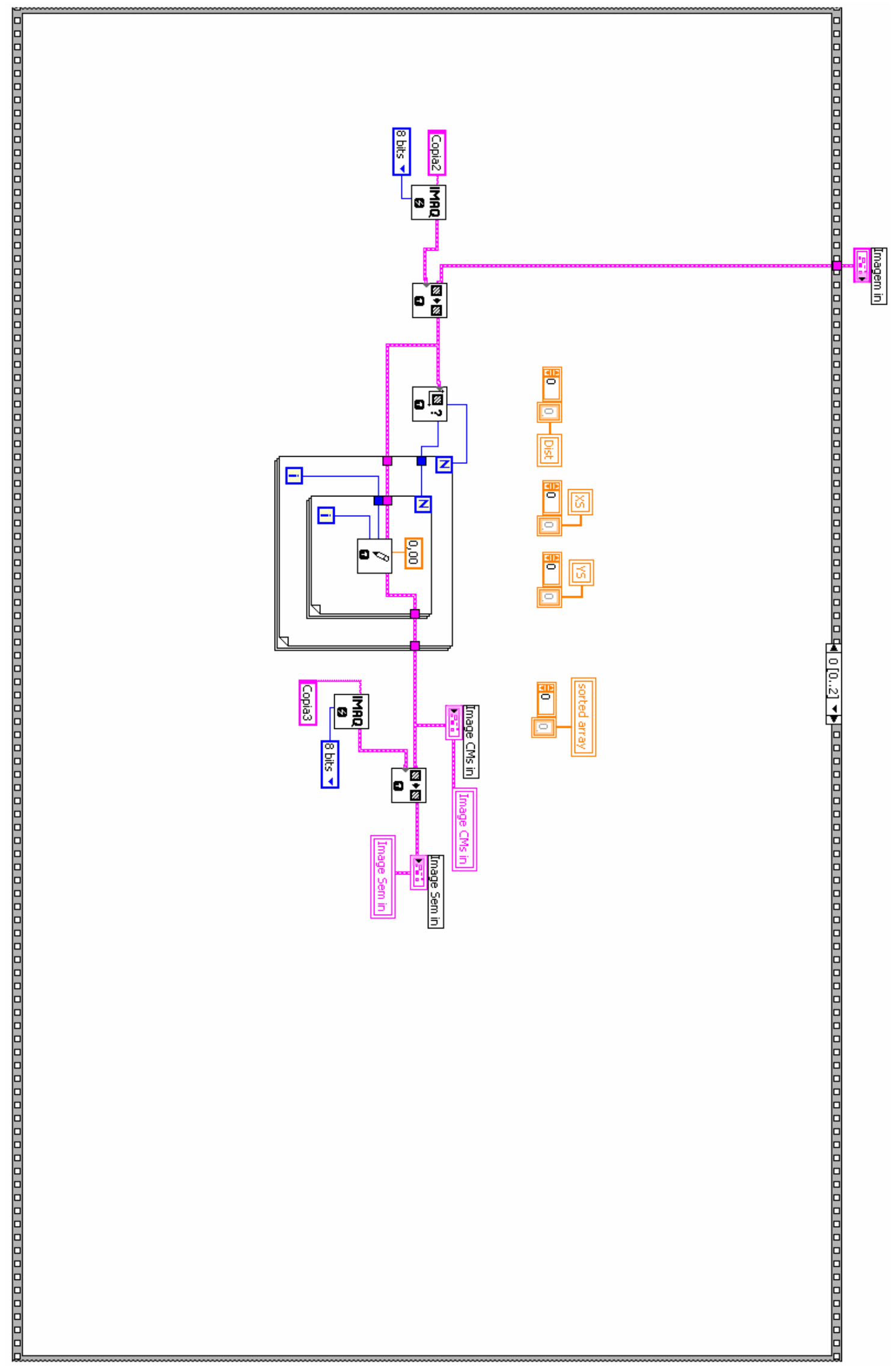

Figura B.23: Bloco critério de segmentação. 


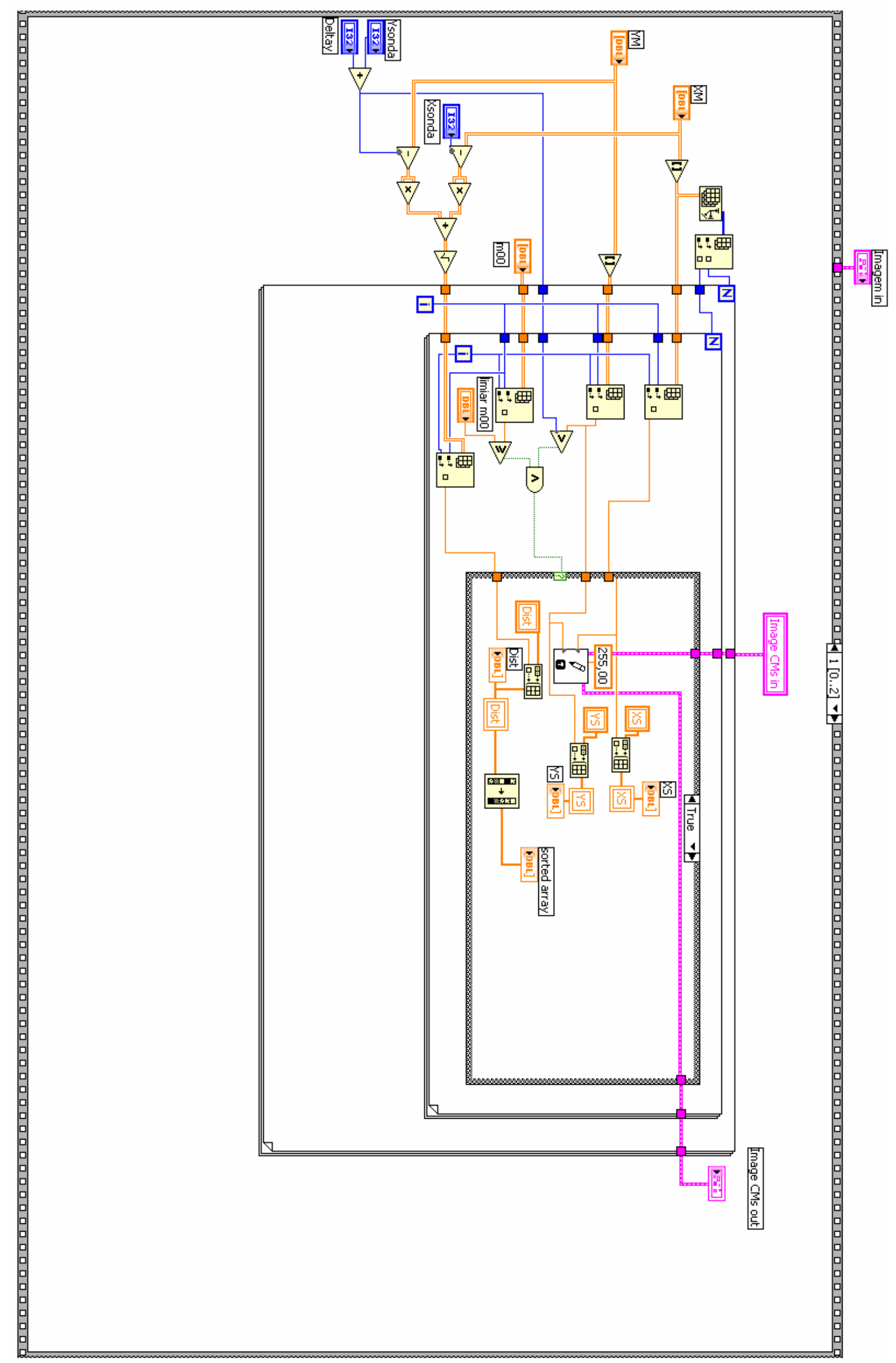

Figura B.24: Bloco critério de segmentação(Cont.). 


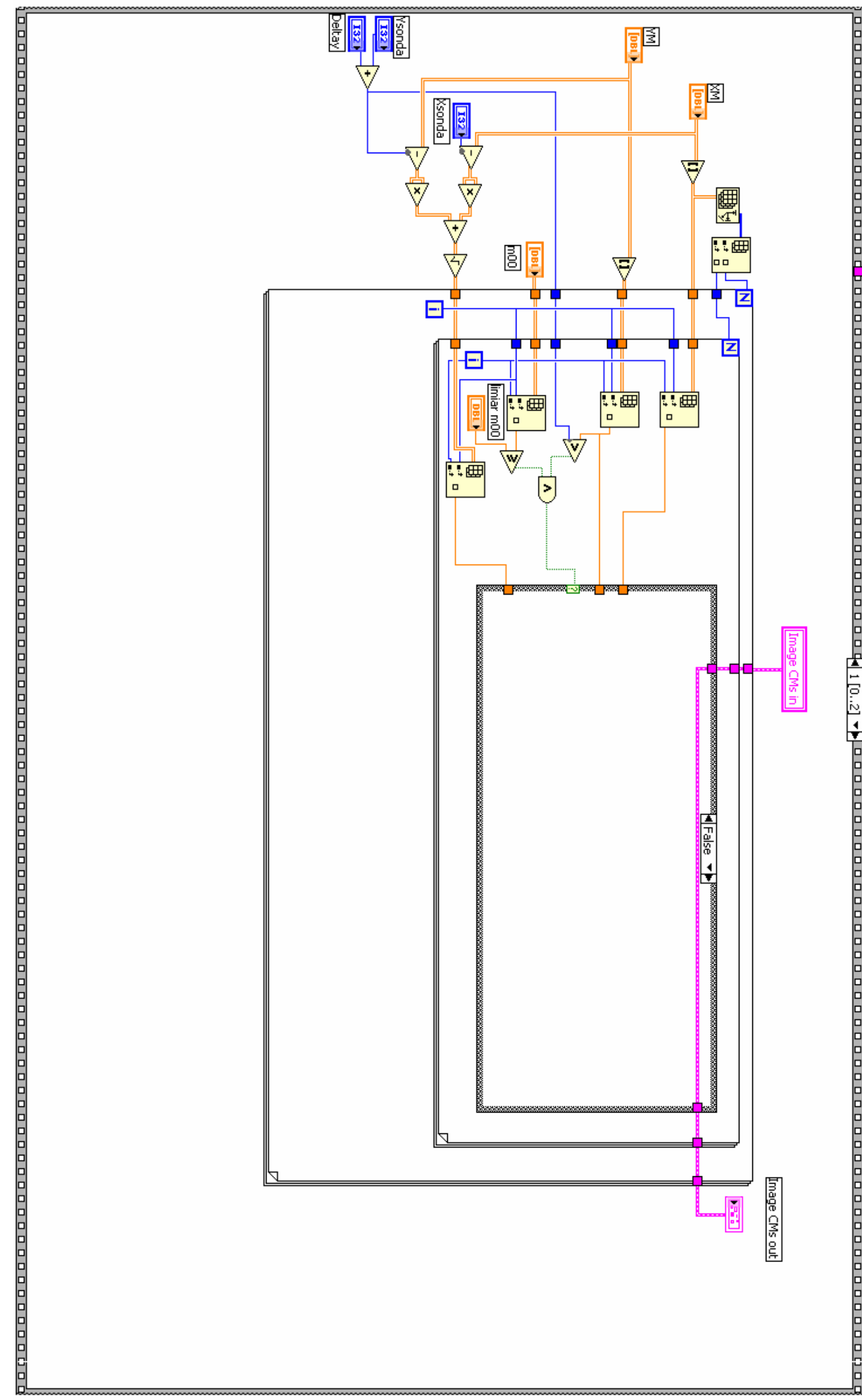

Figura B.25: Bloco critério de segmentação(Cont.). 


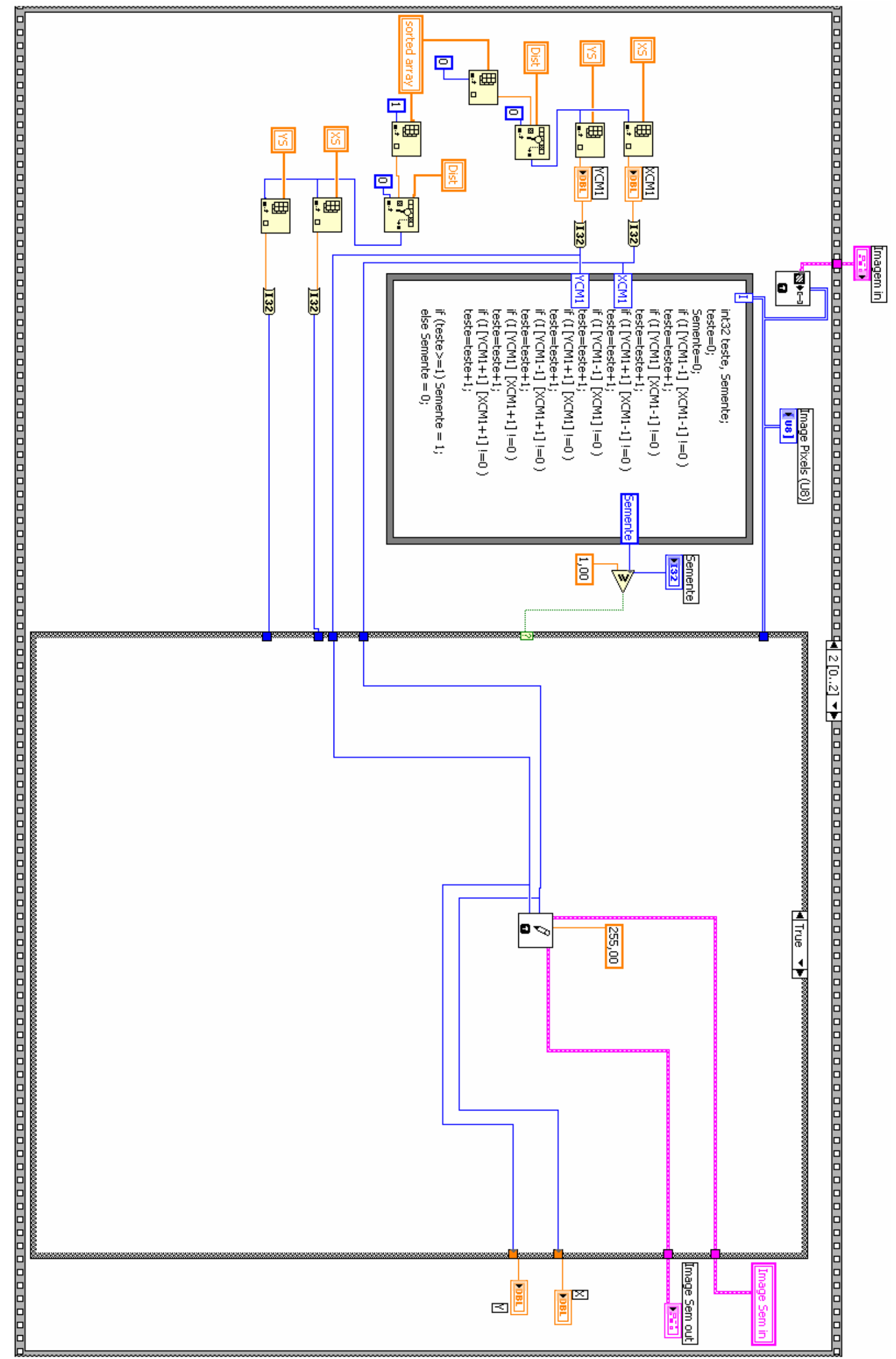

Figura B.26: Bloco critério de segmentação(Cont.). 


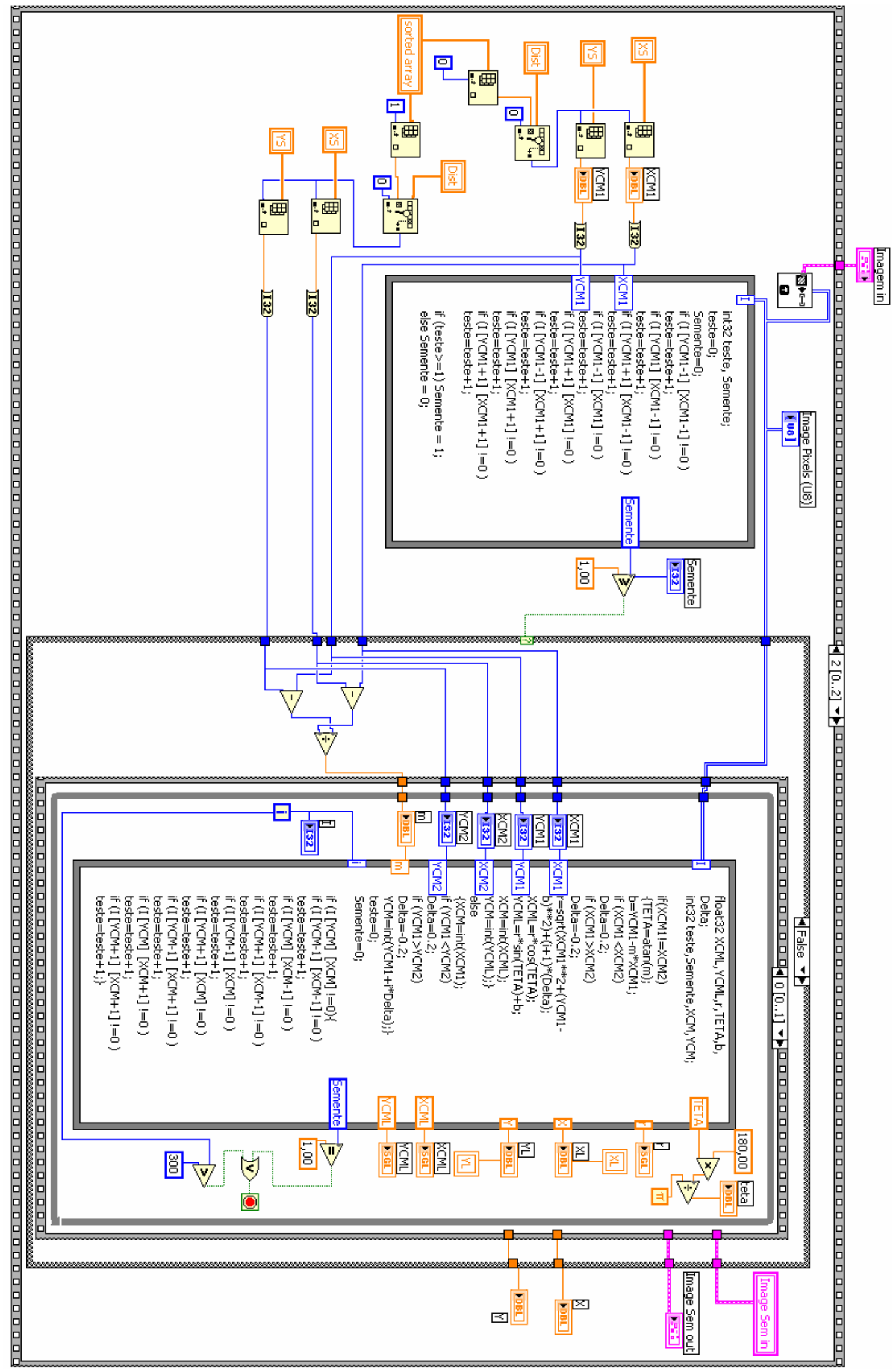

Figura B.27: Bloco critério de segmentação(Cont.). 


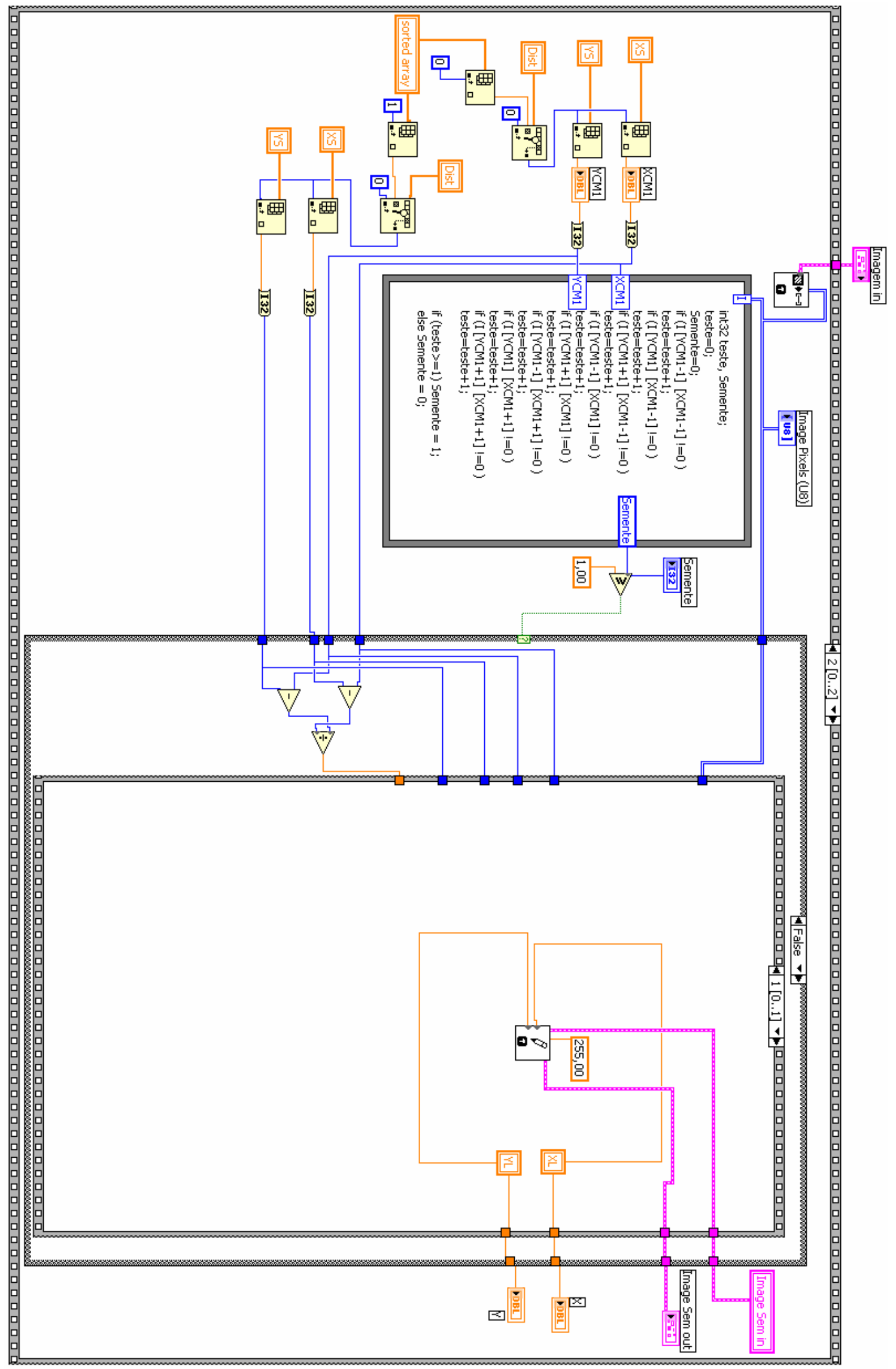

Figura B.28: Bloco critério de segmentação(Cont.). 


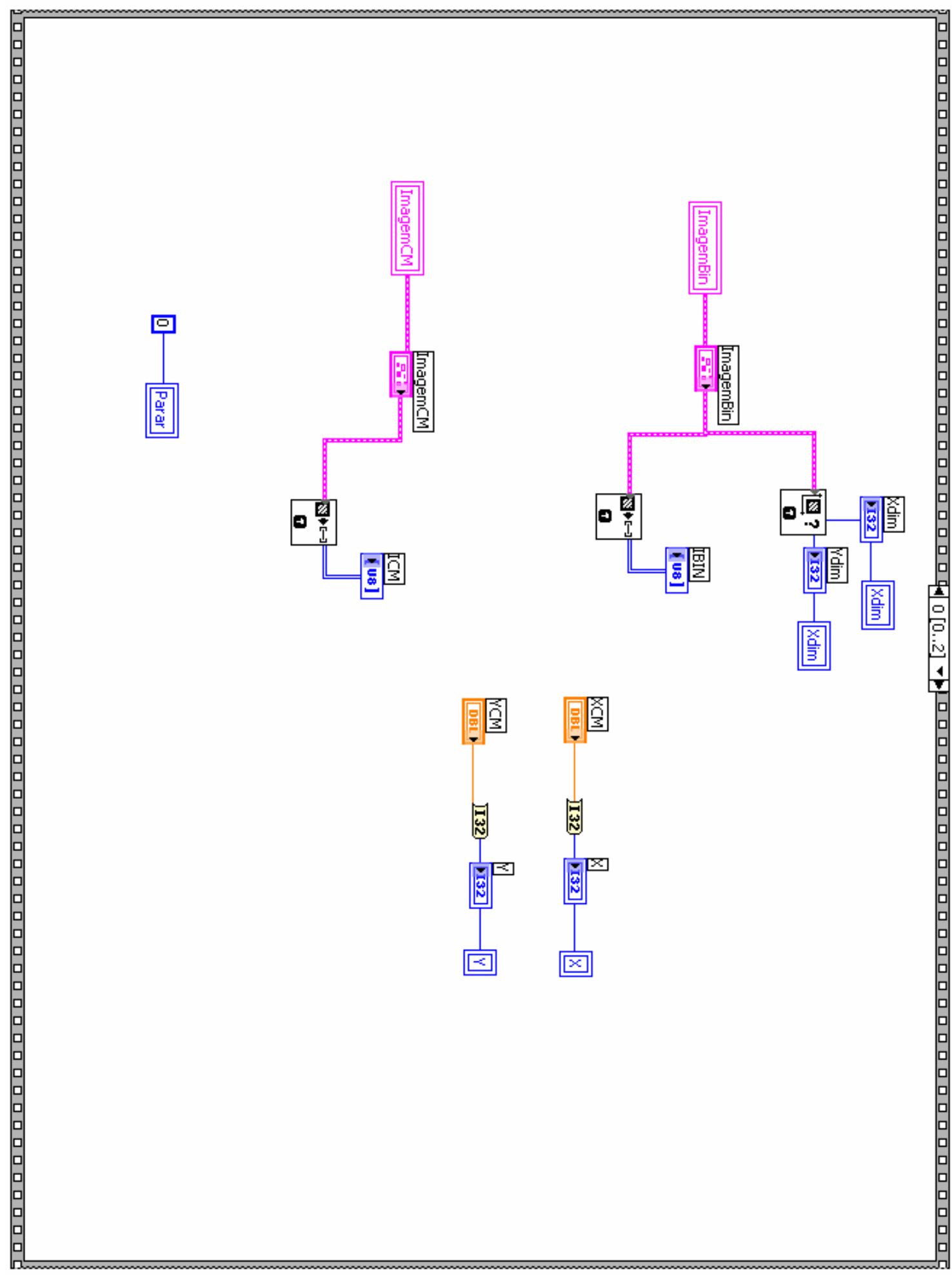

Figura B.29: Bloco crescimento de região. 


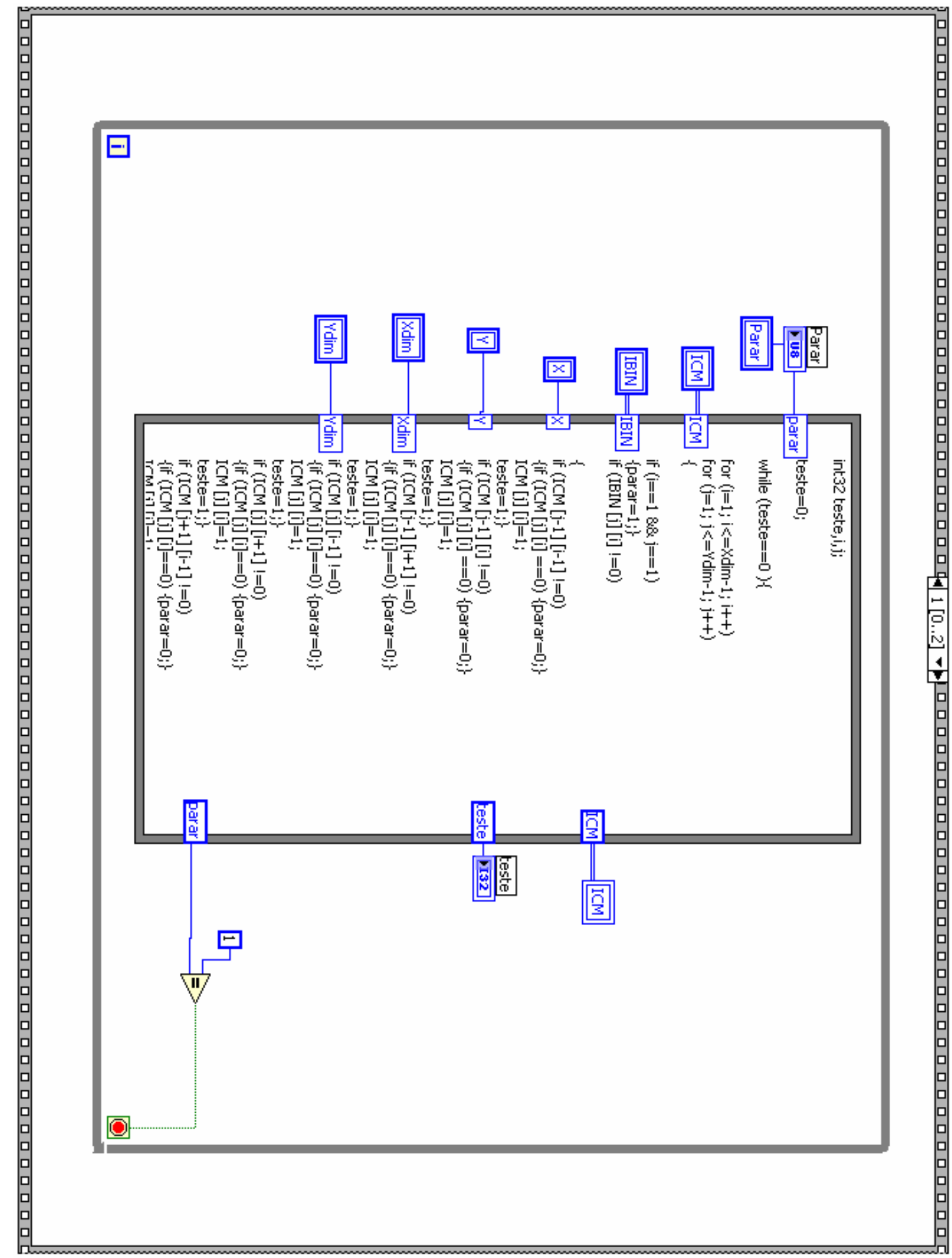

Figura B.30: Bloco crescimento de região (Cont.). 


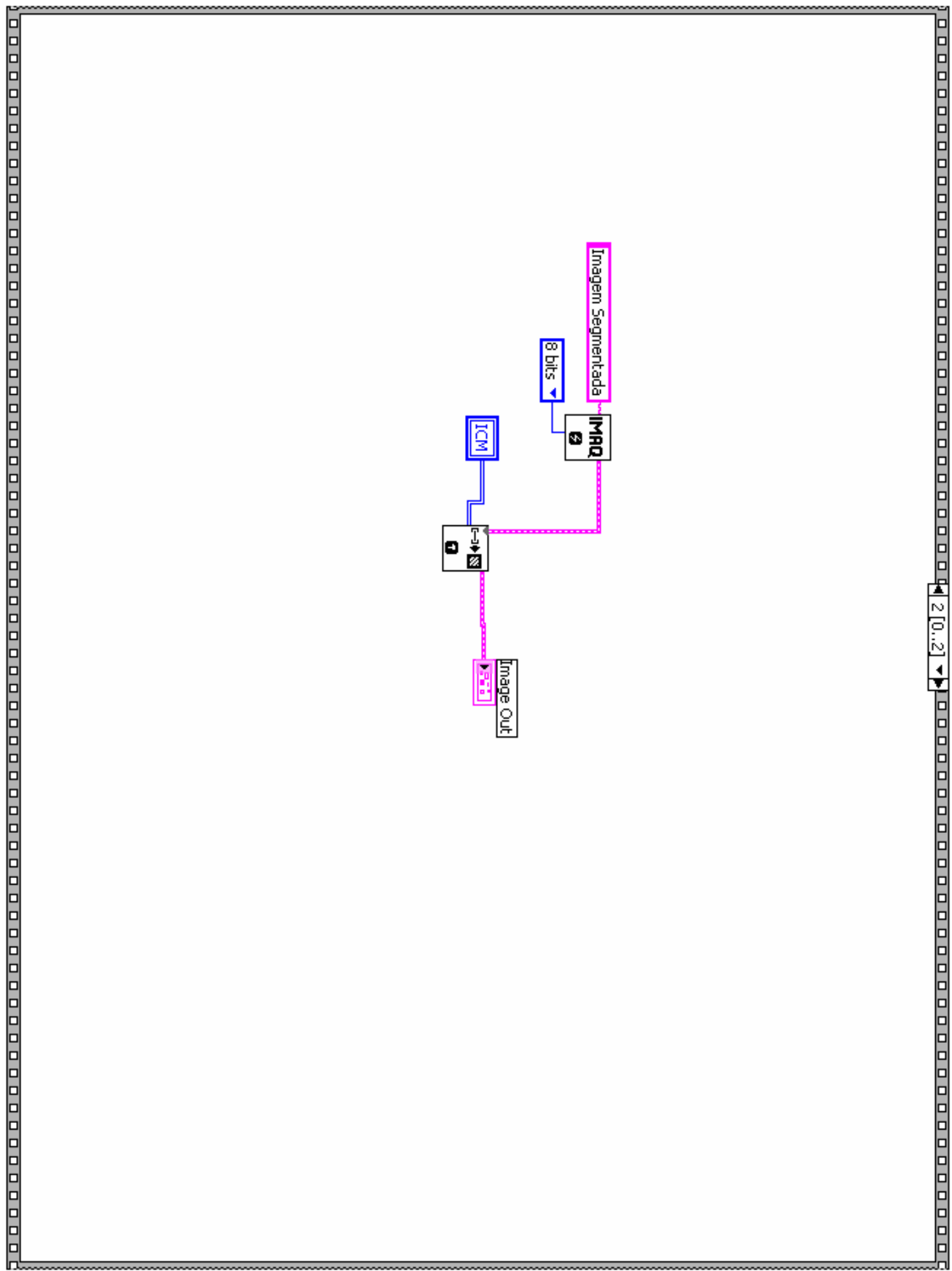

Figura B.31: Bloco crescimento de região (Cont.). 


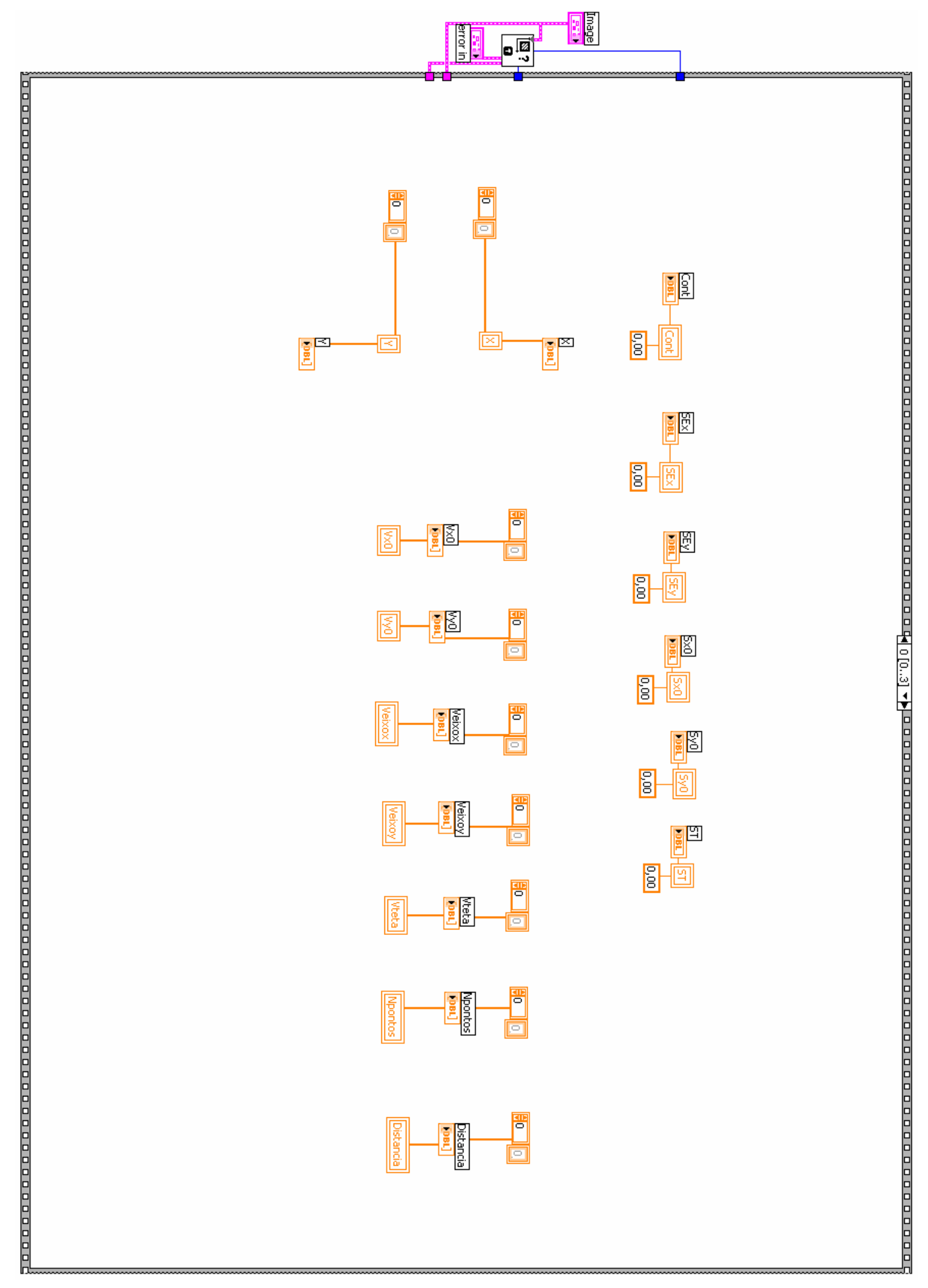

Figura B.32: Bloco de determinação da “melhor” elipse. 


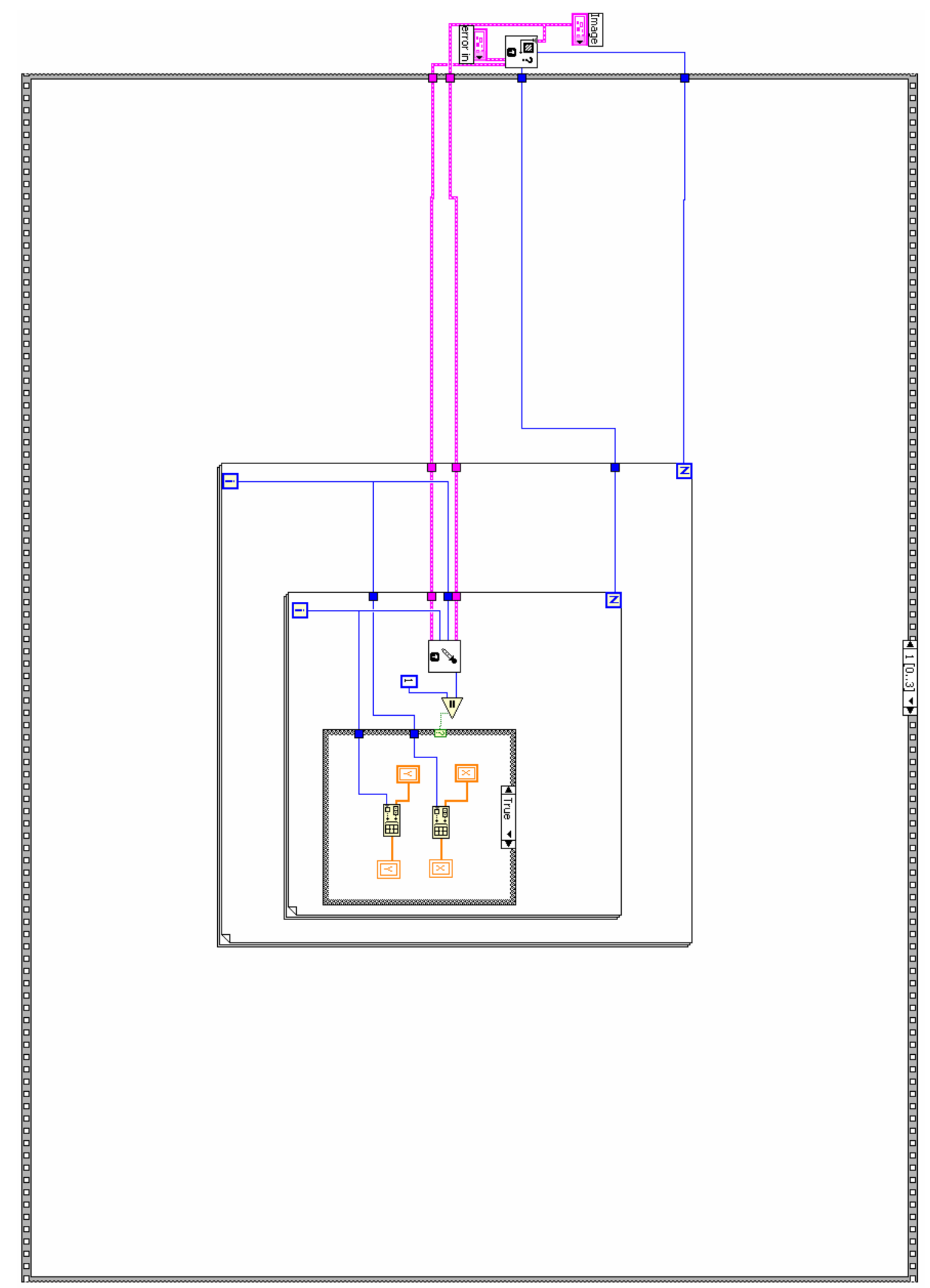

Figura B.33: Bloco de determinação da “melhor” elipse (Cont.). 


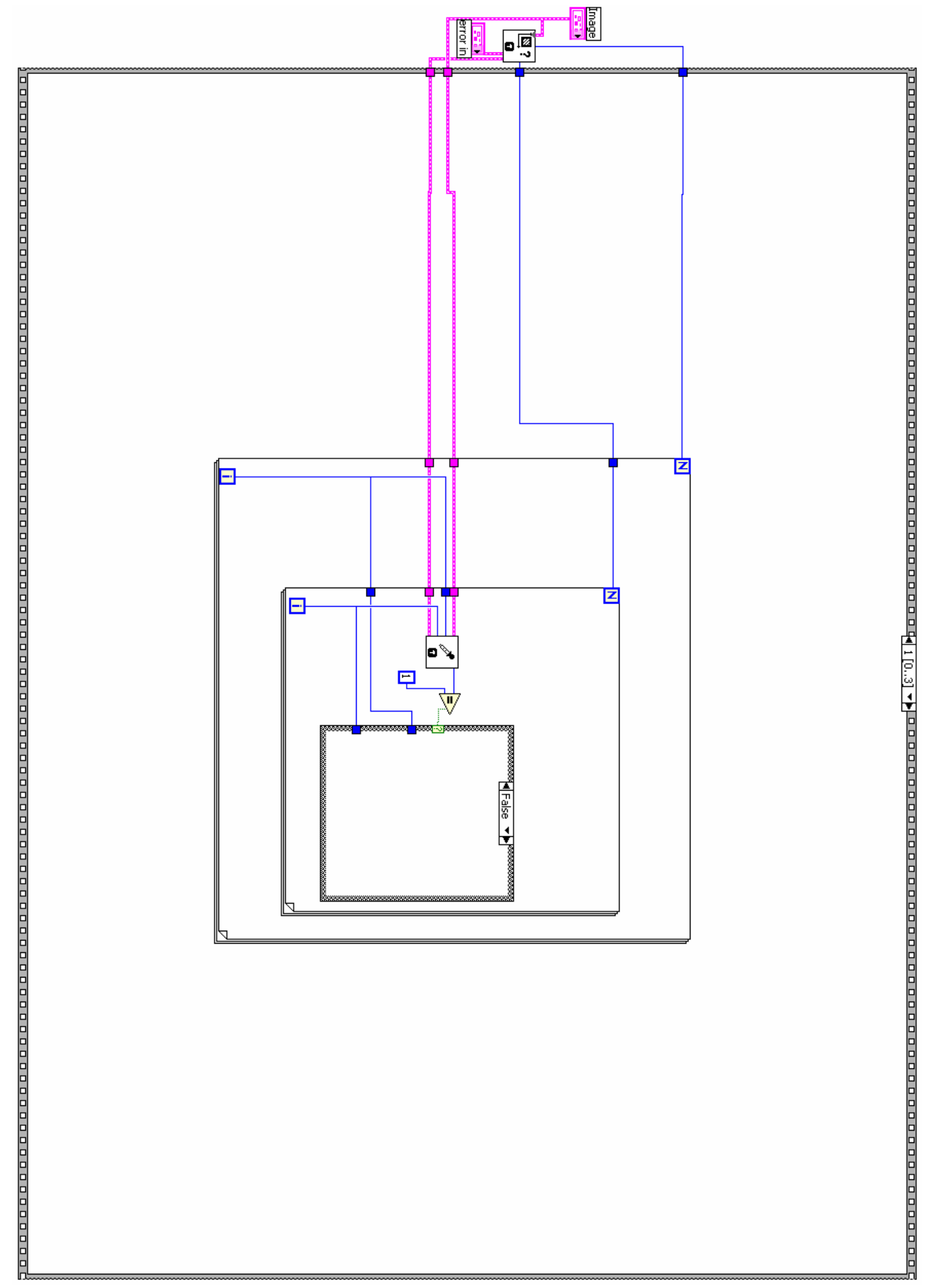

Figura B.34: Bloco de determinação da “melhor” elipse (Cont.). 


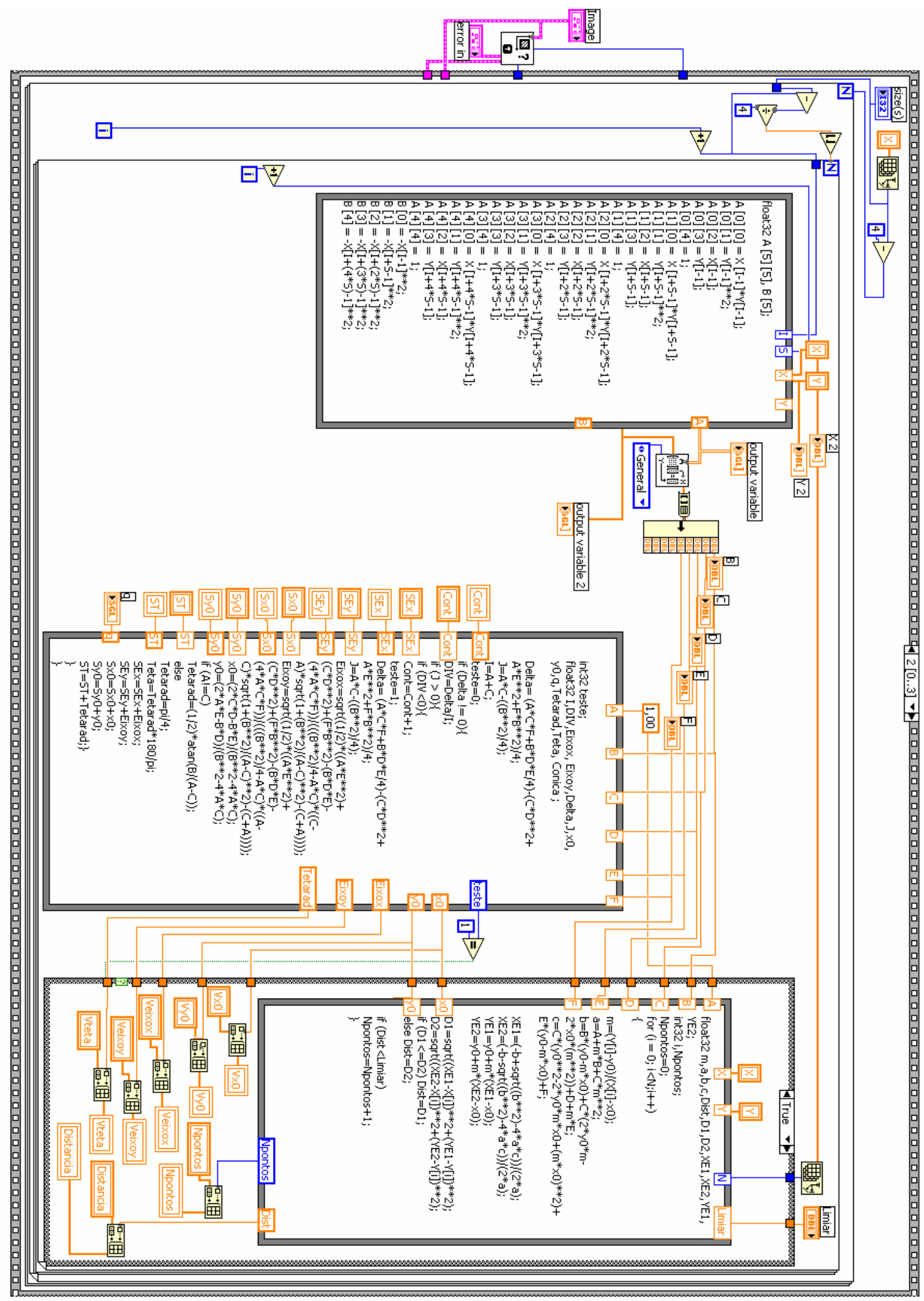

Figura B.35: Bloco de determinação da “melhor” elipse (Cont.). 


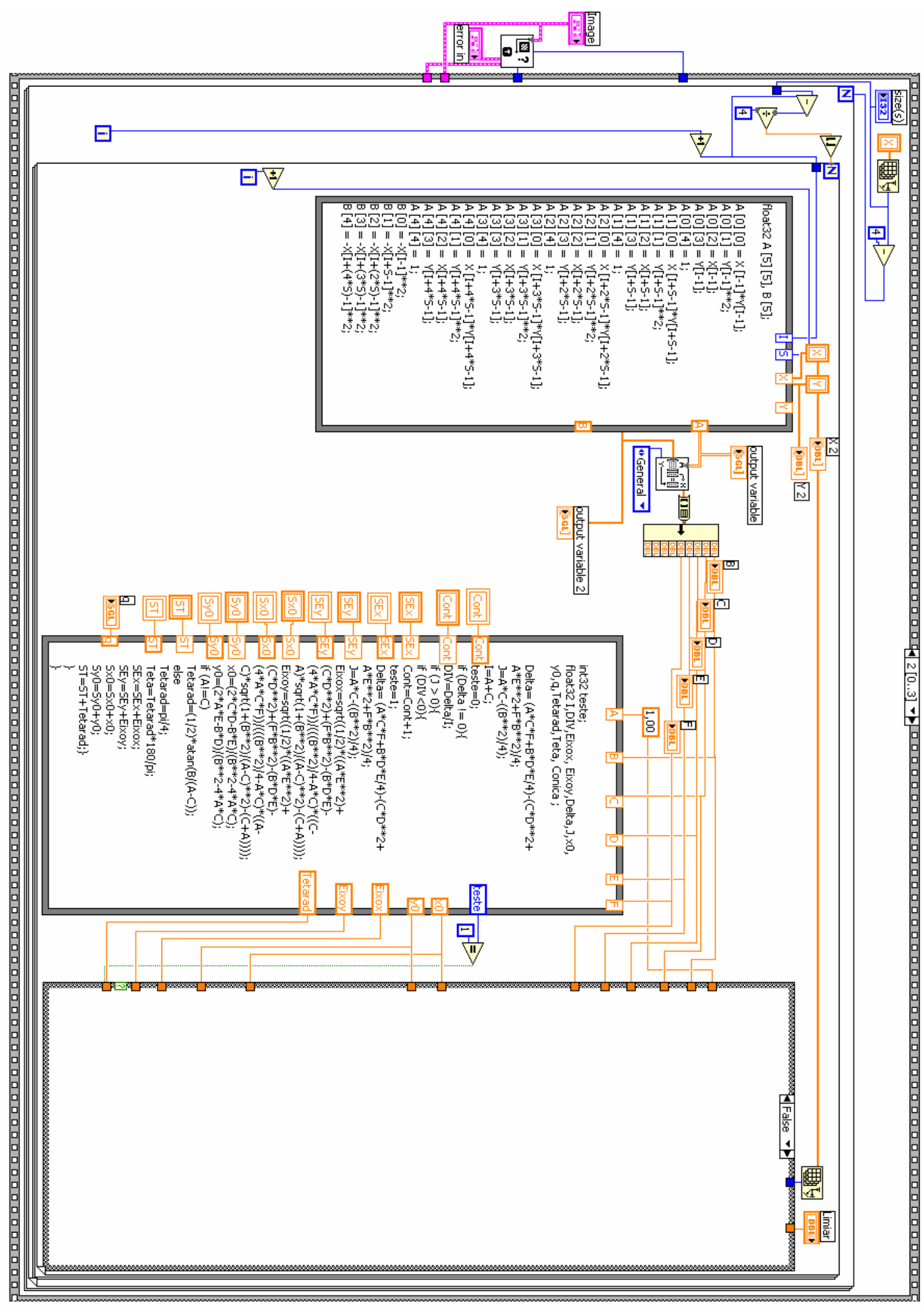

Figura B.36: Bloco de determinação da “melhor” elipse (Cont.). 


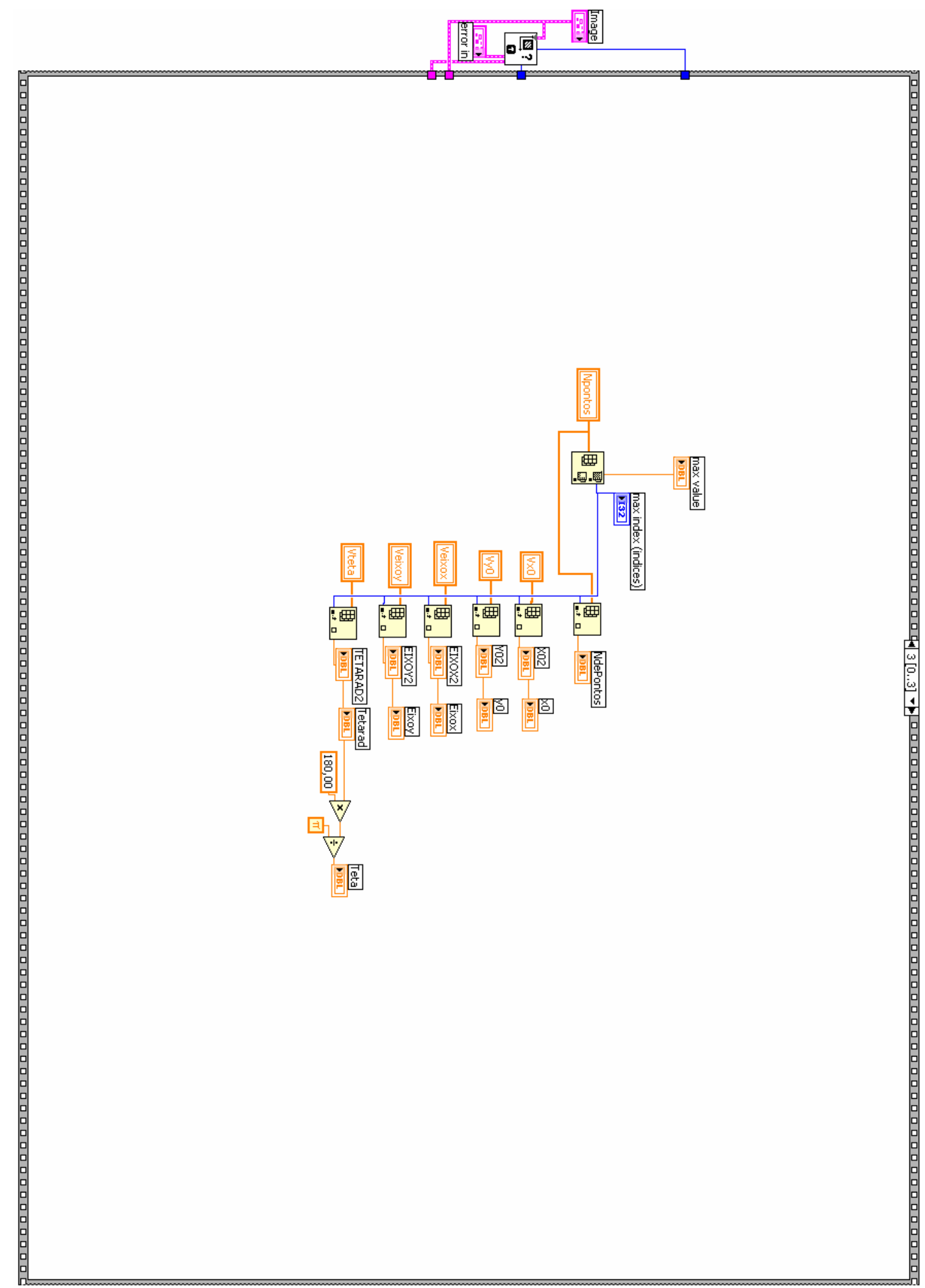

Figura B.37: Bloco de determinação da “melhor” elipse (Cont.). 


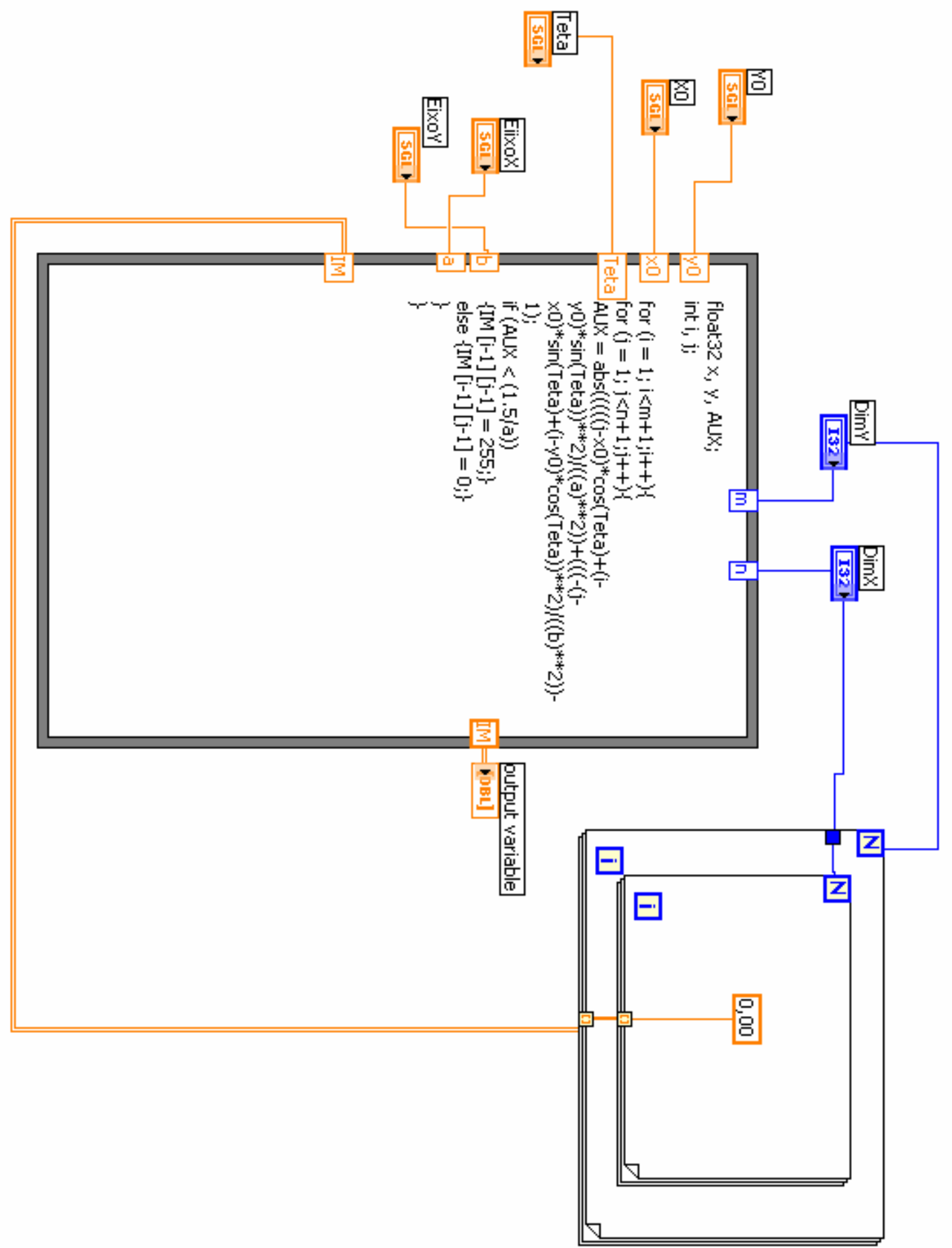

Figura B.38: Bloco utizado para gerar imagem da “melhor" elipse (plot elipse). 


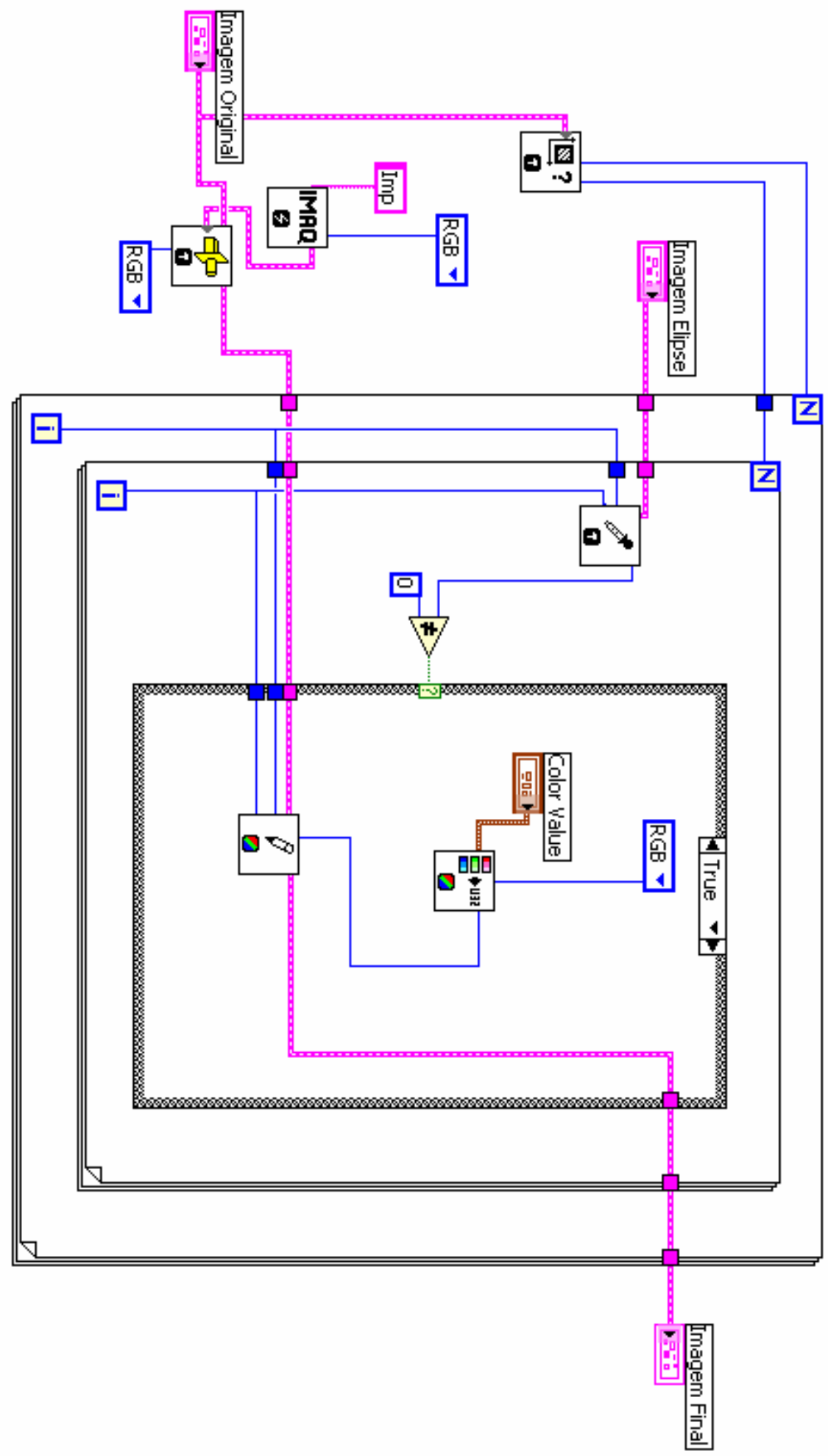

Figura B.39: Bloco utizado para sobrepor a “melhor” elipse à imagem original (multplot). 


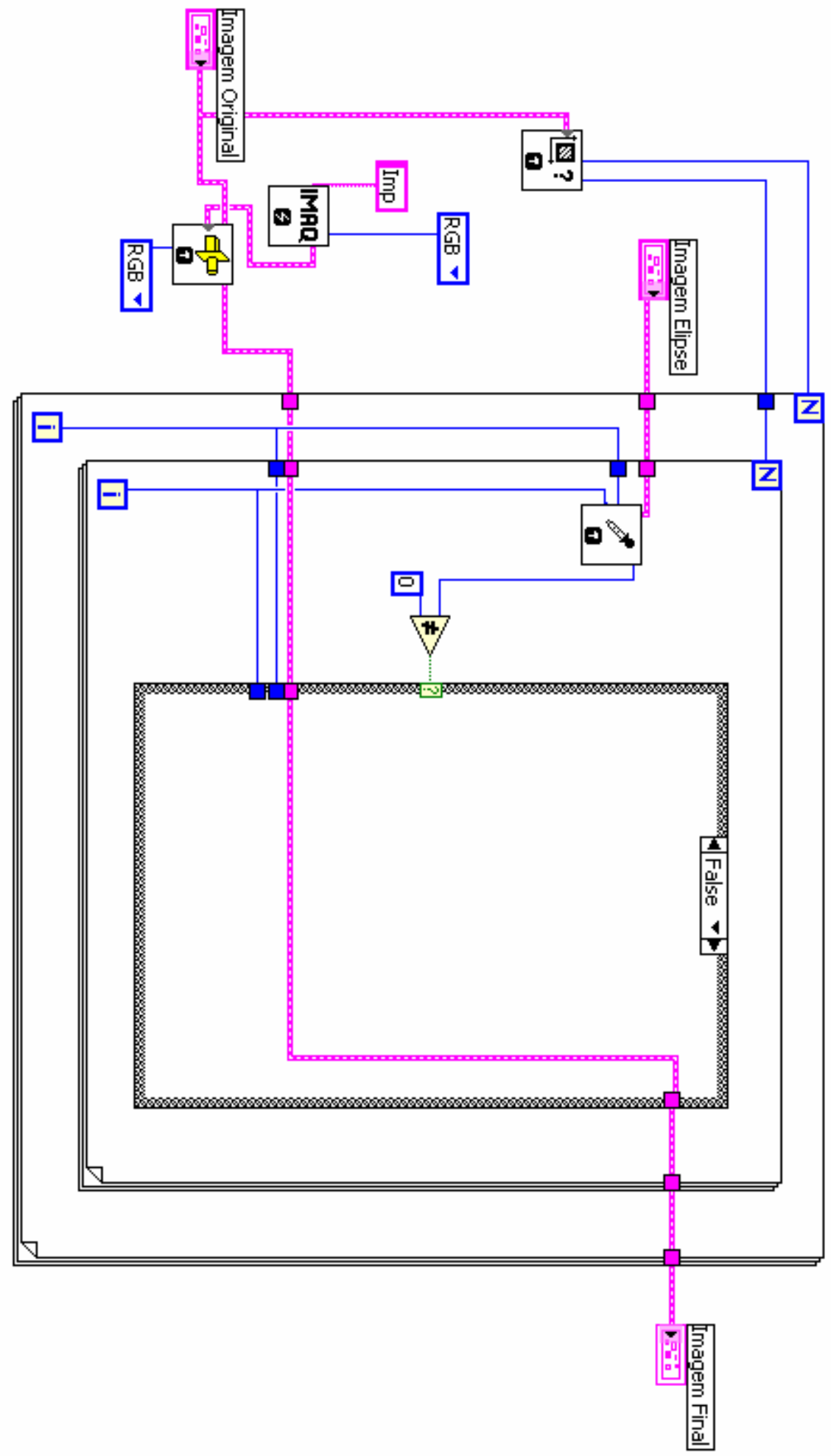

Figura B.40: Bloco utizado para sobrepor a "melhor” elipse à imagem original (multplot) (Cont.). 


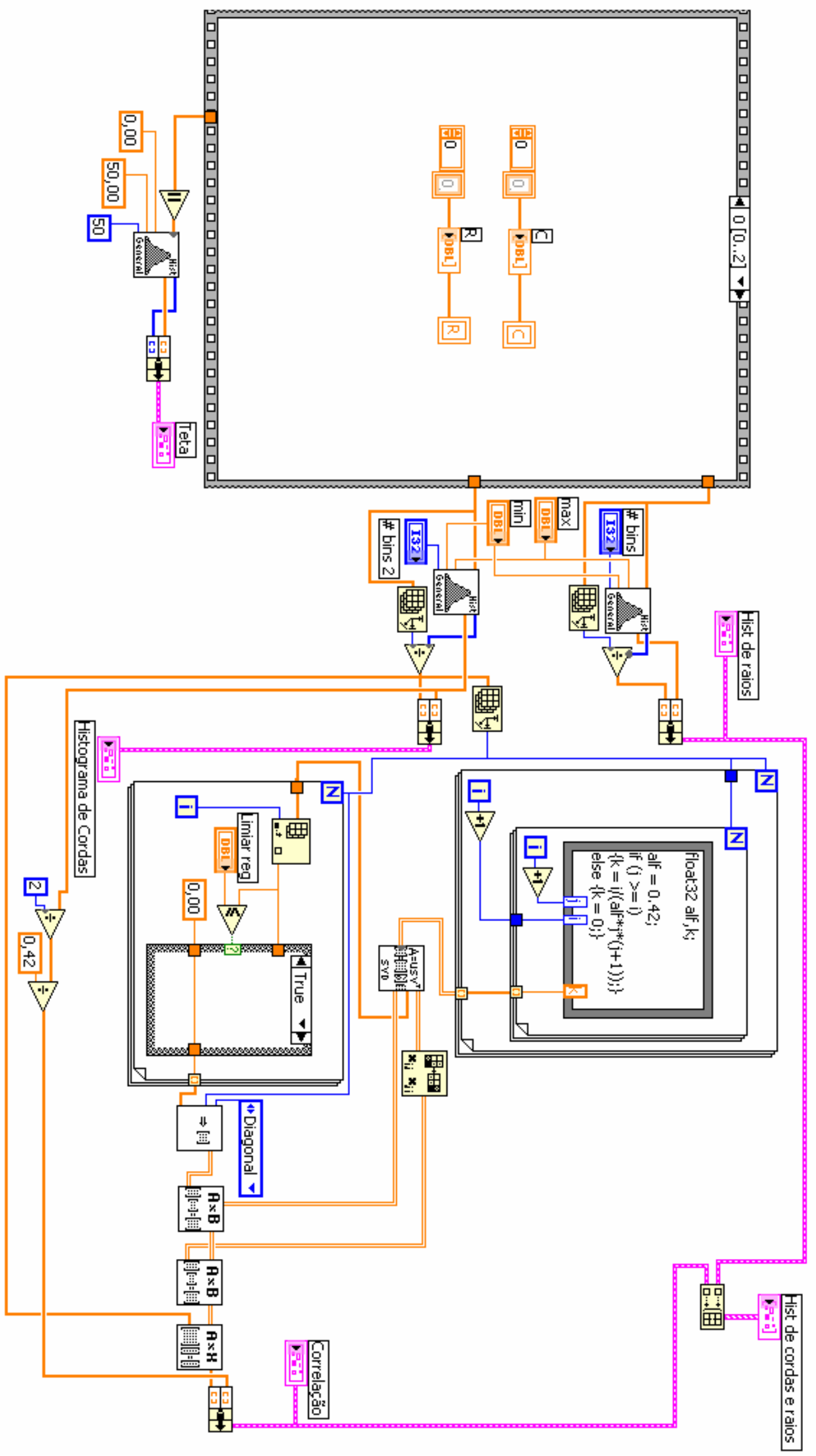

Figura B.41: Programa de correlação entre diagrama de cordas e diagrama de raios. 


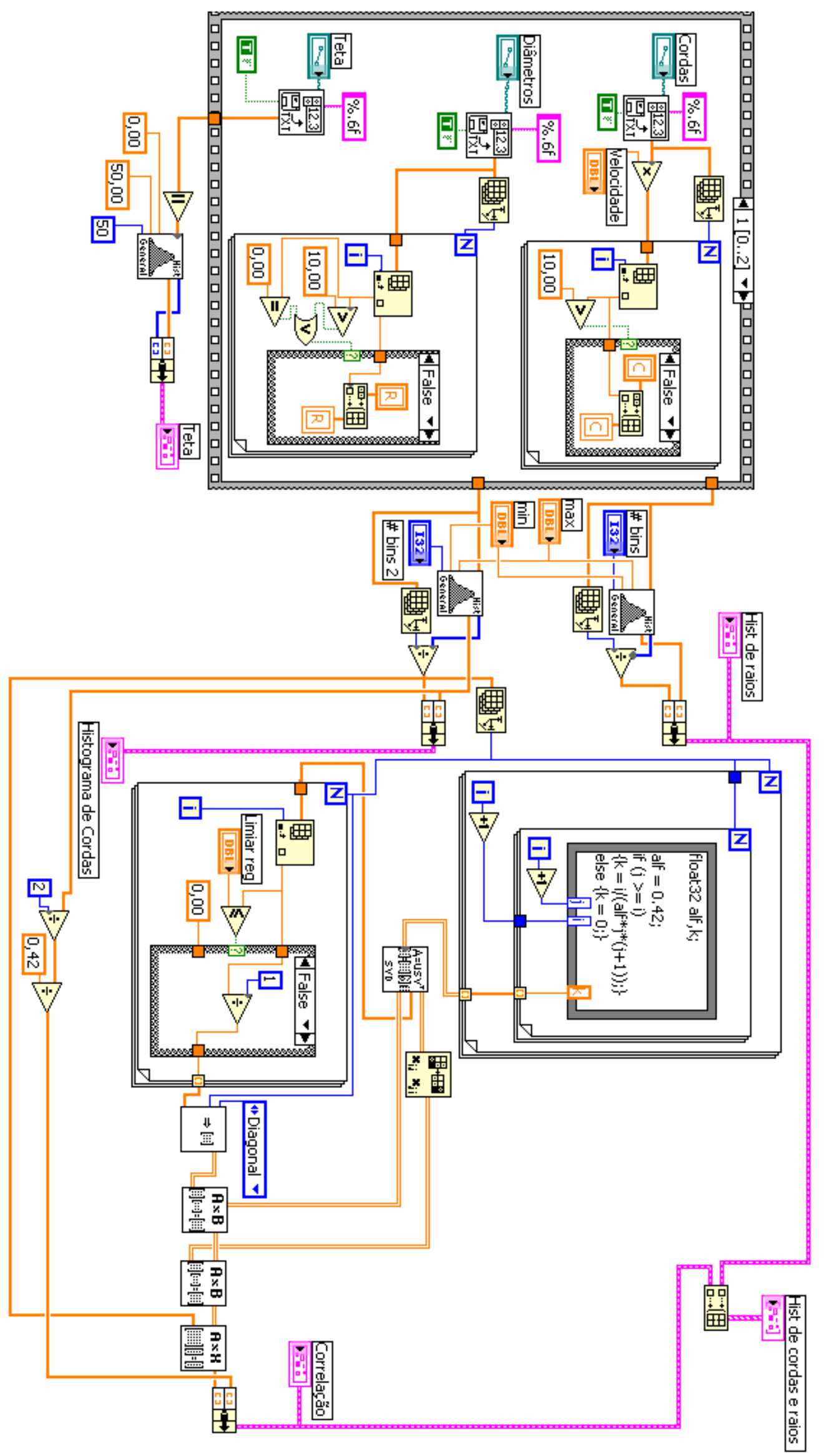

Figura B.42: Programa de correlação entre diagrama de cordas e diagrama de raios (Cont.). 


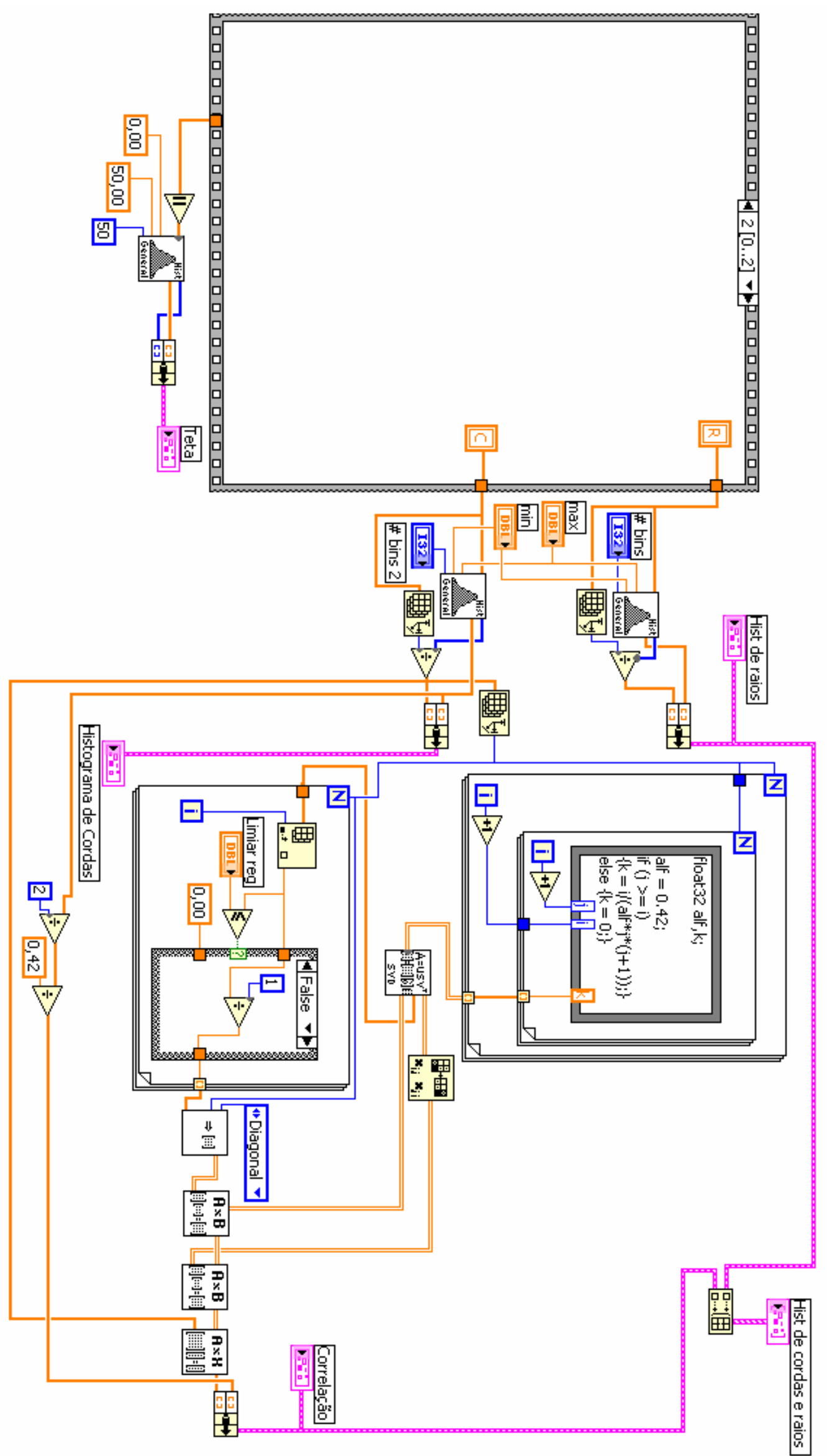

Figura B.43: Programa de correlação entre diagrama de cordas e diagrama de raios (Cont.). 


\section{APÊNDICE C - Exemplo de execução da calibração}


1 Uma imagem é capturada ao inicializar a rotina de calibração:

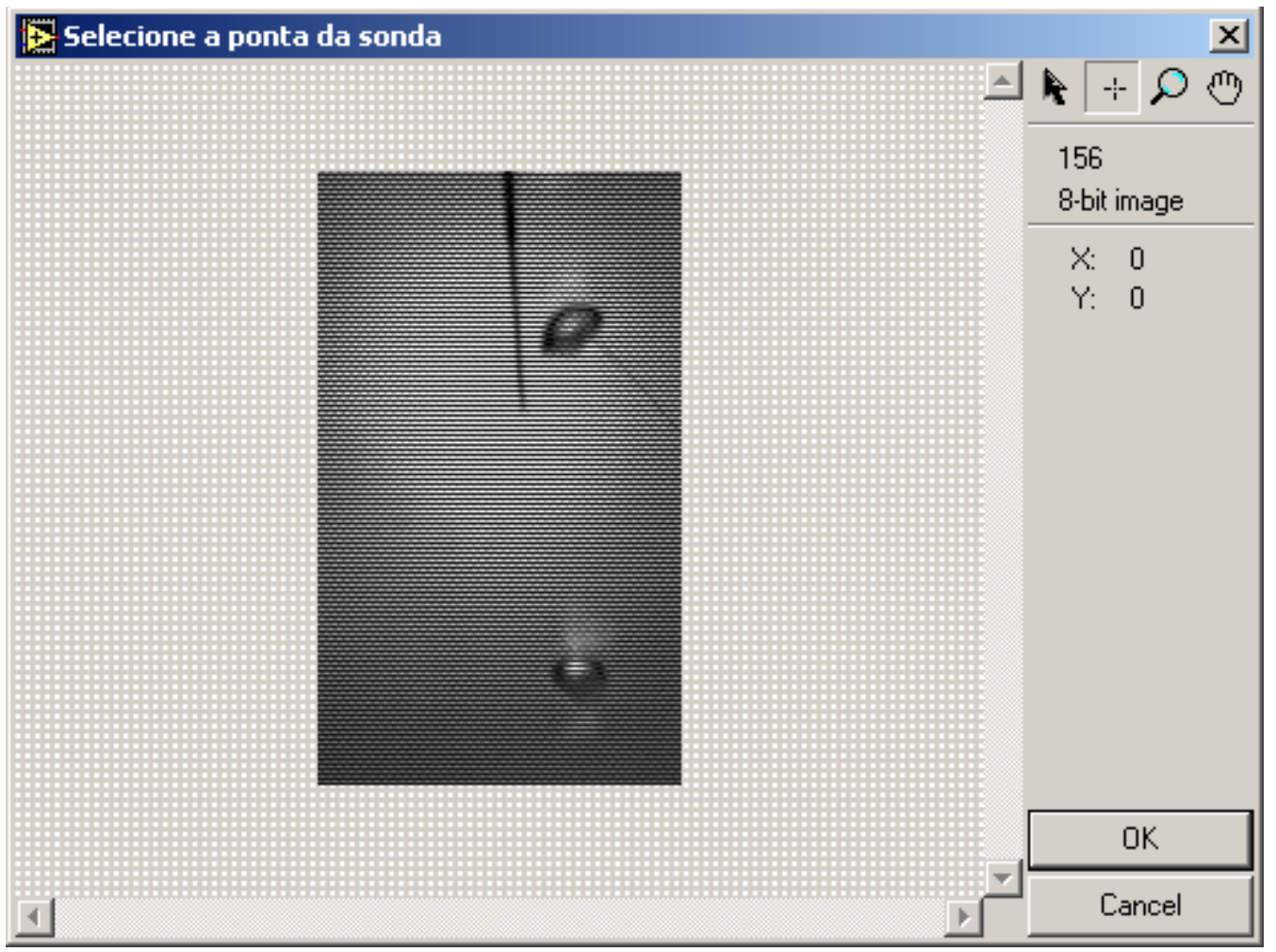

$2 \mathrm{O}$ usuário aumenta o zoom da imagem para selecionar a ponta da sonda com maior precisão:

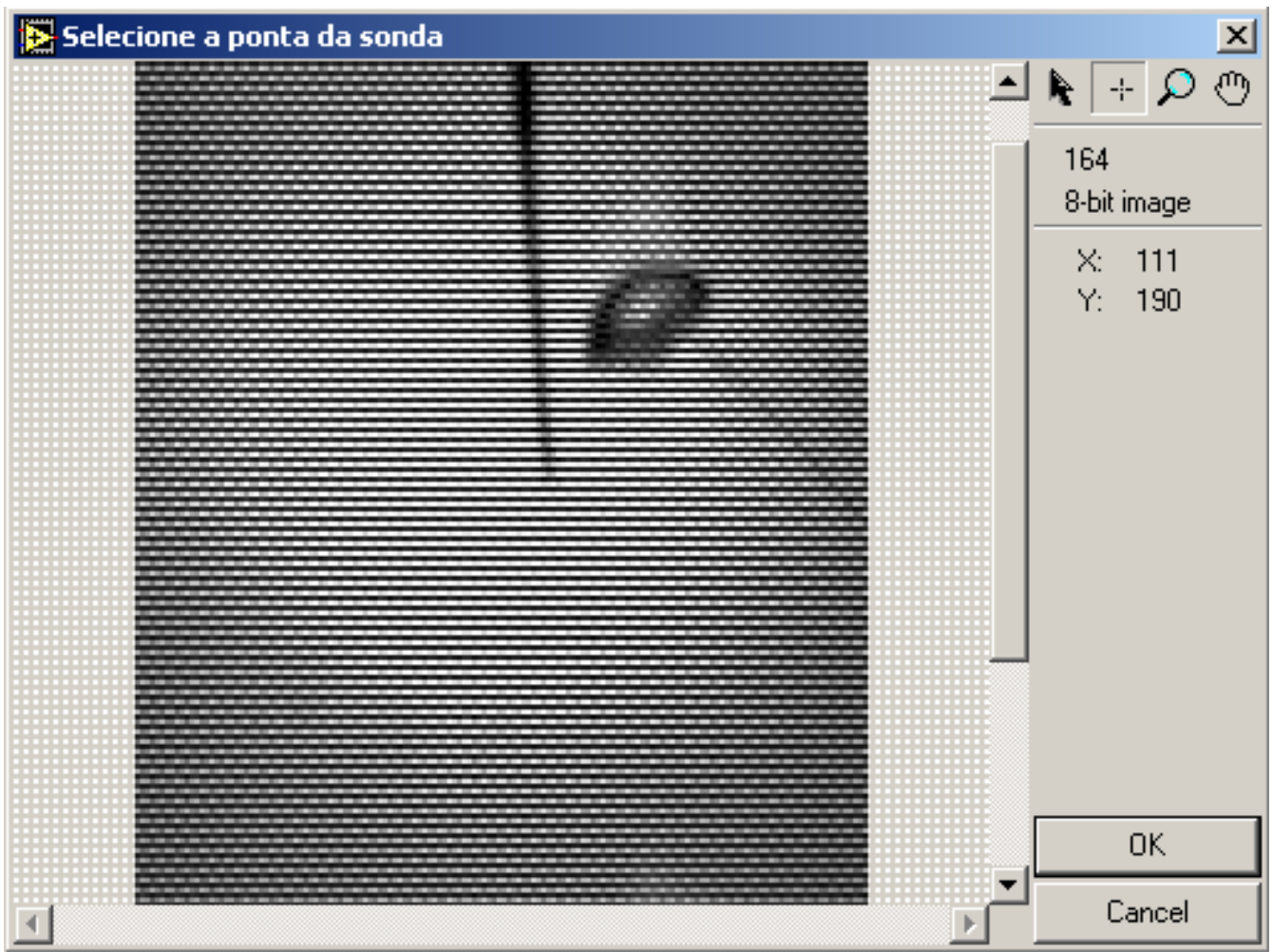


3 O usuário seleciona a ponta da sonda:

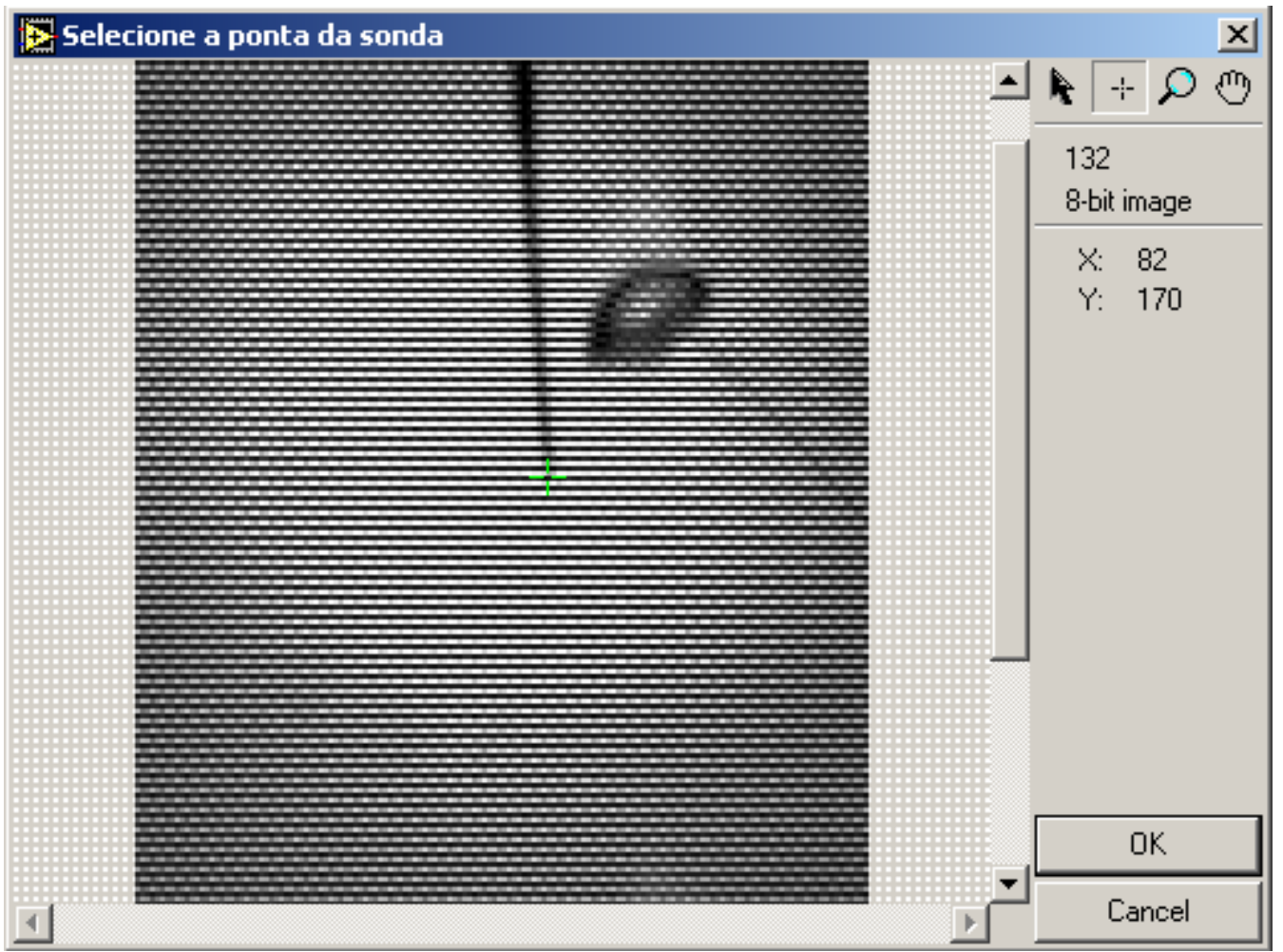

3 A imagem inicial é aberta novamente para que o usuário selecione o segmento de reta que corresponde à agulha hipodérmica:

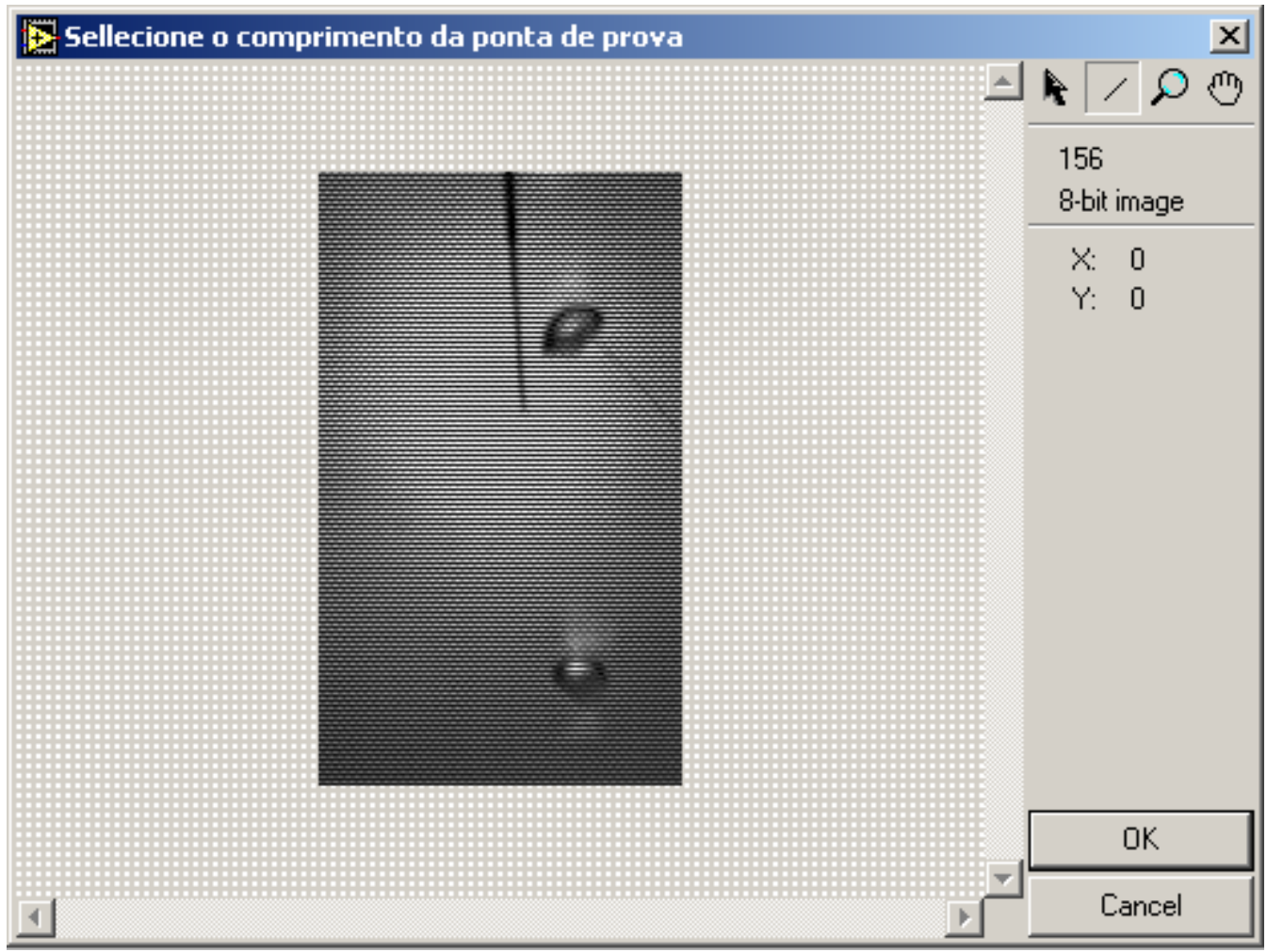


$4 \mathrm{O}$ usuário seleciona o segmento de reta correspondente à agulha hipodérmica:

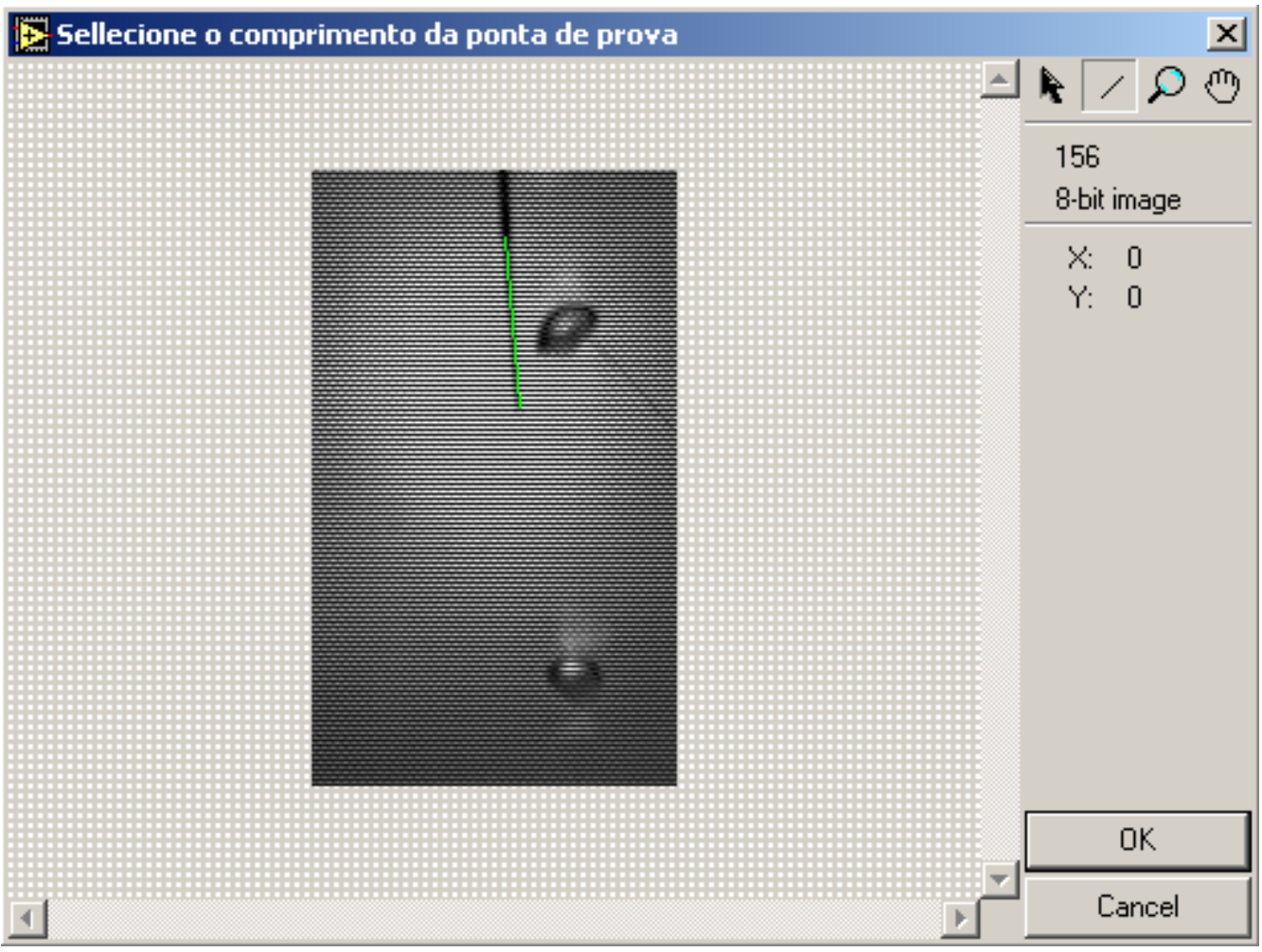

5 No painel do programa são mostradas: a dimensão de um pixel em mm; as coordenadas $x_{\text {SONDA }}$ e $y_{\text {SONDA }}$ da ponta da sonda em pixels:

\begin{tabular}{l} 
Concatenated string \\
\begin{tabular}{|l}
$X=83$ \\
$Y=97$ \\
Dimensão do pixel $=0,2296 \mathrm{~mm}$
\end{tabular} \\
\hline
\end{tabular}




\section{APENDICE D - Processamento de imagens de bolhas}


À esquerda imagens binárias segmentadas; ao centro bordas das imagens; à direita imagem original e "melhor" elipse encontrada.
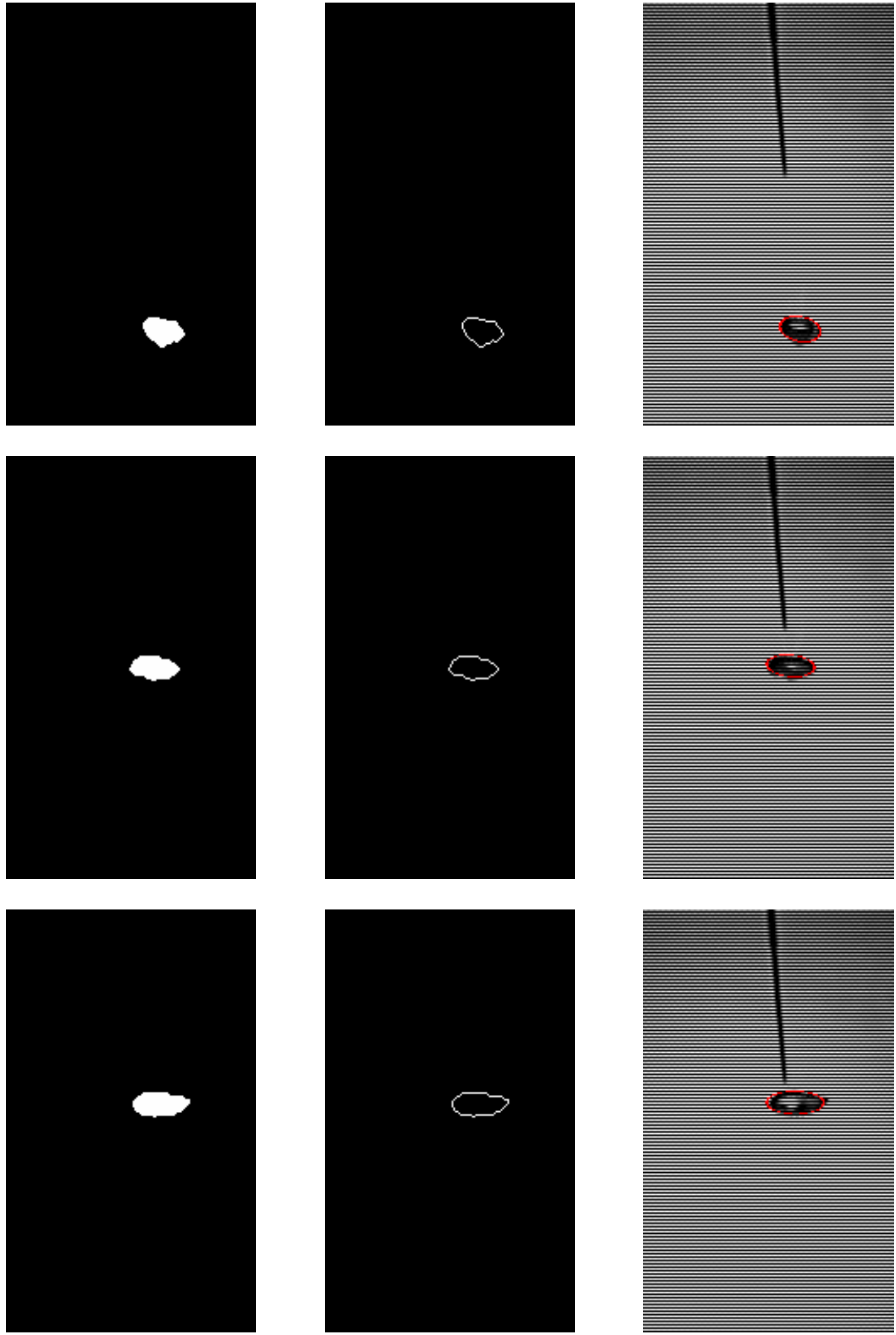

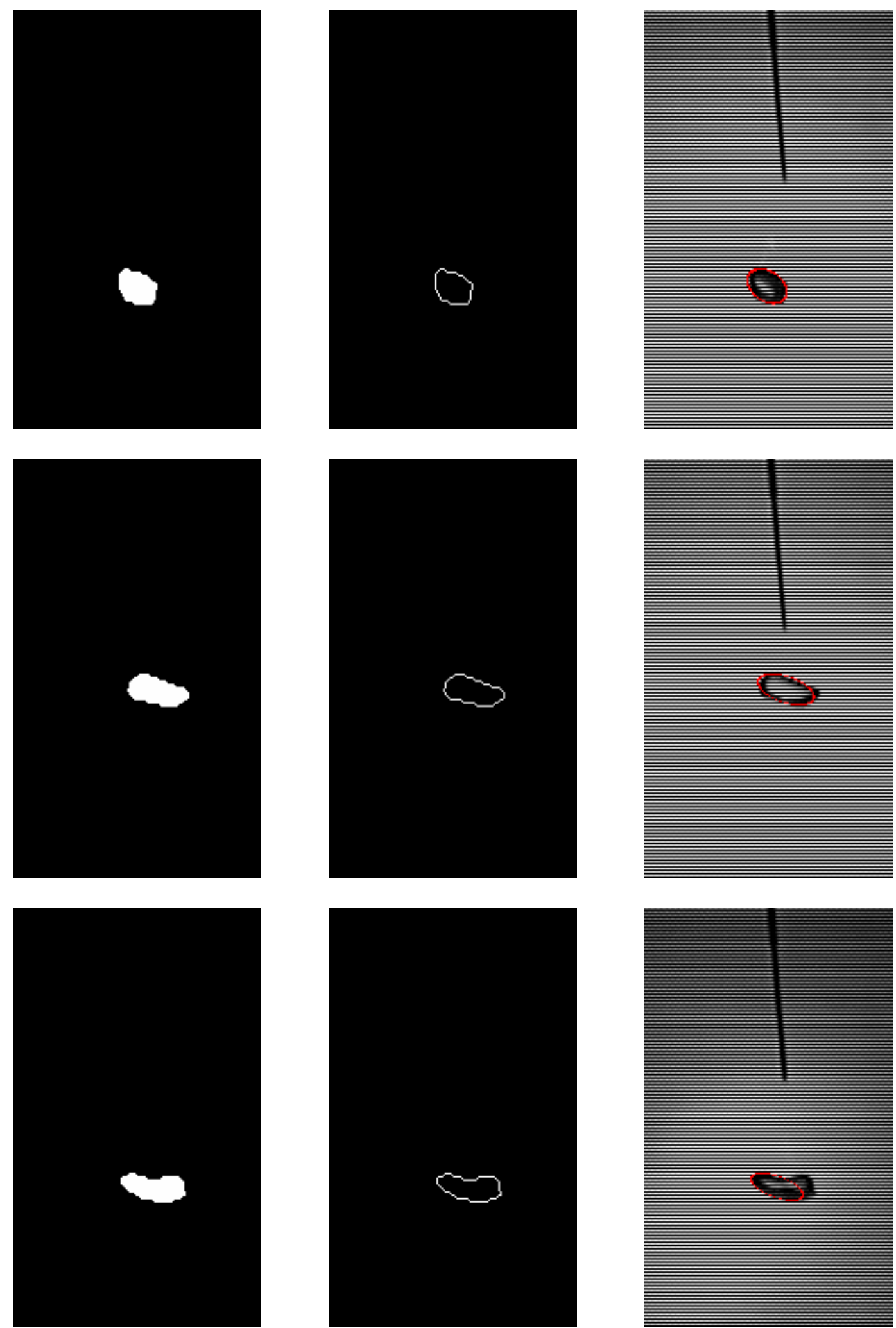

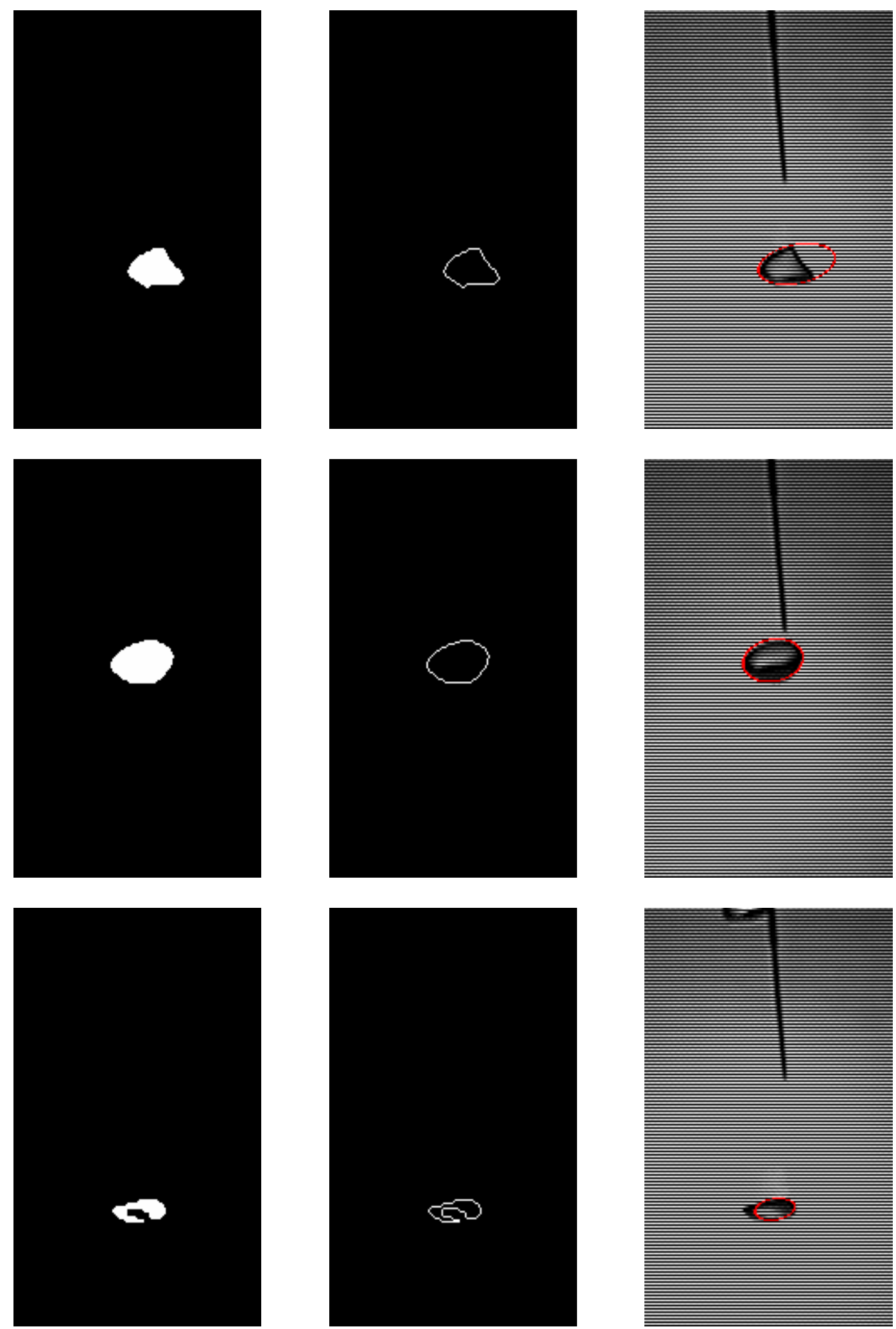


\section{APÊNDICE E - Fotos da coluna de borbulhamento}




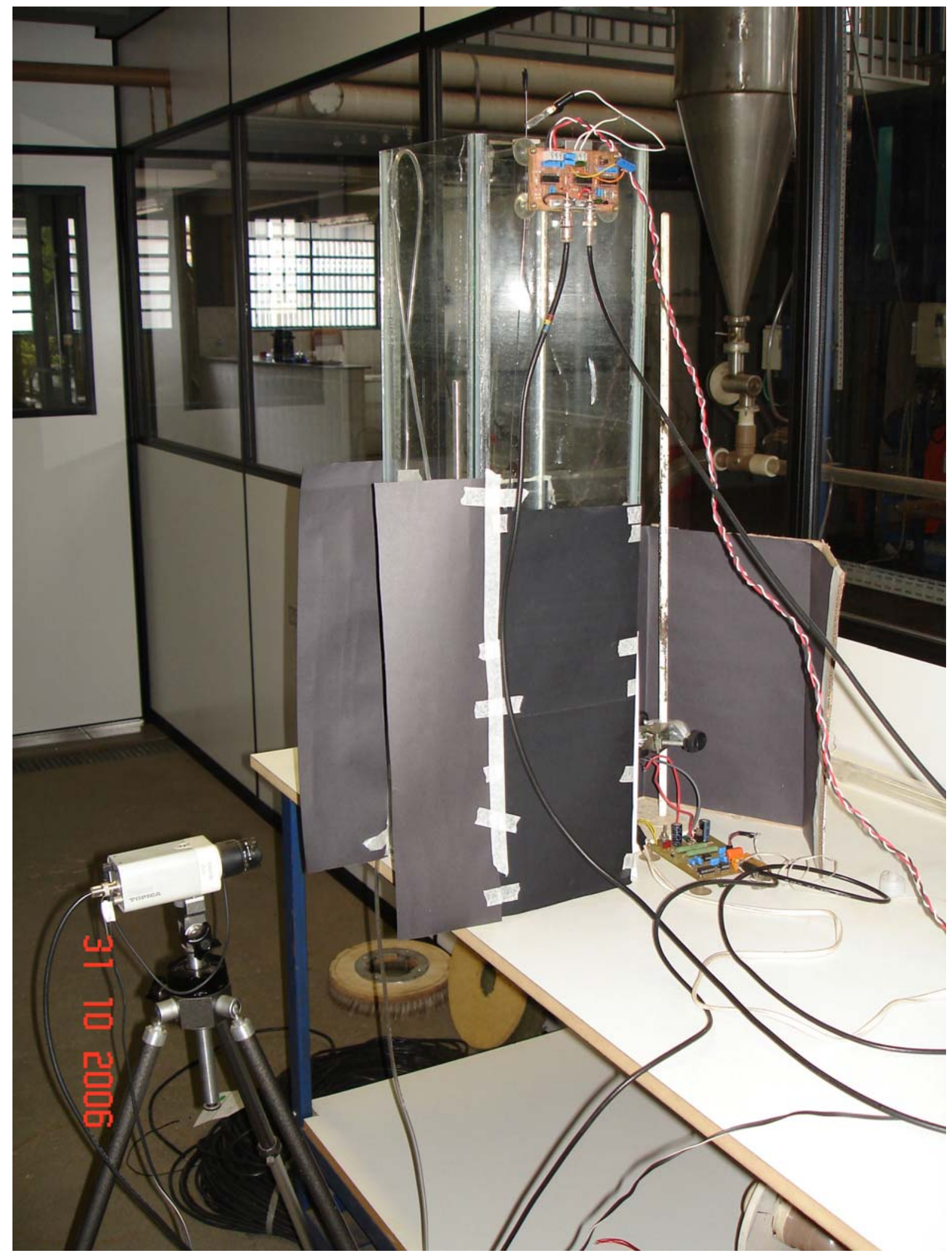

Figura E.1: Foto da coluna de borbulhamento. 


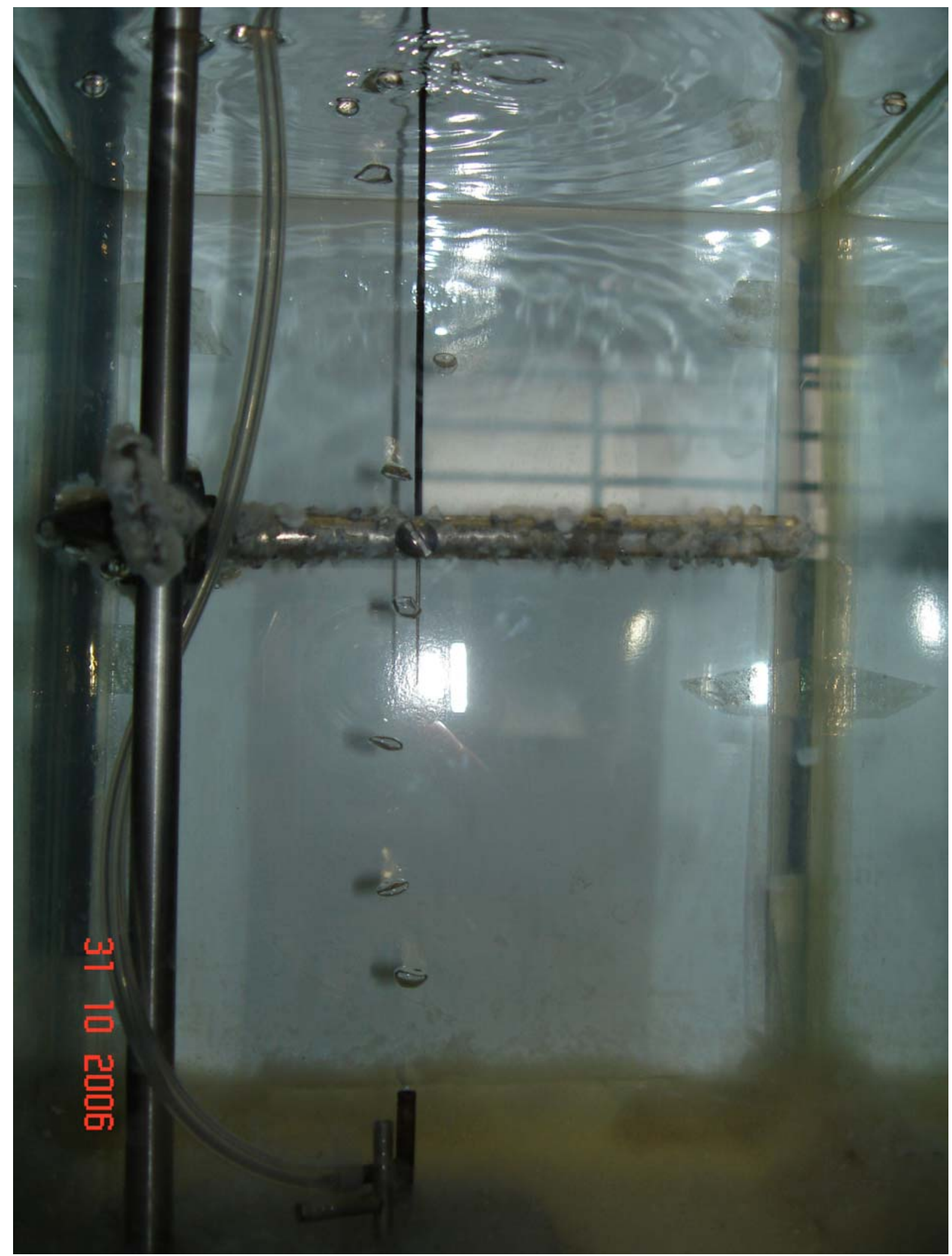

Figura E.2: Foto da coluna de borbulhamento, incluindo detalhes do fluxo e posicionamneto da sonda. 